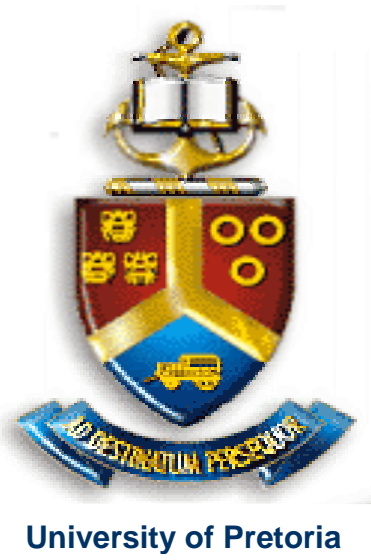

\title{
HEAT TRANSFER THROUGH MOULD FLUX WITH TITANIUM OXIDE ADDITIONS
}

\author{
by \\ JAN ANDRIES (DRIES) BOTHMA
}

Dissertation submitted in fulfilment of the requirements for the degree:

\section{MASTER OF ENGINEERING (METALLURGY)}

Department of Materials Science and Metallurgical Engineering, Faculty of Engineering, Built Environment and Information Technology, University of Pretoria, South Africa 
TITLE:

HEAT TRANSFER THROUGH MOULD FLUX WITH TITANIUM OXIDE ADDITIONS.

STUDENT:

JAN ANDRIES (DRIES) BOTHMA

NUMBER:

23272156

DEGREE:

MASTER OF ENGINEERING (METALLURGY)

DEPARTMENT: DEPARTMENT OF MATERIALS SCIENCE AND METALLURGICAL ENGINEERING, FACULTY OF ENGINEERING, BUILT ENVIRONMENT AND INFORMATION TECHNOLOGY

UNIVERSITY: $\quad$ UNIVERSITY OF PRETORIA, SOUTH AFTRCA

SUPERVISOR: $\quad$ PROF. P.C. PISTORIUS

STUDY YEAR: $\quad 2003-2006$ 


\section{ABSTRACT}

KEY WORDS: $\quad$ continuous casting, crystallisation, cuspidine, heat transfer, heat barrier, mould flux, perovskite, slag, stainless steel, titanium.

Mould powders are synthetic slags that contain mixtures of silica $\left(\mathrm{SiO}_{2}\right)$, lime $(\mathrm{CaO})$, sodium oxide $\left(\mathrm{Na}_{2} \mathrm{O}\right)$, fluorspar $\left(\mathrm{CaF}_{2}\right)$, and carbon $(\mathrm{C})$. When heated to elevated temperatures these powders liquefy and float on the liquid steel in the mould. Mould oscillation helps the liquid flux to penetrate the tiny gap between the mould and the newly formed solid steel shell. In this position the liquid flux partially solidifies against the water cooled mould, while a small portion of the flux remains liquid next to the steel shell to provide lubrication between the moving parts.

Effective horizontal heat transfer in the mould is critical for solidifying the liquid steel in the mould. This process is largely influenced by the thickness and the nature of the flux layer that infiltrates the mould/shell gap. When casting titanium stabilised stainless steels the alloying element reacts with the molten flux, ultimately changing the behaviour of the flux. During the casting process, titanium from the liquid steel reacts with the molten flux producing solids at high temperatures known as perovskite $\left(\mathrm{CaTiO}_{3}\right)$. Research has shown that perovskite reduces the lubrication capabilities of casting fluxes leading to detrimental effects on product quality while posing a serious threat of machine damage (breakout).

The focus of this study is to investigate the effect of titanium pickup on the solidification nature of mould flux and the consequences on horizontal heat transfer. To achieve this, an experimental setup was constructed to simulate the behaviour of mould flux during continuous casting. Analyses of the test flux indicated that the liquid flux closest to the cold side (mould) instantly froze to produce a glassy solid structure. Closer to the hot side (steel shell), solid particles such as perovskite, cuspidine $\left(\mathrm{Ca}_{4} \mathrm{Si}_{2} \mathrm{O}_{7} \mathrm{~F}_{2}\right)$, olivine ( $\mathrm{Ca}, \mathrm{Mg}, \mathrm{Mn})_{2} \mathrm{SiO}_{4}$ and nepheline $\left(\mathrm{Na}_{2} \mathrm{O} \cdot \mathrm{Al}_{2} \mathrm{O}_{3} \cdot\left(\mathrm{SiO}_{2}\right)_{2}\right)$ could be identified. Similar solid particles were also found in a slag rim sample taken during the industrial casting of 321titanium stabilised stainless steel using SPH-KA1 mould powder. 
Further investigations of the crystalline flux layers showed the entrapment of many tiny gas bubbles during solidification. This porous structure acted as a thermal heat barrier limiting horizontal heat transfer. Experimental testing on 3.0 and $6.0 \mathrm{~mm}$ flux thickness revealed that the overall thermal conductivity of mould flux decreased as the flux porosity increased. Larger amounts of gas entrapment (in the solid flux structure) resulted in higher thermal resistances which ultimately reduced the heat transfer capabilities of the flux.

A second heat barrier, which has a far more dominating effect on the overall heat transfer, is created on mould surface during flux solidification. This thermal contact resistance is also found to be the result of entrapped gas bubbles. Experimental results concluded that the effect of titanium pickup on heat transfer is primarily overshadowed by the larger effect of the thermal contact resistance that is formed during mould flux solidification. The contact resistance in combination with gas entrapment in the solid crystalline structure is considered to be the key factors preventing horizontal heat transfer during continuous casting. 


\section{ACKNOWLEDGEMENTS}

I would like to thank the following people for making this research project possible:

- Professor P.C Pistorius for his excellent mentorship and guidance.

- Columbus Stainless for making this project financially possible.

I would also like to express my gratitude to my family and friends for there assistance during the course of this project. Special thanks to my grand mother, Suzie van Biljon and my loving sister, Tanya Swanepoel and her husband Andrew for spending countless hours on compiling this report.

And finally, none of this would be possible without the grace of our loving God and heavenly Father Jesus Christ. 


\section{TABLE OF CONTENTS}

ABSTRACT III

ACKNOWLEDGEMENTS $\quad \mathrm{V}$

TABLE OF CONTENTS $\quad$ VI

LIST OF FIGURES IX IX

LIST OF TABLES XII

ABBREVIATIONS XIV

LIST OF SYMBOLS XV XV

CHAPTER 1 - INTRODUCTION

1.1 SCOPE OF WORK 1

1.2 PROJECT AIM 3

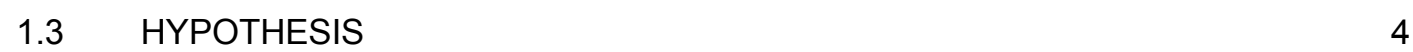

CHAPTER 2 - BACKGROUND 5

2.1 STAINLESS STEEL 5

$\begin{array}{lll}2.2 & \text { THE MANUFACTURING PROCESS } & 7\end{array}$

CHAPTER 3 - LITERATURE SURVEY

$\begin{array}{lll}3.1 & 11\end{array}$

3.2 FLUX BASICITY AND CHEMICAL COMPOSITION OF MOULD POWDER 14

3.3 FLUX PROPERTIES AND PROCESS PARAMETERS

3.3.1 MOULD FLUX VISCOSITY 17

3.3.2 PROCESS PARAMETERS AFFECTING MOULD LUBRICATION 19

$\begin{array}{lll}3.4 & \text { MOULD FLUX SOLIDIFICATION } & 21\end{array}$

3.4.1 MOULD FLUX CRYSTALLIZATION 21

3.4.2 MOULD FLUX SOLIDIFICATION DURING CONTINUOUS CASTING 25

3.4.3 THE EFFECT OF TITANIUM ON FLUX CRYSTALLIZATION 27

$\begin{array}{lll}3.5 & \text { HEAT TRANSFER } & 30\end{array}$

3.5.1 THERMAL INSULATION AND VERTICAL HEAT LOSS 30

3.5.2 HORIZONTAL HEAT TRANSFER DURING CONTINUOUS CASTING 31

3.5.3 THE EFFECT OF GAS ENTRAPMENT IN SOLID FLUX ON HORIZONTAL HEAT TRANSFER

3.5.4 THE EFFECT OF STEEL GRADE ON FLUX CHEMISTRY AND THE INFLUENCE ON HORIZONTAL HEAT TRANSFER 
3.5.5 PROCESS PARAMETERS AFFECTING HORIZONTAL HEAT TRANSFER $\quad 40$

3.6 MOULD FLUX RELATED PROBLEMS AND DEFECTS 41

3.6.1 LONGITUDINAL CRACKING 42

3.6.2 STAR CRACKS 43

3.6.3 OSCILLATION MARKS $\quad 44$

3.6.4 CASTING BREAKOUT $\quad 45$

CHAPTER 4 - EXPERIMENTAL SETUP - DESIGN \& CONSTRUCTION 47

4.1 DESIGN REQUIREMENTS AND LIMITATIONS 47

4.2 CONCEPT DESIGNS FOR EXPERIMENTAL TESTING 50

4.3 EXPERIMENTAL CONSTRUCTION 53

4.4 BASIC COMPONENTS OF THE EXPERIMENTAL CONSTRUCTION 55

CHAPTER 5 - EXPERIMENTAL PROCEDURE
59

$\begin{array}{lll}5.1 & \text { MOULD POWDER PREPARATION } & 59\end{array}$

5.2 PREPARING THE EXPERIMENTAL APPARATUS 60

5.3 HEATING SEQUENCE 61

5.4 COOLING SEQUENCE $\quad 62$

5.5 SAMPLING PROCEDURE 63

CHAPTER 6 - SLAG RIM ANALYSES AND THE PREDICTED EFFECT

OF $\mathrm{TiO}_{2}$ PICK-UP DURING FLUX SOLIDIFICATION 64

6.1 SEM ANALYSES OF THE SPH-KA1 SLAG RIM 64

6.2 PREDICTED EFFECT OF TIO2 PICK-UP DURING FLUX SOLIDIFICATION 71

CHAPTER 7 - EXPERIMENTAL RESULTS

$\begin{array}{lll}7.1 & \text { EXPERIMENTAL OBSERVATIONS } & 75\end{array}$

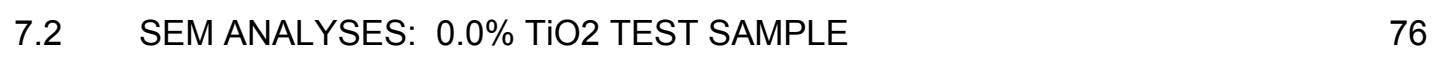

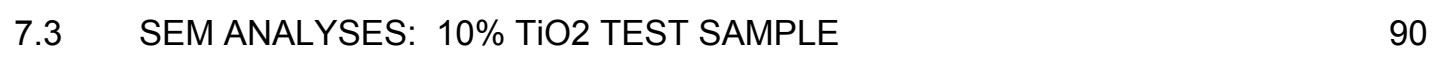

7.4 RECORDING TEMPERATURE PROFILES 86

7.5 CALCULATION MODEL TO PREDICT TEMPERATURE PROFILES 87

$\begin{array}{lll}7.6 & \text { FLUX THERMAL RESISTANCE RESULTS } & 93\end{array}$

$\begin{array}{lr}\text { CHAPTER } 8 \text { - CONCLUSION } & 97\end{array}$ 
APPENDICES

APPENDIX A: DETAIL DRAWING OF THE EXPERIMENTAL APPARATUS.

APPENDIX B: DETAIL DRAWING OF THE CUP AND PROBE.

APPENDIX C: EXPERIMENTAL HEATING SEQUENCE.

APPENDIX D: EXPERIMENTAL COOLING SEQUENCE.

APPENDIX E: MAJOR FLUX PHASES IDENTIFIED BY X-RAY POWDER

DIFFRACTION FOR SPH-KA1 SLAG RIM.

APPENDIX F: VISUAL BASIC CODE OF FINITE-DIFFERENCE MODEL 


\section{LIST OF FIGURES}

FIGURE 1.1: POSSIBLE HEAT TRANSFER EFFECT OF TITANIUM PICK-UP DURING CONTINUOUS CASTING.

FIGURE 2.1: THE EFFECT OF CHROMIUM CONTENT ON ATMOSPHERIC CORROSION RESISTANCE.

FIGURE 2.2: HEAT AFFECTED ZONE IN A WELDMENT.

FIGURE 2.3: PROCESS FLOW DIAGRAM FOR THE CONTINUOUS CASTING MACHINE.

FIGURE 2.4: SKETCH OF THE CONTINUOUS CASTING MOULD.

FIGURE 3.1: SCHEMATIC REPRESENTATION OF THE CONTINUOUS CASTING PROCESS.

FIGURE 3.2: MOULD POWDER LAYERS DURING CONTINUOUS CASTING.

FIGURE 3.3: INFLUENCE OF CALCIUM AND MAGNESIUM ON

THE SILICATE NETWORK.

FIGURE 3.4: EFFECTS OF TEMPERATURE AND TiO ${ }_{2}$ ADDITIONS ON MOULD FLUX VISCOSITY. 18

FIGURE 3.5: TIME-TEMPERATURE-TRANSFORMATION CURVE. 22

FIGURE 3.6: MOULD COOLING RATES DURING CONTINUOUS CASTING.

FIGURE 3.7: REPRESENTATION OF THE LAYERS THAT FORM DURING MOULD FLUX SOLIDIFICATION.

FIGURE 3.8: $\quad$ CHANGING $\mathrm{TiO}_{2}$ (A) AND $\mathrm{SiO}_{2}$ (B) CONTENTS IN MOULD FLUX USED FOR THE CASTING OF 321-AUSTENITIC STAINLESS STEEL. 28

FIGURE 3.9: PHASE DIAGRAM $\left(\mathrm{CaO}-\mathrm{TO}_{2}-\mathrm{SiO}_{2}\right)$.

FIGURE 3.10: ILLUSTRATING THE HORIZONTAL HEAT TRANSFER THROUGH DIFFERENT FLUX LAYERS.

FIGURE 3.11: THERMAL RESISTANCE DURING HORIZONTAL HEAT TRANSFER IN THE MOULD.

FIGURE 4.1: SCHEMATIC REPRESENTATION OF THE SiC-HEATER

EXPERIMENTAL APPARATUS.

FIGURE 4.2: ILLUSTRATION OF THE GAS FLAME EXPERIMENTAL SETUP.

FIGURE 4.3: ILLUSTRATION OF THE RESISTANCE HEATING

EXPERIMENTAL SETUP.

FIGURE 4.4: ILLUSTRATION OF THE INDUCTION HEATING APPARATUS FOR MOULD FLUX MELTING.

FIGURE 4.5: THE EXPERIMENTAL APPARATUS. 
FIGURE 4.6: DETAILED DRAWING OF THE EXPERIMENTAL APPARATUS.

FIGURE 4.7: $\quad \mathrm{Al}_{2} \mathrm{O}_{3}-\mathrm{SiO}_{2}$ BASED FIBRE BOARD USED FOR

THERMAL INSULATION.

FIGURE 4.8: 310-STAINLESS STEEL PROBE.

FIGURE 4.9: MILD STEEL CUP. 58

FIGURE 5.1: SPH-KA1 - CONTINUOUS CASTING MOULD POWDER. 59

FIGURE 5.2: THE CUP, MOULD POWDER AND BASE REFRACTORY ASSEMBLY. 60

FIGURE 5.3: PROBE AND CUP ASSEMBLY. 62

FIGURE 6.1: SEM-ANALYSES: BACK SCATTERED ELECTRON IMAGE OF THE SLAG RIM FORMED DURING INDUSTRIAL CASTING OF 321-STAINLESS STEEL USING SPH-KA1 MOULD POWDER. 66

FIGURE 6.2: SEM BACK-SCATTERED ELECTRON IMAGE OF SPH-KA1 SLAG RIM: MOULD SIDE

FIGURE 6.3: SEM BACK-SCATTERED ELECTRON IMAGE OF SPH-KA1

SLAG RIM: MIDWAY BETWEEN THE MOULD AND THE SHELL

FIGURE 6.4: SEM BACK-SCATTERED ELECTRON IMAGE OF SPH-KA1 SLAG RIM: SHELL SIDE

FIGURE 6.5: ENLARGED BACK-SCATTERED ELECTRON IMAGE OF THE SPH-KA1 SLAG RIM (SHELL SIDE).

FIGURE 6.6: PREDICTED EFFECTS OF $\mathrm{TiO}_{2}$ PICK-UP, USING FACTSAGE CALCULATIONS: LIQUIDUS TEMPERATURES AND PHASE COMPOSITION OF SOLIDIFIED FLUX AT THE SOLIDUS TEMPERATURE.

FIGURE 6.7. PREDICTED SOLIDIFICATION BEHAVIOUR OF MOULD FLUX, USING FACTSAGE CALCULATIONS.

FIGURE 7.1: VIEW OF THE CUP AFTER TESTING MOULD POWDER (SPH-KA1). 75

FIGURE 7.2: TOP VIEW OF THE CUP CONTAINING SOLIDIFIED MOULD FLUX (SPH-KA1) WITH TITANIUM OXIDE.

FIGURE 7.3: SEM-ANALYSES: BACK-SCATTERED ELECTRON IMAGE OF THE $0.0 \% \mathrm{TiO}_{2}$ TEST FLUX AFTER EXPERIMENTAL TESTING.

FIGURE 7.4: SEM-ANALYSES: BACK SCATTERED ELECTRON IMAGE OF THE $0.0 \% \mathrm{TiO}_{2}$ TEST FLUX AFTER EXPERIMENTAL TESTING. IMAGE OF THE CRYSTALLINE STRUCTURES FOUND IN PURE SPH-KA1- TEST FLUX 
FIGURE 7.5: OPTICAL IMAGE OF SOLIDIFIED TEST FLUX

CONTAINING $10.0 \% \mathrm{TiO}_{2}$.

FIGURE 7.6: SEM-ANALYSES: BACK-SCATTERED ELECTRON IMAGE OF SOLIDIFIED TEST FLUX CONTAINING 10.0\% $\mathrm{TiO}_{2}$.

FIGURE 7.7: SEM-ANALYSES: BACK SCATTERED ELECTRON IMAGE OF CRYSTALLINE TRANSITION ZONE FOUND IN SOLIDIFIED TEST POWDER (SPH-KA1) DOPED 10.0\% $\mathrm{TiO}_{2}$.

FIGURE 7.8 SEM-ANALYSES: BACK-SCATTERED ELECTRON IMAGE OF THE CRYSTALLINE FLUX PHASES FOUND IN SOLID TEST POWDER (SPH-KA1) DOPED WITH 10.0\% $\mathrm{TiO}_{2}$.

FIGURE 7.9: SEM-ANALYSES: BACK SCATTERED ELECTRON IMAGE OF THE NEEDLE SHAPED CRYSTALLINE STRUCTURE FOUND IN SOLIDIFIED TEST POWDER (SPH-KA1) DOPED 10.0\% $\mathrm{TiO}_{2}$ UNDER RAPID COOLING CONDITIONS.

FIGURE 7.10: SEM-ANALYSES: BACK SCATTERED ELECTRON IMAGE OF THE CRYSTALLINE TO GLASSY STRUCTURE FOUND IN SOLIDIFICATION FRONT OF TEST POWDER (SPH-KA1) DOPED WITH $10.0 \% \mathrm{TiO}_{2}$.

FIGURE 7.11: SEM-ANALYSES: BACK-SCATTERED ELECTRON IMAGE OF THE GLASSY STRUCTURE FOUND IN SOLIDIFIED TEST POWDER (SPH-KA1) DOPED WITH 10.0\% $\mathrm{TiO}_{2}$. 85

FIGURE 7.12: THERMOCOUPLE POSITION DURING EXPERIMENTAL TESTING. 86

FIGURE 7.13: TEMPERATURE PROFILES FOR THE EXPERIMENTAL DATA RECORDED DURING EXPERIMENTAL TESTING OF FLUX

FIGURE 7.14 ILLUSTRATION OF THE CALCULATION MODEL.

FIGURE 7.15 COMPARING MEASURED AND PREDICTED TEMPERATURE CHANGES AT POSITIONS 1, 2 AND 3, FOR TWO DIFFERENT RUNS 90

FIGURE 7.16 DATA FITTING OF T3 USING THE CALCULATED MODEL PREDICTION T2 AS BOUNDARY CONDITION TO SELECT THE LOWEST MAE TO CALCULATE THE SLAG THERMAL CONDUCTIVITY

FIGURE 7.17: CALCULATED COOLING CURVES OF THE PROBE TIP (T3) FOR MOULD FLUX THERMAL CONDUCTIVITY VALUES.

FIGURE 7.18: BOX-AND-WHISKER PLOTS: THERMAL CONDUCTIVITIES FOR 3.0mm THICK TEST FLUX WITH VARIOUS ADDITIONS OF $\mathrm{TiO}_{2}$.

FIGURE 7.19: BOX-AND-WHISKER PLOTS: THERMAL CONDUCTIVITIES FOR 6.0mm TEST FLUX HAVING VARIOUS ADDITIONS OF $\mathrm{TiO}_{2}$.

FIGURE 7.20: THERMAL RESISTANCES FOR SPH-KA1 MOULD FLUX WITH ADDITIONS OF $\mathrm{TiO}_{2}$. 


\section{LIST OF TABLES}

TABLE 2.1: CHEMICAL COMPOSITIONS REQUIREMENTS (WEIGHT \%) FOR TYPICAL TITANIUM STABILISED STAINLESS STEELS

TABLE 3.1: CHEMICAL COMPOSITIONS FOR TYPICAL MOULD FLUX

TABLE 3.2: SOLID CRYSTAL FORMATION FROM BASIC MOULD POWDER ELEMENTS.

TABLE 5.1: WEIGHT \% $\mathrm{TiO}_{2}$ ADDED TO MOULD POWDER.

TABLE 6.1: CHEMICAL COMPOSITIONS (WEIGHT\%) OF SPH-KA1 MOULD POWDER AS PROVIDED BY THE POWDER MANUFACTURER.

TABLE 6.2: XRF-ANALYSES OF THE CRUSHED SLAG RIM THAT FORMED FROM SPH-KA1 MOULD POWDER DURING THE CASTING OF 321-STAINLESS STEEL.

TABLE 6.3: MAJOR PHASES IDENTIFIED BY X-RAY POWDER DIFFRACTION OF THE SLAG RIM THAT FORMED FROM SPH-KA1 MOULD POWDER DURING THE PRODUCTION OF 321-STAINLESS STEEL. 65

TABLE 6.4: EDS-AREA-ANALYSES OF THE SPH-KA1 SLAG RIM THAT FORMED ON THE MOULD SIDE, CENTRAL AND SHELL SIDE DURING THE CASTING OF 321-STAINLESS STEEL.

TABLE 6.5: EDS-POINT-ANALYSES OF SPH-KA1 SLAG RIM THAT FORMED ON THE MOULD SIDE DURING THE CASTING OF 321-STAINLESS STEEL

TABLE 6.6: EDS-POINT-ANALYSES OF THE SPH-KA1 SLAG RIM THAT FORMED MIDWAY BETWEEN THE MOULD AND THE SHELL (CENTRE) DURING THE CASTING OF 321-STAINLESS STEEL (AVERAGE MASS PERCENTAGES, WITH 95\% CONFIDENCE INTERVALS WHERE AVAILABLE).

TABLE 6.7: $\quad$ EDS-POINT-ANALYSES OF THE SPH-KA1 SLAG RIM THAT FORMED ON THE STEEL SHELL DURING THE CASTING OF 321-STAINLESS STEEL (AVERAGE MASS PERCENTAGES, WITH 95\% CONFIDENCE INTERVALS).

TABLE 6.8: $\quad$ ESTIMATED THERMODYNAMIC DATA OF CUSPIDINE, AS USED IN FACTSAGE CALCULATIONS.

TABLE 6.9: MOULD FLUX COMPOSITION (BEFORE $\mathrm{TIO}_{2}$ PICK-UP) AS USED IN EQUILIBRIUM CALCULATIONS. 
TABLE 7.1: $\quad$ SUMMARIZED COMPOSITIONS OF THE TEST SAMPLE WITH 0.0\% $\mathrm{TiO}_{2}$ ADDED.

TABLE 7.2: POINT ANALYSES ON THE INDIVIDUAL PHASES/SUB-REGIONS FOR THE SAMPLE CONTAINING $0.0 \% \mathrm{TiO}_{2}$.

TABLE 7.3: SUMMARIZED COMPOSITIONS OF THE TEST SAMPLE WITH 10.0\% $\mathrm{TiO}_{2}$ ADDED (AVERAGE MASS PERCENTAGES, WITH 95\% CONFIDENCE INTERVALS)

TABLE 7.4: POINT ANALYSES ON THE INDIVIDUAL PHASES/SUB-REGIONS FOR THE SAMPLE CONTAINING 10.0\% TIO2 - HOT SIDE (PROBE). 83

TABLE 7.5: SINGLE POINT ANALYSES OF THE SOLIDIFICATION FRONT: SAMPLE WITH $10.0 \% \mathrm{TiO}_{2}$ ADDED - COLD SIDE (CUP). 85

TABLE 7.6: THERMAL PROPERTIES USED IN FINITE-DIFFERENCE MODEL.

TABLE 7.7: CALCULATED THERMAL CONDUCTIVITY (W/MK) FOR 3.0mm THICK TEST FLUX WITH VARIOUS ADDITIONS OF $\mathrm{TiO}_{2}$.

TABLE 7.8: CALCULATED THERMAL CONDUCTIVITY (W/MK) FOR $6.0 \mathrm{~mm}$ THICK TEST FLUX WITH VARIOUS ADDITIONS OF TiO ${ }_{2}$.

TABLE 7.9: CALCULATED THERMAL RESISTANCES (M2•K/W) FOR SPH-KA1 TEST FLUX HAVING VARIOUS ADDITIONS OF $\mathrm{TiO}_{2}$, AND FOR FLUX THICKNESSES OF 3 MM AND $6 \mathrm{~mm}$. 


\section{ABBREVIATIONS}

\begin{tabular}{|c|c|}
\hline ABS & Argon Bubbling Station \\
\hline AOD & Argon Oxygen Decarburisation \\
\hline $\mathrm{Ar}$ & Argon (gas) \\
\hline $\mathrm{BCC}$ & Body Centred Cubic \\
\hline C & Carbon \\
\hline $\mathrm{CaO}$ & Calcium Oxide (Lime) \\
\hline CCT & Continuous Cooling Transformation \\
\hline $\mathrm{Cr}$ & Chromium \\
\hline DHTT & Double Hot Thermocouple Technique \\
\hline EAF & Electric Arc Furnace \\
\hline EDS & Energy Dispersive Spectroscopy \\
\hline FCC & Face Centred Cubic \\
\hline $\mathrm{Fe}$ & Iron \\
\hline $\mathrm{HAZ}$ & Heat Affected Zone \\
\hline $\mathrm{He}$ & Helium (gas) \\
\hline $\mathrm{Mg}$ & Magnesium \\
\hline $\mathrm{MgO} \cdot \mathrm{CaO}$ & Dolomite \\
\hline $\mathrm{MnO}$ & Manganese Oxide \\
\hline Mo & Molybdenum \\
\hline$N$ & Nitrogen \\
\hline $\mathrm{Ni}$ & Nickel \\
\hline$P$ & Phosphorus \\
\hline S & Sulphur \\
\hline SEM & Scanning Electron Microscope \\
\hline SEN & Submerged Entry Nozzle \\
\hline SHTT & Single Hot Thermocouple Technique \\
\hline $\mathrm{Si}$ & Silicon \\
\hline $\mathrm{SiO}_{2}$ & Silicon Dioxide (Silica) \\
\hline $\mathrm{Ti}$ & Titanium \\
\hline $\mathrm{TiO}_{2}$ & Titanium Dioxide (reverde to as Titanium Oxide) \\
\hline TTT & Time Temperature Transformation \\
\hline XRD & X-Ray Diffraction (analysis) \\
\hline XRF & X-Ray Fluorescence (analysis) \\
\hline
\end{tabular}




\section{LIST OF SYMBOLS}

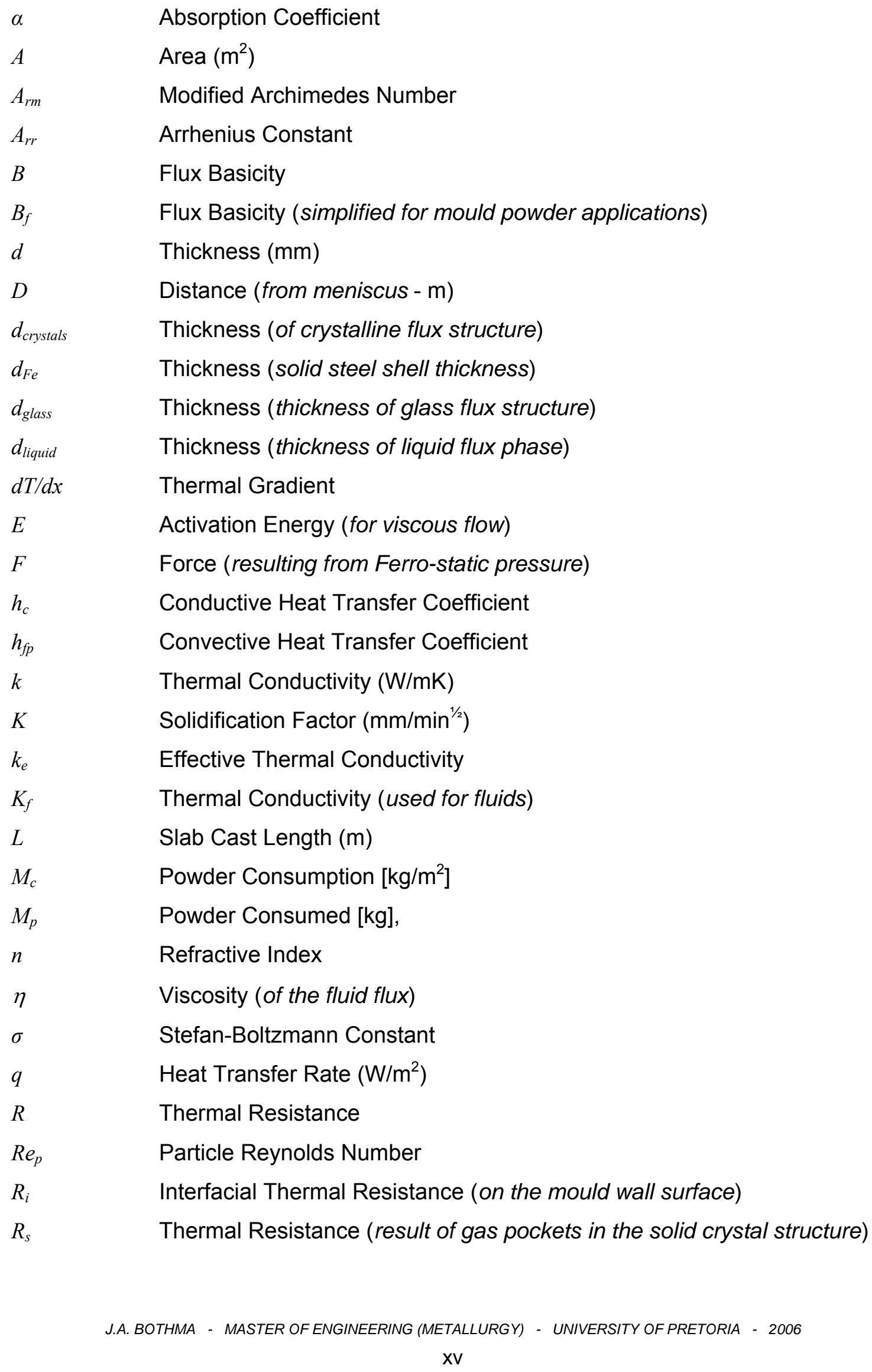


Scattering Coefficient (radiation)

Shear Stress (force per unit area $-\mathrm{N} / \mathrm{m}^{2}$ )

Time (seconds - s)

Temperature (Kelvin - K)

Break Temperature (point of change in viscosity)

Liquid temperature (Kelvin -K)

Solidification temperature (Kelvin - K)

Casting speed ( $\mathrm{m} / \mathrm{min})$

Mould velocity $(\mathrm{m} / \mathrm{s})$

Slab width $(\mathrm{m})$

Slab thickness $(m)$ 


\section{CHAPTER 1}

\section{INTRODUCTION}

\subsection{SCOPE OF WORK}

To provide adequate lubrication to the continuous casting process, synthetic powders are fed to the molten metal surface in the mould. When heated, these powders form a sinter layer, then a mushy layer, and eventually melt to form a liquid flux pool floating in the mould. Mould powders were mainly designed to lubricate the casting process, but also play a very important role in protecting the liquid steel surface in the mould from atmospheric contamination. Liquid flux from the molten pool infiltrates into the mould/strand channel and lubricates the newly-formed steel shell. However, most of the first liquid flux entering the channel freezes against the water-cooled copper mould and forms a solid glassy layer. A thin layer of liquid flux moves with the steel shell and provides liquid lubrication between mould and shell. In time, the glassy slag may partially crystallise. The solid flux layer (slag) is usually considered to stay attached to the mould wall or, if it does move, it must do so more slowly than the velocity of the shell. The mould is also oscillated to prevent the shell from sticking to the mould. The horizontal heat transfer is controlled by both the thickness and the nature of the solid slag layer. Thus, in summary, the liquid flux layer controls the lubrication and the solid slag layer controls the horizontal heat transfer during continuous casting (Mills et al., 2004b).

When casting titanium stabilised stainless steel the heat transfer in the mould becomes very complex. A chemical analysis indicates that the titanium, in solution with liquid steel, reacts with the molten flux and changes the characteristics of the mould powder. The basic reaction can be represented as follows:

$$
\mathrm{SiO}_{2 \text { (flux) }}+\mathrm{Ti}_{\text {[steel] }} \rightarrow \mathrm{TiO}_{2 \text { (flux) }}+\mathrm{Si}_{\text {[steel] }}
$$

Silica $\left(\mathrm{SiO}_{2}\right)$ in the molten flux reacts with titanium $(\mathrm{Ti})$ in the liquid steel (cast material). This reaction reduces the silica concentration in the mould flux, causing a change in flux basicity and therefore changing the viscosity of the liquid flux. Silicon reaction product reports to the steel, but these concentrations are so low that it does 
not affect the steel chemistry. However, this leads to an increase in the $\mathrm{CaO}$ concentration that influences flux properties in two ways. Firstly the rise in flux basicity may change lubrication properties and secondly, the higher $\mathrm{CaO}$ concentration is believed to promote the formation of a secondary solid phase, perovskite that solidifies at higher temperatures.

$$
\mathrm{TiO}_{2 \text { (flux) }}+\mathrm{CaO} \text { (flux) } \rightarrow \mathrm{CaTiO}_{3}
$$

In order to prevent any change in basicity, (SPH-KA1-188/KA1) was introduced at Columbus Stainless as a casting powder for casting austenitic stainless steel. This casting powder contains fairly large amounts of manganese oxide ( $\mathrm{MnO} \approx 4.5$ to $6.0 \%$ ) to counter the loss of $\mathrm{SiO}_{2}$ concentrations. The proposed mechanism is that $\mathrm{MnO}$ would act as a sacrificial oxide, preventing the loss of $\mathrm{SiO}_{2}$ in the presence of titanium at high temperatures.

$$
2 \mathrm{MnO}_{\text {(flux) }}+\mathrm{Ti}_{\text {[steel] }} \rightarrow \mathrm{TiO}_{2} \text { (flux) }+2 \mathrm{Mn}_{\text {[steel] }}
$$

In terms of basicity and lubrication, $\mathrm{MnO}$ seemed to have solved the problem. $\mathrm{MnO}$ however, did not completely solve the heat transfer problems associated with the formation of perovskite.

To investigate the effect of horizontal heat transfer a laboratory setup was built to simulate the solidification of liquid flux under continuous casting conditions. Mould powder was doped with titanium oxide $\left(\mathrm{TiO}_{2}\right)$ and tested to measure the effect on heat transfer through the different layers that form during solidification. Three different variations of titanium oxide doping $(0.0 \%, 5.0 \%$ and $10.0 \%)$ were compared with each other. Test samples were heated to approximately $1300^{\circ} \mathrm{C}$ allowing the mould flux to completely melt and stabilise. Under controlled conditions the test samples were then cooled using helium gas $(\mathrm{He})_{\mathrm{g}}$ while logging all temperature changes during cooling. The aim was to investigate the heat transfer associated with different levels of titanium contaminated mould powder. To complete the investigation test samples from the experimental setup were compared to actual plant samples using SEM, XRF and XRD analyses.

It has been found that thermal conductivity is largely independent of flux layer thicknesses that form in the mould/shell gap (Holzhauser et al., 1999). However, a 
thermal contact resistance is created as a result of the wrinkled slag surface that is formed during the chilling of liquid flux on the cold copper mould. This thermal contact resistance constitutes a considerable part of the total resistance to heat transfer, and is thus very important.

On the other hand, it is evident that thermal conductivity depends on the composition of the flux layers in the mould/shell gap (Mills et al., 2004b). Rapid cooling of liquid flux gives a glassy solid structure which promotes heat transfer, whereas slow cooling promotes crystal growth which tends to limit horizontal heat transfer. Therefore, solid structures formed during flux crystallisation also have a definite effect on the horizontal heat transfer in the continuous casting mould.

\subsection{PROJECT AIM}

The project aim was to investigate horizontal heat transfer in the continuous casting mould during the production of titanium stabilised stainless steel, analysing the effects of mould flux crystallisation on heat transfer.

"A slag film is formed in the channel between the mould and the shell during the continuous casting of steel, and the amount of crystalline material in the slag film has a significant effect on the heat transfer between the steel shell and the mould" (Mills et al., 2004b).

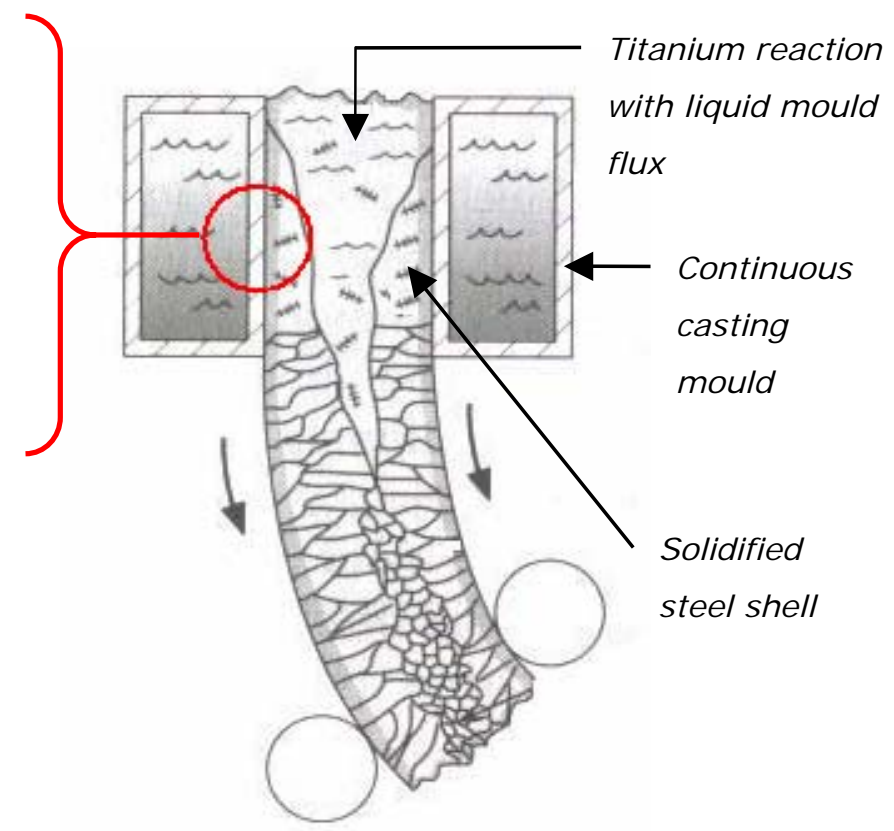

FIGURE 1.1: Possible heat transfer effect of titanium pick-up during continuous casting. (Budinski, 1999) 
When casting titanium stabilised stainless steel, mould powder used for lubrication in the mould reacts with the dissolved titanium present in the liquid steel. This reaction of titanium changes the properties of the liquid mould powder (flux) and ultimately affects the solidification behaviour of the mould flux in the gap between the mould and the steel shell. This in turn influences the heat transfer capabilities of the mould flux and thus the casting capabilities of the mould. The aim of this investigation is to determine the effect of titanium pick-up in mould powder and the effect on the overall horizontal heat transfer in the mould.

\subsection{HYPOTHESIS}

When casting titanium stabilised stainless steel, titanium oxide $\left(\mathrm{TiO}_{2}\right)$ is formed during the process. Reactions between titanium oxide and calcium oxide $(\mathrm{CaO})$, found in mould powders, lead to the formation of a solid structure known as perovskite $\left(\mathrm{CaO} \cdot \mathrm{TiO}_{2}\right)$. Perovskite not only solidifies at higher temperatures compared to other flux solids but also affects the overall mould flux basicity. These changes have serious implications for the behaviour of the flux in the mould.

Previous studies on titanium pick-up in the mould indicated that the viscosity of the mould flux increased as the $\mathrm{TiO}_{2}$ concentration increased. It is also expected that the heat transfer capabilities of the mould flux will be changed due to the formation of high temperature solids such as perovskite.

Therefore, the hypothesis is:

An increase in $\mathrm{TiO}_{2}$ content in the mould flux will decrease the heat transfer rate through the mould flux. 


\section{CHAPTER 2}

\section{BACKGROUND}

\subsection{STAINLESS STEEL}

Stainless steels are alloys of mainly iron ( $\mathrm{Fe})$ and chromium $(\mathrm{Cr})$. These metals are characterized by their shiny appearance and corrosion resistance ability. To improve the properties of stainless steels alloying elements such as nickel $(\mathrm{Ni})$, molybdenum (Mo) and titanium (Ti) are added to the material, while impurities such as carbon (C), phosphor $(\mathrm{P})$ and sulphur $(\mathrm{S})$ are removed. Alloying elements are generally very costly making stainless steel far more expensive than ordinary carbon steels (Camisani-Calzolari et al., 2003).

TABLE 2.1: Chemical compositions requirements (weight \%) for typical titanium stabilised stainless steels (ASTM, 2003).

\begin{tabular}{|c|c|c|c|c|c|c|c|c|c|c|}
\hline \multicolumn{2}{|c|}{ code } & C & Mn & $\mathbf{P}$ & $\mathbf{S}$ & $\mathbf{S i}$ & $\mathbf{C r}$ & $\mathbf{N i}$ & $\mathbf{N}$ & $\mathbf{T i}$ \\
\hline $\mathbf{3 2 1}$ & $\begin{array}{c}1.4541 \\
(\mathrm{X} 6 \mathrm{C} \text { (NiTi18-10) }\end{array}$ & 0.08 & 2.00 & 0.05 & 0.03 & 0.75 & $\begin{array}{c}17.0- \\
19.0\end{array}$ & $\begin{array}{c}9.0- \\
12.0\end{array}$ & 0.10 & $5(\mathrm{C}+\mathrm{N})$ \\
\hline $\mathbf{4 0 9}$ & $\begin{array}{c}1.4512 \\
(\mathrm{X} 2 \mathrm{CrTi12})\end{array}$ & 0.03 & 1.00 & 0.04 & 0.02 & 1.00 & $\begin{array}{c}10.5- \\
11.7\end{array}$ & 0.50 & 0.03 & $6(\mathrm{C}+\mathrm{N})$ \\
\hline
\end{tabular}

Stainless steels have the ability to form a very thin protective oxide layer on the material surface to prevent corrosion. In order to form such a layer, exposed chromium on the metal surface reacts with oxygen from the surrounding environment. The keyword is passivity. Passivity is defined as a condition of corrosion resistance due to the formation of a thin surface layer with high anodic polarisation which forms under oxidizing conditions (Jones, 1996). In ordinary terms this means that the protective layer on the material surface has a very low chemical reactivity when it is further exposed to oxygen in the environment and is therefore passive.

By increasing the chromium content in a metal, the ability of the metal to resist corrosion also increases. In general terms when a metal is exposed to a corrosive environment the severity of corrosion is determined by calculating the weight loss of 
the exposed metal over a period of time. Figure 2.1 demonstrates the reduced weight loss effect that chromium additions have on ordinary steels. The minimal chromium content needed to effectively prevent corrosion under normal conditions is about $12 \%$, as shown in figure 2.1 .

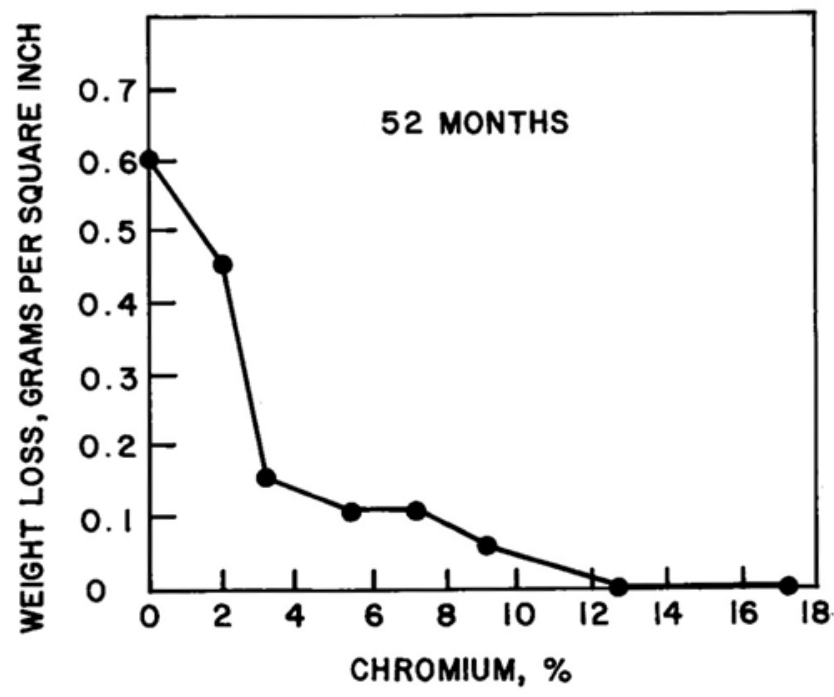

FIGURE 2.1: The effect of chromium content on atmospheric corrosion resistance. (Sedriks, 1996)

Stainless steel also has a very low solid solubility for carbon which causes a problem during welding. This is better known as weld decay or sensitisation. During welding, heat is applied to the material which changes the microstructure of the stainless steel. The areas surrounding the weld are heated to temperatures between $500^{\circ} \mathrm{C}$ to $800^{\circ} \mathrm{C}$. In this temperature range carbon atoms are activated to react with the nearby chromium to form localised chromium carbides. This area next to the weld is referred to as the heat-affected-zone as indicated in figure 2.2 (Jones, 1996).

Chromium carbides are highly enriched with chromium, containing up to four times the normal amount of chromium compared to the metal composition before welding. The result is a dual metal structure containing localised areas with high chromium concentrations and neighbouring areas with low chromium contents. These chrome depleted areas do not have sufficient chrome content (higher than 12\%) in order to fight corrosion. Therefore severe corrosion is often found in the heat affected zone (HAZ) next to the welded area. 


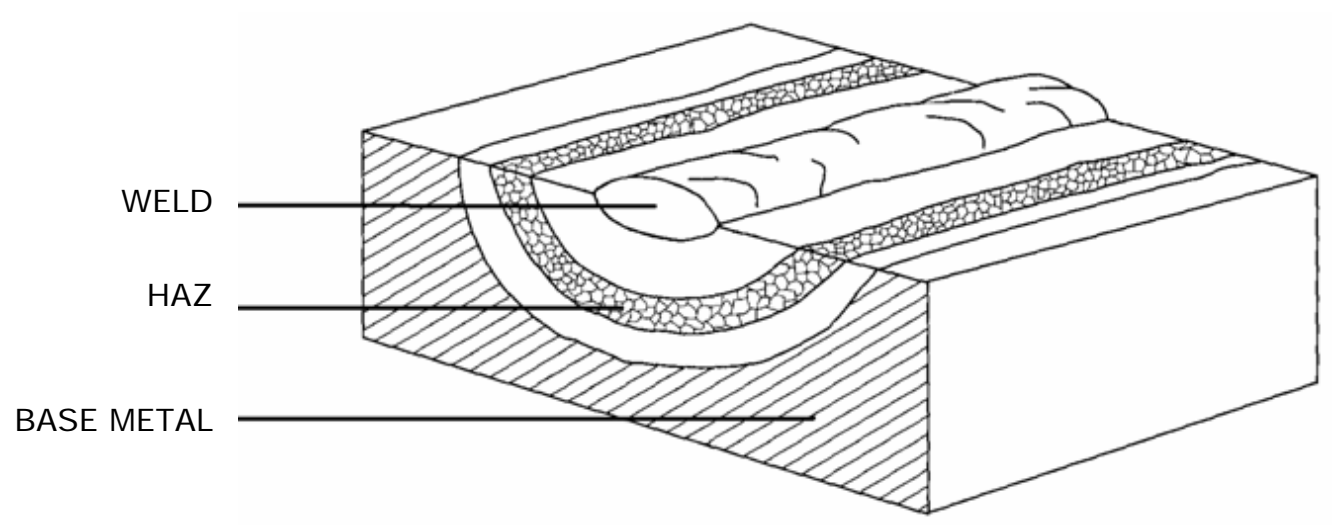

FIGURE 2.2: Heat affected zone in a weldment.

(Jones, 1996)

To prevent sensitisation titanium is added to stainless steel to act as a sacrificial element. The role of titanium is to consume any free carbon in the steel preventing the formation of chromium carbides. Normally, free nitrogen is also soluble in stainless steel causing the formation of titanium-carbon-nitrides. These solid structures are generally found in titanium stabilised stainless steel and are normally too small to have an effect on the properties of the material. The more familiar titanium stabilised stainless steels are 409 and 321 containing about 0.2 to $0.4 \%$ titanium (Mukongo et al., 2003).

\subsection{THE MANUFACTURING PROCESS}

The manufacturing process is vastly simplified by selecting the appropriate raw materials for each stainless steel type. Using scrap metal for the production of stainless steel has the advantage that the base metal (iron) is already cleansed of ore impurities (Columbus, 2006). To reduce production cost, charge-chrome $(50 \% \mathrm{Cr}$, $35 \% \mathrm{Fe}$ and $\pm 4 \% \mathrm{C}$ ) is used as a substitute for pure chromium. Unfortunately chargechrome also contains fairly large quantities of carbon and silicon. During the melting process in the electric arc furnace (EAF) silicon reacts with oxygen to form a highly corrosive component named silica $\left(\mathrm{SiO}_{2}\right)$. At high temperatures silica attacks the refractory material in the EAF, causing irreplaceable damage. To neutralise this effect slag formers such as lime $(\mathrm{CaO})$ and dolomite $(\mathrm{MgO} \cdot \mathrm{CaO})$ are added to the process (Rocabois et al., 2001). Once melted, slag formers cover the liquid metal preventing heat loss to the environment. 
To remove excess carbon from the steel the argon-oxygen-decarburisation (AOD) process is used. During this process oxygen is blown through liquid steel. In this process oxygen reacts with carbon in the liquid metal to produce carbon monoxide gas that leaves the system. The end result is a metal and chromium mixture containing very low levels of carbon which is ideal for stainless steel applications. Final alloy additions to the liquid steel are done at the argon-bubbling-station (ABS). During this process argon (which does not react with the steel) is used to gently stir the liquid metal mixture before casting.

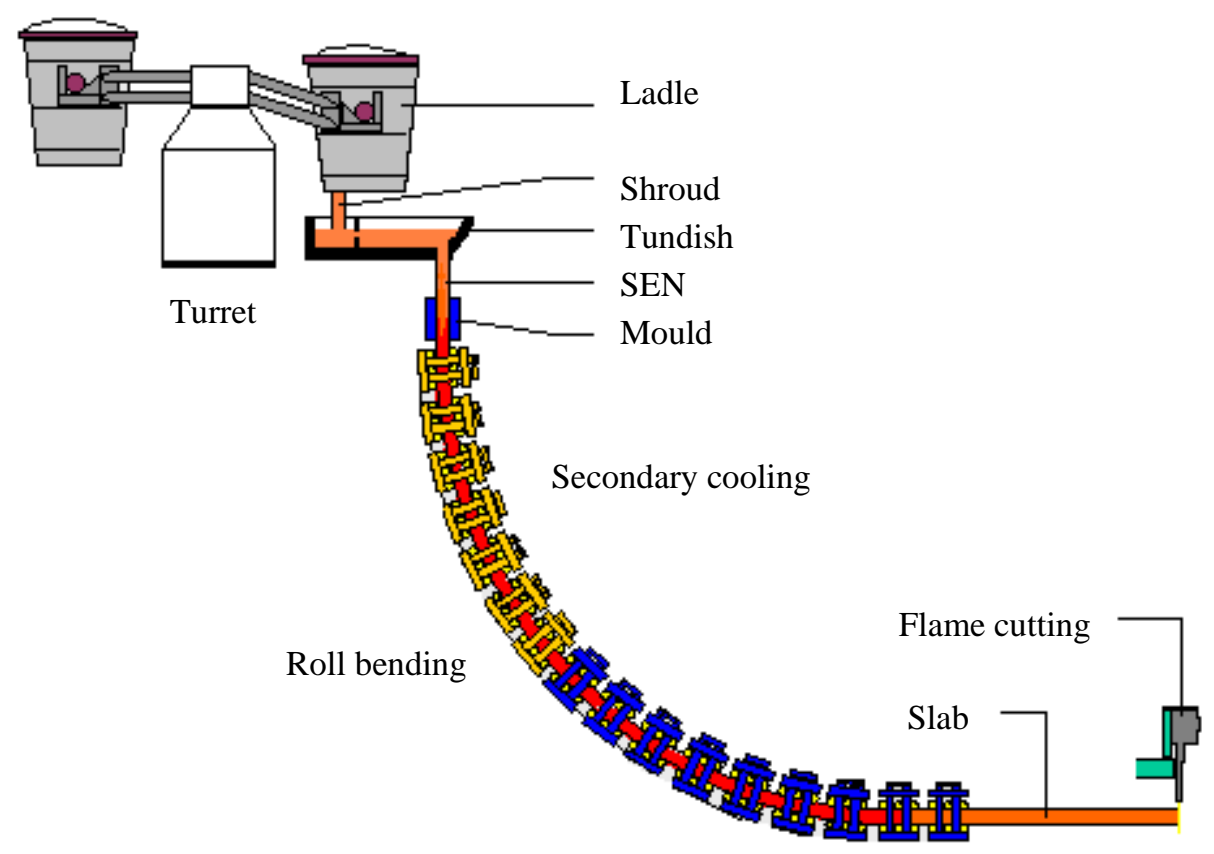

FIGURE 2.3: Process flow diagram for the continuous casting machine.

(http://www.columbus.co.za., 2006)

Continuous casting is the process where liquid steel is solidified into a semi finished billet, bloom or slab. Continuous casting was introduced in the 1950's to meet the demand for more cost effective methods to improve productivity. The continuous casting process consists mainly of a rotary turret, a tundish (which acts as a reservoir for liquid steel), an oscillating copper mould and secondary cooling nozzles (figure 2.3). Liquid steel is poured into a ladle and transported to the turret that rotates the ladle into position above the tundish. The tundish is used to provide a stable flow of liquid steel when transferring molten metal through a submerged entry nozzle (SEN). The SEN discharges liquid steel at a controlled rate into the mould, creating a constant flow level (meniscus) of liquid steel in the mould. 
The continuous casting mould is basically an open-ended box structure that is constantly cooled with water (figure 2.4). The mould is manufactured from pure copper to optimise heat flow from the solidifying steel to the cooling water between the mould walls. Sometimes the working area of the mould is nickel plated to provide a harder working surface to resist the friction associated with continuous casting.

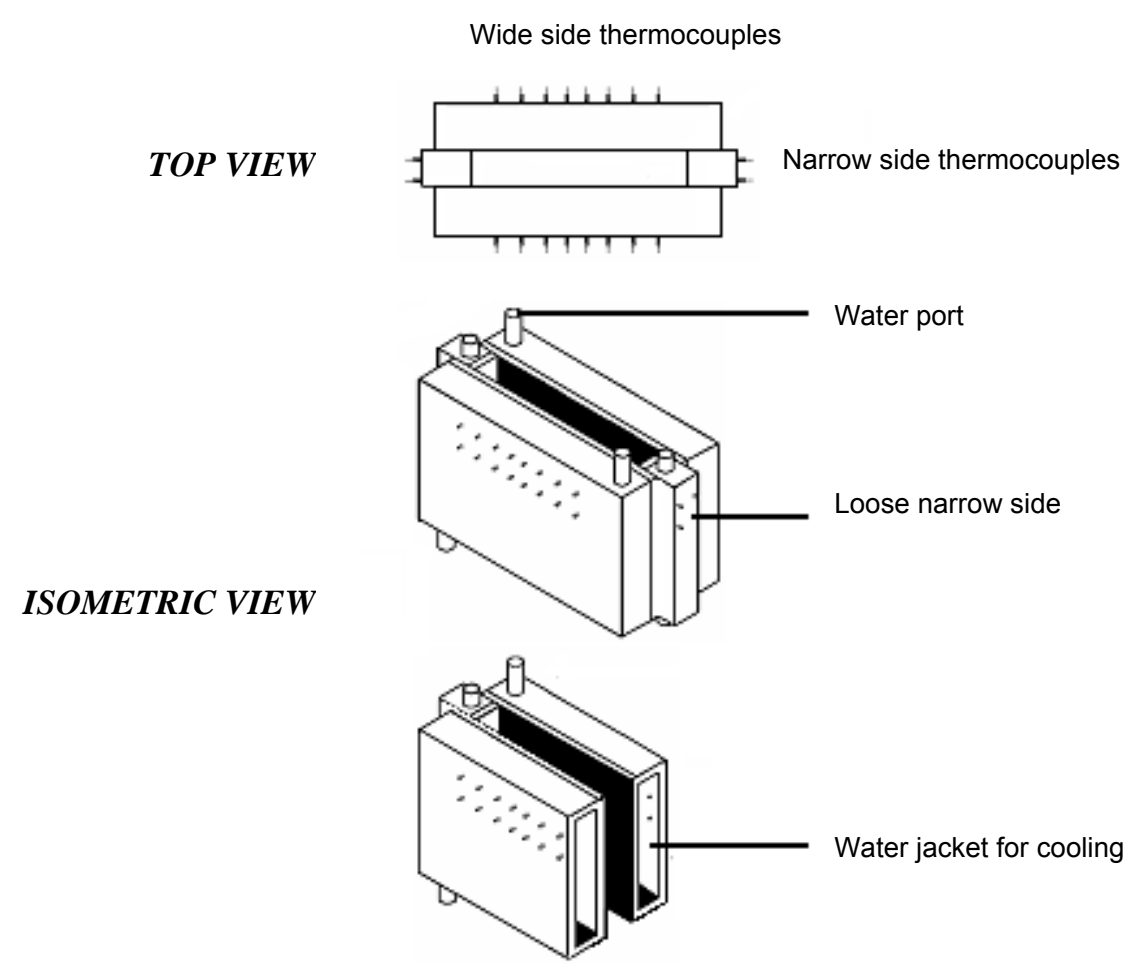

FIGURE 2.4: Sketch of the continuous casting mould.

(Camisani-Calzolari et al., 2003)

The main function of the mould is to cool and solidify liquid steel. The aim is to create a solid outer shell by rapidly cooling the steel in the mould, thus preventing the liquid in the centre from escaping. The mould thus acts as the primary cooling zone, producing a solid steel strand on the outside with a liquid core in the centre. To control the casting process the mould is fitted with thermocouples to continuously measure the temperature in the mould (Camisani-Calzolari et al., 2003). The thermocouples are placed on the outside of the mould but are extended to measure the temperature on the inner mould wall. Temperature profiles are monitored on all four sides of the mould and can be used to detect any problems during the casting process. 
To start a cast, the mould is sealed with a steel dummy bar to prevent liquid steel from pouring out of the mould bottom. Once the steel shell reaches the required thickness, it is slowly pulled from the mould to enter a secondary cooling zone. This secondary cooling zone consists of a large number of cooling nozzles, spraying water directly onto the newly formed steel slab. The withdrawal rate of the slab from the caster depends on the cross-section, grade and quality of the steel being produced, but is normally in the order of $1 \mathrm{~m} / \mathrm{min}$. When exiting the mould the partially solidified steel strand is guided and supported by various sections of metal rollers. Eventually the rollers are used to bend the solid steel slab from a vertical position to a horizontal position. At the end of the roller segments, a cutting torch is used to cut the solidified steel into various slab lengths (figure 2.3). Normally the slab surface is inspected after casting to decide if slab grinding is needed to remove impurities on the surface. 


\section{CHAPTER 3}

\section{LITERATURE SURVEY}

\section{$3.1 \quad$ INTRODUCTION}

The modern way of manufacturing slab material is by means of the bow curved continuous casting process where liquid steel is continually solidified. The casting process is designed to make use of a submerged entry nozzle (SEN) that controls the supply of liquid steel from the tundish to the mould (Figure 3.1 - Budinski, 1999). The SEN helps to maintain a virtually constant meniscus in the mould, making it possible to add mould powder onto the liquid steel in the mould (Ogibayashi et al., 1987). As the mould powder is consumed during the casting process new powder is constantly added to ensure that the steel surface is always completely covered with mould powder.

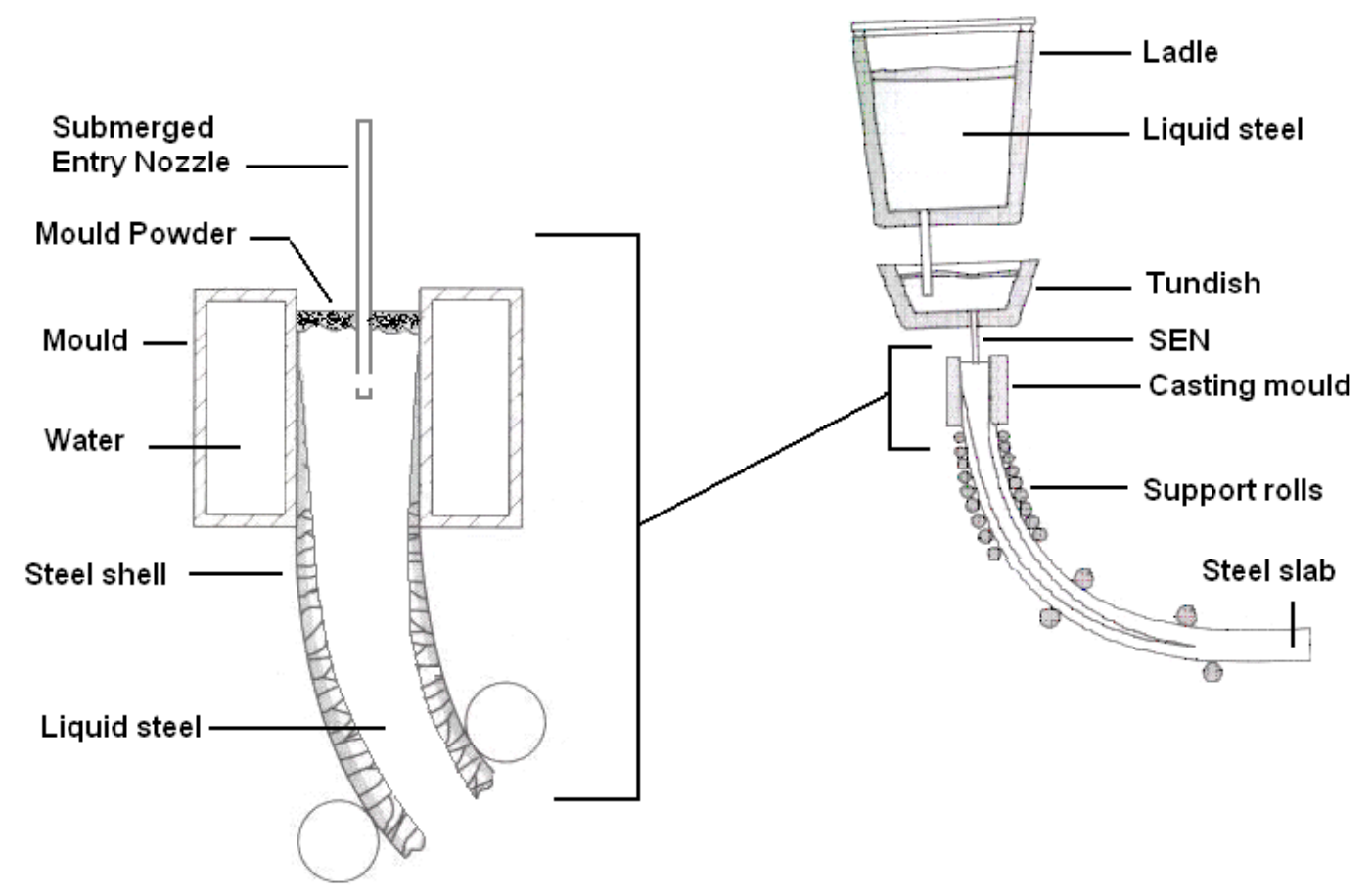

FIGURE 3.1: Schematic representation of the continuous casting process.

(Budinski, 1999)

Mould powder covers the liquid steel surface in the mould, preventing excessive heat loss to the surroundings. Insufficient thermal insulation near the meniscus can lead to the partial solidification of the liquid steel in this area. This is detrimental to the 
casting process because lump formation due to partial solidification is associated with the entrapment of unwanted impurities and can seriously affect the quality of the steel (Irving et al., 1982). Horizontal thermal insulation is dependent on the thickness of the mould powder, but the powder type (granulated or fine particles) and chemical composition of the powder also play an extremely important role (http://www.stollberg.com/functions).

The powder in the mould gradually heats up as it descends towards the liquid steel surface. This allows the carbon in the mould powder to combust. During the combustion process, carbon consumes the nearby oxygen, releasing more heat to the system. This promotes the sintering process while also eliminating oxygen near the steel surface and reducing the possibility of surface inclusions in the final product. This sintering process continues with further heating and eventually transforms the powder to liquid flux (figure 3.2). As the molten flux accumulates a liquid flux pool is formed covering the steel surface in the mould (Mills et al., 2004). The flux pool floats on the steel simply because of the difference in liquid density.

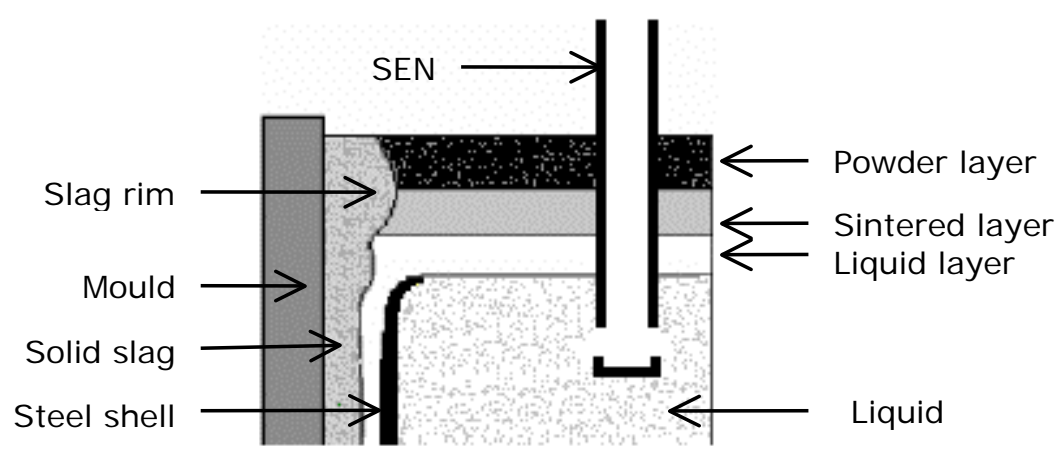

FIGURE 3.2: Mould powder layers during continuous casting.

(Mills et al., 2004b)

At high temperatures (especially when liquid) iron and chromium are highly reactive with oxygen. The function of the molten flux pool is to prevent oxidation by insulating the steel surface from the atmosphere. The molten flux pool also contains elements that will absorb any non-metallic inclusions floating up out of the steel during casting. The metal flow in the mould is also designed to create distinct flow patterns that will allow impurities to float to the top of the mould (Görnerup et al., 2004). Removing impurities during casting is vital for quality products. 
The molten flux pool eventually extends to the sides of the mould and penetrates the gap between the mould and the newly formed steel shell. Due to the rapid cooling of flux against the mould wall a slag rim is formed near the meniscus. The slag rim combined with mould oscillation creates a pumping action that forces liquid flux to flow down the sides of the mould (Shin et al., 2005). As liquid flux is drawn into the mould/shell gap it quickly freezes against the colder walls of the mould. To ensure good lubrication during continuous casting it is important to maintain a thin layer of liquid flux between the moving parts to minimize friction and wear in the mould. To achieve this, theoretically a thin layer of flux must remain liquid against the hot steel shell throughout the entire length of the mould (Ludlow et al., 2004). In practice this is not always feasible because the viscosity of the liquid flux increases as the temperature drops near the bottom of the mould. These areas of the mould are therefore always more exposed to wear.

The lubricating substances i.e. mould flux undoubtedly has an enormous effect on the horizontal heat transfer in the mould. The solidification of liquid flux, including the type of solid slag that forms, depends largely on the cooling rate, and the solidified layer varies in thickness from hotter to colder parts in the mould. The solidified flux (slag) against the mould is usually much thicker than the liquid flux film and is typically of the order of 2 to $3 \mathrm{~mm}$ thick (Schwerdtfeger et al., 1993). This combination of solid and liquid flux, trapped between the mould wall and steel shell, affects the horizontal heat transfer in the mould. In other words, the overall horizontal cooling rate in the mould, to a certain extent, is dependent on the flux layers that form between the mould and shell. In practice the liquid flux used for mould lubrication solidifies in the mould/shell gap and creates a thermal barrier. This affects the mould cooling during casting (Cho et al., 1998).

Because casting is a continuous process it is very important to maintain an overall constant heat removal rate in the mould. The heat removal rate also varies at different heights in the mould. This is due to a combination of factors such as casting speed, mould taper, thermal contraction of the shell and to a lesser extent the solidification of flux. To compensate for metal shrinkage during solidification the narrow sides of the mould is normally designed to taper to the exit side (CamisaniCalzolari et al., 2003). This mould taper also plays an important role in optimising heat transfer in the mould. Controlling heat transfer is essential to obtain good product quality, but mostly heat transfer is controlled to prevent casting failures. 


\subsection{FLUX BASICITY AND CHEMICAL COMPOSITION OF MOULD POWDER}

When steel is melted, the manufacturing process relies on metal oxides known as slags to protect the liquid steel surface from atmospheric contamination. The chemical composition of slag varies for different applications and steel types. Slag powders known as mould powders are also used during the continuous casting process. Mould powders were introduced to the casting process around 1960. Today, many years later, mould powder is still regarded to work in a mysterious way (Mills et al., 2004b).
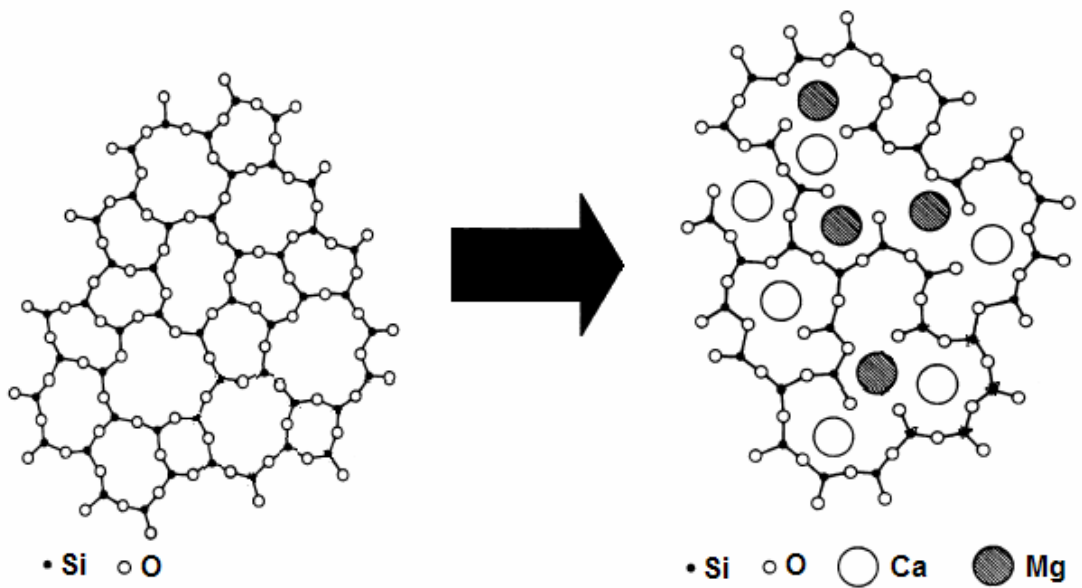

FIGURE 3.3: Influence of calcium and magnesium on the silicate network.

(Mueller et al., 2004)

The exact working mechanism of mould powders is still in dispute, but the chemical nature of these powders is well understood. Equilibrium conditions during the steel making process can be controlled by controlling the slag basicity. Slag basicity refers to the free oxygen anion content of the slag. In general, slags contain a mixture of basic oxides such as $\mathrm{CaO}$ and $\mathrm{MgO}$ and acidic oxides such as $\mathrm{SiO}_{2}$ and $\mathrm{P}_{2} \mathrm{O}_{5}$. The $\mathrm{CaO}$ and $\mathrm{MgO}$ tend to dissociate during heating to form cations $\left(\mathrm{Ca}^{2+}, \mathrm{Mg}^{2+}\right)$ and free oxygen anions $\left(\mathrm{O}^{2-}\right)$. Acidic oxides tend to take up free oxygen anions to form complex $\mathrm{SiO}_{4}{ }^{4-}$ and $\mathrm{PO}_{4}{ }^{3-}$ networks (Turkdogan, 1996) (see figure 3.3).

In the case of mould fluxes the fundamental building block is predominantly the silicate tetrahedron $\mathrm{SiO}_{4}{ }^{4-}$ that forms a crystalline network. To change the physical properties of fluxes, such as viscosity, melting range, glass transition temperature and crystallization temperature, it is necessary to make adjustments to the silica network. Adding modifiers such as $\mathrm{CaO}, \mathrm{MgO}$, and $\mathrm{Na}_{2} \mathrm{O}$ (metal oxides) the silicate network is broken down at high temperatures. In highly basic slags the silicate 
network is completely dissolved to form a mixture of metal cations, oxygen anions $\left(\mathrm{O}^{2-}\right)$ and free $\mathrm{SiO}_{4}{ }^{4-}$.

Other chemical compounds such as $\mathrm{Al}_{2} \mathrm{O}_{3}$ and $\mathrm{B}_{2} \mathrm{O}_{3}$ extend the chain lengths of the Si-O matrix influencing the melting temperature and melting rate of the slag. Fine adjustments to the Si-O matrix can also be made by adding fluoride and carbon. Fluoride $\left(\mathrm{F}^{-}\right)$is known as a fluidizer that decreases the viscosity of the molten flux by breaking down the Si-O network (Pinhero et al., 2004). To control the melting rate, carbon is added in various concentrations. The reaction of carbon with oxygen is exothermic, releasing energy to the system. Other basic compounds such as $\mathrm{BaO}$, $\mathrm{SrO}, \mathrm{Na}_{2} \mathrm{O}, \mathrm{Li}_{2} \mathrm{O}$ and $\mathrm{K}_{2} \mathrm{O}$ are also commonly found in mould powders. These modifiers are used to perform specific tasks depending on the casting process and steel grade that is being manufactured (http://www.stollberg.com/functions).

Slag basicity is the chemical indication of the free oxygen anion content of a slag and can be expressed as follows (Turkdogan, 1996):

$$
\operatorname{Basicity}(B)=\frac{\% \mathrm{CaO}+1.4(\% \mathrm{MgO})}{\% \mathrm{SiO}_{2}+0.84\left(\% \mathrm{P}_{2} \mathrm{O}_{5}\right)}
$$

If the basicity of the slag is greater than one, the slag is classified as a basic slag, and if the basicity is less than one the slag is classified as an acidic slag. Due to the dominating concentrations of $\mathrm{CaO}$ and $\mathrm{SiO}_{2}$ in mould powders and, in general, due to the absence of $\mathrm{P}_{2} \mathrm{O}_{5}$, the slag basicity of mould powders can be simplified to the following equation.

$$
\operatorname{Basicity}\left(B_{F}\right)=\frac{\% \mathrm{CaO}}{\% \mathrm{SiO}_{2}}
$$

Mould flux basicity normally ranges between 0.8 and 1.25 depending on the application and plant conditions. Higher flux solidification temperatures are associated with basic slags, while lower solidification temperatures are associated with acidic slags (Pinheiro et al., 2004). A typical mould powder composition is indicated in the table 3.1 . 
TABLE 3.1: Chemical compositions for typical mould flux (Pinheiro et al., 2004)

\begin{tabular}{|c|c|c|c|c|c|c|}
\hline $\mathbf{A l}_{2} \mathbf{O}_{3}$ & $\mathbf{B a O}$ & $\mathbf{B}_{2} \mathbf{O}_{3}$ & $\mathbf{C}$ & $\mathbf{C a O}$ & $\mathbf{F}$ & $\mathbf{F e O}$ \\
$0-10 \%$ & $0-10 \%$ & $0-10 \%$ & $1-25 \%$ & $25-42 \%$ & $4-10 \%$ & $0-5 \%$ \\
\hline $\mathbf{K}_{2} \mathbf{O}$ & $\mathbf{L i}_{2} \mathbf{O}$ & $\mathbf{M g O}$ & $\mathbf{M n O}$ & $\mathbf{N a}_{2} \mathbf{O}$ & $\mathbf{S i O}_{2}$ & $\mathbf{T i O}_{2}$ \\
$0-5 \%$ & $0-10 \%$ & $0-10 \%$ & $0-10 \%$ & $1-20 \%$ & $20-50 \%$ & $0-5 \%$ \\
\hline
\end{tabular}

Mould powders with the chemistry in table 3.1 are the result of research and development. Today there are many different casting powders all specially manufactured for each steel type and application. Casting fluxes or mould powders used for continuous casting can be found in one of the following forms:

\section{- FLY ASH BASED MOULD POWDERS}

Fly ash powders were the first powders to be introduced to continuous casting and contained fly ash obtained from coal fired power stations. These powders were carbon based (18 to $20 \%$ ), but also contained a mixture of $\mathrm{Al}_{2} \mathrm{O}_{3}$ and $\mathrm{SiO}_{2}$ which made the powder very acidic. Fluxing agents such as $\mathrm{Na}_{2} \mathrm{CO}_{3}$ were added to increase the basicity (Pinheiro et al., 2004).

\section{- SYNTHETIC MOULD POWDERS}

With more development ash powders were replaced by synthetic mould powders. These powders are mechanical blends of raw materials such as lithium feldspars, sodium feldspars and wollastonite (Grieveson et al., 1988).

\section{- RE-FUSED MOULD FLUXES}

These fluxes were produced to improve the non-uniformity in chemical composition associated with mechanical mixtures. Re-fused mould flux contains pre-melted flux that is crushed and mixed with carbon particles (http://www.stollberg.com/functions).

\section{- GRANULATED MOULD FLUXES}

Granulated (extruded) powders are mainly designed to have less dust for better quality control and to minimise health hazards. Water is added to the mould powder to produce a "slurry" or suspension that is extruded to form spherical granules. Hot air is used to evaporate the water and the result is a dried granular mould flux ideal for automatic flux feeding during continuous casting. 


\section{- STARTING POWDERS}

Mould powders with a low melting point are used to start the casting process and are therefore named start-powders. Start-powders are designed to melt quickly when in contact with the incoming liquid steel from the tundish. The function of start-powders is to create a large molten flux pool that can easily infiltrate the mould/strand gap to provide adequate lubrication at the beginning of the casting process. Chemically these powders contain high levels of $\mathrm{Na}_{2} \mathrm{O}$ and fluorides to ensure the low melting point needed for lubrication (Pinheiro et al., 2004). Start-powders also contain virtually no carbon $(\% \mathrm{C}<1)$ to prevent carburisation of the steel. As a result of the low carbon content, these powders cannot provide the necessary protection against atmospheric contamination. Hence the first part of the cast is usually removed and recycled. It is therefore recommended that start-powders should not be used for longer than necessary.

\subsection{FLUX PROPERTIES AND PROCESS PARAMETERS}

\subsubsection{MOULD FLUX VISCOSITY}

One of the main functions of mould flux is to lubricate the moving parts in the mould during casting to prevent shell-to-mould friction. Mould flux is specifically engineered to remain fluid close to the steel shell in order to provide the liquid lubrication needed to prevent wear. To quantify this effect the viscosity of the liquid flux must be measured.

$$
\tau=\eta \frac{d v}{d x}
$$

Viscosity is used to quantify a liquid's resistance to flow in the presence of an external force. In general a liquid having a high viscosity is not highly fluid and vice versa. In short, Newton defined viscosity $(\eta)$ as a measure of the shear stress $(\tau)$ generated by a liquid between two adjacent layers moving under the influence of a velocity gradient $(d v / d x)$. All fluids obeying equation 6 , including liquid fluxes, are called Newtonian fluids.

The primary factors determining flux viscosity are temperature and flux chemistry. The effect of temperature is fairly obvious (temperature increase would result in viscosity decrease), but the effect of chemistry is much more complex. Recent 
studies on titanium pickup by mould fluxes for stainless steel showed a gradual increase in titanium oxide $\left(\mathrm{TiO}_{2}\right)$ content, reaching steady state compositions within 20 minutes of the start of the cast (Mukongo et al., 2004).
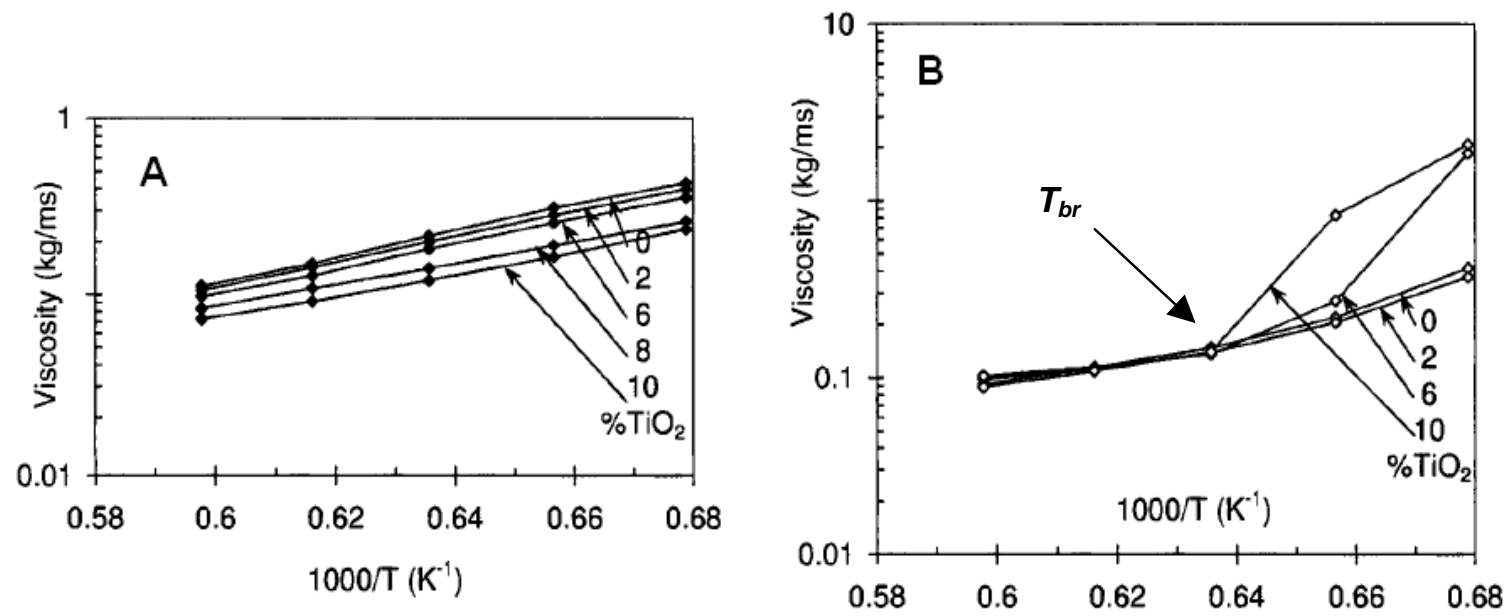

FIGURE 3.4: Effects of temperature and $\mathrm{TiO}_{2}$ additions on mould flux viscosity.

A) Austenitic steel, basicity as received; B) Austenitic steel, basicity increased to $(\% \mathrm{CaO}) /\left(\% \mathrm{SiO}_{2}\right)=1.2$

(Mukongo et al., 2004)

The pickup of titanium oxide resulted in the reduction of silica and ultimately changing the flux basicity. This change in basicity resulted in partial solidification of the liquid flux causing a sharp increase in the apparent viscosity, and hence a greater likelihood of lubrication difficulties.

Figure 3.4 shows the effects of increased titanium oxide on flux viscosity. This sharp increase in viscosity is often considered as a breakpoint. When measuring the viscosity of a particular flux during cooling, there is a point at which the viscosity suddenly increases (Sridhar et al., 2000). Usually the flux starts to crystallise at this point becoming less fluid as the viscosity increases. The temperature at this point is also known as the solidification temperature, but is commonly referred to as the breakpoint temperature $\left(T_{b r}\right)$. Since viscosity is closely related to lubrication during the casting process, the breakpoint temperature is a useful guide to select mould flux for casting. The correct measure would be to ensure that the temperature near the exit of the mould always stays above the liquidus breakpoint temperature of the flux. 


\subsubsection{PROCESS PARAMETERS AFFECTING MOULD LUBRICATION}

In this section plant parameters will be discussed briefly.

\section{- MOULD OSCILLATION}

During continuous casting, the mould is continually reciprocated, typically by making use of a cam or hydraulic oscillatory system. This was primarily introduced in 1945 to reduce the sticking of the solidifying steel shell to the mould wall. Mould oscillation causes marks on the surface of the cast product known as oscillation marks (Howe et al., 1987). The cavities between oscillation marks sometimes trap mould powder that could lead to serious quality issues in downstream processes. Deep oscillation marks also result in a decrease in heat transfer and give rise to heat transfer fluctuations. Oscillation mark depths can be manipulated by changing the oscillating frequency and the casting speed. However, this in turn could lead to serious lubrication problems (Sridhar et al., 2000).

\section{- NEGATIVE STRIP}

Negative strip is the term used to describe the downward movement of the mould when oscillated. Negative strip is usually measured in seconds and is a function of the oscillating frequency. In practice the mould instantaneously moves downward at a speed slightly higher than the withdrawal rate of the strand. This is done to prevent mould-shell adhesion during the subsequent upward motion of the strand in order to avoid shell rupture. Negative strip is sometimes referred to as the "healing time" since the strand is in compression allowing the steel shell to grow in thickness and strength.

\section{- POSITIVE STRIP}

Positive strip is the term used to describe the upward movement of the mould during casting. Positive strip is the difference between an oscillating cycle and the negative strip time. On the upstroke the mould movement is opposing the withdrawal direction creating tension in the newly formed shell. Poor lubrication between the shell and the mould can lead to the rupture of the shell. The positive stripping time is therefore sometimes referred to as the "tension time" (Mills et al., 1991).

\section{- FLUX INFILTRATION}

Mould oscillation gives rise to the infiltration of liquid flux into the gap between the mould wall and steel shell. Two theories have been proposed regarding the period 
when liquid flux flows into the mould/shell gap (Itoh et al., 2000). In the first theory it is believed that flux inflow occurs during the negative strip period. This downward movement of the mould causes the slag rim to create a "pumping" action down the sides of the mould. It is believed that liquid flux is forced to flow in between the mould and the solid steel shell by the vertical movement of the slag rim. The second theory suggests that flux flow is predominant during the positive strip period. During the negative strip period, the flow of liquid flux is prevented by semi-solidified flux (slag rim), blocking the flow of liquid into the mould/shell gap. This allows the inflow of liquid flux only when the mould is moving upwards (Mills et al., 2004b).

\section{- POWDER CONSUMPTION}

The powder consumption during casting can be used as a reasonable measure to predict the flow of flux into the mould/shell gap. The powder consumption in other words, is a good measure of lubrication. It is estimated that about $90 \%$ of the flux consumed is used for the formation of the liquid flux film. The rest of the flux is mainly lost to the slag rim and trapped flux in the oscillation marks (Mills et al., 2004b).

$M_{c}=\frac{M_{p}}{2\left(x_{t}+W\right) L}=\frac{\text { powder_mass }}{\text { total_slab_area }}$

$M_{c}=$ powder consumption $\left[\mathrm{kg} / \mathrm{m}^{2}\right], \quad M_{p}=$ powder consumed $[\mathrm{kg}]$, $x_{t}=$ Slab thickness $[\mathrm{m}], \quad W=$ Slab width $[\mathrm{m}], \quad L=$ Slab cast length [m]

The average powder consumption is calculated by weighing the powder used during the cast and measuring the total cast area. (Mass loss due to carbon combustion must be subtracted.) Normally powder consumption increases with decreasing casting speed, mould oscillation and flux viscosity. Research also indicates that the mould powder consumption rate per oscillation cycle depends strongly on positive strip time and also correlates with frequency and negative strip time (Shin et al., 2005). 


\subsection{MOULD FLUX SOLIDIFICATION}

\subsubsection{MOULD FLUX CRYSTALLIZATION}

At steady state conditions liquid mould flux solidifies to form crystals. Many different solids crystallise from the basic elements found in mould powders and these crystalline phases each has a distinct solidification temperature. In practice crystals do not normally crystallize individually, but are rather found in combination with several other crystal types (especially if the crystal types have roughly the same crystallization temperature). The results from the cumulative annealing of decarburized mould powders are summarized in table 3.2 (Grieveson et al., 1988). These results give an indication of the expected crystal types that form when cooling liquid flux under steady state conditions.

TABLE 3.2: Solid crystal formation from basic mould powder elements.

(after Grieveson et al., 1988).

\begin{tabular}{|c|c|c|c|c|}
\hline \multicolumn{2}{|c|}{ POWDER COMPOUNDS } & ELEMENTS & \multicolumn{2}{|c|}{ CRYSTALS IN SOLID SLAG } \\
\hline Lime & $\mathrm{CaO}$ & $\mathrm{Ca}, \mathrm{Si}$ & $\begin{array}{l}\text { Pseudo }(\beta)- \\
\text { wollastonite }\end{array}$ & $\mathrm{CaO} \mathrm{SiO}_{2}$ \\
\hline Silica & $\mathrm{SiO}_{2}$ & Ca SiAl & Anorthite & $\mathrm{CaO} . \mathrm{Al}_{2} \mathrm{O}_{3} .\left(\mathrm{SiO}_{2}\right)_{2}$ \\
\hline Alumina & $\mathrm{Al}_{2} \mathrm{O}_{3}$ & & Gehlenite & $(\mathrm{CaO})_{2} \cdot \mathrm{Al}_{2} \mathrm{O}_{3} \cdot \mathrm{SiO}_{2}$ \\
\hline Calcium fluoride & $\mathrm{CaF}_{2}$ & $\mathrm{Ca}, \mathrm{Si}, \mathrm{F}$ & Cuspidine & $(\mathrm{CaO})_{3}\left(\mathrm{SiO}_{2}\right)_{2} \cdot \mathrm{CaF}_{2}$ \\
\hline Sodium oxide & $\mathrm{Na}_{2} \mathrm{O}$ & $\mathrm{Ca}, \mathrm{Si}, \mathrm{Na}$ & Pectolite & $\mathrm{Na}_{2} \mathrm{O} \cdot \mathrm{CaO} \cdot\left(\mathrm{SiO}_{2}\right)_{3}$ \\
\hline $\begin{array}{l}\text { Sodium-aluminium- } \\
\text { fluoride }\end{array}$ & $\mathrm{Na}_{3} . \mathrm{Al} . \mathrm{F}_{6}$ & $\mathrm{Si}, \mathrm{Al}, \mathrm{Na}$ & $\begin{array}{l}\text { Nepheline / } \\
\text { Carnegieite }\end{array}$ & $\mathrm{Na}_{2} \mathrm{O} \cdot \mathrm{Al}_{2} \mathrm{O}_{3} \cdot\left(\mathrm{SiO}_{2}\right)_{2}$ \\
\hline
\end{tabular}

Casting powders are essentially mixtures of lime $(\mathrm{CaO})$, silica $\left(\mathrm{SiO}_{2}\right)$, alumina $\left(\mathrm{Al}_{2} \mathrm{O}_{3}\right)$, calcium-fluoride $\left(\mathrm{CaF}_{2}\right)$, sodium oxide $\left(\mathrm{Na}_{2} \mathrm{O}\right)$, with minor additions of magnesium oxide $(\mathrm{MgO})$, iron oxide $(\mathrm{FeO})$ and manganese oxide $(\mathrm{MnO})$. The variation in these constituents depends largely on the powder manufacturer. For example the fluoride content can be made up from $\mathrm{CaF}_{2}$ or sodium-aluminiumfluoride $\left(\mathrm{Na}_{3} \mathrm{AlF}_{6}\right)$.

Studying the solidification of liquid flux under isothermal conditions indicated that cuspidine was generally the first solid phase to crystallise in all mould powders containing fluoride. Pectolite and pseudo-wollastonite are also frequently formed when liquid flux is solidifying at high temperatures. When $\mathrm{Al}_{2} \mathrm{O}_{3}$ is present in the mould powder the most likely crystal phase to form are anorthite, gehlenite and 
nepheline (Grieveson et al., 1988).

When liquid flux solidifies the true nature of the flux functionality in the mould is revealed. The behaviour of the mould flux is drastically changed when the flux transfers from a liquid to a solid state. In general the flux viscosity rapidly increases and the heat transfer capability of the flux decreases. To understand the effect of flux solidification on the properties of mould flux, it is essential to study the crystal types that form during solidification.

Key parameters determining the crystal type and the crystal structure of solid flux are essentially solidification temperature and time. A number of isothermal experiments were carried out at high temperatures to develop time-temperature-transformation curves for a specific solidifying mould powder (figure 3.5). The following graph illustrates the solidification temperature $\left({ }^{\circ} \mathrm{C}\right)$ against time $(\mathrm{sec})$ of mould powder with the following basic chemical composition: $\mathrm{CaO}=44.5 \%, \mathrm{SiO}_{2}=44.5 \%, \mathrm{Na}_{2} \mathrm{O}=7.0 \%$ and $\mathrm{Al}_{2} \mathrm{O}_{3}=4.0 \%$

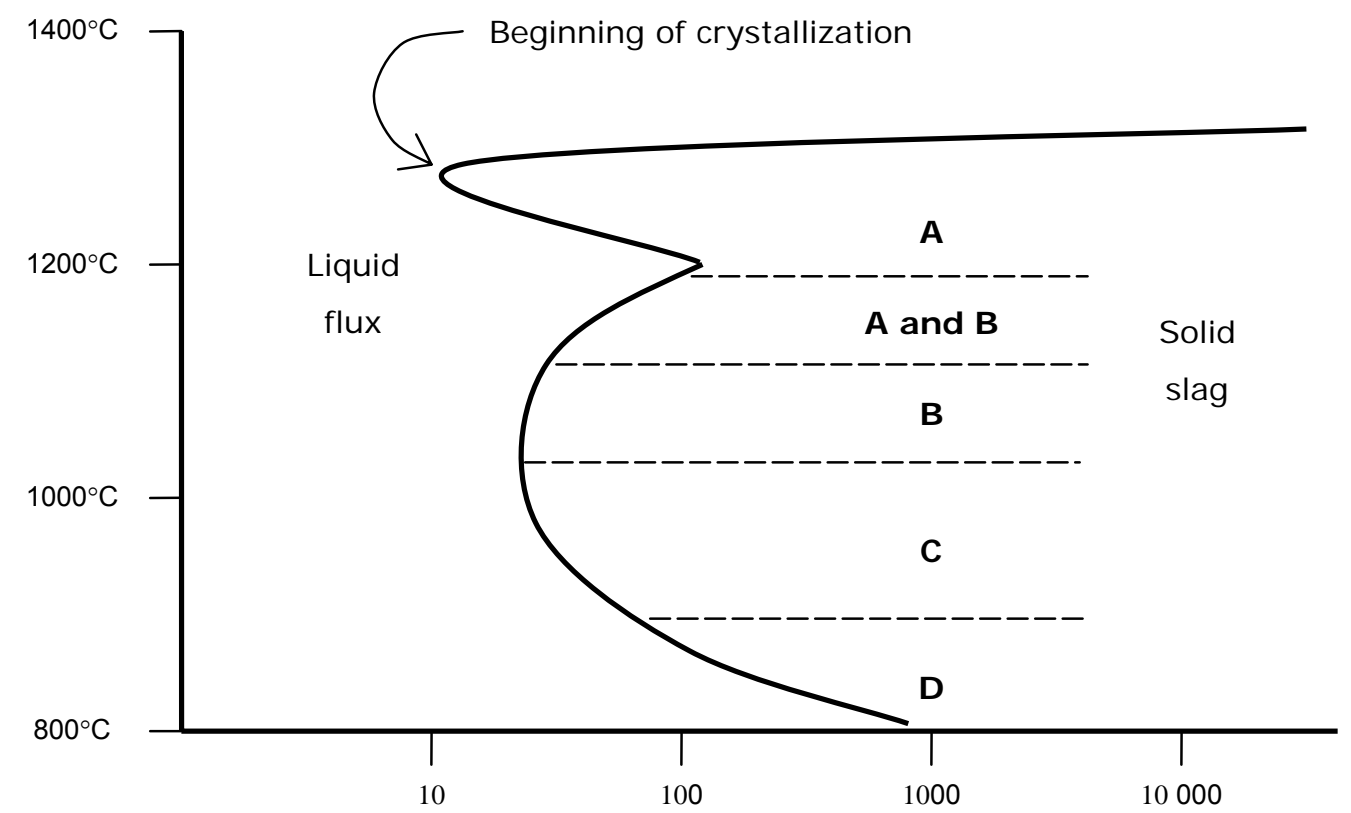

Log time (seconds)

FIGURE 3.5: Time-Temperature-Transformation curve.

(Orrling et al., 2000) 
For the specific mould powder in figure 3.5 the flux remains completely liquid at temperatures above $1350^{\circ} \mathrm{C}$. In practice this temperature should roughly be close to the solidifying temperature of the cast material. When the temperature drops to about $1300^{\circ} \mathrm{C}$ the first crystals start to solidify. With more cooling the second crystalline structure will start to solidify at roughly $1000^{\circ} \mathrm{C}$ (Orrling et al., 2000). This indicated that mould flux, under isothermal conditions, solidifies at different stages to form more than one solid phase. (Essentially the start of crystallization was signified by the presence of $0.5 \%$ crystalline fraction in the test sample while the remainder of the flux was still in the liquid phase.) (Orrling et al., 2000)

During isothermal solidification the formation of solids leads to segregation in the remaining liquid (Reed-Hill, 1994). Segregation is also commonly found during flux solidification. Slow cooling causes $\mathrm{CaO}$-solids (mainly cuspidine) to solidify first, leaving the remaining liquid flux enriched with $\mathrm{SiO}_{2}$. The reason for this is because $\mathrm{CaO}-$ solids in general have a higher solidification temperature compared to $\mathrm{SiO}_{2}-$ based crystals (Itoh et al., 2000).

During continuous casting isothermal conditions are only present in the mould near the hot steel shell. The mould flux in this region is theoretically a combination of solidus and liquid flux. This partially solidified flux with a varying chemical composition affects the viscosity of the liquid flux. More importantly, segregation greatly influences the solidifying nature of the mould flux, directly affecting the solids temperature and crystalline phases that form in the mould/shell gap (Yamauchi et al., 2002).

As the solidifying temperature of mould flux is decreased the crystallization size is also affected. In general, large crystals are associated with slow cooling at high temperatures, while smaller crystals are formed at higher cooling rates. The first crystals to solidify from a liquid flux are generally large dendritic type crystal structures that grow into the liquid phase (Reed-Hill, 1994).

Crystal formation is also associated with the precipitation of crystals in a solid solution. In other words, at elevated temperatures crystals will start to form in the solid glassy structure. These crystals are generally very small in size and associated with structural porosity. Porosity in solid flux forms when a glassy flux structure transforms to a crystalline structure with a higher density creating voids in the solid 
structure. This effect is largely influenced by flux basicity that changes as a result of solid-to-liquid segregation. When using a mould flux of a larger basicity $\left(\mathrm{CaO} / \mathrm{SiO}_{2} \approx 1.41\right)$ the effect of shrinkage during crystallization will be larger. When using a flux with a low basicity $\left(\mathrm{CaO} / \mathrm{SiO}_{2} \approx 0.96\right)$, the shrinkage effect will be less severe (Cho et al., 2001).

Considering the factors affecting crystal growth, the expected crystal structure during isothermal cooling conditions as indicated in figure 3.5 can now be divided into four groups. Crystal types A, B, C and D formed at specific temperatures after specific times and the results can be summarized as follows (Orrling et al., 2000):

\section{- EQUIAXED CRYSTALS - TYPE A}

The first crystals to form at a high temperature are normally equiaxed crystals. These crystals have a clear dendritic microstructure and when they solidify they "grow" into the liquid flux phase. Equiaxed crystals are not necessarily equilibrium phases and can eventually transform to a smaller and more stable crystalline phase.

\section{- COLUMNAR CRYSTALS - TYPE B}

With increased cooling the flux microstructure will consist of two morphologies (equiaxed dendrites and columnar crystals). At this point the slag viscosity will increase as the temperature decreases. It is believed that fluid flow motion of the flux causes dendrite fragmentation that results in equiaxed crystals.

\section{- FACETED CRYSTALS - TYPE C}

As the degree of under cooling further increases, faceted crystals begin to form. Faceted crystals are the result of homogeneous nucleation as the microstructure transforms at some temperature below the solidus temperature.

\section{- FINE CRYSTALS - TYPE D}

When under cooling exceeds $360^{\circ} \mathrm{C}$, fine crystals precipitate from the faceted crystals. The size of the faceted crystals decreases with decreasing temperature to form fine crystals with the same morphology. This microstructure is typically formed at low temperatures and associated with porosity. 


\subsubsection{MOULD FLUX SOLIDIFICATION DURING CONTINUOUS CASTING}

In the continuous caster, mould powder will be subjected to various different rates of cooling. To simulate the cooling process and to understand the effect of nonisothermal conditions on the solidification behaviour of mould flux, experimental tests were done to construct the CCT diagrams (continuous cooling transformation) (Orrling et al., 2000). Experiments were also done on various mould fluxes using double and single hot thermocouple techniques to verify the behaviour of mould flux under constant cooling conditions (Kashiwaya et al., 1998).

The following graph illustrates the cooling rates $\left({ }^{\circ} \mathrm{C} / \mathrm{s}\right)$ for a mould powder with the following basic chemical composition: $\mathrm{CaO}=44.5 \%, \mathrm{SiO}_{2}=44.5 \%, \mathrm{Na}_{2} \mathrm{O}=7.0 \%$ and $\mathrm{Al}_{2} \mathrm{O}_{3}=4.0 \%$

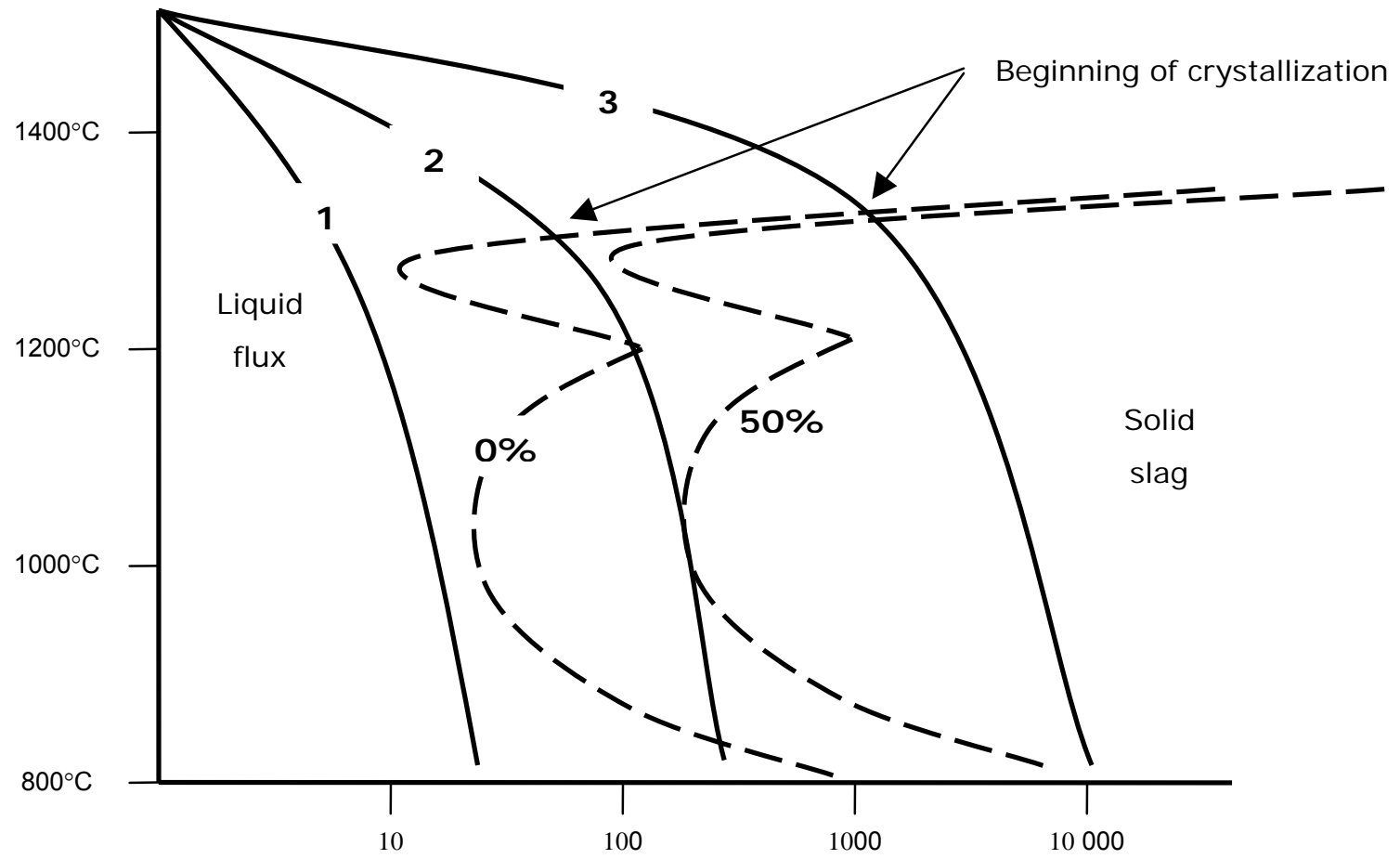

Log time (seconds)

FIGURE 3.6: Mould cooling rates during continuous casting.

(Orrling et al., 2000)

\section{- COOLING RATE 1 - GLASSY STRUCTURE}

This cooling rate represents the quenching of liquid flux. The solid structure that forms during rapid cooling is a solid glass-like structure. This solid solution is a 
mixture of all the elements found in mould powder without the formation of any crystals. In other words the cooling rate is so severe that there is no time for solid crystals to form. The glassy structure is usually a homogeneous solid solution containing all the mould powder elements without forming crystals.

\section{- COOLING RATE 2 - GLASSY \& CRYSTALLINE STRUCTURE}

This cooling rate represents the formation of roughly $50 \%$ solid crystals while the remainder of the liquid flux will solidify as a glassy phase. Cooling-rate-2 (figure 3.6) is, in other words, low enough for high solidification temperature crystals to form, but not for crystals that solidify at lower temperatures. Referring to figure 3.5 , crystals from the upper nose $\left(1300^{\circ} \mathrm{C}\right)$ are therefore more likely to form while crystals from the lower nose $\left(1000^{\circ} \mathrm{C}\right)$ will not form. The elements for these crystals will still be in solution when the remainder of the liquid flux solidifies.

The formation of a combination solid structure (glass/crystal) is normally associated with liquid flux segregation and porosity. As previously mentioned this largely depends on the changing effect of flux chemistry and basicity.

\section{- COOLING RATE 3 - CRYSTALLINE STRUCTURE}

Cooling rate 3 (figure 3.6) represents the ultimate slow cooling of liquid flux to completely transform to solid crystals. This cooling rate approximates the isothermal conditions that are normally found closer to the steel shell as discussed in the previous section.

Investigating the solid layers that form in the mould/shell gap during continuous casting, characteristics can be seen that are similar to the cooling rates represented in figure 3.6. When the liquid flux is quenched a glassy structure is formed owing to rapid cooling (cooling-rate-1 figure 3.6). This type of solid structure is normally found on the mould walls where the cooling rate is more severe. When glass is formed liquid flux directly transforms to a solid solution.

Investigating the crystalline layer that formed between the mould and steel shell also showed the nucleation of many solid particles in a glass base matrix. Slower cooling therefore allowed more time for crystal formation during solidification representing cooling-rate-2 (figure 3.6) (Courtney et al., 2001). Crystals found next to the steel shell are much bigger compared with the crystals found closer to the mould. Cooling 
next to the shell therefore represented by cooling-rate-3 (figure 3.6).

There is normally no distinct transition from glassy to crystalline flux, but in many cases the sharp transition from liquid to crystalline flux can be seen. The combined glassy and crystalline flux layer is called the solid slag layer, while the liquid flux layer is sometimes referred to as the lubricating flux layer.

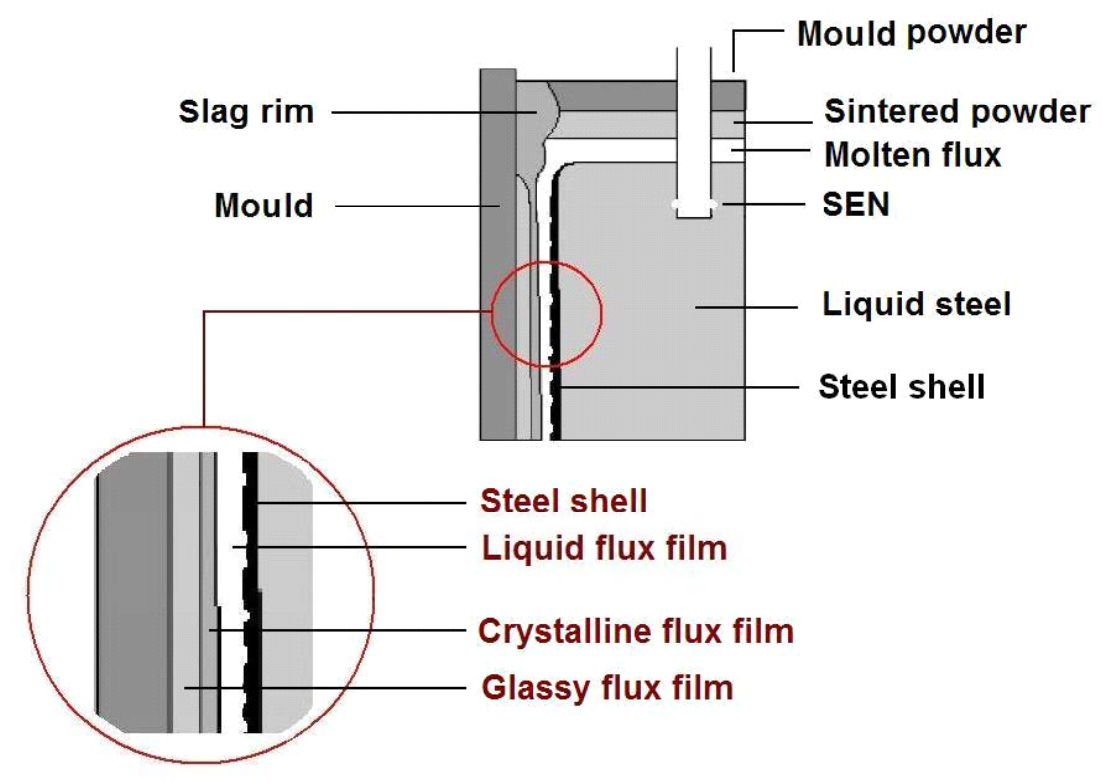

FIGURE 3.7: Representation of the layers that form during mould flux solidification. (Mills et al., 2004b)

To conclude, repeated studies indicated that liquid flux from the molten flux pool penetrates the mould/shell gap and solidifies to form three very important flux layers (Mills et al., 2004b):

i) The glassy flux layer adjacent to the mould.

ii) The liquid flux layer in contact with the steel shell.

iii) The crystalline flux layer between the solid glassy layer and the liquid flux.

\subsubsection{THE EFFECT OF TITANIUM ON FLUX CRYSTALLIZATION}

For titanium stabilised stainless steel, precipitation of some titanium nitride (TiN) appears unavoidable during continuous casting, because the intentionally added titanium can react with residual nitrogen in the steel at temperatures approaching the liquidus temperature of the steel (equation 8 - Mukongo et al., 2004). 
$[\mathrm{Ti}]+[\mathrm{N}] \rightarrow<\mathrm{TiN}>$

$<\mathrm{TiN}>+\left(\mathrm{SiO}_{2}\right) \rightarrow\left(\mathrm{TiO}_{2}\right)+[\mathrm{Si}]+1 / 2\left(\mathrm{~N}_{2}\right)_{\mathrm{g}}$

[ ] = species dissolved in the liquid stainless steel, $<>=$ solids ,

$($ ) = species dissolved in the mould flux,

However, the solubility of titanium nitride in mould fluxes is very small (less than $0.5 \%$ by mass). This causes the oxidation reaction of solid titanium nitride by silica $\left(\mathrm{SiO}_{2}\right)$ which is present in the mould flux, to yield titanium oxide $\left(\mathrm{TiO}_{2}\right.$ and $\left.\mathrm{Ti}_{2} \mathrm{O}_{3}\right)$ which dissolves in the mould flux as indicated in equation 9.

Titanium, which is dissolved in the steel, can also react directly with silica in the mould flux to form titanium oxide. The oxides that may form mainly include $\mathrm{TiO}_{2}$ and occasionally sub oxides such as $\mathrm{Ti}_{3} \mathrm{O}_{5}$.

$$
\begin{gathered}
{[\mathrm{Ti}]+\left(\mathrm{SiO}_{2}\right) \rightarrow\left(\mathrm{TiO}_{2}\right)+[\mathrm{Si}]} \\
6[\mathrm{Ti}]+5\left(\mathrm{SiO}_{2}\right) \rightarrow 2\left(\mathrm{Ti}_{3} \mathrm{O}_{5}\right)+5[\mathrm{Si}]
\end{gathered}
$$
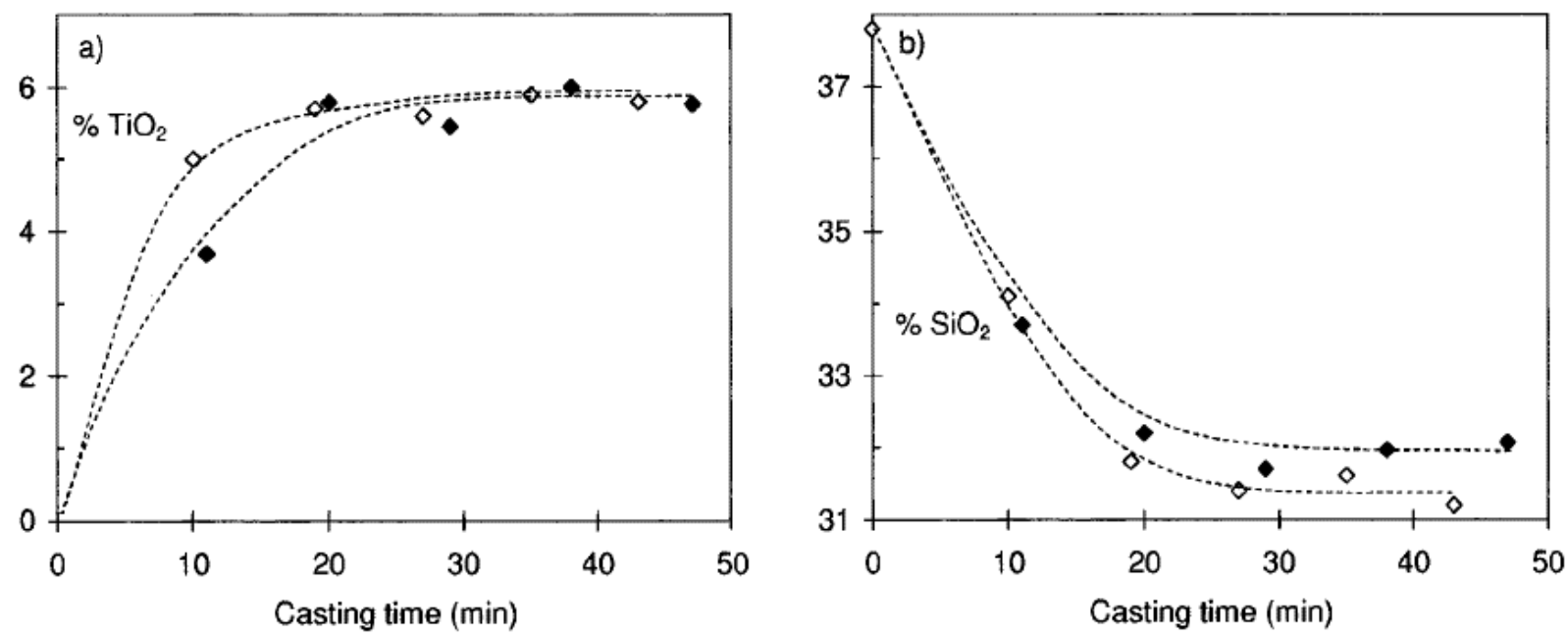

FIGURE 3.8: Changing $\mathrm{TiO}_{2}$ (a) and $\mathrm{SiO}_{2}$ (b) contents in mould flux used for the casting of 321-austenitic stainless steel.

(Mukongo et al., 2004).

Regardless of the reaction route, a constant ratio of $\mathrm{TiO}_{2}$ pickup to $\mathrm{SiO}_{2}$ loss is expected during the continuous casting process. It has also been shown that steady 
state compositions in the liquid mould flux are achieved within 20 minutes of the start of the cast (figure 3.8 - Mukongo et al., 2004). The basicity is dramatically increased due to the pickup of $\mathrm{TiO}_{2}$ and the loss of $\mathrm{SiO}_{2}$. These increases in flux basicity enhance the possibility of perovskite $\left(\mathrm{CaTiO}_{3}\right)$ formation because of the higher activity of $\mathrm{CaO}$ in the mould.

$\left(\mathrm{TiO}_{2}\right)+(\mathrm{CaO}) \rightarrow<\mathrm{CaTiO}_{3}>$
$\left(\mathrm{Ti}_{2} \mathrm{O}_{3}\right)+2(\mathrm{CaO}) \rightarrow<\mathrm{Ca}_{2} \mathrm{Ti}_{2} \mathrm{O}_{5}>$

The perovskite precipitate can be a solid solution between $\mathrm{Ca}_{2} \mathrm{Ti}_{2} \mathrm{O}_{6}$ (containing $\mathrm{TiO}_{2}$ ) and $\mathrm{Ca}_{2} \mathrm{Ti}_{2} \mathrm{O}_{5}$ (containing $\mathrm{Ti}_{2} \mathrm{O}_{3}$ ). Figure 3.9 indicates the solid phases present for various concentrations of $\mathrm{CaO}, \mathrm{SiO}_{2}$ and $\mathrm{TiO}_{2}$ at equilibrium.

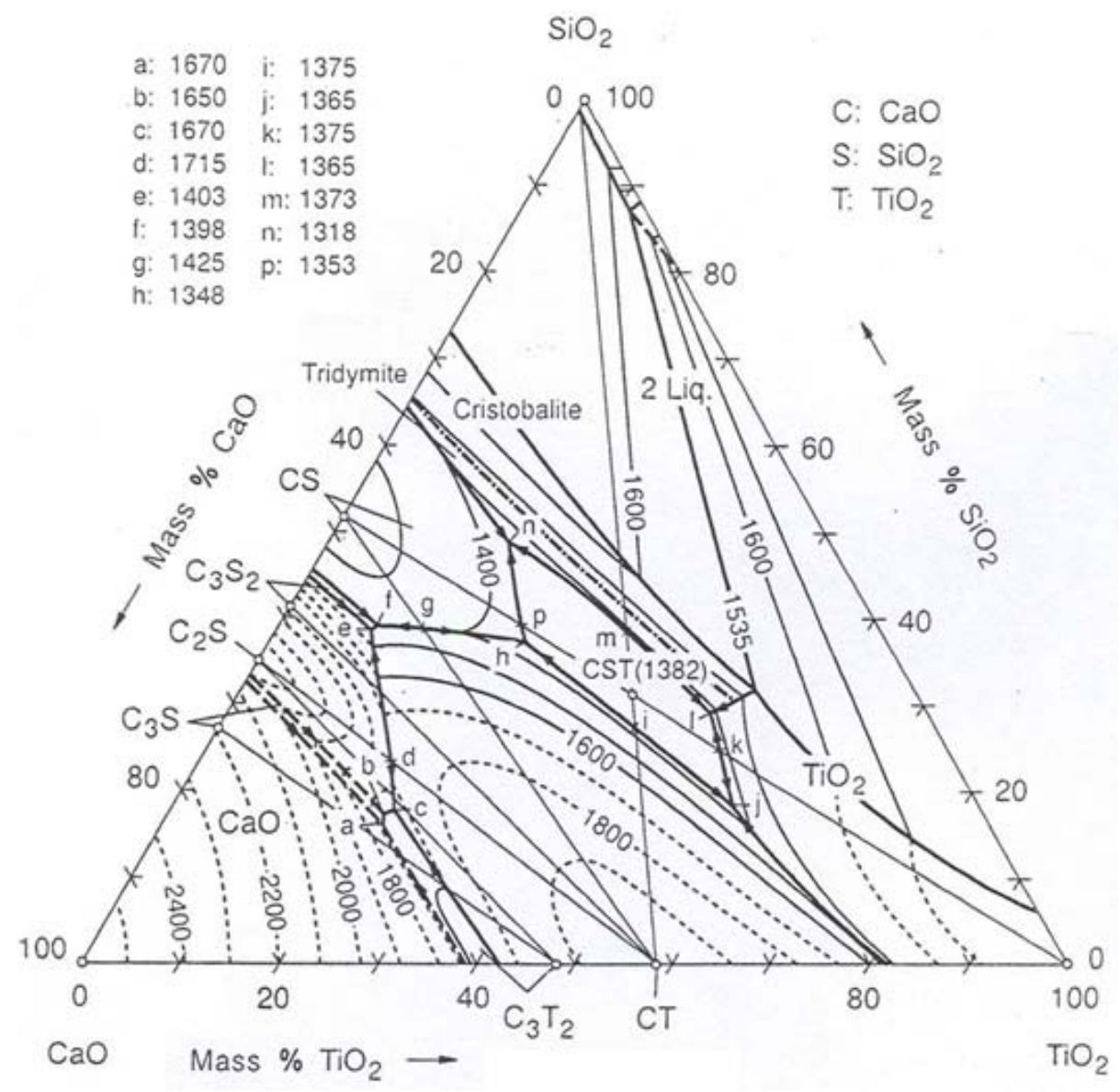

FIGURE 3.9: Phase diagram $\left(\mathrm{CaO}-\mathrm{TiO}_{2}-\mathrm{SiO}_{2}\right)$.

(Kowalski et al., 1995)

Perovskite is solidifying at much higher temperatures compared to the normal flux solids that are found in the mould (cuspidine and nepheline). In practice partial solidification of the mould fluxes used for casting 321-stainless steel causes a sharp 
increase in the apparent viscosity, and hence a greater likelihood of lubrication difficulties. The implication is that the selection of mould fluxes for titanium stabilised stainless steels should be done more carefully taking the chemical changes in the mould into consideration (Kishi et al., 1987).

\subsection{HEAT TRANSFER}

\subsubsection{THERMAL INSULATION AND VERTICAL HEAT LOSS}

The primary function of the continuous caster is to solidify liquid steel, making heat transfer in essence the most important factor to consider during casting. For the continuous caster to function effectively horizontal heat transfer must be promoted while other heat losses to the surrounding environment must be minimised.

The main sources of heat loss on the mould during continuous casting can be narrowed down to heat loss through the SEN and vertical mould cooling. SEN clogging is a great industrial concern and is mainly caused by poor thermal insulation (premature solidification of steel in the SEN), and deposition of non-metallic solids such as $\mathrm{TiN}, \mathrm{Ti}_{3} \mathrm{O}_{5}$ and $\mathrm{Al}_{2} \mathrm{O}_{3}$ in the SEN. These solids cause build up in the SEN ultimately blocking the flow of liquid steel from the tundish to the mould.

Vertical heat loss is mainly the result of cooling when hot off-gases leave the mould. Refer to the previous discussion where mould powder is fed to the top of the molten metal surface in the caster. One of the main functions of mould powders was to insulate the meniscus in order to prevent early solidification. The powder bed covered the exposed liquid steel, limiting vertical heat loss. The thermal insulation is mainly dependent on the thickness of the powder bed and the chemical nature of the flux. Other factors such as powder particle size and the addition of exothermic agents (carbon) can also be used to limit heat loss from the steel surface.

The vertical heat loss through spherical packed (granulated) mould powder can be estimated using the following equation (Balakrishnan et al., 1979):

$$
H_{C}(\Delta T)=-k_{e}\left[\frac{d T}{d x}\right]
$$


In a gas-solid packed bed system, the overall heat transfer is comprised of conductive and convective components. The conductive component is characterised by the heat transfer coefficient $\left(H_{c}\right)$, which is related to the effective conductivity $\left(k_{e}\right)$ of the solid particles.

Convective heat transfer between the powder particles is represented by the heat transfer coefficient $\left(h_{f p}\right)$ used for gas flow (Balakrishnan et al., 1979).

$h_{f p}=0.016\left(\frac{k_{f}}{2 a}\right)\left(A_{r m}\right)^{0.25}\left(\operatorname{Re}_{p}\right)^{0.5}$

$K_{f}=$ Thermal conductivity of the fluid,

$A=$ Radius of spheres in packed bed

$R e_{p}=$ Particle Reynolds number, $A_{r m}=$ Modified Archimedes number

In general heat transfer by convection is significantly lower than heat transfer by conduction. By reducing the bulk density of the mould flux, both the conduction and convection heat transfer modes are reduced. This significantly increases the insulating capacity of the flux bed and is one of the main reasons for using spherical mould powder.

\subsubsection{HORIZONTAL HEAT TRANSFER DURING CONTINUOUS CASTING}

Liquid flux used as lubricant during the continuous casting of steel unquestionably affects the horizontal heat transfer in the mould. The flux chemistry is adapted to provide the liquid lubrication needed during casting, but the balance between lubrication and heat transfer is often neglected. Unfortunately, once the liquid flux solidifies in the mould/shell gap the heat transfer is negatively influenced.

In general it is well understood that the horizontal heat transfer is greatly influenced by the solidification behaviour of the liquid flux (Cho et al., 2001). If the rate of heat removal during casting is too low a thin steel shell will be produced that could easily rupture when exiting the mould. On the other hand if the rate of heat removal is excessive or uneven, the cast material will experience thermal stresses, which will cause cracking of the steel shell. Heat removal is thus a very delicate process and must be carefully controlled to avoid serious failures.

The thickness and characteristics of the solid flux film that forms between the mould 
and shell are the key factors determining heat transfer in the mould. In most cases the horizontal heat transfer increases as the thickness of the slag film decreases. A thicker slag film is also more susceptible to gas entrapment resulting in an even greater barrier to heat transfer and cooling.

Investigating the horizontal heat transfer between the steel shell and mould wall, steady state conditions for heat transfer can be assumed (Mills et al., 2004b). By implementing Fourier's law for one-dimensional-heat-transfer, the thermal heat flux (also known as the heat transfer per area: $q / A$ ) can be calculated by applying the following equation (Mills et al., 2004b):

$$
\frac{q}{A}=k \frac{d T}{d x}
$$

The thermal conductivity $(\mathrm{k})\left[\mathrm{W} / \mathrm{m}^{\circ} \mathrm{C}\right]$ is the proportionality constant for the transport of heat energy caused by a temperature gradient $(d T / d x)$.

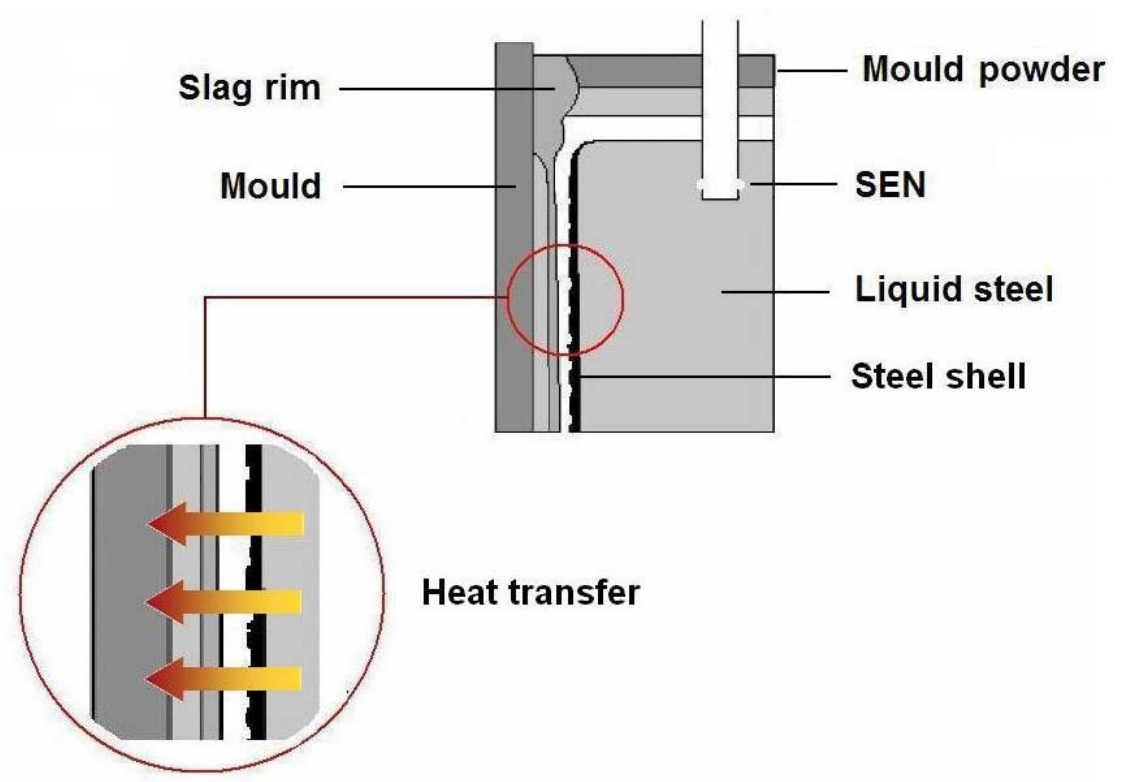

FIGURE 3.10: Illustrating the horizontal heat transfer through the different flux layers. (Mills et al., 2004b) 
Equation 16 can be rewritten to fit plant conditions if the horizontal heat transfer in the mould is caused by the temperature difference between the outer shell-surface $\left(T_{\text {shell }}\right)$ and the inner mould wall $\left(T_{\text {mould }}\right)$.

$$
\frac{q}{A}=\frac{1}{R}\left(T_{\text {Shell }}-T_{\text {Mould }}\right)
$$

Equation 17 is only valid if the overall thermal resistance $(R)$ between the shell and the mould is taken into account.

The overall thermal resistance $(R)$ is made up of the different heat barriers that form in the shell/mould gap. At first the liquid flux enters the gap between the mould wall and the newly formed steel shell where most of the flux freezes against the watercooled copper mould. Extreme cooling on the mould surface causes the formation of many tiny gas pockets when the liquid flux is rapidly solidified. Once the gas pockets are formed they are trapped on the mould surface by the solidifying mould flux. It is also believed that the roughness of the mould surface promotes the formation of gas entrapment (Holzhauser et al., 1999). The entrapped gas (air) creates a large thermal heat barrier for heat transfer. It is believed that gas entrapment normally contributes about $50 \%$ to as much as $80 \%$ of the overall thermal resistance during horizontal heat transfer and is therefore the key factor determining horizontal heat transfer (Cho et al., 1998). The thermal resistance at the interface between the mould wall and the solid flux film is generally referred to as the mould contact resistance.

The thermal resistance between the mould and the steel shell can now be simplified as follows (Schwerdtfeger, 2003):

$$
R=R_{\text {gas }}+R_{f l u x}
$$

$R_{\text {gas }}=$ Thermal contact resistance due to microscopically gas entrapment.

$R_{f l u x}=$ Thermal resistances due to the different layers of mould flux that form between the mould and the steel shell.

The thermal resistance of the mould flux in the mould/shell gap $\left(R_{f l u x}\right)$ can be classified according to the different flux phases that form between the mould and 
shell. The liquid flux phase next to the steel shell is normally very thin and because the heat transfer in this phase is far better compared to the solid flux phase, the liquid flux phase is often neglected when considering heat transfer between the mould and the shell. The solid flux layer is typically 2 to $3 \mathrm{~mm}$ thick, while the liquid flux layer varies between 0.1 and $0.3 \mathrm{~mm}$. In a liquid phase convection also greatly enhances the heat transfer capabilities of the flux. This further minimises the influence of liquid flux on the overall horizontal heat transfer (Mills et al., 2004b).

The thermal resistance between the mould and the steel shell as a result of mould flux can now be classified according to the phases that form in the mould/shell gap:

$$
R_{\text {flux }}=R_{\text {liquid flux }}+R_{\text {solid flux }}
$$

$R_{\text {liquid flux }}=\quad$ Thermal resistance due to the liquid flux layer next to the steel shell.

$R_{\text {solidflux }}=\quad$ Thermal resistance due to the solid slag that forms next to the mould.

The solid flux (slag) in the mould/shell gap consists of the glassy layer next to the mould wall and the crystalline layer that forms towards the steel shell. Solid crystals in the flux film between the mould and steel shell form at slower cooling rates further away from the mould wall. Generally, solid crystals form when the liquid flux layer next to the shell solidifies, but it is also believed that the glassy slag may partially crystallise at high temperatures to form a solid crystalline phase.

The thermal resistance in solid mould flux can be classified according to the different flux layers that form during solidification (Cho et al., 1998).

$$
R_{\text {solid }}=R_{\text {glass }}+R_{\text {crystalline }}
$$

$R_{\text {glass }}=$ Thermal resistance due to the solid glassy flux layer.

$R_{\text {crystalline }}=\quad$ Thermal resistance due to the solid crystalline flux layer.

The laws of one dimensional heat transfer plainly state that the thickness of a heat barrier directly affects the perpendicular heat flux. In other words the combined thicknesses of each flux layer present between the mould and the shell directly affect the horizontal heat transfer in the mould. 
The thermal resistance of the mould flux in the mould/shell gap $\left(R_{f f u x}\right)$ can now be defined by the following equation (Holzhauser et al., 1999):

$$
R_{\text {flux }}=R_{\text {glass }}+R_{\text {crystalline }}+R_{\text {liquid flux }}
$$

If the thicknesses of each flux layer is known the thermal heat barrier between the mould and shell can be calculated.

$$
\begin{aligned}
& R_{\text {flux }}=\left(\frac{d}{k}\right)_{\text {glass }}+\left(\frac{d}{k}\right)_{\text {crystals }}+\left(\frac{d}{k}\right)_{\text {liquid }} \\
& R_{\text {flux }}=\frac{d_{\text {glass }}+d_{\text {crystals }}+d_{\text {liquid }}}{k_{\text {eff }}} \\
& =\text { Thickness of glass layer next to the mould } \\
& d_{\text {glass }}=\text { Thickness of crystal layer between the glassy layer and liquid layer } \\
& d_{\text {crystals }}=\text { Thi } \\
& d_{\text {liquid }}=\text { Thickness of liquid layer next to the steel shell. }
\end{aligned}
$$

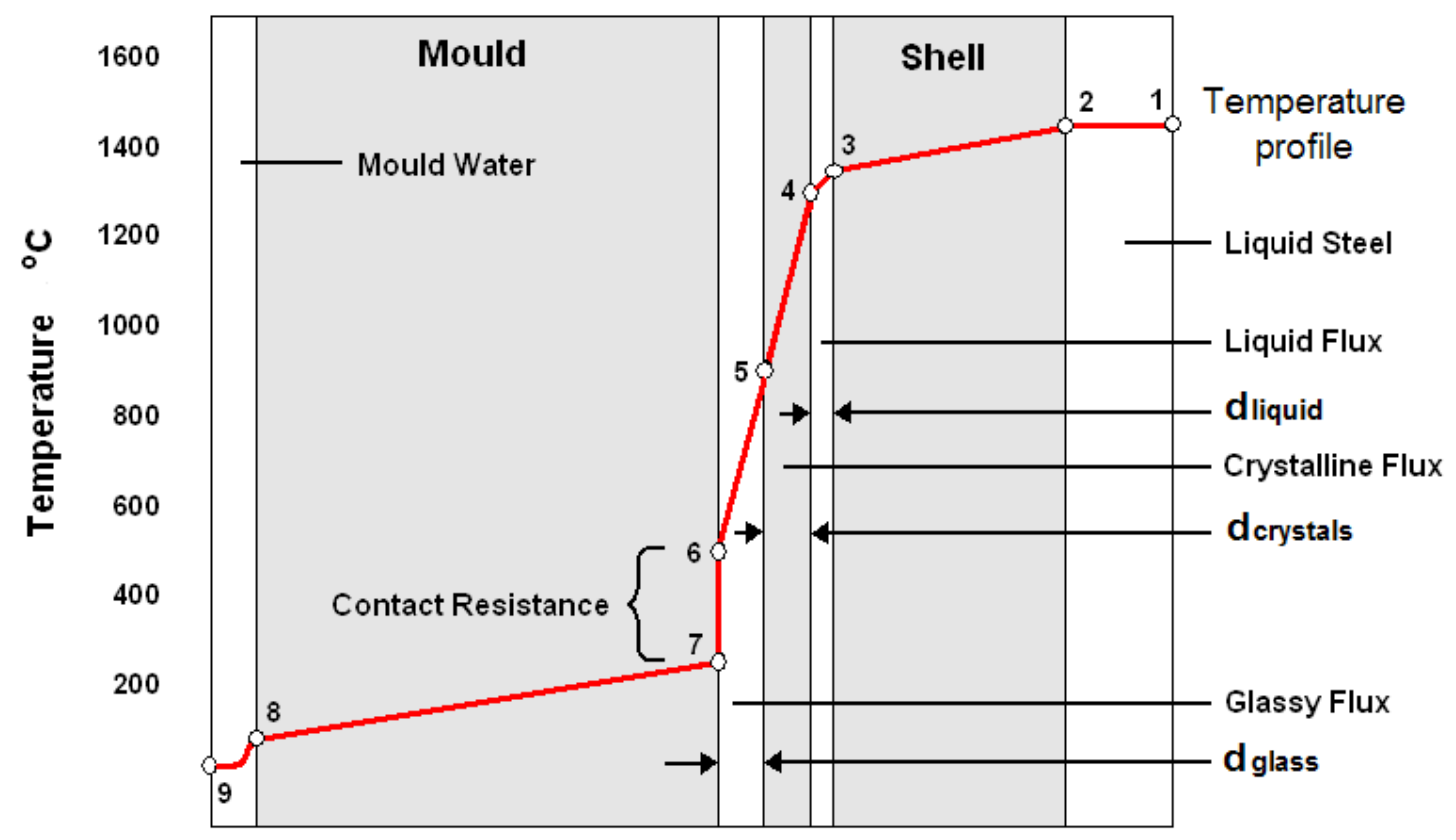

FIGURE 3.11: Thermal resistance during horizontal heat transfer in the mould. (Mills et al., 2004b) 
To be more precise, Fourier's expression for heat transfer can be extended by including radiation in the mould. The effective horizontal heat transfer in the mould can be expressed as follows (Cho et al., 1998):

$$
k_{\text {eff }}=k+k_{R}
$$

Heat transfer by radiation is dominant in glassy materials at high temperatures. It is estimated that the glassy structure provides more than $90 \%$ of the total heat transfer, which means that heat transfer rate through the glassy layer could be much higher than heat transfer through the crystalline slag layer. In the presence of the crystalline phase, the effect is significantly reduced due to the scattering effect of crystals. The equation below quantifies the radiation conductivity $\left(k_{R}\right)$ due to the scattering effect of the crystalline flux (Mills et al., 2004).

$$
k_{R}=\frac{16 \sigma n^{2} T^{3}}{3 \alpha}
$$

$\alpha=$ absorption coefficient

$\sigma=$ Stefan Boltzmann constant

$n=$ refractive index

$T=$ Temperature $[\mathrm{K}]$

For solid mould flux the absorption coefficient should be replaced by the extinction coefficient $(E)$ since radiation can be scattered by crystallites, grain boundaries etc. The absorption coefficient can be calculated by equation 26 if the scattering coefficient $(S)$ is known.

$$
E=\alpha+S
$$

Finally, the horizontal heat transfer in the mould can be calculated using the following equation (Holzhauser et al., 1999):

$$
\frac{q}{A}=\frac{1}{R_{\text {gas }}+R_{\text {flux }}}\left(T_{\text {Shell }}-T_{\text {Mould }}\right)
$$

The thermal profile in figure 3.11 schematically represents the heat transfer from the liquid steel in the mould to the water flowing through the mould. During casting the liquid steel is evenly distributed in the mould by the turbulence of the SEN. In this 
case the liquid steel temperature in the mould at $T_{1}$ is equal to $T_{2}$ (at the solidification front). The slight temperature difference between $T_{2}$ and $T_{3}$ is as a result of the slower heat transfer by conduction through the solid steel shell.

As previously mentioned, the contact resistance between the mould and the glassy flux layer is the primary heat barrier. The temperature drop from $T_{6}$ to $T_{7}$ in figure 3.11 schematically illustrates the effect of the thermal contact resistance on the overall horizontal heat transfer.

The temperature decrease from $T_{7}$ to $T_{8}$ is the linear heat transfer in the mould. The mould is made of copper and is a very good conductor of heat. Finally the mould is cooled by a high flow rate of demineralised cooling water $\left(T_{9}\right)$. The temperature difference between the incoming mould water and the water leaving the mould can be used to calculate the average heat transfer in the mould. At a constant flow rate the overall heat flux in a mould is estimated to be of the order of $1 \mathrm{MW} / \mathrm{m}^{2}$ of exposed mould area.

\subsubsection{THE EFFECT OF GAS ENTRAPMENT IN SOLID FLUX ON HORIZONTAL HEAT TRANSFER}

It has always been assumed that gas entrapment occurs mostly between the mould wall and solidified flux, creating the thermal contact resistance mentioned in the previous section. Researchers also based their mathematical modelling (to calculate horizontal heat transfer) on the assumption that the thermal resistance in the glassy and solid phase is more or less the same (Stone et al., 1999).

However, new insight shows that gas entrapment is also very possible in the solid flux layer. To be more precise, gas entrapment is to a large extent prominent in the crystalline phase. The solid transformation from the glassy phase to the crystalline phase results in structural shrinkage and porosity. The effect of increasing thermal resistance due to slag crystallization is best understood as shrinkage resulting in the formation of air gaps in the crystalline structure. The main factor restricting heat flow through solid flux is porosity. Porosity is caused by crystallization and is dependent on the basicity of the flux (refer to equation 5). Significant shrinkage during flux solidification will cause more gas formation on the mould surface and a greater interfacial thermal resistance (Cho et al., 2001). 
Generally mould fluxes with lower solidification temperatures produce a thicker solid flux layer that promotes the formation of a larger porous structure. The reason for this is that a thicker flux film has the tendency to produce a larger crystalline fraction resulting in a larger area for gas entrapment. More gas entrapment increases the overall thermal resistance of the solid flux layer and reduces the horizontal heat transfer in the mould. Gas entrapment as a thermal heat barrier is considered to be the key factor determining horizontal heat transfer during continuous casting.

Investigating the porosity of solid fluxes during industrial casting the pore size was found to be between 2 and $20 \mu \mathrm{m}$, but many pore diameters greater than $50 \mu \mathrm{m}$ were also found (Ludlow et al., 1995). The investigation also indicated that the amount of porosity varied as the slag film thickness varied. Remarkably the porosity location was often associated with pore bands between the glassy and crystalline phases.

A second source of probable gas entrapment is due to bubble formation. This phenomenon is rarely studied, but is often mentioned by various researchers as a possible method of trapping gas in the solidified mould flux. During the sintering process gases are usually generated by the combustion of carbon. Bubble formation during melting was also observed at the first melting of mould powder and it is believed to originate from carbonate and hydrate contamination (moisture pickup) during powder mixing (Orrling et al. 2000).

Generated gasses find their way to the liquid flux pool in the mould. These gas bubbles and are then trapped by the liquid flux and are carried to the mould/shell gap. During solidification the trapped gas bubbles create pores in the solid flux structure creating an interfacial thermal resistance on the mould surface and porosity in the solid flux structure. The total thermal resistance due to gas entrapment can now be expressed as follows:

$$
R_{\text {gas }}=R_{i}+R_{s}
$$

$R_{\text {gas }}=$ Thermal contact resistance due to microscopically gas entrapment

$R_{i}=$ Thermal contact resistance due to gas entrapment on the mould surface.

$R_{s}=$ Thermal resistance due to gas entrapment in the solid flux structure. 


\subsubsection{THE EFFECT OF STEEL GRADE ON FLUX CHEMISTRY AND THE INFLUENCE ON HORIZONTAL HEAT TRANSFER}

As discussed in section 3.4.3 alloying elements from the liquid stainless steel (refer to table 2.1) react with the mould powder compounds and change the behaviour of the flux in the mould. The most likely reaction when casting titanium-stabilised steel is the formation of perovskite $\left(\mathrm{CaTiO}_{3}\right)$ (Mukongo et al., 2004). When investigating the solidification of perovskite it has been found that the solidifying temperature of this compound is much higher compared to the normal solids that crystallise during continuous casting. The end result is that premature flux solidification in the liquid flux pool affects the flux viscosity and horizontal heat transfer in the mould. A higher flux solidification temperature also leads to the formation of more crystals during flux solidification. A larger crystalline fraction generates a greater porous structure due to gas entrapment in the solid flux. This increases the thermal resistance during horizontal heat transfer and is believed to decrease the heat transfer in the mould (Cho et al., 1998).

Although not primarily influenced by the mould flux the horizontal heat transfer in the mould is also related to the cast material steel grade. There is almost 4 to $5 \%$ difference between the solidification shrinkage of ferritic and austenitic steel types. Larger volume contractions during solidification can greatly influence the heat transfer in the mould especially if the mould taper does not compensate for this shrinkage effect.

On the whole an austenitic steel shell is much stronger then a ferritic shell when casting stainless steel. This may become a problem when the steel shell exits the mould as the ferro-static pressure of the liquid steel (that increases with distance from the meniscus) pushes against the thin sections of the shell causing buckling. The effect of buckling is also increased with fluctuating chemistries during the transformation of $\delta$-ferrite to the austenite phase (Siyasiya et al., 2005). In severe cases buckling could cause rippling of the steel shell and severe damages to the continuous casting machine. Bulging is prevented by increasing the shell thickness. This is normally done by decreasing the casting speed to allow more time for horizontal heat transfer. 


\subsubsection{PROCESS PARAMETERS AFFECTING HORIZONTAL HEAT TRANSFER}

In this section plant parameters will be discussed briefly.

\section{- CASTING SPEED}

Increasing the casting speed leads to the formation of a thinner shell simply because of the shortened solidification time in the mould. The growth of the steel shell is dependent on the overall heat removal in the mould. Greater heat removal results in more solidification and a thicker steel shell. If the rate of heat removal in the mould is kept constant (in general a valid assumption) a shorter time in the mould would result in a thinner shell especially near the meniscus (Shin et al 2005).

$$
d_{F e}=K \sqrt{\frac{D}{V_{C}}}
$$

$d_{F e}=$ Solid shell thickness [mm], $\quad K=$ Solidification factor $\left[\mathrm{mm} / \mathrm{min}^{1 / 2}\right]$

$D=$ Distance from meniscus $[\mathrm{mm}], \quad V_{c}=$ Casting speed $[\mathrm{mm} / \mathrm{min}]$

\section{- MOULD TURBULENCE}

The SEN creates turbulence and flow patterns in the mould, when liquid metal enters the mould. Convection in the mould allows even heat distribution resulting in uniform shell growth. When the SEN is not aligned correctly, turbulence and uneven heat flow in the mould can result in uneven shell growth. This can lead to serious failures during casting (Mills et al., 2004b).

\section{- MOULD TAPER}

Longitudinal variations of horizontal heat transfer in the mould are mainly caused by the separation of the steel shell from the mould wall because of shrinkage forces. Further down the mould the ferro-static pressure caused by the liquid steel causes the shell to again make contact with the mould. This causes a slight increase in the overall mould heat transfer. Improved mould design, to compensate for the steel shrinkage, leads to mould tapers. Mould tapers improve heat transfer, but have their limitations. Insufficient mould taper can lead to hot spots and introduce insufficient cooling, while excessive mould tapers can increase the friction resistance between the steel strand and the mould (Billany et al., 1991). 


\section{- POURING TEMPERATURE}

In general it has been observed that an increase in casting temperature (within reasonable limits) has a negligible effect on heat transfer. Some literature, however, state that higher pouring temperature retards solidification in the early stages of metal solidification, reducing the strength of the newly formed steel shell. Higher pouring temperatures will give rise to increased breakouts if the casting speed is not reduced to compensate for the increased temperature (Columbus, 2006).

\section{- MOULD LEVEL FLUCTUATIONS AND SLAG ENTRAPMENT}

Large mould level fluctuations can lead to variability in heat transfer, but this process is normally well controlled and has little or no effect on the overall heat transfer. The mould level or float level is sometimes changed to prolong the life of the SEN, but this affects the working of the slag rim. The great danger of mould level fluctuations is that parts of the slag rim could easily be sucked into the mould/shell gap. The slag rim travels down preventing sufficient shell growth. The result is localised blocking of heat transfer in the area.

\section{- MOULD COOLING WATER}

Experimental studies on cooling water-velocity and water-temperature revealed that increased cooling above $6 \mathrm{~m} / \mathrm{s}$ does not improve the overall heat transfer in the mould. In practice demineralised water is used for cooling in order to prevent the build up of solidifying minerals on the inside of the mould. This is also used to prevent pipe clogging (Pinheiro et al., 1995).

\subsection{MOULD FLUX RELATED PROBLEMS AND DEFECTS}

Mould powders for continuous casting have been selected for years on a trial and error basis. New research and development has led to the fine-tuning of mould powders in order to reduce casting related problems (Schwerdtfeger, 2003). With the demand for new steel types the continuous casting process is constantly growing giving rise to new problems and challenges.

Casting is sometimes described as a most delicate process, as it is recognised that the majority of surface defects originate during the initial solidification of steel. Surface defects easily develop into cracks depending on the heat transfer in the mould and the conditions in the mould. To produce a slab with a good surface 
quality, consistent heat transfer together with adequate lubrication is essential during the cast. Heat transfer and mould lubrication depend on mould powder and the conditions in the mould itself. Classifying and studying mould related problems can help to find the perfect match between caster capabilities and mould powder performance. This section investigates some of the common flux-related defects found during the continuous casting of steel.

\subsubsection{LONGITUDINAL CRACKING}

Longitudinal cracking is most likely to occur in carbon steel grades with a carbon content ranging from 0.08 to $0.14 \%$. The carbon content in the steel creates a relatively large thermal contraction that occurs when $\delta$-ferrite transforms to austenite near the meniscus. This mismatch in shrinkage creates stresses in the newly formed steel shell and causes cracking in the longitudinal direction. It is also believed that the $\delta$-ferrite to austenite transformation creates wrinkles in the solidified shell that lead to localised hot spots in the newly formed steel shell (Billany et al., 1991). These hot spots concentrate tensile strains, which further increase the possibility of longitudinal cracking. Longitudinal cracking can be classified into two types (i) gross cracks (up to $400 \mathrm{~mm}$ long) associated with casting problems such as poor mould level control, and (ii) surface cracks (shallow cracks on the surface) that are usually found when casting peritectic steel grades.

Longitudinal cracking can be prevented by the following:

\section{- INCREASING THE THICKNESS OF THE MOULD FLUX POOL}

The melting rate of mould powder is the most important factor to consider when optimising the slab surface quality (Ogibayashi et al., 1987). Without taking the effect of casting speed into consideration the recommended molten flux pool depth should be in the order of $10 \mathrm{~mm}$ to prevent longitudinal cracking.

\section{- CONTROLLING THE CASTING SPEED}

To optimise casting conditions research suggests the use of a casting parameter that links the casting speed $\left(V_{C}\right.$ - given in $\mathrm{mm} / \mathrm{min}$ ) to the liquid viscosity $(\eta$ given in poise) of the mould flux (Wolf et al., 1982).

Casting parameter $\left(\eta V_{c}^{2}\right)=3$ to 7 
In order to minimise longitudinal cracking the casting parameter should be between 3 and 7 to give the optimal overall horizontal heat transfer and minimal frictional force between the shell and the mould.

\section{- CONTROLLING THE HORIZONTAL HEAT TRANSFER}

It has been proposed that the best way to minimise longitudinal cracking is to produce a thin, uniform solid steel shell at the meniscus by reducing both the magnitude and variation of the heat transfer in the mould (Billany et al., 1991). One way of reducing the horizontal heat flux is to allow the formation of air gaps at the mould/flux interface and/or in the solid slag by promoting glass to crystalline transformation. Mould fluxes formed by more basic powders are expected to have a larger portion of crystalline phase and crystallization is expected to start at higher temperatures. This will result in a decrease of overall mould heat transfer preventing excessive shell shrinkage and cracking (Mills et al., 1991).

\subsubsection{STAR CRACKS}

Star cracks are associated with infiltration of copper between the grain boundaries of the newly formed steel shell surface. Star cracking is known to occur in the lower half of the mould, where the copper is scraped from the mould plates by the descending solid shell. In essence star cracking occurs when the low melting copper plates from the mould wall are partially melted and penetrate the steel strand through the grain boundaries. The copper pickup in the steel shell remains liquid and prevents the formation of a solid intergranular bond. As the steel solidifies, cracks form that run along the grain boundaries forming a star-like crack.

Star cracks can be avoided by doing the following:

\section{- IMPROVE THE LUBRICATION BETWEEN THE MOULD AND THE SHELL}

By maintaining the liquid lubrication layer between the mould and the shell, contact between the mould and the shell is avoided. Star cracking can also be caused by variations in heat transfer that may be related to failure of the solid flux film in the lower half of the mould. This would lead to partial mould/strand contact and thus to solid/solid friction. Powder selection is thus very important to prevent the formation of star cracks. 


\section{- NICKEL PLATING OF THE MOULD WALL}

The best way to avoid star cracking is to plate the copper walls of the mould with a high melting alloy with good thermal properties. Nickel plating is by far the most popular plating material for this application, but $\mathrm{Mo}$ and $\mathrm{Cr}$ are also used.

\subsubsection{OSCILLATION MARKS}

Oscillation marks are classified as horizontal indentations occurring at regular intervals along the surface of the cast material. As previously mentioned oscillation marks are formed by the compression and tension to which the thin steel shell is subjected during mould oscillation. This action also causes slag entrapment in the cavities created by oscillation marks. Deep oscillation marks filled with solidified flux create large localised thermal resistances between the mould wall and shell surface. This causes the shell to have a non-uniform shell profile as well as sub-surface structures that are preferential sites for cracking. It has been suggested that the formation of oscillation marks can act as a notch to enhance the propagation of cracks (Howe et al., 1987).

The normal way to restore surface quality is by grinding the cast material after it has cooled. This procedure is very time consuming and generates a large amount of waste material, especially when the oscillation marks are deeply formed in the steel surface. Unfortunately the formation of oscillation marks cannot be prevented, but it is essential to minimise the depth of these defects on the metal surface in order to improve product quality.

Once again mould powder is used to control heat transfer, and lubrication to minimise the effect of oscillation marks on the steel surface. Oscillation mark depth and pitch are, in principle, determined by the oscillation characteristics of the caster. Depth is found to decrease as the mould flux viscosity increases. Research has shown that a decrease in the vertical heat transfer may help to prevent deep, irregular oscillation marks on the surface. By increasing the thermal insulation on the meniscus (using a thicker powder layer $150-200 \mathrm{~mm}$ ) it is possible to obtain more heat at the liquid float level. This results in fewer pinholes and inclusion entrapment on the surface as the steel shell starts to form during solidification. Again mould flux can be used to improve product quality. 


\subsubsection{CASTING BREAKOUT}

Without question, a breakout is the most catastrophic phenomenon associated with the continuous casting process. Breakouts are not only a serious safety hazard, but also cause serious damage to the casting machine and consume a lot of maintenance time. This makes breakouts the most feared casting defect and must be avoided at all costs (Mills et al., 1991).

Generally there are two types of breakouts. The first being a breakout that is associated with heat transfer problems and the second being a breakout that is associated with lubrication problems, better known as a sticker breakout or a plug breakout. In continuous casting it is generally estimated that 60 to $80 \%$ of the time, breakouts are caused by mould-sticking related to lubrication problems, rather than heat transfer related problems.

Sticker breakouts are related to lack of lubrication between the mould wall and steel strand. This lack of lubrication is simply due to the poor performance of the casting powder and results in a dramatic increase in friction between the shell and mould wall. This increase in friction causes the newly formed steel shell to rupture near the meniscus. The ruptured shell sticks to the mould until the steel strand exits the mould. At this point the defect in the steel shell is too weak to withstand the increased ferro static pressure of the liquid steel and forms a breakout. When this happens liquid steel breaks through the steel shell. The friction force should therefore be reduced to prevent the rupture of the steel shell at the meniscus. The usual way to achieve this is by lowering the viscosity of the mould flux, increasing the fluidity of the liquid flux and increasing powder consumption. If this is not possible it should be attempted to increase the flux film thickness to ensure adequate lubrication throughout the mould, especially near the meniscus (Mills et al., 1991).

Breakouts due to heat transfer problems are the direct results of poor localised horizontal heat transfer. Breakouts of this type occur when shell growth is prevented by a localised heat barrier. There are generally three ways to create a localised heat barrier, but the failure mechanism is the same. A heat barrier in this context is a localised region between the mould and steel shell that prevents or retards the horizontal heat transfer. The shell growth with regard to thickness and strength is extremely reduced due to the slower cooling of the steel shell in this area. When this defected-area exists in the steel shell, the shell tears and a breakout is formed.

J.A. BOTHMA - MASTER OF ENGINEERING (METALLURGY) - UNIVERSITY OF PRETORIA - 2006 
Heat transfer problems that lead to breakouts can be caused by the following:

\section{- ALLOY PICK UP CHANGING MOULD FLUX BEHAVIOUR}

Mould powders tend to pick-up alloys or elements in one of two ways. The first being elements such as $\mathrm{Al}_{2} \mathrm{O}_{3}$ or $\mathrm{ZrO}_{2}$ during SEN-erosion, and the second (less common) being alloy pick-up from the liquid steel. Oxides of elements like Ti and $\mathrm{Zr}$ cause premature solidification of mould powder when new substances crystallise at high temperatures. When this occurs air or gas pockets form when the liquid flux solidifies to a denser crystalline solid. Large quantities of gasentrapment causes a heat barrier due to the low heat transfer capabilities of gas or air. This heat barrier reduces the cooling rate of the steel shell and may result in a breakout failure.

\section{- GAS ENTRAPMENT CAUSING A THERMAL HEAT BARRIER}

Research shows that gas bubbles form during the melting process of mould flux. Gas bubbles and other impurities can easily be trapped between the mould and steel shell, especially when vertical thermal insulation is insufficient. Gasentrapment causes localised heat barriers that can result in breakouts, similar to those found in mould powder and alloy pick-up (see section 3.5.3).

\section{- CAPTURING OF THE SLAG RIM FORMING A THERMAL HEAT BARRIER}

This phenomenon is not well known, but tends to occur when the float level at the meniscus does not remain constant. Sometimes the steel level in the mould is deliberately altered to allow uniform SEN-erosion (liquid mould flux chemically attacking the submerged entry nozzle at the meniscus). As the float-level moves higher in the mould, part of the slag rim is re-melted, causing chunks of the slag rim to break off and enter the mould/strand gap. Once a part of the solid slag rim is captured it prevents localised cooling and shell growth. The captured part of the slag rim also prevents liquid slag (from the slag pool) from entering and lubricating the gap between the mould and steel shell. Further down in the mould this undeveloped steel shell tears and fails under the increased frictional forces and results in a breakout (Mills et al., 1991). 


\section{CHAPTER 4}

\section{EXPERIMENTAL SETUP - DESIGN \& CONSTRUCTION}

\subsection{DESIGN REQUIREMENTS AND LIMITATIONS}

Apart from the crystallization of mould flux, the aim of this study is also to investigate heat transfer through mould flux layers. In order to do this, the continuous casting process during stainless steel manufacturing must be simulated. Several laboratory experiments have been attempted during similar investigations, but as it turns out, the continuous casting process has proven to be far more complex than expected. To investigate the heat transfer capabilities and the behaviour of mould flux in the mould, the thermal conditions during casting must be replicated. The following design requirements and limitations were used as guidelines to design and build a smallscale experimental model for simulating the continuous casting process.

To simulate the main functions of the continuous casting mould the following factors were taken into consideration:

\section{- SIMULATING MOULD OSCILLATION}

The mould is designed to oscillate during casting to improve lubrication between the mould and a relatively stationary steel shell. Mould oscillation is often neglected during a laboratory test, especially when the focus of the study is not bound to the lubricating capabilities of the mould flux. From the literature, fairly consistent results have been obtained during experimental testing using a stationary experimental setup, and these results accurately represented the continuous casting process. In order to simplify the experimental setup, mould oscillation was not taken into consideration during this study.

\section{- TEMPERATURE MEASUREMENT}

Temperature measurements are crucial for controlling any casting process. Temperature measurements were also taken during experimental testing in order to control the heating sequences of the experimental apparatus and these are also extremely important when measuring the experimental heat transfer. The most effective way is to use thermocouples that can withstand the required operating temperatures. Unfortunately, thermocouples are very sensitive to any

J.A. BOTHMA - MASTER OF ENGINEERING (METALLURGY) - UNIVERSITY OF PRETORIA - 2006 
form of electrical disturbances, especially induced magnetic fields. Temperature readings must also be calibrated to ensure correct measurements.

\section{- REPEATABLE TESTS}

Like the casting mould the experimental apparatus must be re-usable. In order to make accurate comparisons, experimental testing under similar conditions is essential. The primary requirement is therefore to build an experimental apparatus that delivers the same test results each time under the same test parameters. It is therefore important to design an experimental apparatus with replaceable parts in case of any damage. This also reduced the running costs of the experiment.

To simulate the heat transfer between the mould and the steel shell the following factors were taken into consideration:

\section{- HEATING TO HIGH TEMPERATURES}

At any stage during the casting of stainless steel, liquid metal is contained at about $1450^{\circ} \mathrm{C}$ in the mould. Experimentally this temperature can only be reached under closely controlled conditions. These extremely high temperatures will allow the experimental operations to be very close to the melting point of the solidifying material. Great care must be taken when heating the experimental apparatus, not to melt the components and to cause irreparable damage.

\section{- MAINTAINING A FIXED MOULD FLUX THICKNESS}

The normal mould flux thickness between the copper wall and steel shell varies between 1 to $3 \mathrm{~mm}$. It is therefore important to build an experimental apparatus that can maintain a constant test gap at a specified dimension (normally $3 \mathrm{~mm}$ ). This is not always possible because factors such as thermal expansion during heating and thermal contraction during cooling cause stress build-up in the operating component (giving distortion), resulting in inaccurate gap thicknesses.

\section{- THERMAL GRADIENT}

Probably the most challenging aspect of all is to simulate the extremely high thermal gradient between the steel strand and copper mould wall. The mould is constantly water-cooled allowing a temperature difference of about $1200^{\circ} \mathrm{C}$ from the steel surface to the mould surface over a thickness of about 1 to $3 \mathrm{~mm}$. The 
overall heat flux during the continuous casting process is estimated to be about $1 \mathrm{MW} / \mathrm{m}^{2}$. This is an average value and at times (in the upper parts of the mould) can be twice as high. To achieve the required heat flux under steady state conditions in a physical experimental setup, required careful planning.

During experimental testing the mould powder (test powder) must be subjected to the same conditions that are found during the continuous casting process. To create the same working environment during experimental testing the following key factors were taken into consideration:

\section{- PREVENT HEAT LOSSES}

During the casting process mould powder is used to prevent heat loss to the surroundings. Fundamentally the experimental apparatus must be designed to minimise heat loss in order to obtain accurate heat transfer measurements. When choosing insulating material for this purpose, the high operating temperatures of the experimental setup must be kept in mind. Ordinary refractory material can handle high temperatures and usually makes good thermal insulators.

\section{- INERT GAS SYSTEM}

One of the main functions of mould flux is to exclude oxygen from the liquid steel in order to prevent atmospheric contamination. Experimentally, inert gas is normally used to achieve the same conditions. The second reason for the removal of oxygen during test conditions is to prevent scale formation when heating steel components. Experimentally, inert gas was therefore used to remove oxygen from the system.

\section{- PREVENT SAMPLE CONTAMINATION}

Sample contamination during experimental testing can have detrimental effects on the final results. Refractory materials normally contain $\mathrm{Al}_{2} \mathrm{O}_{3}, \mathrm{MgO}$ and $\mathrm{CaO}$. When the mould flux is melted these compounds can easily contaminate the test powder and this must be prevented at all times to ensure good results.

\section{- FLUORIDE (F)}

Mould fluxes contain active fluorides $\left(\mathrm{F}^{-}\right)$which cause major problems during experimental testing. At elevated temperatures fluoride compounds tend to 
evaporate, resulting in lower levels of fluoride in the test sample after heating. Especially when using small samples, the effect of fluoride evaporation can once again seriously affect the test results. It is therefore required to test relatively large amounts of mould powder ( $20 \mathrm{~g}$ in these tests).

Another major point of concern is that fluorides are highly reactive with the $\mathrm{Al}_{2} \mathrm{O}_{3}$, $\mathrm{MgO}$ and $\mathrm{CaO}$ compounds found in refractory material. This corrosive effect therefore eliminates the use of any refractory based material to contain molten flux.

\section{- INVESTIGATING TEST SAMPLES}

To investigate the relationship between the heat transfer measurements and the crystallographic nature of the test powder, sampling must be possible after each experiment. The test apparatus was therefore be designed to allow this.

\subsection{CONCEPT DESIGNS FOR EXPERIMENTAL TESTING}

From the literature, several attempts have been made to simulate the continuous casting process. This short discussion mainly highlights the different experimental possibilities.

Looking at previous research the most important factors to be considered are a hot zone to simulate the steel shell, a cold zone to simulate the mould and a fixed distance between the hot and cold zones (filled with mould powder). Heating the hot zone was usually done by making use of gas, electrical resistance or induction heating. Cooling was done by making use of water or air. Usually the experimental apparatus was enclosed in a gas tight casing while flushing the environment with an inert gas to avoid atmospheric contamination.

Yamauchi et al. (1993) conducted studies to measure the heat transfer between the mould and steel shell. The thermal resistance of the mould flux was measured by the steady state method using the experimental apparatus shown in figure 4.1. The casting process was simulated by using an aluminium nitride plate (AIN) to represent the hot zone. The temperature of the AIN-plate was kept at $1100^{\circ} \mathrm{C}$, providing constant heat to the liquid flux. An air cooled stainless steel block $(25 \times 30 \times 30 \mathrm{~mm})$ served as the cold zone. This cooling block was connected to a precision driving unit, 
which enabled the block to be moved up and down. This was done to control the flux thickness between the hot and cold zones. The apparatus was placed in a sealed steel chamber in order to maintain the $\mathrm{N}_{2}$ inert gas atmosphere that would prevent oxidation of the AIN-plate.

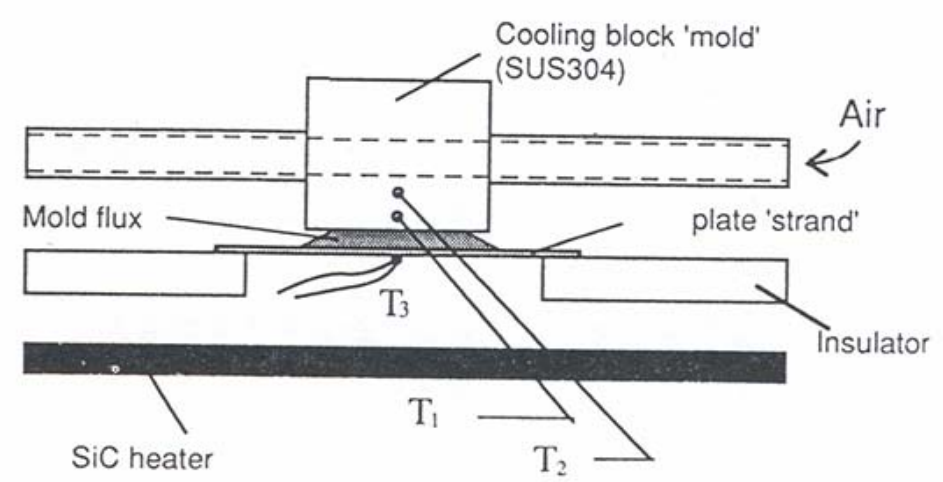

FIGURE 4.1: Schematic representation of the SiC-heater experimental apparatus. (Yamauchi et al., 1993)

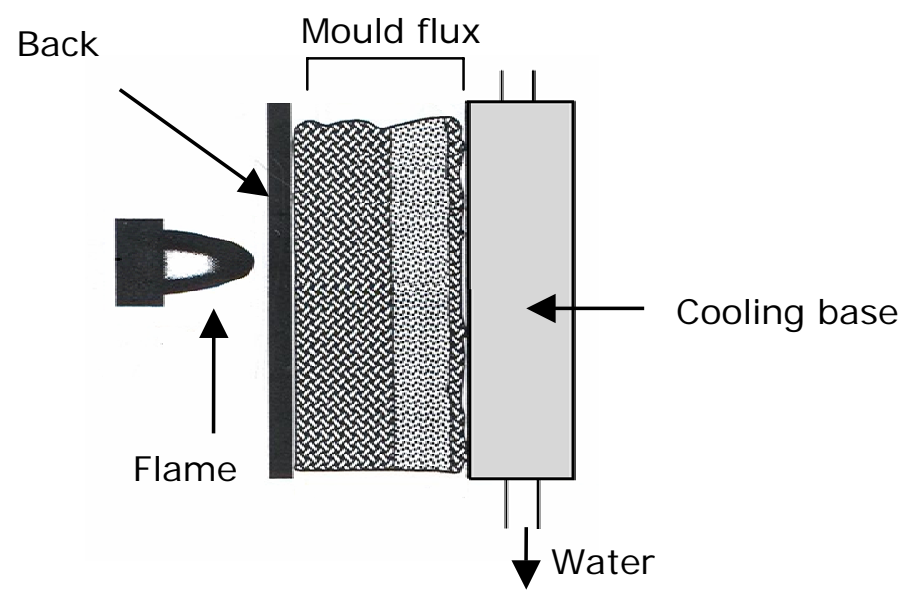

FIGURE 4.2: Illustration of the gas flame experimental setup.

(Stone et al., 1999)

The same type of experiment was done by Stone et al. (1999) using a gas flame as heating source. The hot zone consisted of a heated metal plate (409-stainless steel) while the cold zone was represented by a water cooled copper block. A spacer of known thickness was used to create a fixed gap between the metal plate and the copper block. The set-up was then bolted together and the space between the two plates was filled with mould powder. Heating was controlled by adjusting the position of the flame, while thermocouples were used to measure the required temperatures. 
Holzhauser et al. (1999) made use of electrical current (resistance heating) to heat a machined base plate that represented the hot zone. The upper part of the apparatus was used to simulate the continuous casting mould (cold zone). This part, known as the probe, was made from copper and was cooled with a constant supply of water or air. Thermocouples were placed in strategic points in the probe to calculate the heat transfer. The experimental apparatus was also assembled in an air tight steel casing, which was flushed with inert gas.

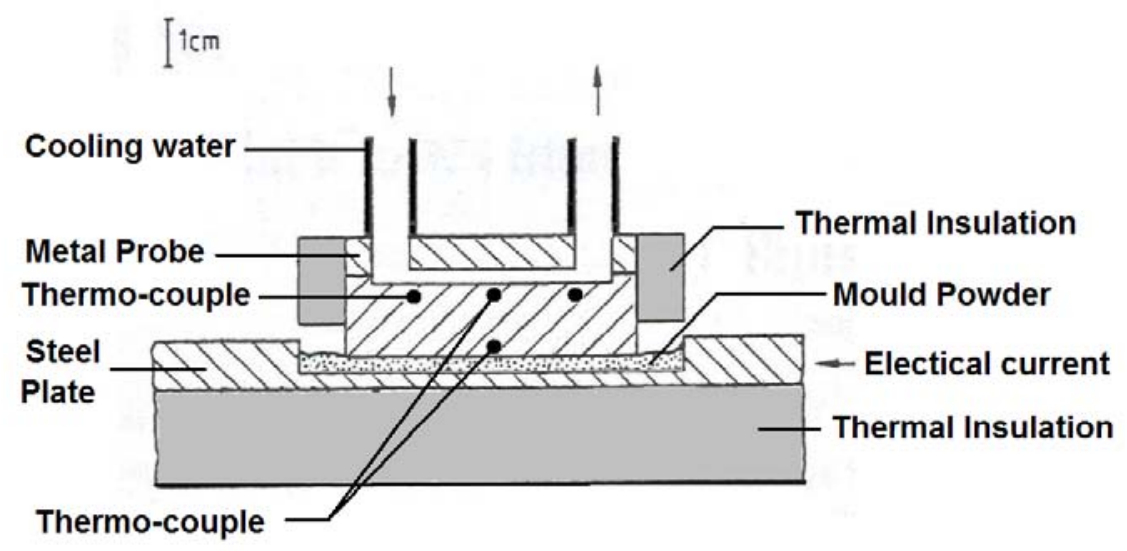

FIGURE 4.3: Illustration of the resistance heating experimental setup.

(Holzhauser et al., 1999)

The experimental procedure was to firstly heat the base plate to about $1400^{\circ} \mathrm{C}$ and then to lower the copper probe using a dial gauge to control the distance between the base plate and the probe.

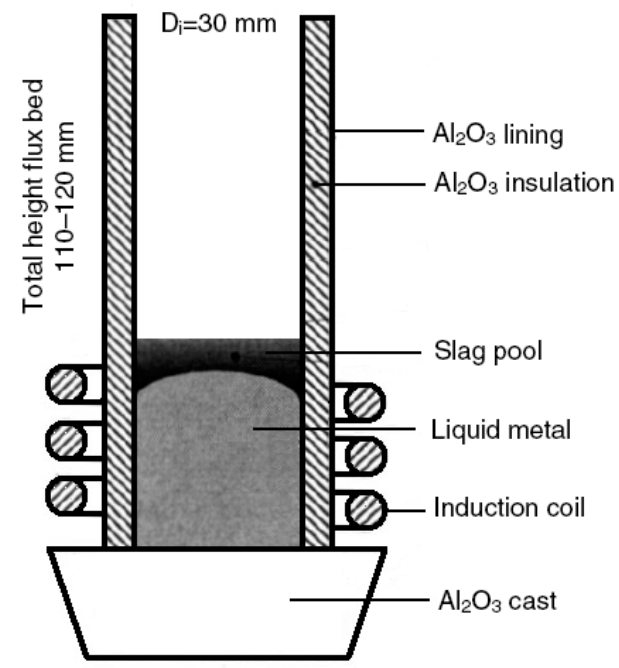

FIGURE 4.4: Illustration of the induction heating apparatus for mould flux melting.

(Görnerup et al., 2004). 
Finally, Görnerup et al. (2004) made use of induction heating to characterize the performance of mould fluxes during the continuous casting of steel. Heating and melting of mould flux were done making use of a specially designed laboratory apparatus. An alumina $\left(\mathrm{Al}_{2} \mathrm{O}_{3}\right)$ tube of $30 \mathrm{~mm}$ inner diameter acted as the vessel containing liquid steel. A water-cooled copper coil was placed around the alumina tube and functioned as an induction coil when connected to a heat source. The power input was controlled manually and the temperature was measured using an optical pyrometer. Heating and cooling could easily be controlled by adjusting the power input to the induction coil (figure 4.4).

\subsection{EXPERIMENTAL CONSTRUCTION}

In the present project, an experimental apparatus was constructed to simulate the horizontal heat transfer during the continuous casting process. The function of this simulating apparatus was to completely melt mould powder and then to solidify the same melted sample while measuring the heat transfer. The experimental apparatus was therefore designed to function in two stages:

(i) Heating stage - to melt the mould powder.

(ii) Cooling stage - cooling the liquid flux while measuring the heat transfer.

A basic construction was made from a silica tube (alumina in later versions, such as that shown in Figure 4.5) and a $6 \mathrm{~mm}$ copper pipe that was coiled around the tube (see Appendix A). The coiled copper pipe was connected to a radio-frequency power source and acted as an induction coil. During the heating cycle the copper pipe was water cooled to prevent over-heating.

A stainless steel probe was designed to simulate the hot steel shell during the casting process and a mild steel cup was machined to represent the continuous casting mould (see Appendix A). The cup carried the test powder and would later be cooled at the bottom in order to act as the mould (cold zone). The probe could be moved up and down in the silica tube and was fitted with platinum thermocouples to measure the temperature profile during experimentation. The probe was heavily insulated against heat loss to act as a constant heat source during the experiment. 
The ends of the silica tube were sealed off from the surrounding environment and flushed with argon (Ar) gas to prevent oxygen contamination. When conducting an experiment the cup and probe were heated to $1350^{\circ} \mathrm{C}$ to allow the test powder in the cup to completely liquefy and the probe to build up heat. The probe was then lowered to the cup leaving a $3 \mathrm{~mm}$ gap filled with liquid flux. During the subsequent cooling stage the bottom of the cup was cooled using helium $(\mathrm{He})$ gas. In this way heat transfer was directed from the probe to the cup through the solidifying mould flux in the probe/cup gap. Temperature measurements were taken during the cooling stage to simulate the horizontal heat transfer in the continuous casting mould.

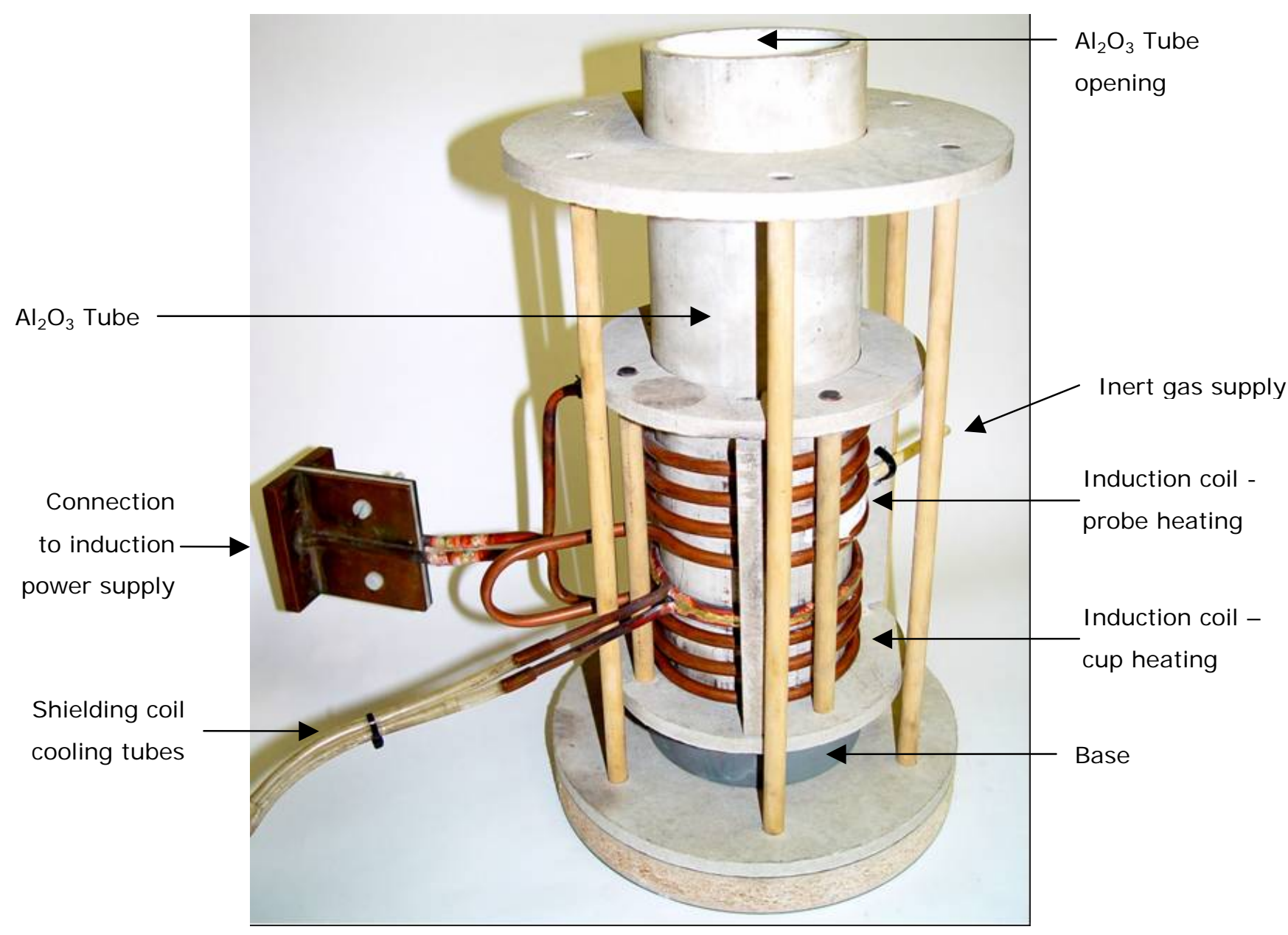

FIGURE 4.5: The experimental apparatus. 


\subsection{BASIC COMPONENTS OF THE EXPERIMENTAL CONSTRUCTION}

\section{MULLITE THERMOCOUPLE SHIELD}

The function of this component is twofold. Firstly, the mullite tube can withstand extremely high temperatures and is used to protect the thermocouple wires that are connected to the probe. Secondly, the mullite tube is connected to the probe and is used to position the probe. For this reason the tube is extended through the refractory cup.

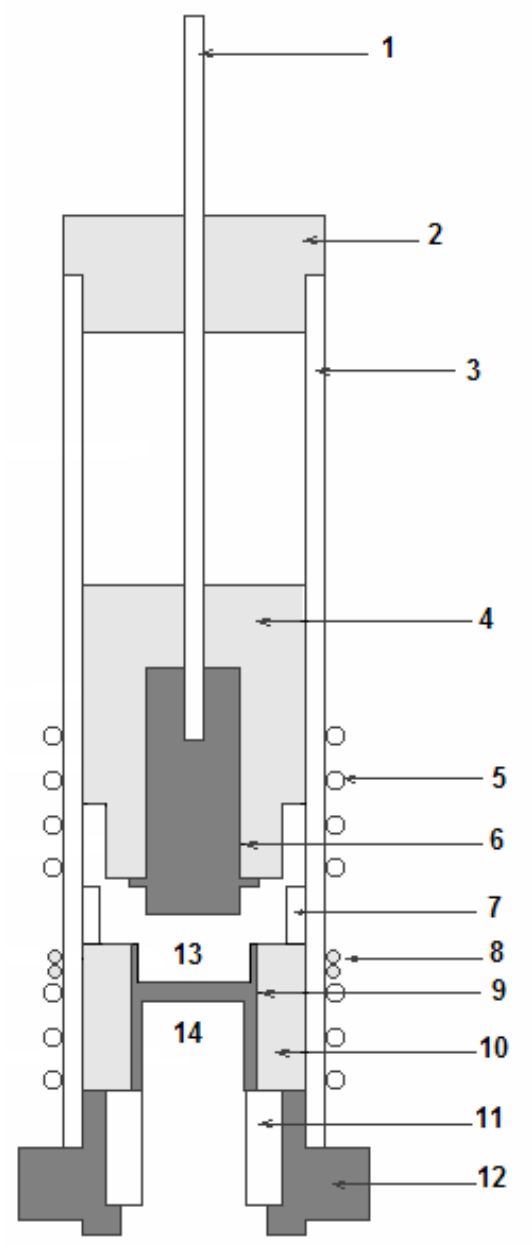

$$
\begin{aligned}
1 & \text { Mullite Thermo-couple shield } \\
2 & \text { Refractory Cap } \\
3 & \text { Silica Tube } \\
4 & \text { Probe Thermal-insulation } \\
5 & \text { Induction Coil } \\
6 & \text { Probe (Stainless Steel) } \\
7 & \text { Cup Ring Shield } \\
8 & \text { Shielding Coil } \\
9 & \text { Cup (Mild Steel) } \\
10 & \text { Cup Thermal-insulation } \\
11 & \text { Base Refractory } \\
12 & \text { Base (Pyrophyllite) } \\
13 & \text { Mould Powder position } \\
14 & \text { Cooling zone }
\end{aligned}
$$

FIGURE 4.6: Detailed drawing of the experimental apparatus.

\section{REFRACTORY CAP}

This silica-based $\left(\mathrm{Al}_{2} \mathrm{O}_{3}-\mathrm{MgO}\right)$ refractory cap is machined to act as a lid (figure 4.7). The main function of the cap is to seal off the top part of the silica tube (component 3 ) in order to protect the internal components from atmospheric contamination. The cap is also used to guide the movement of the mullite thermocouple shield (component 1 ) when the probe is moved. 


\section{SILICA TUBE}

The silica tube acts as the main structure, keeping all the components of the experimental apparatus in place. Silica is used in many refractory applications and can withstand very high temperatures. The silica tube also acts as a sleeve, guiding the movement of the probe. The induction coil (component 5) is coiled around the silica tube to keep the helical coil distance and pitch fixed.

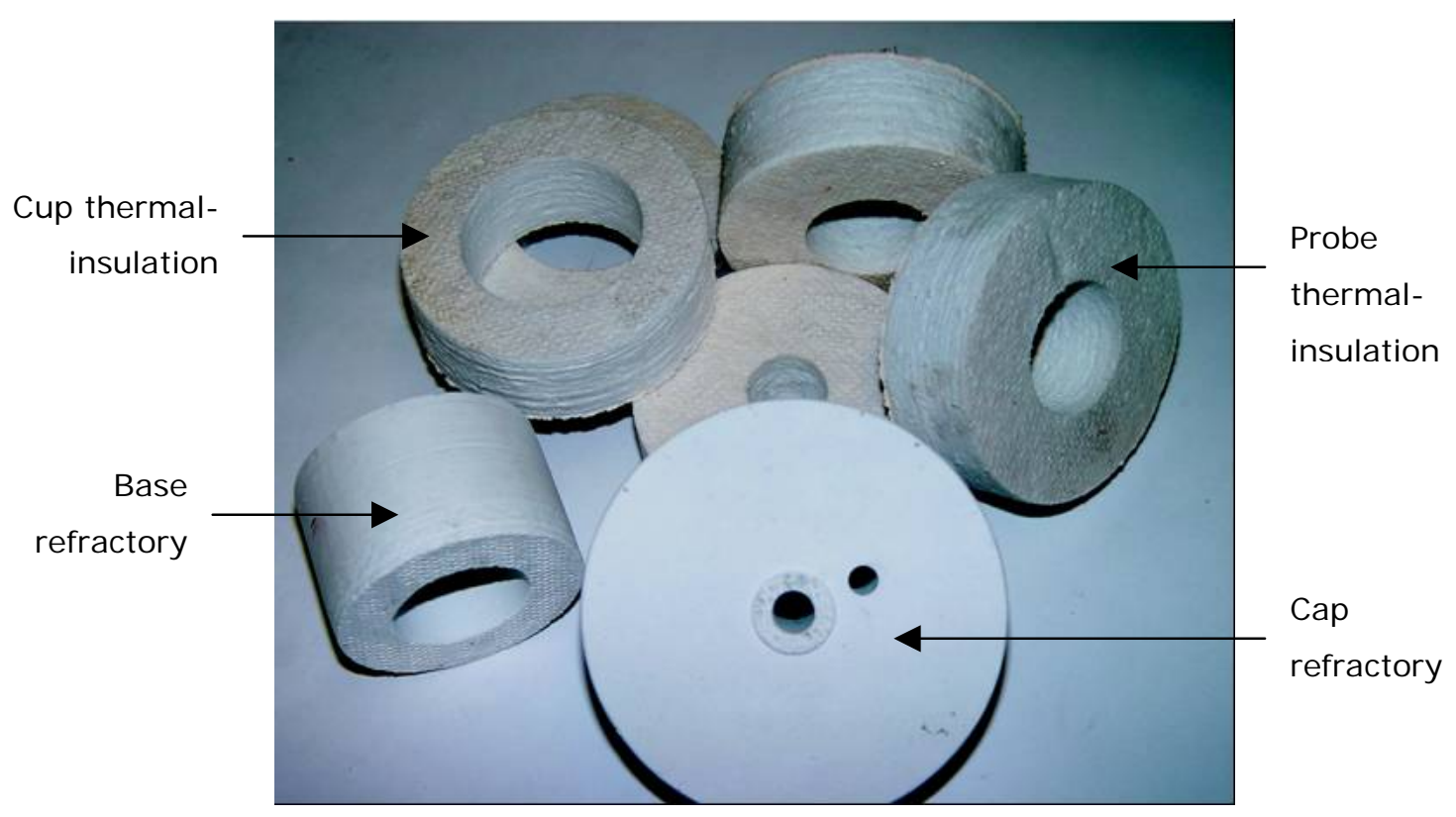

FIGURE 4.7: $\quad \mathrm{Al}_{2} \mathrm{O}_{3}-\mathrm{SiO}_{2}$ based fibre board used for thermal insulation. Max temperature $=1500^{\circ} \mathrm{C}$. Thermal conductivity $=0.05 \mathrm{~W} / \mathrm{m} . \mathrm{K}$

\section{PROBE THERMAL-INSULATION}

Heat loss to the surroundings must be prevented at all times to optimise the thermal efficiency of the experimental setup. The function of the probe thermal insulation is to minimise heat loss from the probe. $\mathrm{Al}_{2} \mathrm{O}_{3}-\mathrm{SiO}_{2}$ based fibre board, having a maximum operating temperature of about $1500^{\circ} \mathrm{C}$ and an overall thermal conductivity of $0.05 \mathrm{~W} / \mathrm{m} . \mathrm{K}$, was used for this application. The insulating material is also designed to push against the inner wall of the silica tube to guide the movement of the probe. 


\section{INDUCTION COIL}

The induction coil is manufactured from copper tubing (6mm inner diameter). The coil is water cooled and used to generate the magnetic field needed to heat the probe and cup.

\section{PROBE}

The probe is manufactured from 310 -stainless steel to minimise scale formation at high temperatures. The probe is heated to about $1350^{\circ} \mathrm{C}$ and represents the hot steel shell during continuous casting. The probe can be moved up and down and is designed to engage with the cup (component 9) to leave a $3 \mathrm{~mm}$ gap between the cup surface and probe nose.

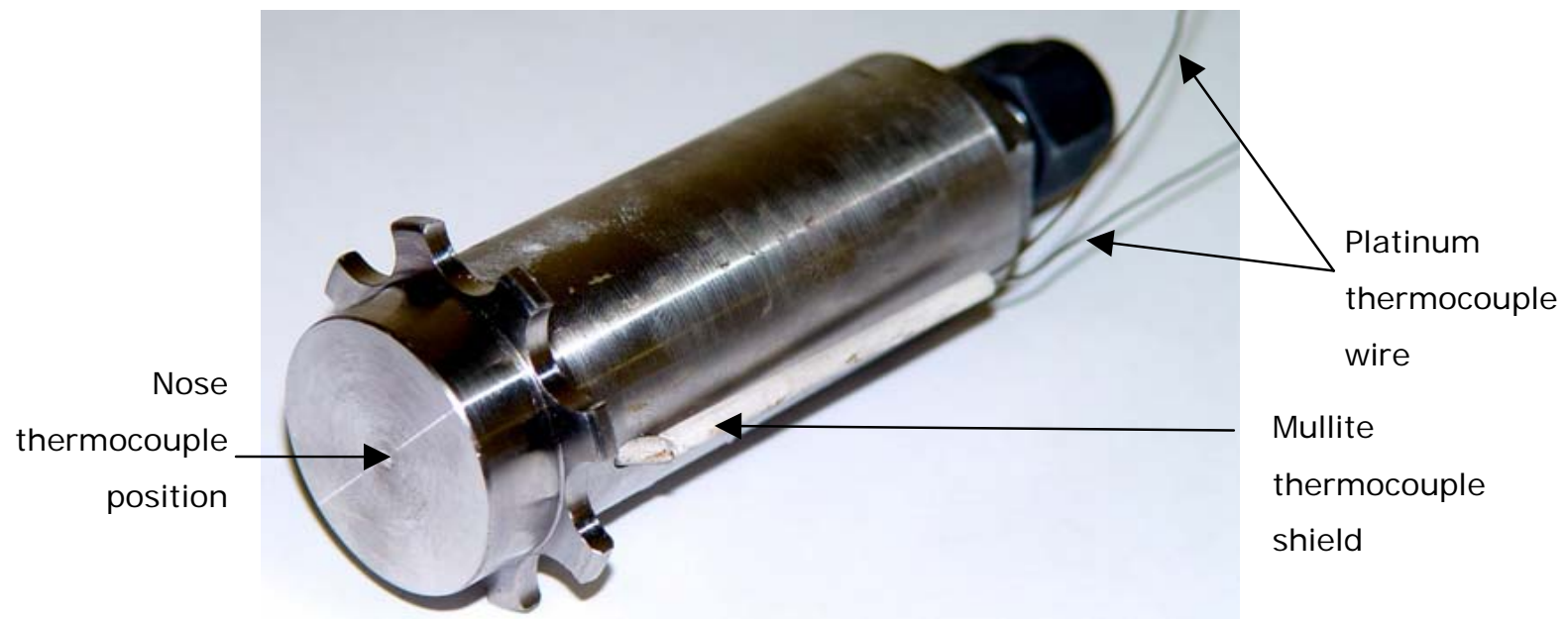

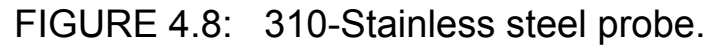

\section{CUP RING SHIELD}

The function of the ring shield is to protect the silica tube (component 3 ) from the heat radiating from the probe (component 6). The heat shield limits heat loss to the surroundings and is also manufactured from $\mathrm{Al}_{2} \mathrm{O}_{3} / \mathrm{SiO}_{2}$-based fibre board.

\section{SHIELDING COIL}

The function of the shielding coil is to neutralise the magnetic field induced in the thin cup rim. Applying excessive heat to the thin portions of the cup will cause the metal in these areas to melt, ultimately damaging the cup. This may result in the loss of the test powder that can cause even further corrosive 
damage to the apparatus. The main function of the shielding coil is therefore to create a Faraday-cage effect, preventing over heating to the fragile parts of the cup. The shielding coil is manufactured from a $3.5 \mathrm{~mm}$ copper pipe which is also water cooled.

\section{CUP}

The cup is manufactured from mild steel and designed to perform two main functions. Firstly the cup carries about $20 \mathrm{~g}$ of mould powder that eventually melts down to liquid flux when the cup is heated by induction. The cup holds the liquid flux in position when the probe is lowered into position.

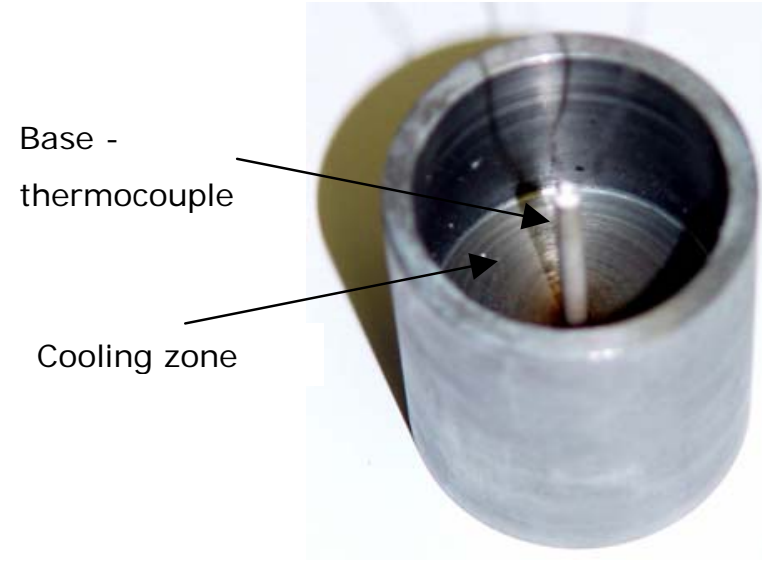

Bottom view

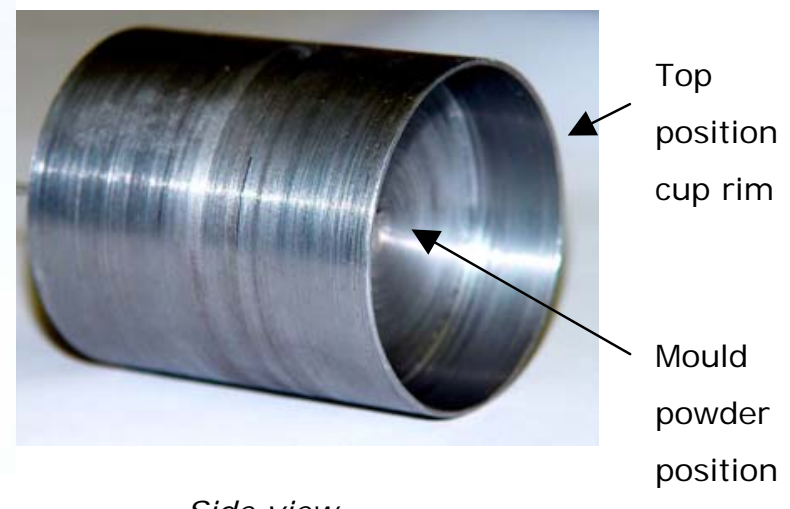

Side view

FIGURE 4.9: Mild steel cup.

Secondly, when the cup base is cooled, the cup acts as the water cooled mould during the continuous casting process. The cup is fitted with thermocouples to measure the temperatures during cooling.

\section{CUP THERMAL-INSULATION}

As in the case of the probe thermal-insulation, the cup thermal-insulation also prevents excessive heat loss from the cup to the silica tube (component 3 ).

\section{BASE REFRACTORY}

The cup is placed on the base refractory during the experiment. The function of the base refractory is to protect the base (component 12) from the highly corrosive mould flux if flux should be spilled from the cup. This component is specifically designed to be replaced if damaged. 


\section{CHAPTER 5}

\section{EXPERIMENTAL PROCEDURE}

\subsection{MOULD POWDER PREPARATION}

The experimental construction was designed to test about $20 \mathrm{~g}$ of mould powder. For this purpose, large quantities of mould powder were prepared for testing. The mould powder was in granulated form (figure 5.1A) and was ground to a fine powder. This would speed up the decarburising process.
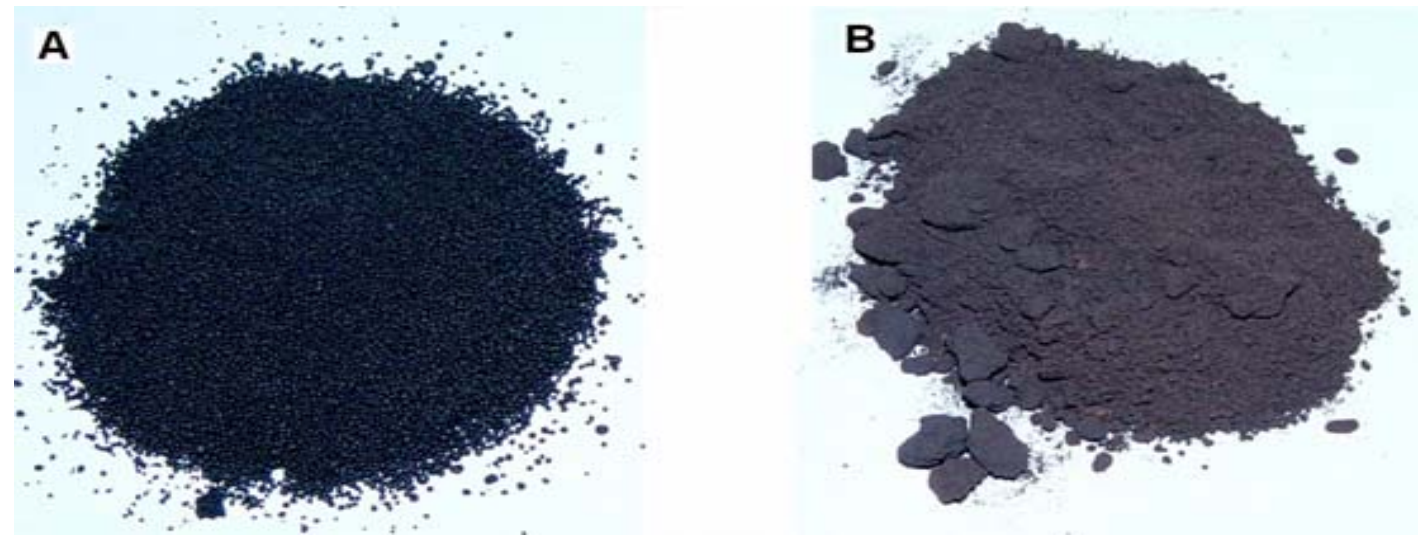

FIGURE 5.1: SPH-KA1 - Continuous casting mould powder.

A) Granulated powder B) Ground - decarburised powder

Small quantities of mould powder $(100 \mathrm{~g})$ were placed in a flat stainless steel container to speed up the decarburisation process (air and carbon combustion). The container was placed in a furnace at $650^{\circ} \mathrm{C}$ for approximately 18 hours to allow the carbon in the mould powder to react with the surrounding air in the furnace. Thereafter the furnace was switched off and allowed to cool to room temperature.

TABLE 5.1: Weight $\% \mathrm{TiO}_{2}$ added to mould powder.

\begin{tabular}{|c|c|c|}
\hline Test group & Test code & Weight $\% \mathbf{~ T i O}_{\mathbf{2}}$ added to mould powder \\
\hline 1 & 000 & $0.0 \%$ \\
\hline 2 & 050 & $5.0 \%$ \\
\hline 3 & 100 & $10.0 \%$ \\
\hline
\end{tabular}

The decarburised mould powder (figure 5.1B) was divided into three equal parts and doped with $\mathrm{TiO}_{2}$ (table 5.1). Each test group was ground for a second time to allow 
proper mixing of the $\mathrm{TiO}_{2}$. Finally the mould powders were stored in separate desiccators to prevent moisture pickup.

\subsection{PREPARING THE EXPERIMENTAL APPARATUS}

Firstly the experimental apparatus was connected to the induction power supply. The cooling water for the induction coil was then initiated and the coiled copper pipe was inspected for water leakage. The shielding coil was also connected to tap water and the flow was regulated in order to provide the required cooling during the experiment.

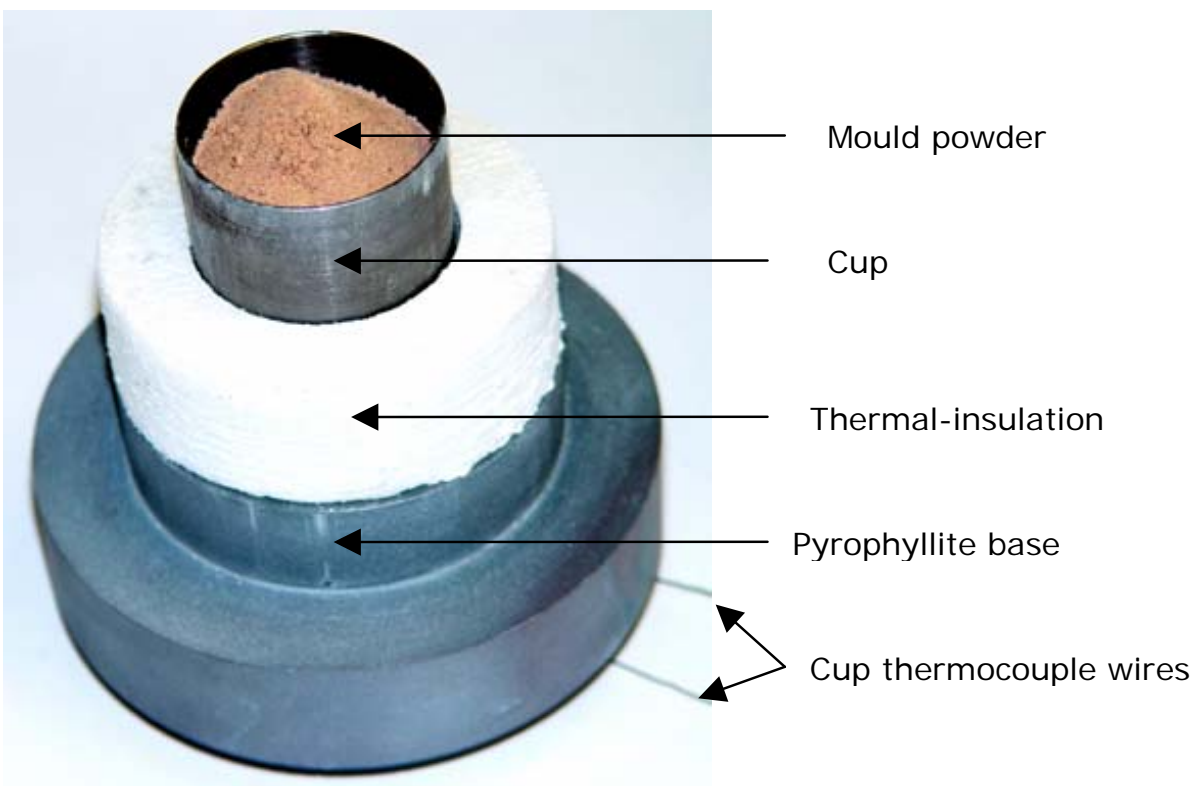

FIGURE 5.2: The cup, mould powder and base refractory assembly.

The cup and probe dimensions were carefully measured to accurately determine the probe/cup gap. (This gap determines the flux thickness during the experiment and was noted each time before a test). Thermocouples from the cup and the probe were inspected and connected to the data system. The readings on the data logger were checked and calibrated.

The consumable base refractory was placed inside the pyrophyllite base and the required thermal insulation on the cup and probe were also put in position. Test powder was weighed $(20 \mathrm{~g})$ and added to the cup. The powder in the cup was compacted to help with the sintering and melting process. The cup was then placed on the base refractory inside the silica tube (figure 5.2). 
The probe was lowered from the top of the silica tube to check if the insulated probe assembly could freely move up and down. This was done to check if the probe could be engaged with the cup during a test. The refractory cap was placed on top of the silica tube and sealed to prevent any gas leakage.

The cooling opening at the base was sealed off and the system was flushed with argon gas $(15 \mathrm{~min})$ to remove all excess oxygen in the system. The cooling nozzle was placed in position (cooling zone - refer to figure 4.6) and connected to the helium gas supply. Finally all water and gas flow systems were checked before commencing with the heating sequence.

\subsection{HEATING SEQUENCE}

The flow of argon gas, used to flush the system, was reduced, maintaining only a slight positive pressure in the system. This would prevent oxygen from entering the silica-tube. Excessive gas flow would cool the system making it difficult to reach the required temperature.

The heating sequence was initiated by allowing electrical current to flow in the induction coil (see Appendix $C$ ). The temperature readings from the cup and the probe were regularly monitored to see if the system was properly heated. The heating sequence took approximately one hour and was done stepwise to a maximum temperature of $1300^{\circ} \mathrm{C}$.

During the heating sequence the aim was to heat the cup and probe simultaneously. The mould powder in the cup absorbed most of the heat for melting and allowed the cup to heat more slowly than the probe. Alternatively if the cup were to heat faster than the probe the helium cooling system was used to gradually reduce the temperature of the cup.

Mostly the probe appeared to heat faster then the cup. The design allowed more induction to the probe because heat supply to this part of the apparatus could be controlled more accurately. When the probe over-heated it was simply moved upward out of the induced magnetic field. This was done without affecting the heating of the cup. The cup and probe were heated to aim temperatures and allowed to stabilise for about 10 to 15 minutes. After the mould powder in the cup was 
completely molten, the heat source was shut down.

\subsection{COOLING SEQUENCE}

After stabilising the experimental apparatus at aim temperatures the probe was slowly lowered to engage with the cup. As the probe was lowered into the cup, excess flux spilled over the sides of the cup and was absorbed by the base refractory to prevent any damage to the apparatus. At this point the small gap between the cup and the probe was completely filled with liquid flux (see Appendix D). This was called the engaging of the probe with the cup to represent the steel shell and the mould wall during continuous casting.

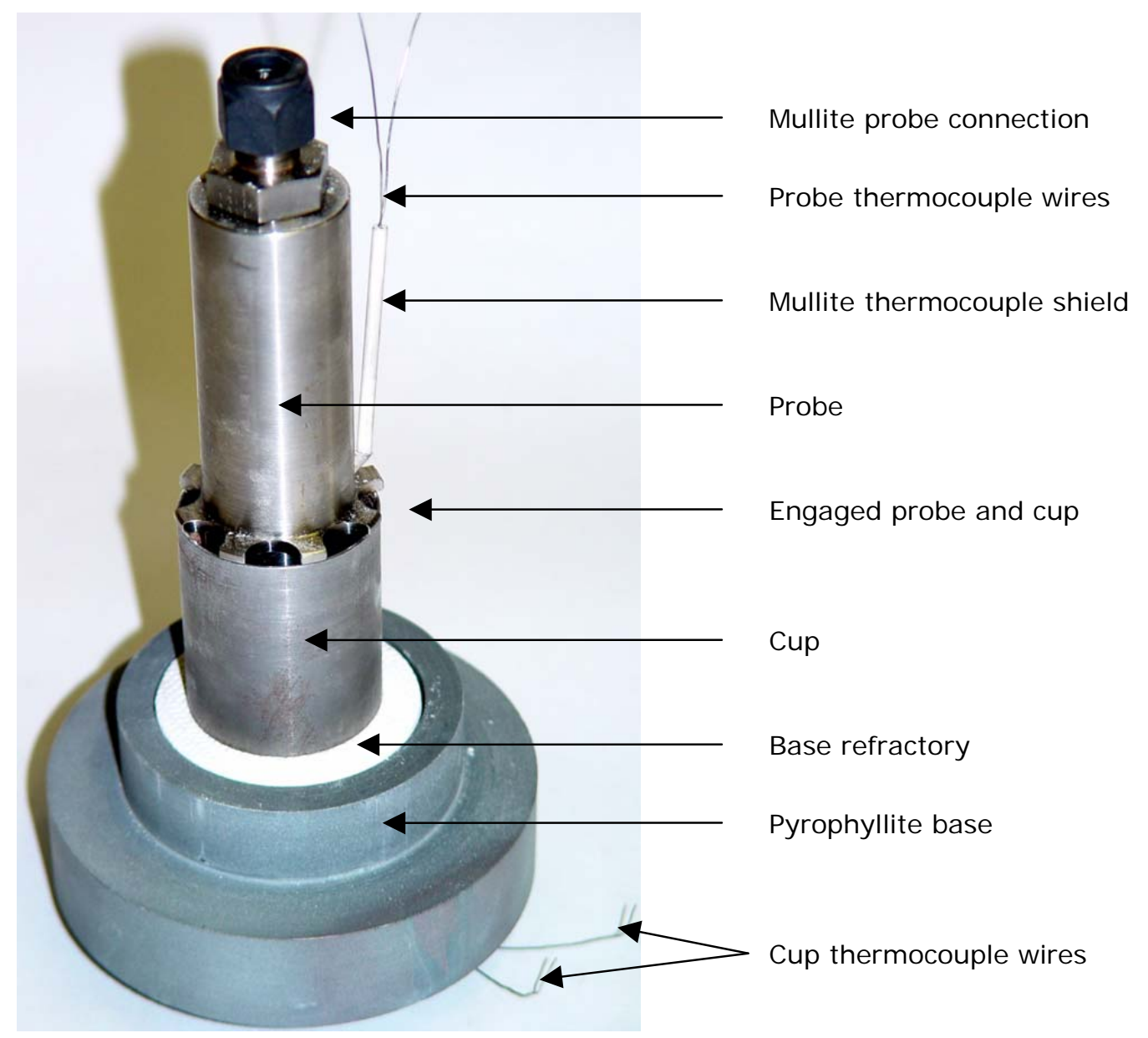

FIGURE 5.3: Probe and cup assembly.

The next step was to start logging all temperature readings using the electronic datataker system. The cooling gas $(\mathrm{He})$ was slowly opened allowing a jet of cold gas to 
cool the bottom of the mild steel cup. This signified the beginning of the cooling sequence (see Appendix D). Cooling took place until the nose of the probe reached a temperature lower then $500^{\circ} \mathrm{C}$. After this temperature was reached, the cooling gas flow was stopped and the system was allowed to cool to room temperature. Finally the temperature reading from the data logging system was downloaded and stored.

\subsection{SAMPLING PROCEDURE}

After the apparatus had cooled, thermocouple wires on the cup and probe were disconnected and the engaged cup/probe system was removed from the silica tube. The cup was then carefully separated from the probe to prevent any damage to the probe thermocouples. The probe was stored and could later be re-used for similar experiments.

The solidified mould powder in the cup was removed by using a lathe to break out the pieces of solid test flux. Removing the flux mechanically allowed the solid flux to break up into small portions. These fractured portions were mounted in an epoxy resin and allowed to harden. Samples were then polished and sputter-coated with gold for SEM analyses. The remainder of the test flux was ground to a fine powder and sent for XRF and XRD analyses. 


\section{CHAPTER 6}

\section{SLAG RIM ANALYSES AND THE PREDICTED EFFECT OF $\mathrm{TiO}_{2}$ PICK-UP DURING FLUX SOLIDIFICATION}

\subsection{SEM ANALYSES OF THE SPH-KA1 SLAG RIM}

To investigate the mineralogical changes in mould powder during continuous casting and to identify the crystalline phases that form during flux solidification, a slag rim was taken from the mould for analyses. The aim of this chapter is to identify the typical crystalline phases associated with casting austenitic stainless steel (table 2.1) using SPH-KA1 mould powder (table 6.1). Analysing an industrial slag rim would therefore give an overall indication of the crystalline phases expected during experimental testing.

TABLE 6.1: chemical compositions (weight \%) of SPH-KA1 mould powder as provided by the powder manufacturer.

\begin{tabular}{|l|c|c|c|c|c|c|c|c|c|}
\hline Weight \% & $\mathrm{SiO}_{2}$ & $\mathbf{C a O}$ & $\mathbf{M g O}$ & $\mathrm{Al}_{2} \mathrm{O}_{\mathbf{3}}$ & $\mathrm{Na}_{2} \mathbf{O}$ & $\mathrm{Fe}_{2} \mathrm{O}_{\mathbf{3}}$ & $\mathrm{MnO}$ & $\mathbf{F}$ & $\mathbf{C}$ \\
\hline Minimum & 28.5 & 31.0 & 4.5 & 2.5 & 5.0 & 1.0 & 5.5 & 6.5 & 3.0 \\
\hline Maximum & 30.5 & 33.0 & 6.0 & 4.0 & 6.5 & 2.5 & 7.0 & 7.5 & 4.5 \\
\hline Average & 29.5 & 32.0 & 5.3 & 3.3 & 5.8 & 1.8 & 6.3 & 7.0 & 3.8 \\
\hline
\end{tabular}

SPH-KA1 mould powder is manufactured to have a basicity ranging between 1.03 and 1.05 with a bulk density of 0.55 to $0.75 \mathrm{~kg} / \mathrm{dm}^{3}$. The mould powder has a melting point of $1100^{\circ} \mathrm{C}$ and is highly fluid at $1150^{\circ} \mathrm{C}$. At temperatures above $1300^{\circ} \mathrm{C}$ the viscosity of the flux is in the order of $0.6 \mathrm{dPa} \cdot \mathrm{s}$ and decreases to $0.3 \mathrm{dPa} \cdot \mathrm{s}$ at about $1500^{\circ} \mathrm{C}$. The carbon content is made up of carbon dioxide $\left(6-7 \% \mathrm{CO}_{2}\right)$ and small amounts of free carbon $(1-2 \% \mathrm{C})$ while the moisture pickup at $600^{\circ} \mathrm{C}$ is estimated to be below $1.0 \%$.

To assess changes in the mould flux composition during casting, a sample of the slag rim which formed at the meniscus on the mould plates was taken midway between the SEN and the narrow side of the mould, after casting for about one hour. The steel grade was 321 and the mould flux SPH-KA1 (starting composition given in Table 6.1). A scanning electron micrograph of a polished cross-section of this slag rim sample is shown in Figure 6.1, with its chemical analysis and identified phases 
given in Tables 6.2 and 6.3. Micro-analysis was performed on the polished crosssection. Three main areas, with differences in composition and microstructure, were identified. As Figure 6.1 indicates, these regions were next to the mould, a central region, and next to the steel (shell). Area analyses of these regions are given in Table 6.4.

Representative micrographs of the three regions are given in Figures 6.2 to 6.4, with point analyses of individual phases in the three regions in Tables 6.5 to 6.7. These phases were identified on the basis of their chemical composition. Discussion of these structures follows after these figures and tables.

TABLE 6.2: XRF-analyses of the crushed slag rim that formed from SPH-KA1 mould powder during the casting of 321-stainless steel.

\begin{tabular}{|c|c|c|c|c|c|c|c|c|c|}
\hline Crushed slag rim & $\mathrm{Na}_{2} \mathrm{O}$ & $\mathrm{MgO}$ & $\mathbf{F}$ & $\mathrm{CaO}$ & $\mathrm{TiO}_{2}$ & $\mathrm{Al}_{2} \mathrm{O}_{3}$ & $\mathrm{SiO}_{2}$ & $\mathrm{MnO}$ & $\mathrm{FeO}$ \\
\hline XRF analysis & 5.0 & 5.4 & 1.8 & 39.6 & 10.5 & 3.5 & 27.2 & 3.2 & 1.6 \\
\hline
\end{tabular}

TABLE 6.3: Major phases identified by X-ray powder diffraction of the slag rim that formed from SPH-KA1 mould powder during the production of 321stainless steel (see Appendix E for spectrum).

\begin{tabular}{|c|c|c|c|}
\hline \multirow{4}{*}{$\begin{array}{l}\frac{1}{5} \\
\frac{5}{5} \\
\frac{1}{1} \\
\frac{\pi}{2} \\
\frac{\pi}{n}\end{array}$} & Name & Crystal type & Composition \\
\hline & Cuspidine & Monoclinic & $\mathrm{Ca}_{4} \mathrm{Si}_{2} \mathrm{O}_{7} \mathrm{~F}_{2}$ \\
\hline & Perovskite & Orthorhombic & $\mathrm{CaTiO}_{3}$ \\
\hline & Nepheline & Hexagonal & $\mathrm{NaAlSiO}_{4}$ \\
\hline
\end{tabular}


TABLE 6.4: EDS-area-analyses of the SPH-KA1 slag rim that formed on the mould side, central and shell side during the casting of 321-stainless steel.

(Average mass percentages, with 95\% confidence intervals)

\begin{tabular}{|c|c|c|c|c|c|c|c|c|c|}
\hline Region & $\mathrm{Na}_{2} \mathrm{O}$ & $\mathrm{MgO}$ & $\mathbf{F}$ & $\mathrm{CaO}$ & $\mathrm{TiO}_{2}$ & $\mathrm{Al}_{2} \mathrm{O}_{3}$ & $\mathrm{SiO}_{2}$ & $\mathrm{MnO}$ & $\mathrm{FeO}$ \\
\hline Mould side & $5.1 \pm 2.3$ & $4.9 \pm 2.0$ & $0.0-3.3$ & $39.9 \pm 0.1$ & $5.9 \pm 1.7$ & $4.7 \pm 2.3$ & $32.0 \pm 2.8$ & $5.2 \pm 2.6$ & $0.7 \pm 0.2$ \\
\hline Central & $3.1 \pm 2.5$ & $3.7 \pm 2.9$ & $0.0-4.7$ & $39.5 \pm 2.0$ & $25.8 \pm 12.7$ & $0.0-7.0$ & $19.3 \pm 7.4$ & $2.7 \pm 2.3$ & $0.4 \pm 0.3$ \\
\hline Shell side & $5.7 \pm 1.9$ & $6.2 \pm 1.6$ & $0.0-7.1$ & $33.2 \pm 7.5$ & $1.6 \pm 1.0$ & $8.1 \pm 3.6$ & $33.5 \pm 2.5$ & $7.5 \pm 1.6$ & $1.7 \pm 1.2$ \\
\hline
\end{tabular}

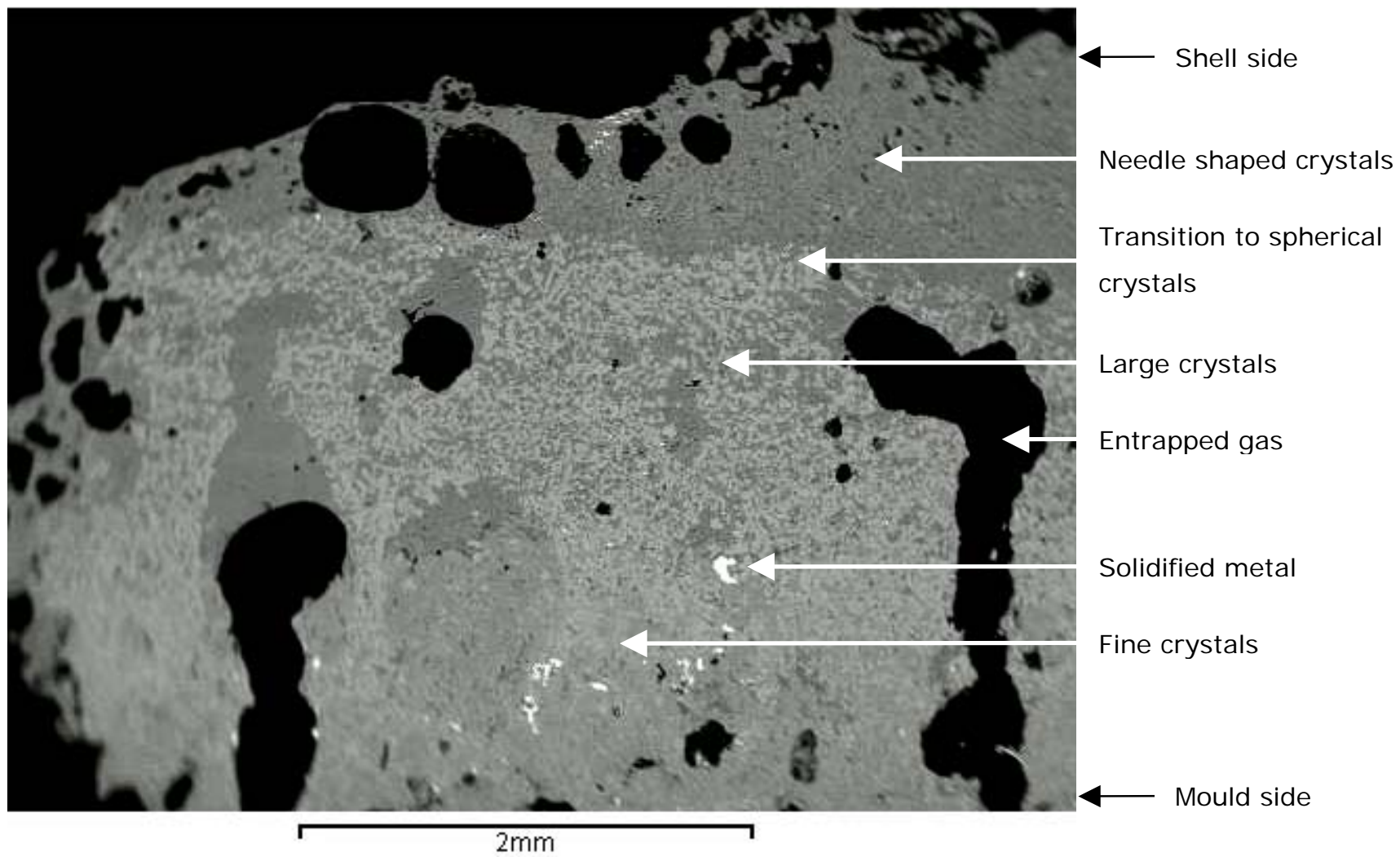

FIGURE 6.1: SEM-analyses: Back scattered electron image of the slag rim formed during industrial casting of 321-Stainless steel using SPH-KA1 mould powder. 
TABLE 6.5: EDS point analyses of phases in SPH-KA1 slag rim: mould side (average mass percentages, with 95\% confidence intervals).

\begin{tabular}{|c|c|c|c|c|c|c|c|c|c|}
\hline Phase & $\mathrm{Na}_{2} \mathrm{O}$ & $\mathrm{MgO}$ & $\mathrm{F}$ & $\mathrm{CaO}$ & $\mathrm{TiO}_{2}$ & $\mathrm{Al}_{2} \mathrm{O}_{3}$ & $\mathrm{SiO}_{2}$ & $\mathrm{MnO}$ & $\mathrm{FeO}$ \\
\hline Olivine & $0.0-0.9$ & $16.6 \pm 1.0$ & 0.0 & $37.0 \pm 3.2$ & $0.0-1.4$ & 0.0 & $35.4 \pm 1.0$ & $10.6 \pm 1.2$ & $0.0-2.6$ \\
\hline Cuspidine & $0.0-1.8$ & $0.0-1.3$ & $0.0-13.5$ & $61.5 \pm 5.5$ & 0.0 & 0.0 & $29.6 \pm 1.5$ & $0.0-2.6$ & $0.3 \pm 0.1$ \\
\hline Perovskite & $1.4 \pm 0.3$ & $0.8 \pm 0.6$ & 0.0 & $39.1 \pm 3.9$ & $53.1 \pm 8.3$ & $0.0-3.2$ & $0.0-11.9$ & $0.0-3.1$ & $0.0-1.7$ \\
\hline $\begin{array}{l}\text { Nepheline } \\
\text { and others }\end{array}$ & $11.5 \pm 4.3$ & $4.7 \pm 0.9$ & $0.0-1.4$ & $0.0-8.3$ & $0.5 \pm 0.4$ & $26.2 \pm 2.6$ & $48.1 \pm 7.5$ & $4.6 \pm 0.5$ & $0.3 \pm 0.3$ \\
\hline
\end{tabular}

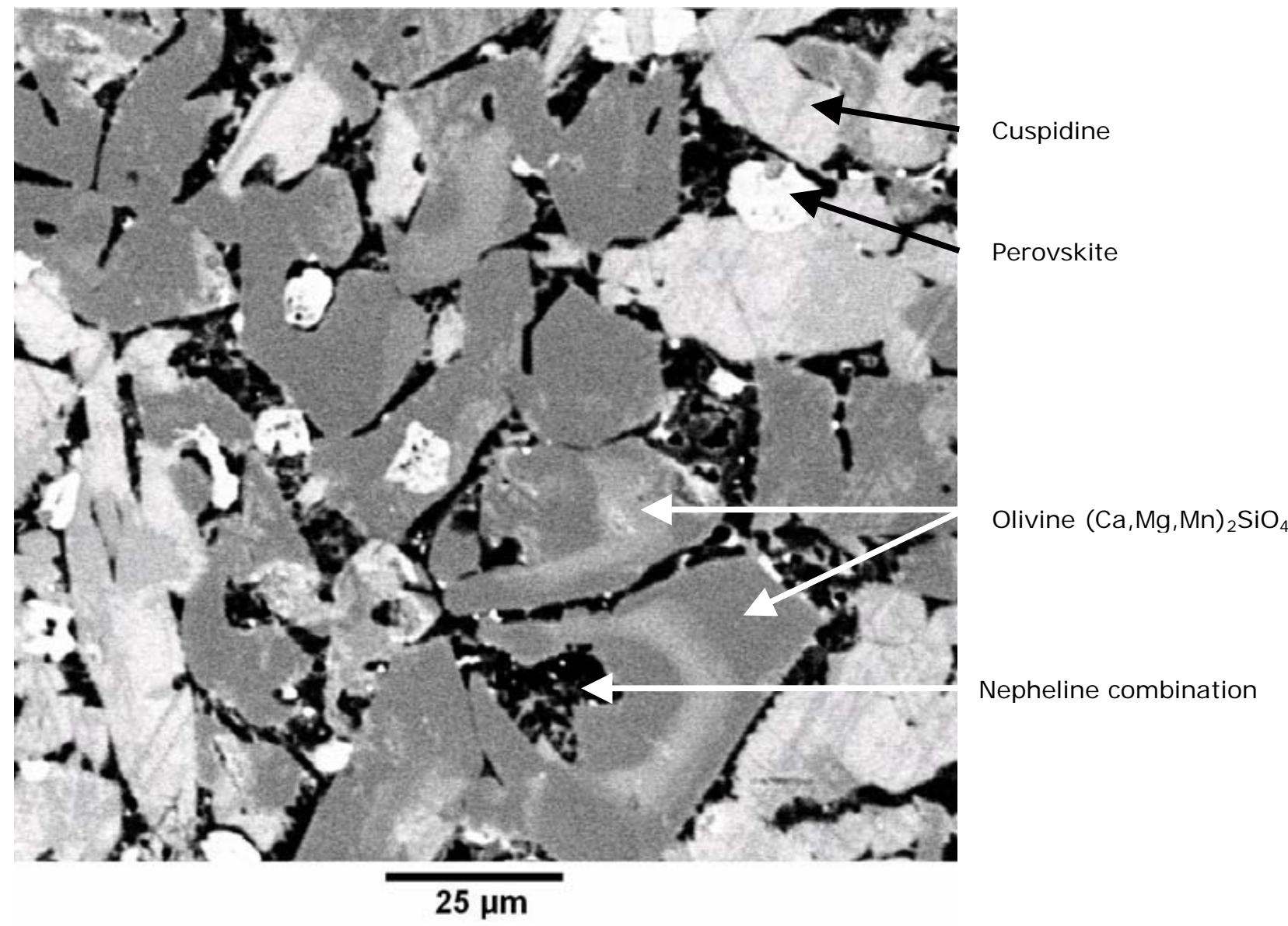

FIGURE 6.2: SEM back-scattered electron image of SPH-KA1 slag rim: mould side 
TABLE 6.6: EDS point analyses of phases in SPH-KA1 slag rim: midway between the mould and the shell (average mass percentages, with 95\% confidence intervals where available).

\begin{tabular}{|c|c|c|c|c|c|c|c|c|c|}
\hline Phase & $\mathrm{Na}_{2} \mathrm{O}$ & $\mathrm{MgO}$ & $\mathrm{F}$ & $\mathrm{CaO}$ & $\mathrm{TiO}_{2}$ & $\mathrm{Al}_{2} \mathrm{O}_{3}$ & $\mathrm{SiO}_{2}$ & $\mathrm{MnO}$ & $\mathrm{FeO}$ \\
\hline Cuspidine & $0.5 \pm 0.1$ & $0.0-2.3$ & $5.6 \pm 1.5$ & $61.7 \pm 5.0$ & $0.0-2.0$ & 0.0 & $29.7 \pm 0.7$ & $0.9 \pm 0.6$ & $0.0-0.7$ \\
\hline Perovskite & 0.4 & 0.1 & 0.0 & 39.1 & 59.1 & 0.9 & 0.0 & 0.4 & 0.0 \\
\hline $\begin{array}{l}\text { Nepheline } \\
\text { and others }\end{array}$ & $9.3 \pm 3.3$ & $13.1 \pm 5.6$ & $0.0-2.1$ & $6.4 \pm 4.0$ & $5.1 \pm 4.1$ & $13.9 \pm 5.4$ & $41.0 \pm 6.5$ & $10.4 \pm 6.0$ & $0.0-0.8$ \\
\hline
\end{tabular}

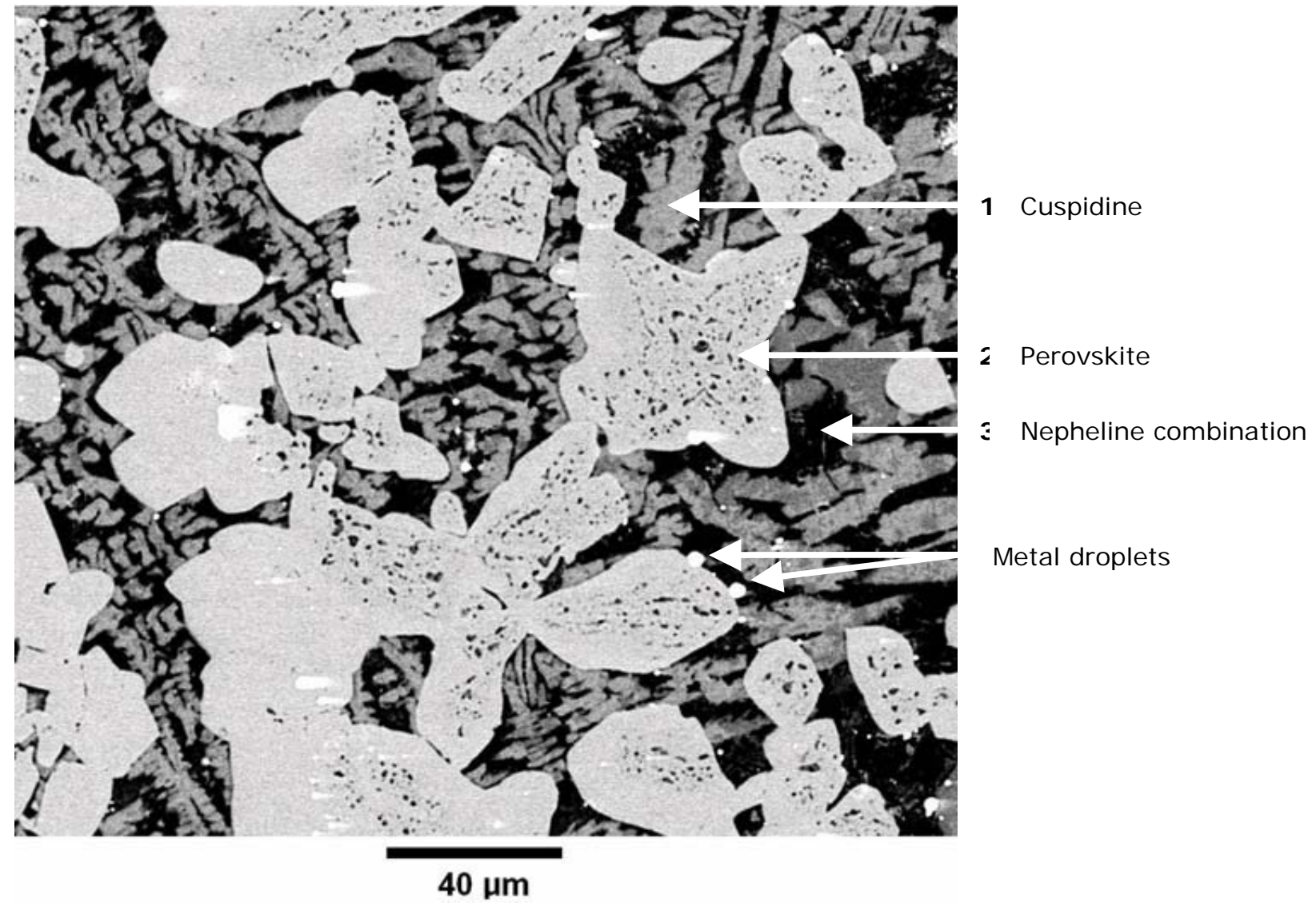

FIGURE 6.3: SEM back-scattered electron image of SPH-KA1 slag rim: midway between the mould and the shell. 
TABLE 6.7: EDS point analyses of phases in SPH-KA1 slag rim: shell side (average mass percentages, with 95\% confidence intervals).

\begin{tabular}{|c|c|c|c|c|c|c|c|c|c|}
\hline Phase & $\mathrm{Na}_{2} \mathrm{O}$ & $\mathrm{MgO}$ & $\mathrm{F}$ & $\mathrm{CaO}$ & $\mathrm{TiO}_{2}$ & $\mathrm{Al}_{2} \mathrm{O}_{3}$ & $\mathrm{SiO}_{2}$ & $\mathrm{MnO}$ & $\mathrm{FeO}$ \\
\hline Cuspidine & $0.3 \pm 0.2$ & $0.7 \pm 0.3$ & $6.6 \pm 0.4$ & $61.5 \pm 1.3$ & $0.8 \pm 0.7$ & $0.0 \pm 0.0$ & $29.1 \pm 0.2$ & $0.8 \pm 0.5$ & $0.0-0.6$ \\
\hline Perovskite & $1.5 \pm 0.2$ & $1.6 \pm 0.2$ & 0.0 & $40.3 \pm 0.4$ & $47.5 \pm 0.9$ & $0.0-0.3$ & $6.3 \pm 0.8$ & $1.7 \pm 1.5$ & $0.0-0.5$ \\
\hline $\begin{array}{l}\text { Nepheline } \\
\text { and others }\end{array}$ & $9.2 \pm 1.3$ & $13.8 \pm 2.2$ & 0.0 & $9.7 \pm 5.9$ & $3.3 \pm 0.6$ & $10.2 \pm 1.1$ & $42.5 \pm 3.0$ & $11.0 \pm 3.0$ & $0.2 \pm 0.2$ \\
\hline
\end{tabular}

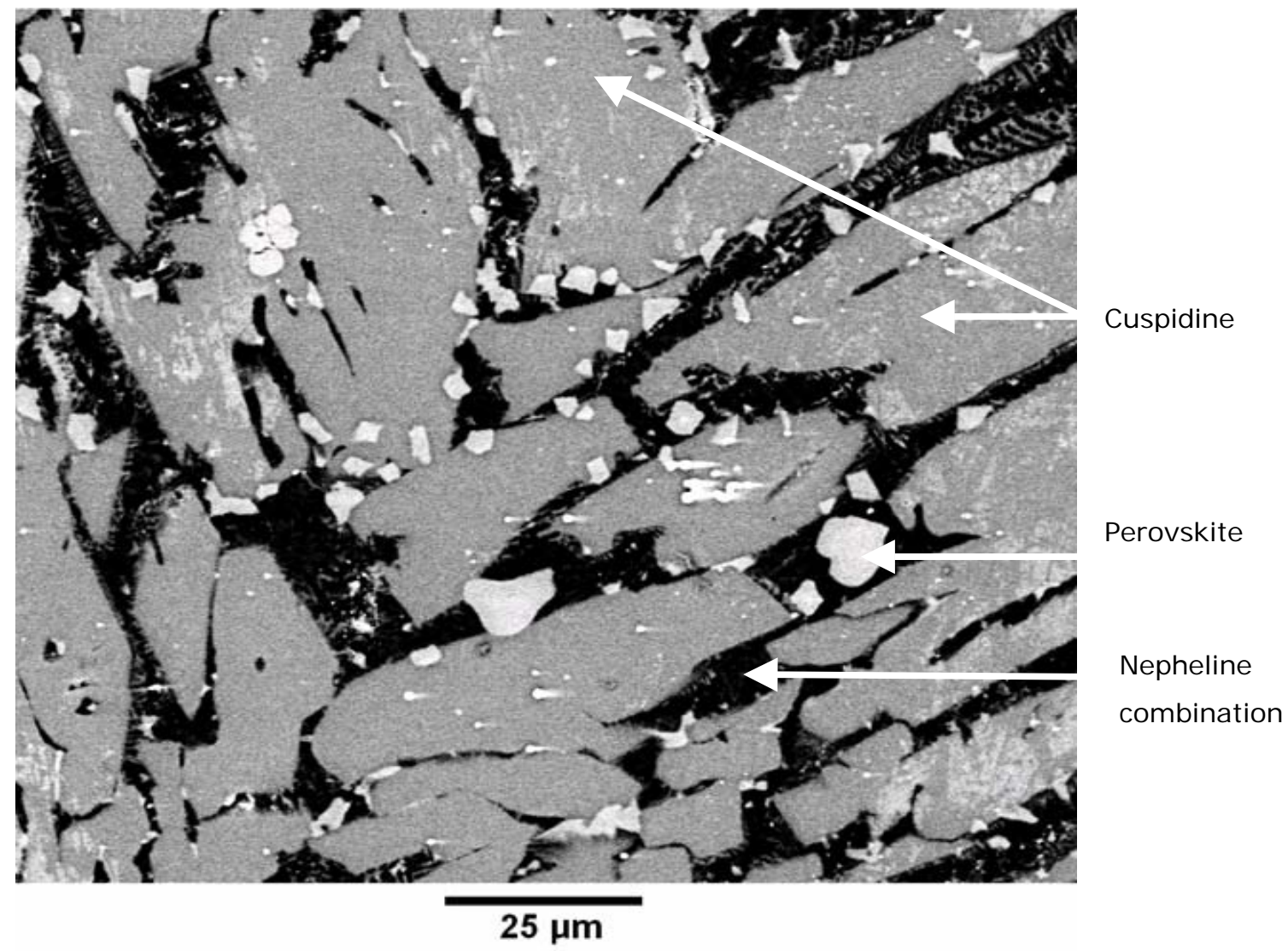

FIGURE 6.4: SEM back-scattered electron image of SPH-KA1 slag rim: shell side

When the XRF analysis of the slag rim in table 6.6 is compared to the original mould powder composition (table 6.1) the pickup of $\mathrm{TiO}_{2}$ is undeniably clear. Higher levels of $\mathrm{CaO}$ are also found in the slag rim and combined with the large pickup of $\mathrm{TiO}_{2}$ promotes the formation of perovskite during casting. 
Table 6.2 also indicates the reduction of manganese oxide $(\mathrm{MnO})$ during casting. $\mathrm{MnO}$ is intentionally added to the mould flux formulation as a sacrificial compound to prevent the loss of silica $\left(\mathrm{SiO}_{2}\right)$ during casting. As mentioned in section 3.4.3 titanium reduces silica to form titanium oxide $\left(\mathrm{TiO}_{2}\right)$. By adding $\mathrm{MnO}$, titanium preferably reduces $\mathrm{MnO}$ (with possible reactions given by equations 28 and 29), minimising the loss of $\mathrm{SiO}_{2}$.

$[\mathrm{Ti}]+2(\mathrm{MnO}) \rightarrow\left(\mathrm{TiO}_{2}\right)+2[\mathrm{Mn}]$

$6[\mathrm{Ti}]+10(\mathrm{MnO}) \rightarrow 2\left(\mathrm{Ti}_{3} \mathrm{O}_{5}\right)+10[\mathrm{Mn}]$

[ ] = species dissolved in liquid stainless steel,

$(\quad)$ species dissolved in mould flux

The XRF analysis (Table 6.2) of the slag rim (and the area analyses in Table 6.4) also indicate a loss in fluorine during casting. One possibility is that the slag rim flux is depleted of fluorine because fluorine (which concentrates in low-melting fluoride compounds) was concentrated in the liquid flux pool which was not sampled for testing.

Comparison of the microstructures and points analyses of the three regions (Tables 6.5 to 6.7 , and Figures 6.2 to 6.4 ) show that cuspidine and perovskite are found throughout, as is the phase combination which is identified as "nepheline and others" in these tables. The latter combination forms during final solidification, and consists of low-melting phases which are rich in sodium. An enlarged view of this region (Figure 6.5) illustrates that it consists of more than one phase.

An exception to this combination of phases is found at the mould side, where a significant amount of a phase which is rich in $\mathrm{CaO}, \mathrm{MgO}$ and $\mathrm{MnO}$ - together with $\mathrm{SiO}_{2}$ - is found; based on its chemical composition, this was identified as an olivinebased solid solution $\left(\mathrm{M}_{2} \mathrm{SiO}_{4}\right)$.

The micro-analyses of cuspidine and perovskite give approximately the same compositions in the three regions, which is as expected since these are stoichiometric phases. In contrast, the region identified as "nepheline and others" is quite variable in composition. This is consistent with this region consisting of variable combinations of different phases. 
A significant difference between the three regions is the variation in perovskite and cuspidine consentrations. This is especially obvious if one compares the structures found in the centre (Figure 6.3) and on the shell side (Figure 6.4). The centre region shows a much higher fraction of perovskite, and a smaller fraction of cuspidine, compared with the shell side. This inverse relationship between the amounts of cuspidine and perovskite are in line with the predicted effect of $\mathrm{TiO}_{2}$ pick-up on the equilibrium solidification behaviour, as discussed in the next section.

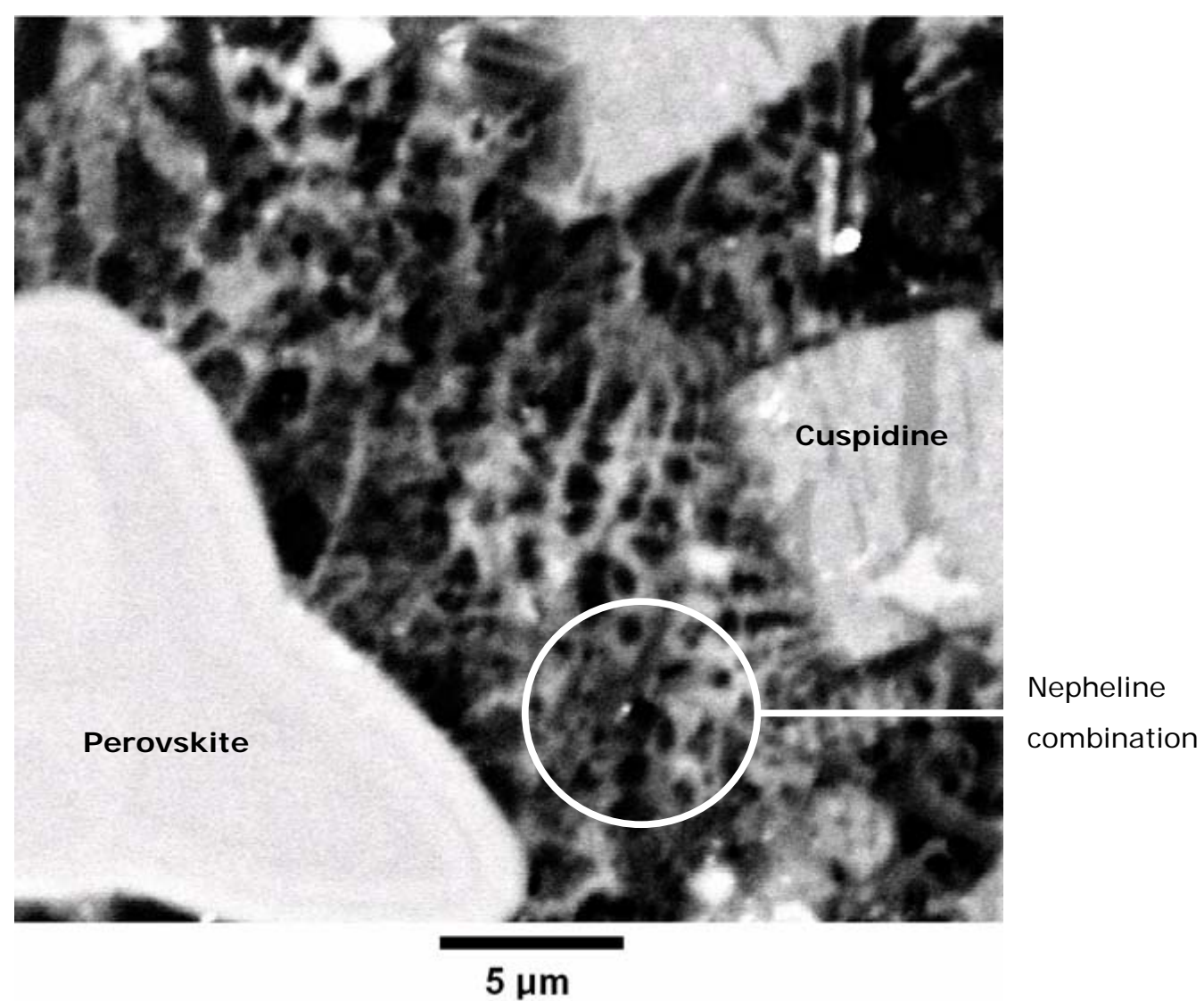

FIGURE 6.5: Enlarged back-scattered electron image of the SPH-KA1 slag rim (shell side).

\subsection{PREDICTED EFFECT OF $\mathrm{TIO}_{2}$ PICK-UP DURING FLUX SOLIDIFICATION}

As discussed in the previous section, investigation of the crystalline flux phases present in the slag rim (formed during the continuous casting of 321-stainless steel with SPH-KA1 mould powder) revealed that perovskite and cuspidine formed at the expense of each other. 
To explain the different microstructures (for example as shown in Figures 6.3 and 6.4) the effect of increased $\mathrm{TiO}_{2}$ contents on the equilibrium solidification behaviour of the mould flux was predicted by using the software package FACTSage 5.4. To be able to perform the calculations, a thermodynamic description of cuspidine was required, since cuspidine is generally the major phase in solidified mould flux. Complete thermodynamic data on cuspidine are not available, but the data of Fukuyama et al. (2003) were used to obtain an estimate. These authors quote an enthalpy of formation (from the elements) of $-5198 \mathrm{~kJ} / \mathrm{mol}$ at 1313 to $1329 \mathrm{~K}$, and small entropy of formation (from $\mathrm{CaO}, \mathrm{SiO}_{2}$ and $\mathrm{CaF}_{2}$ ) of $8.2 \mathrm{~J} / \mathrm{mol} \mathrm{K}$ (in the same temperature range). These data were used to estimate thermodynamic data for cuspidine as listed in the table below. The enthalpy at $298 \mathrm{~K}$ was adjusted slightly to match the measured cuspidine melting point of $1680 \mathrm{~K}$ (Fukuyama et al., 2003).

TABLE 6.8: Estimated thermodynamic data of cuspidine $\left(3 \mathrm{CaO} \cdot 2 \mathrm{SiO}_{2} \cdot \mathrm{CaF}_{2}\right)$, as used in FACTSage calculations.

\begin{tabular}{|c|c|}
\hline Variable & Value \\
\hline$H^{\circ} 298$ & $-5182902 \quad[\mathrm{~J} / \mathrm{mol}]$ \\
\hline$S^{\circ}{ }_{298}$ & $281.07 \quad[\mathrm{~J} / \mathrm{mol} \cdot \mathrm{K}]$ \\
\hline$C_{P}$ & $335.446+0.0624304 T-6274770 T^{-2} \quad[\mathrm{~J} / \mathrm{mol} \cdot \mathrm{K}]$ \\
\hline
\end{tabular}

For equilibrium calculations, the average mould flux composition as stated by the manufacturer was used, expressing the fluorine content as an equivalent amount of $\mathrm{CaF}_{2}$, and neglecting the $\mathrm{MnO}$ and $\mathrm{FeO}_{\mathrm{x}}$ content of the mould flux (see table 6.10 for the composition). The expected effect of excluding these transition metals is to increase the melting point of the flux. However, $\mathrm{MnO}$ and $\mathrm{FeO}_{\mathrm{x}}$ were excluded to ensure that the calculations were tractable and converged within a reasonable calculation period.

TABLE 6.9: Mould flux composition (before $\mathrm{TiO}_{2}$ pick-up) as used in equilibrium calculations.

\begin{tabular}{|l|c|c|c|c|c|c|}
\hline Species & $\mathrm{SiO}_{2}$ & $\mathrm{CaO}$ & $\mathrm{MgO}$ & $\mathrm{Al}_{2} \mathrm{O}_{3}$ & $\mathrm{Na}_{2} \mathrm{O}$ & $\mathrm{CaF}_{2}$ \\
\hline Mass \% & 36.2 & 26.0 & 7.1 & 4.7 & 7.7 & 18.3 \\
\hline
\end{tabular}

In the FACTSage calculations, the molten mould flux was described with the solution model "FACT-SLAG". Solid-solution effects were neglected (that is, all solid phases 
were taken to be pure stoichiometric solids). Where $\mathrm{TiO}_{2}$ pick-up was considered, the $\mathrm{TiO}_{2}$ was simply added to the composition in Table 6.9, as was the case during the experimental measurements. (This means that the loss of $\mathrm{SiO}_{2}$, which actually occurs during $\mathrm{TiO}_{2}$ pick-up when $\mathrm{Ti}$ from the steel reacts with $\mathrm{SiO}_{2}$ from the mould flux, was neglected).
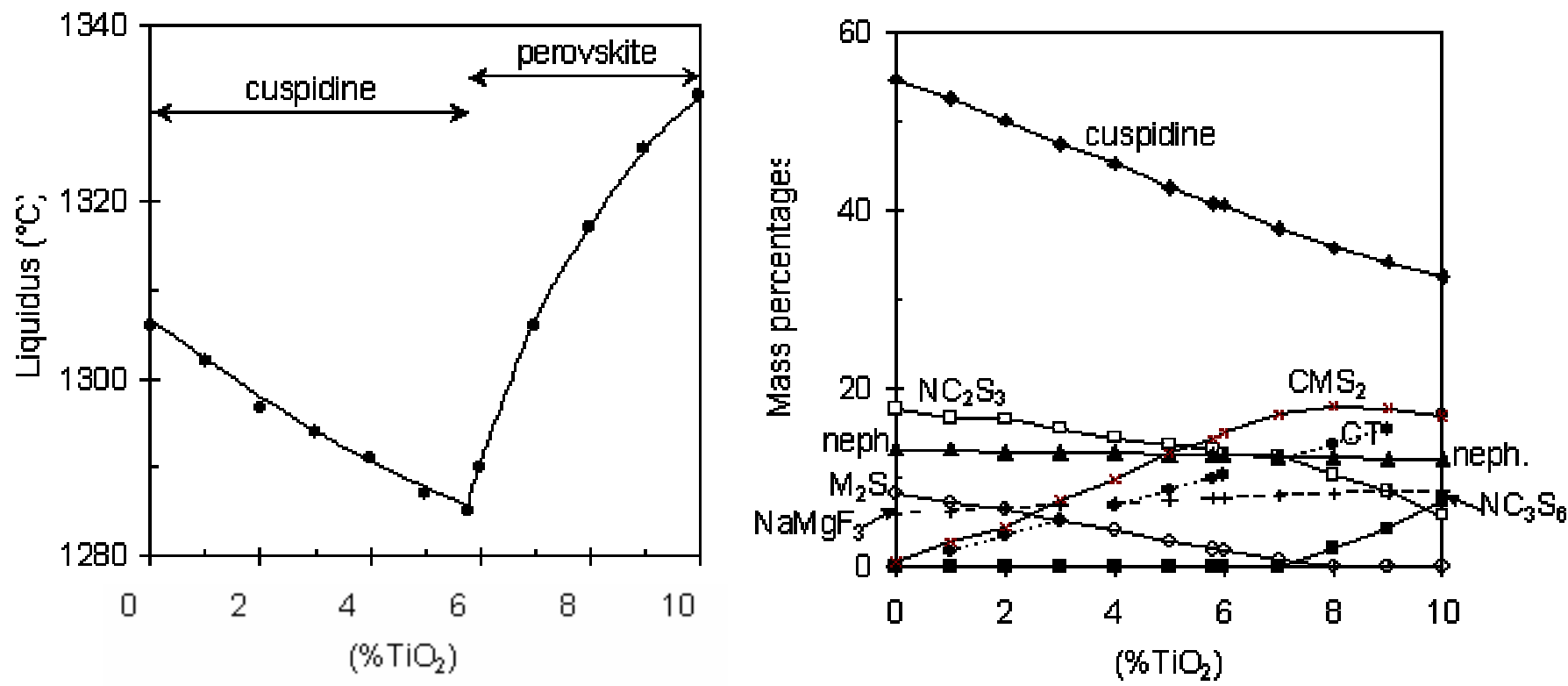

FIGURE 6.6: Predicted effects of $\mathrm{TiO}_{2}$ pick-up, using FACTSage calculations: liquidus temperatures and phase composition of solidified flux at the solidus temperature. The primary phases are indicated in the lefthand figure, and change from cuspidine to perovskite as the amount of $\mathrm{TiO}_{2}$ increases. Components in the different phases are as follows: $\mathrm{C}=\mathrm{CaO}, \mathrm{M}=\mathrm{MgO}, \mathrm{N}=\mathrm{Na}_{2} \mathrm{O}, \mathrm{S}=\mathrm{SiO}_{2}$ and $\mathrm{T}=\mathrm{TiO}_{2}$. "neph"=nepheline.

The predicted effects of $\mathrm{TiO}_{2}$ pick-up are shown in figures 6.6 and figure 6.7. The predicted liquidus temperatures (figure 6.6) are higher than expected, probably because of the exclusion of $\mathrm{MnO}$ and $\mathrm{FeO}_{\mathrm{x}}$ from the calculation. However, the trend is as expected, namely suppression of cuspidine formation by $\mathrm{TiO}_{2}$ pick-up, and formation of perovskite as a primary phase (with the associated sharp increase in liquidus) at $\mathrm{TiO}_{2}$ levels higher than some $6 \%$.

Figure 6.7 illustrates the predicted changes in solidification behaviour with $\mathrm{TiO}_{2}$ pickup; the suppression of cuspidine and formation of perovskite (with increasing levels of $\mathrm{TiO}_{2}$ ) are also evident in this figure. These results imply that $\mathrm{TiO}_{2}$ pick-up is expected to have two opposing effects on heat transfer through the mould flux: 
suppression of cuspidine formation would tend to increase heat transfer, but this effect is counteracted by the formation of perovskite (which would tend to decrease heat transfer).

Figure 6.7 also illustrates that the sodium-containing phases solidify last, forming together. This is in line with the observed microstructure (Figure 6.5).
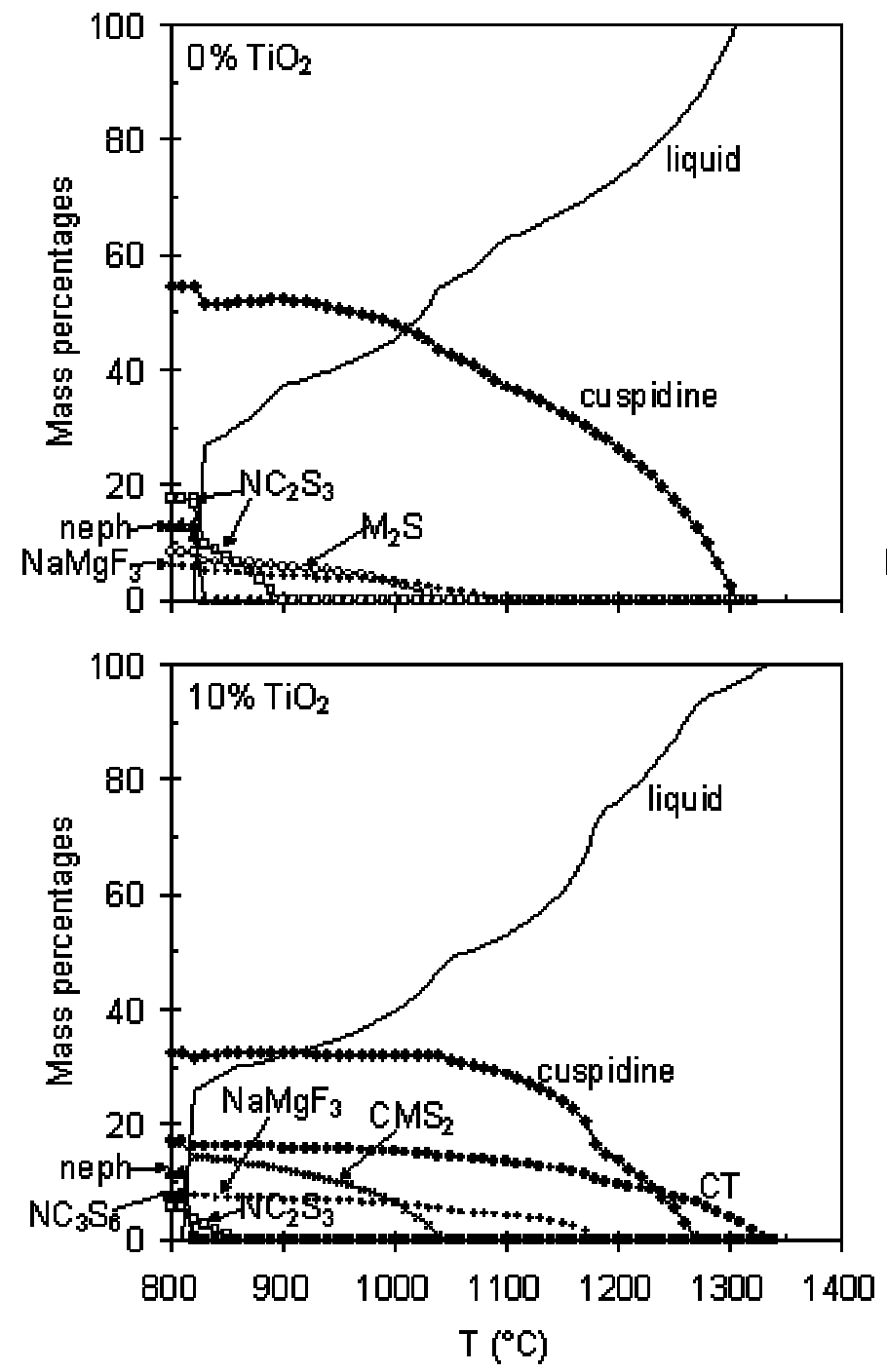

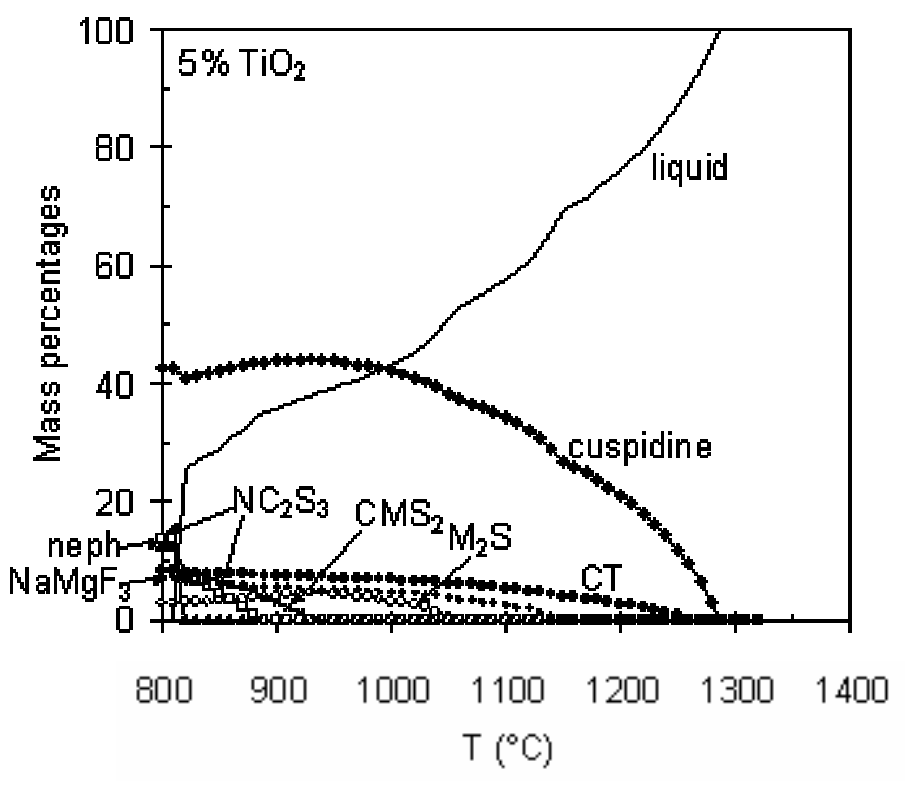

Figure 6.7. Predicted solidification behaviour of mould flux, using FACTSage calculations. The three graphs refer to three different levels of $\mathrm{TiO}_{2}$ pick-up; base composition as given in Table 6.9. Phase identification as in Figure 6.6 


\section{CHAPTER 7}

\section{EXPERIMENTAL RESULTS}

\subsection{EXPERIMENTAL OBSERVATIONS}

After each experiment the cup containing test flux was inspected. Figure 7.1 shows the top view of the cup after testing pure SPH-KA1 (decarburised) mould powder. During the experiment the cup was filled with liquid flux and the probe rested on the cup rim displacing some of the flux in the gap between the cup and the probe. The thickness of the flux between the bottom of the cup and the nose of the probe was exactly $3.0 \mathrm{~mm}$. At a later stage tests were repeated increasing the distance to $6.0 \mathrm{~mm}$ to evaluate the effect of flux thickness on the overall heat transfer.

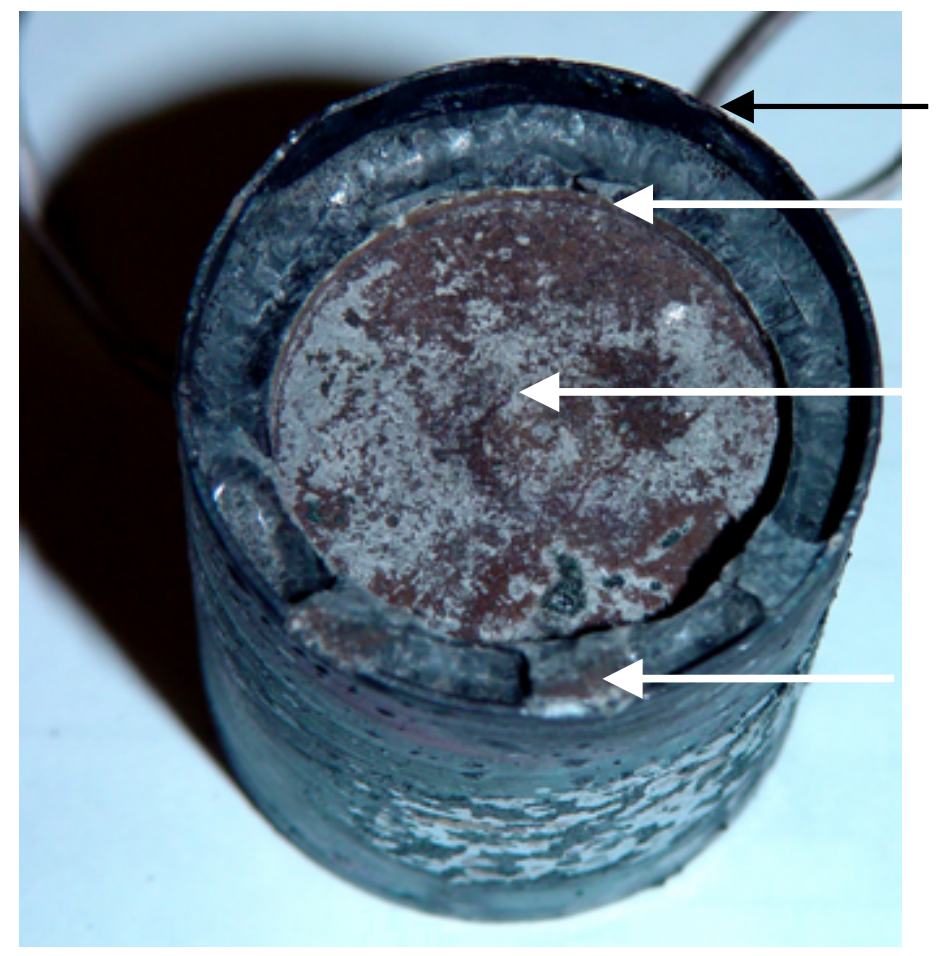

Cup rim

Probe indentation

Test flux solidified on the nose of the probe

Test flux displaced

by the probe

FIGURE 7.1: View of the cup after testing mould powder (SPH-KA1).

Inspection of the cup after experimental testing was done to see if the test flux completely filled the space between the cup and the nose of the probe. Secondly the cup was inspected to verify that the cup rim was still intact. If the cup rim were to be damaged the distance between the cup bottom and probe nose would be influenced, 
ultimately changing the thickness of the test flux. Such test results were discarded to maintain the accuracy of the collected data.
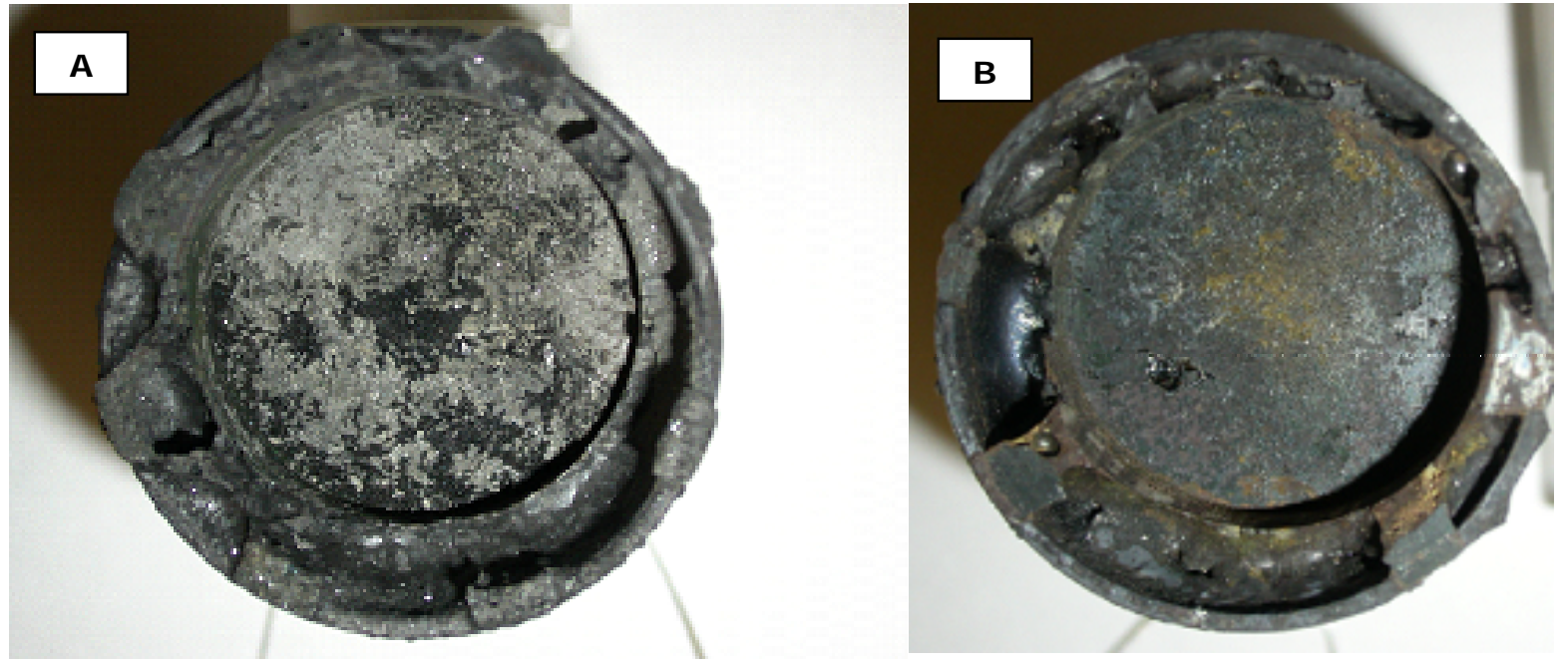

FIGURE 7.2: Top view of the cup containing solidified mould flux (SPH-KA1) with titanium oxide.
A) $5.0 \% \mathrm{TiO}_{2}$
B) $10.0 \% \mathrm{TiO}_{2}$

Figure 7.2 shows the top view of the test flux containing $5.0 \% \mathrm{TiO}_{2}$ and $10 \% \mathrm{TiO}_{2}$. Apart from the visual colour differences there are no physical differences between the cup having $0.0 \% \mathrm{TiO}_{2}$ (figure 7.1 ) and the cups having $5.0 \%$ and $10.0 \% \mathrm{TiO}_{2}$.

\subsection{SEM ANALYSES: $\quad 0.0 \% \mathrm{TiO}_{2}$ TEST SAMPLE}

A fractured piece of the decarburised SPH-KA1 test flux (figure 7.1) was taken from the cup and prepared for SEM analyses. The back scattered electron image in figure 7.3 indicates the crystalline structure found close to the probe (hot side). At the contact surface between the probe and the solidified test flux gas entrapment is clearly visible. A very fine crystalline structure was also found closer to the probe while larger crystals were found deeper into the test flux.

The EDS area-analyses of the crystallised zone closer to the probe indicate an average flux basicity $\left(\mathrm{CaO} / \mathrm{SiO}_{2}\right)$ of 1.24 which is higher then the basicity of the original mould flux (mould powder basicity range: 1.03-1.05). The $0.0 \% \mathrm{TiO}_{2}$ test flux is decarburised SPH-KA1 mould powder and the expected basicity would therefore be in the same order as the original mould powder. 
TABLE 7.1: Summarized compositions of the test sample with $0.0 \% \mathrm{TiO}_{2}$ added.

(Average mass percentages, with 95\% confidence intervals)

\begin{tabular}{|c|c|c|c|c|c|c|c|c|c|}
\hline Sample & $\mathrm{Na}_{2} \mathrm{O}$ & $\mathrm{MgO}$ & $\mathrm{F}$ & $\mathrm{CaO}$ & $\mathrm{TiO}_{2}$ & $\mathrm{Al}_{2} \mathrm{O}_{3}$ & $\mathrm{SiO}_{2}$ & $\mathrm{MnO}$ & $\mathrm{FeO}$ \\
\hline $0.0 \% \mathrm{TiO}_{2}$ & $5.3 \pm 1.7$ & $5.2 \pm 2.3$ & $2.7 \pm 2.1$ & $38.2 \pm 8.2$ & $0.3 \pm 0.2$ & $3.4 \pm 1.5$ & $30.7 \pm 1.9$ & $8.1 \pm 2.5$ & $6.1 \pm 2.4$ \\
\hline
\end{tabular}

However, it should be noted that significant local variations in compositions were found, as reflected by the wide $95 \%$ confidence interval on especially the $\mathrm{CaO}$ content of the flux (table 7.1). From these variable area analyses, the analysed basicity is hence not statistically different from the expected range of 1.03-1.05.

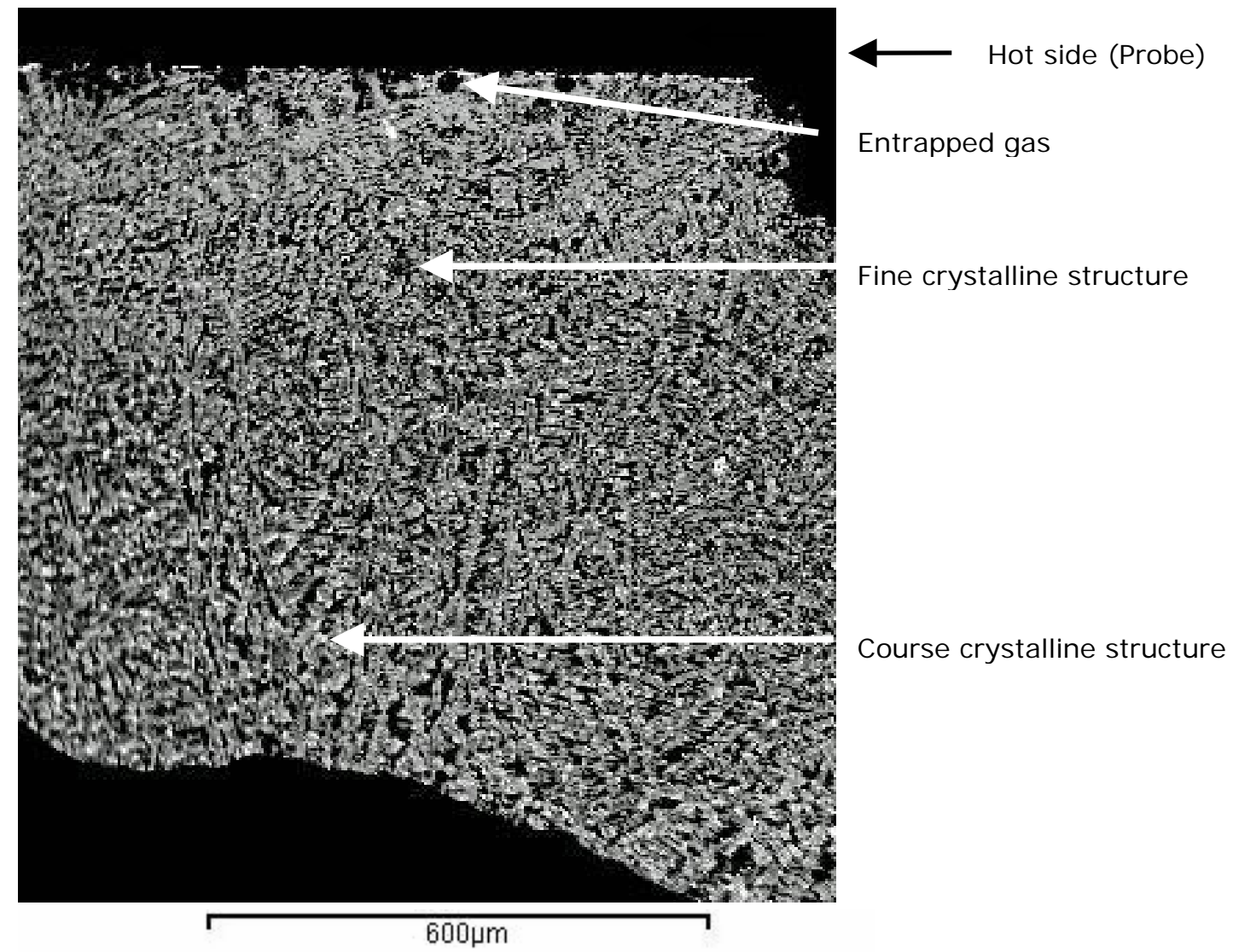

FIGURE 7.3: SEM-analyses: Back-scattered electron image of the $0.0 \% \mathrm{TiO}_{2}$ test flux after experimental testing.

Analysing the chemical composition of the crystalline structures three dominating flux phases could be identified. Large dendrite crystals containing mostly $\mathrm{CaO}, \mathrm{SiO}_{2}$ and fluoride $(F)$ made up the bulk of the crystalline structure and were identified as cuspidine (similar to the analyses reported in chapter 6 ). 
TABLE 7.2: Point analyses on the individual phases/sub-regions for the sample containing $0.0 \% \mathrm{TiO}_{2}$.

\begin{tabular}{|l|c|c|c|c|c|c|c|c|c|c|}
\hline Phase & $\mathrm{Na}_{2} \mathrm{O}$ & $\mathrm{MgO}$ & $\mathrm{F}$ & $\mathrm{CaO}$ & $\mathrm{TiO}_{2}$ & $\mathrm{Al}_{2} \mathrm{O}_{3}$ & $\mathrm{SiO}_{2}$ & $\mathrm{MnO}$ & $\mathrm{FeO}$ & $\mathrm{Cr}_{2} \mathrm{O}_{3}$ \\
\hline Bright spots & $0.0-3.9$ & $5.1 \pm 0.7$ & 0.0 & $0.0-7.0$ & $1.4 \pm 0.8$ & $7.4 \pm 1.0$ & $2.3 \pm 1.9$ & $16.0 \pm 1.5$ & $57.1 \pm 8.9$ & $0.0-14.3$ \\
\hline Cuspidine & $0.9 \pm 0.4$ & $1.0 \pm 0.3$ & $7.1 \pm 2.4$ & $60.1 \pm 2.0$ & $0.0-0.1$ & $0.0-0.1$ & $28.9 \pm 0.9$ & $1.7 \pm 0.7$ & $0.0-0.9$ & - \\
\hline $\begin{array}{l}\text { Nepheline } \\
\text { and others }\end{array}$ & $10.8 \pm 2.7$ & $7.6 \pm 5.4$ & $2.8 \pm 1.8$ & $0.0-13.1$ & $0.0-6.1$ & $10.8 \pm 4.5$ & $43.2 \pm 3.0$ & $12.8 \pm 1.8$ & $5.3 \pm 1.9$ & - \\
\hline
\end{tabular}

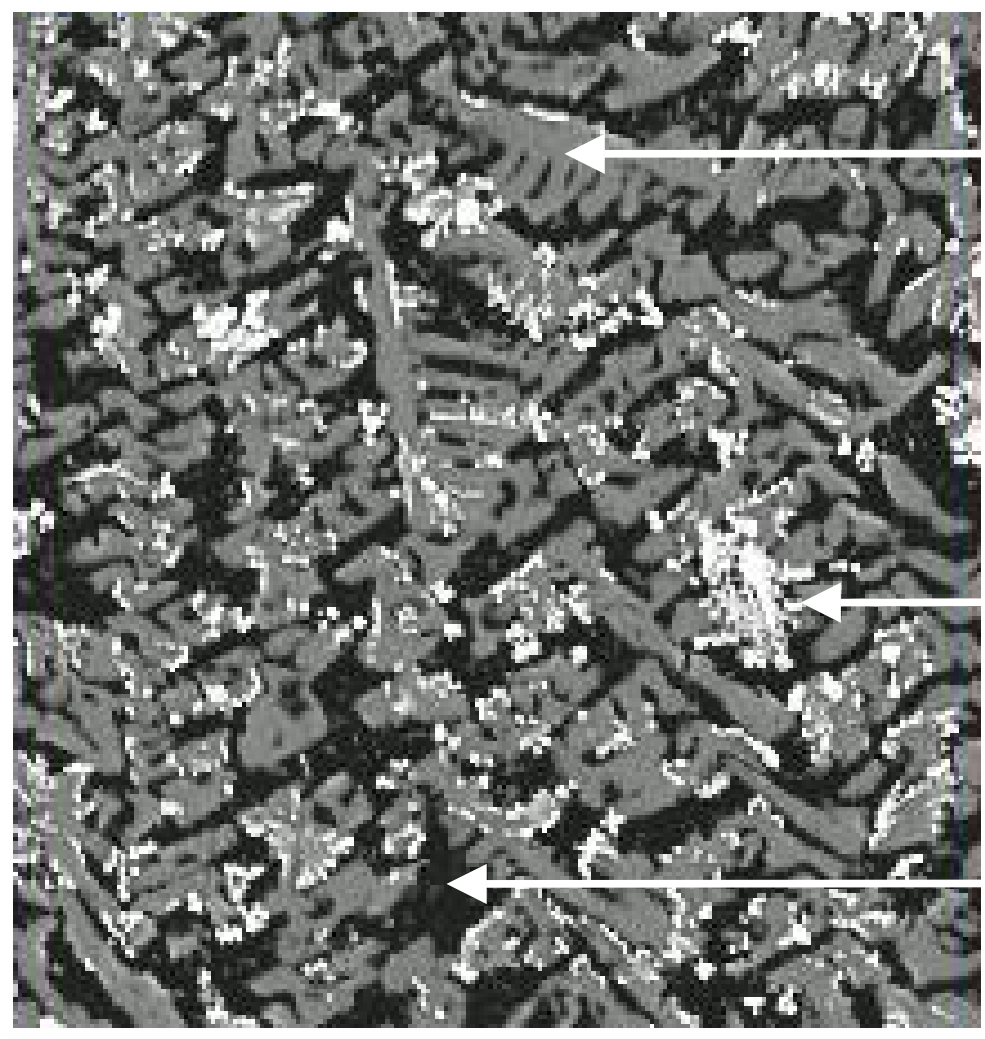

$200 u m$
Large dendrite crystals

Cuspidine

Fine $\mathrm{FeO}_{\mathrm{x}}$-rich

precipitate crystals

Nepheline and other

FIGURE 7.4: SEM-analyses: Back scattered electron image of the $0.0 \% \mathrm{TiO}_{2}$ test flux after experimental testing. Image of the crystalline structures found in pure SPH-KA1- test flux.

Fine $\mathrm{FeO}_{\mathrm{x}}$-rich precipitate crystals were associated with the cuspidine dendrites (these FeO-rich precipitates appear bright in the backscattered electron image); the EDX spectrum in table 7.2 showed the presence of oxygen, so this is an oxide phase (figure 7.4). This compound was a mixture of mostly iron and manganese oxides, with small portions of chromium. The likely origin of these elements is the iron and 
manganese which are present in the unused mould flux, with possible some contamination from the type 310-stainless steel probe (as a source of chromium). As in the slag rim sample, sodium and aluminium were concentrated in the region between the cuspidine crystals, contained in nepheline and the other phases which form upon final solidification.

\subsection{SEM ANALYSES: $\quad 10.0 \% \mathrm{TiO}_{2}$ TEST SAMPLE}

To simulate the solidification behaviour of actual mould flux when casting titanium stabilised stainless steel, $10.0 \% \mathrm{TiO}_{2}$ was added to decarburised SPH-KA1 mould powder and tested in the experimental apparatus at casting temperatures. After experimental testing the flux was removed from the cup (figure 7.2-B), mounted in epoxy resin and polished after the resin had cured.

Area analyses of the $10.0 \% \mathrm{TiO}_{2}$ mould flux in figure 7.6 showed no statistically significant differences in the chemical compositions of the crystalline and glassy flux layers. By analysing the individual crystalline phases/sub-regions in the $10.0 \% \mathrm{TiO}_{2}$ test flux, two distinct solid phases could be identified (cuspidine and perovskite), with a third region which is likely a combination of nepheline and the other phases which form upon final solidification.

TABLE 7.3: Summarized compositions of the test sample with $10.0 \% \mathrm{TiO}_{2}$ added (Average mass percentages, with 95\% confidence intervals)

\begin{tabular}{|c|c|c|c|c|c|c|c|c|c|}
\hline Sample & $\mathrm{Na}_{2} \mathrm{O}$ & $\mathrm{MgO}$ & $\mathbf{F}$ & $\mathrm{CaO}$ & $\mathrm{TiO}_{2}$ & $\mathrm{Al}_{2} \mathrm{O}_{3}$ & $\mathrm{SiO}_{2}$ & $\mathrm{MnO}$ & $\mathrm{FeO}$ \\
\hline $\begin{array}{c}10.0 \% \mathrm{TiO}_{2} \\
\text { glassy }\end{array}$ & $4.1 \pm 0.2$ & $4.6 \pm 0.1$ & $2.5 \pm 1.4$ & $34.6 \pm 1.5$ & $9.9 \pm 2.6$ & $3.2 \pm 0.1$ & $28.4 \pm 1.2$ & $7.7 \pm 0.1$ & $0.0-1.1$ \\
\hline $\begin{array}{c}10.0 \% \mathrm{TiO}_{2} \\
\text { crystalline }\end{array}$ & $4.7 \pm 1.2$ & $4.1 \pm 0.9$ & $0.0-4.8$ & $33.5 \pm 3.3$ & $11.8 \pm 5.4$ & $4.3 \pm 1.2$ & $29.7 \pm 5.8$ & $8.1 \pm 1.7$ & $2.5 \pm 1.4$ \\
\hline
\end{tabular}

These solid phases are similar to the crystals found in the slag rim that formed during continuous casting of 321-stainless steel as analysed in chapter 6. EDS-analyses (reported in Table 7.3) verified that the fine spherical crystals in Figure 7.7 were, in fact, perovskite. 


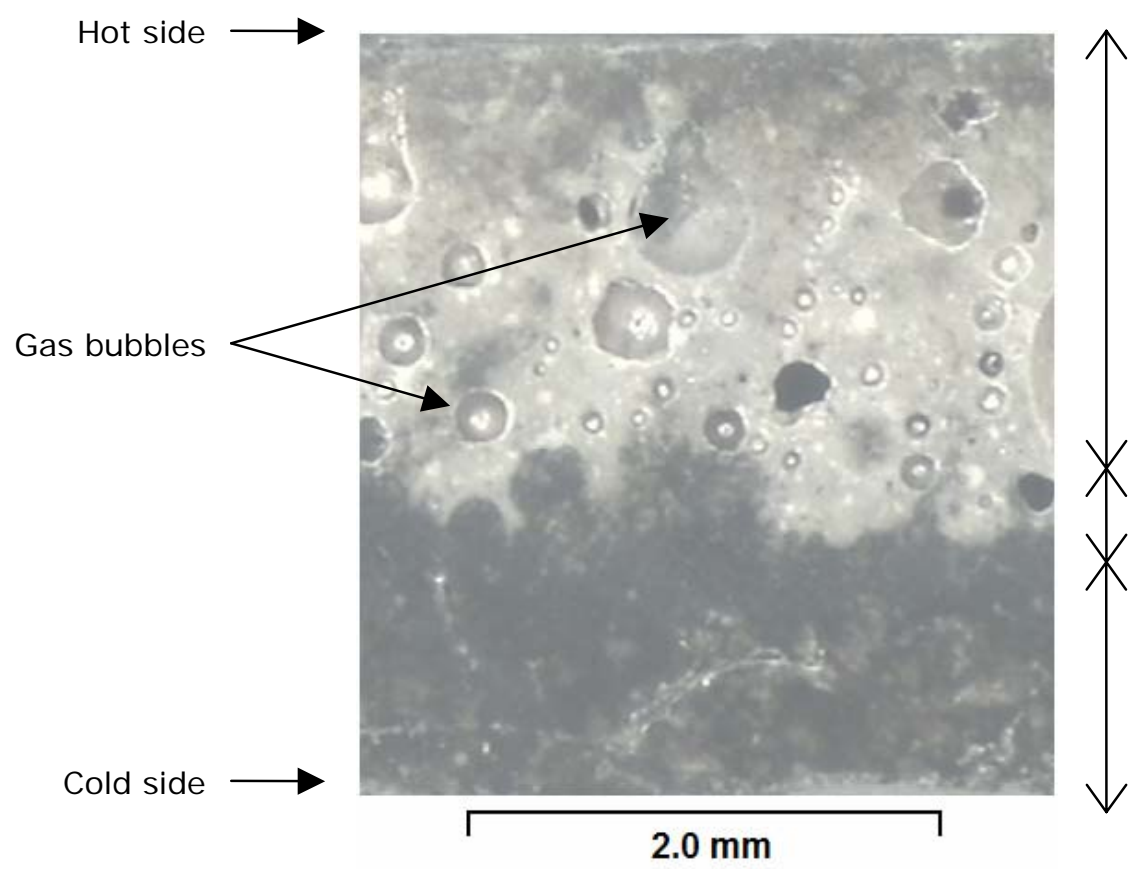

Crystalline structure

Glassy to crystalline transition

Glassy structure

FIGURE 7.5: Optical image of solidified test flux containing $10.0 \% \mathrm{TiO}_{2}$.

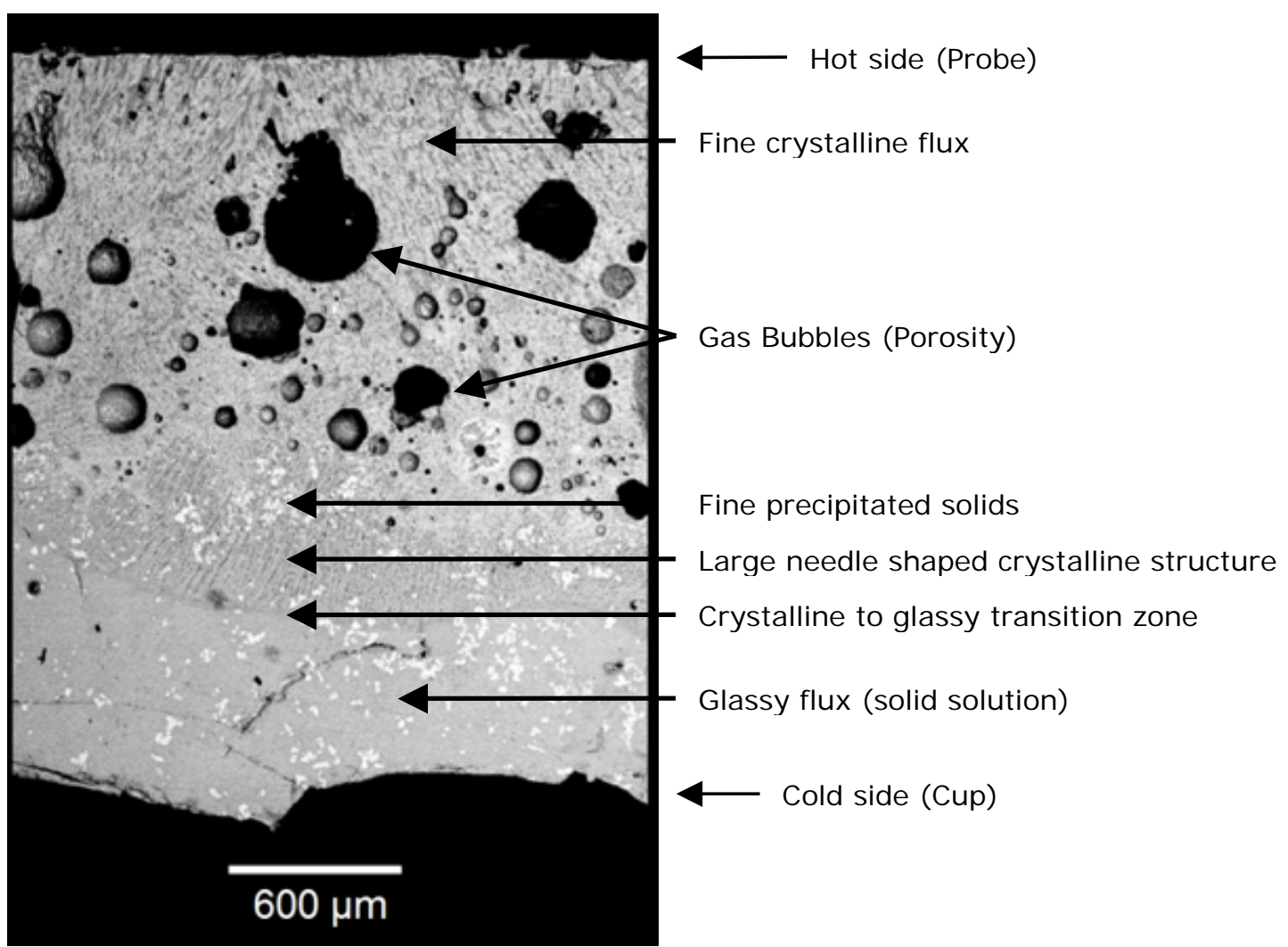

FIGURE 7.6: SEM-analyses: Back-scattered electron image of solidified test flux containing $10.0 \% \mathrm{TiO}_{2}$. 
The optical image (figure 7.5) and the back scattered electron image (figure 7.6) indicate a crystalline flux structure closer to the probe (hot side) and a glassy structure closer to the cup (cold side). The crystalline structure (top side) is very porous due to the large amount of entrapped gas bubbles while the glassy structure (bottom side) is found to be more solid. The optical image also clearly shows a sharp transition from crystalline to glassy flux. The crystalline flux structure has a remarkable lighter appearance compared to the darker glassy zone found at the bottom of optical image in figure 7.5.

The back-scattered electron image in figure 7.6 was taken from the test sample showed in figure 7.5 during SEM analyses. Figure 7.6 shows the formation of very fine crystals next to the probe while larger solid crystals are found at some distance deeper into the crystalline flux zone. The same result was found when analysing the slag rim in the previous chapter which indicated a solid glassy layer on the cold side due to rapid cooling of the liquid flux zone. Gas entrapment and the formation of porosity are much more prominent in the test flux (crystalline zone) compared to the slag rim analyses.

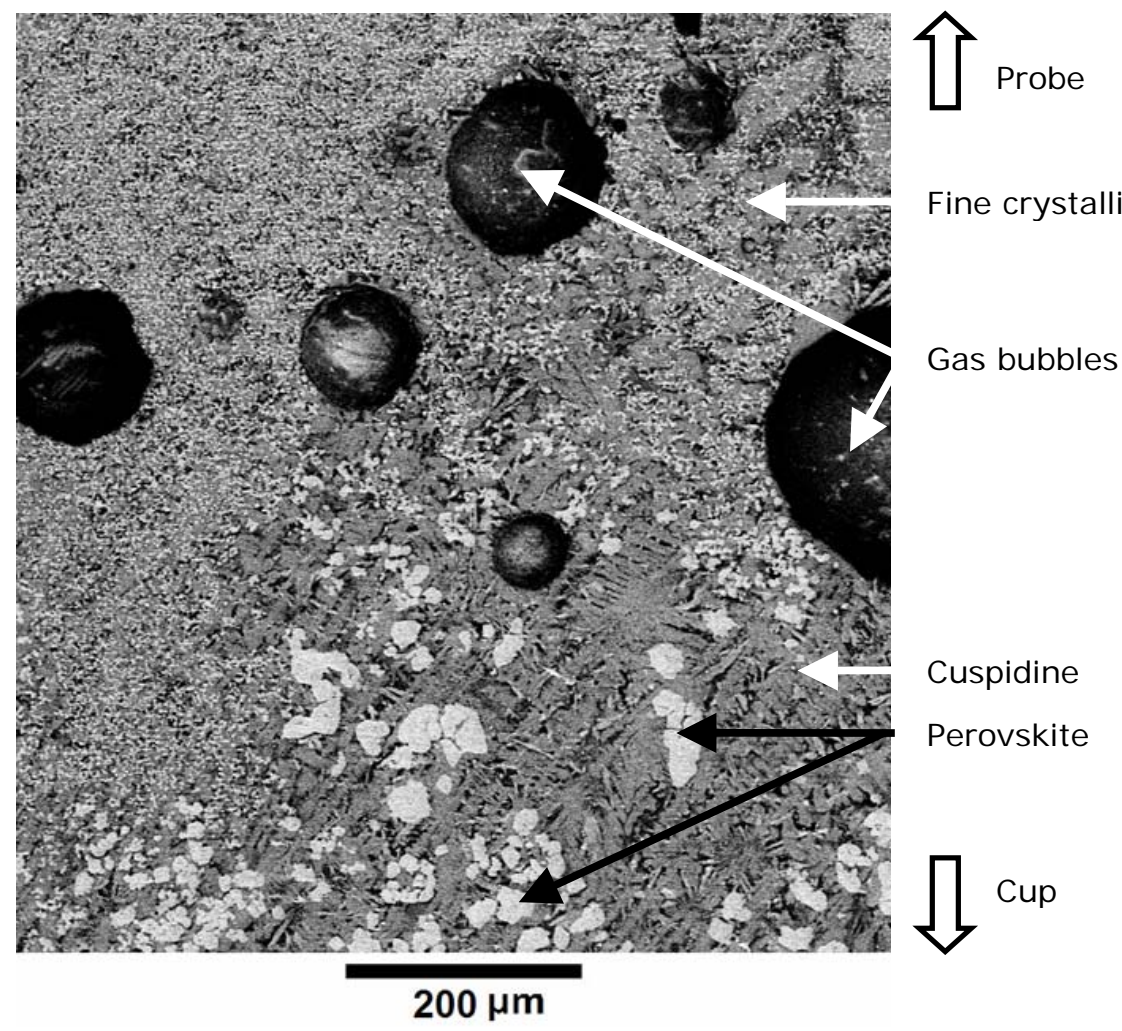

FIGURE 7.7: SEM-analyses: Back scattered electron image of crystalline transition zone found in solidified test powder (SPH-KA1) doped $10.0 \% \mathrm{TiO}_{2}$. 
The optical image in figure 7.5 clearly indicates a transition from the crystalline to glassy structure. This transition is marked by the brightness changes in the optical image, but can also be seen in the back-scattered electron image figure 7.6. The transition zone is characterised by a crystalline transition zone enlarged in figure 7.7. The back-scattered electron image in figure 7.7 indicates the presence of fine solid crystals towards the hot side of the experimental apparatus (probe) and a distinct needle shaped crystalline structure towards the colder side of the apparatus (cup).

The crystalline transition zone in figure 7.7 is characterised by the change-over from fine crystals, that solidified under slower cooling conditions, to needle shaped crystals that formed during faster cooling. Analysing the formation of solid perovskite in both crystal structures showed that smaller perovskite crystals are found during slower cooling (figure 7.8) compared to larger crystals in combination with a needle shaped crystalline structure during increased cooling rates (figure 7.9).

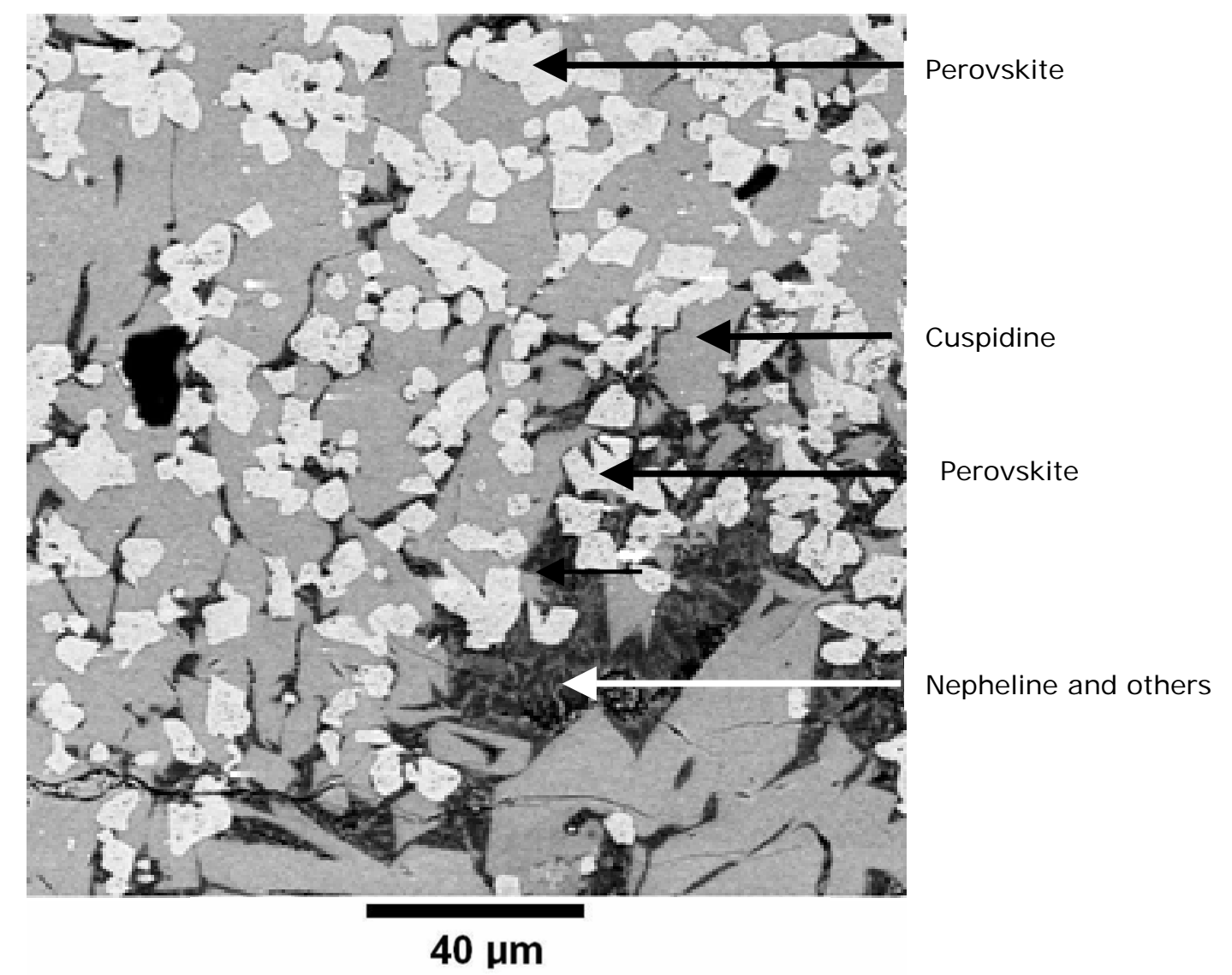

FIGURE 7.8 SEM-analyses: Back-scattered electron image of the crystalline flux phases found in solid test powder (SPH-KA1) doped with $10.0 \% \mathrm{TiO}_{2}$. 
TABLE 7.4: Point analyses on the individual phases/sub-regions for the sample containing $10.0 \% \mathrm{TiO}_{2}$ - Hot side (probe).

\begin{tabular}{|l|c|c|c|c|c|c|c|c|c|}
\hline Phase & $\mathrm{Na}_{2} \mathrm{O}$ & $\mathrm{MgO}$ & $\mathrm{F}$ & $\mathrm{CaO}$ & $\mathrm{TiO}_{2}$ & $\mathrm{Al}_{2} \mathrm{O}_{3}$ & $\mathrm{SiO}_{2}$ & $\mathrm{MnO}$ & $\mathrm{FeO}$ \\
\hline Cuspidine & $0.3 \pm 0.0$ & $0.9 \pm 0.4$ & $5.1 \pm 1.1$ & $60.9 \pm 1.4$ & $0.0-1.2$ & 0.0 & $29.8 \pm 1.0$ & $2.3 \pm 0.0$ & $0.0-2.1$ \\
\hline Perovskite & $0.5 \pm 0.0$ & $0.0-0.7$ & $0.0-4.1$ & $39.7 \pm 4.0$ & $56.7 \pm 4.3$ & $0.6 \pm 0.1$ & $0.0-3.9$ & $0.7 \pm 0.4$ & $0.0-1.7$ \\
\hline $\begin{array}{l}\text { Nepheline } \\
\text { and others }\end{array}$ & $7.6 \pm 2.9$ & $5.0 \pm 3.6$ & $4.4 \pm 4.4$ & $14.6 \pm 14.6$ & $3.4 \pm 0.7$ & $6.7 \pm 2.7$ & $40.4 \pm 8.9$ & $14.0 \pm 8.2$ & $3.8 \pm 1.9$ \\
\hline
\end{tabular}

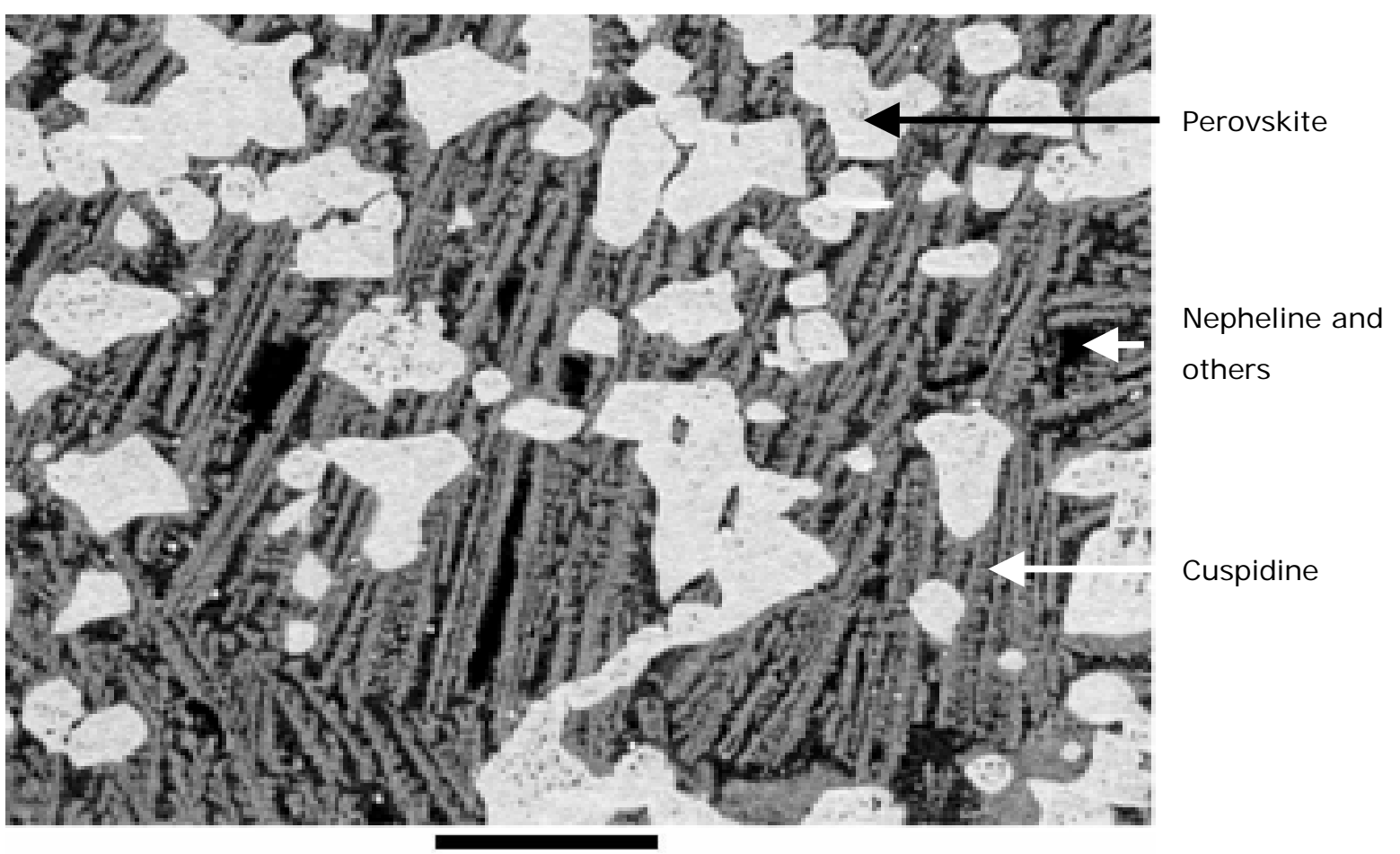

\section{$40 \mu \mathrm{m}$}

FIGURE 7.9: SEM-analyses: Back scattered electron image of the needle shaped crystalline structure found in solidified test powder (SPH-KA1) doped $10.0 \% \mathrm{TiO}_{2}$ under rapid cooling conditions.

The enlarged image of the needle shaped crystalline zone (figure 7.9) once again indicates the presence of perovskite, cuspidine and nepheline and others as found in the crystalline zone (table 7.4). Comparing the relative crystal size and crystal structures of the equiaxed crystalline zone (figure 7.8) with those of the same phases in the needle shaped crystalline zone (figure 7.9 ) the remarkable effect of cooling 
rate can be seen. Although the same crystal phases were formed, the crystal size and even the presence of entrapped gas bubbles are highly influenced by the rate of cooling.

Where the liquid flux was cooled rapidly (closer to the carbon steel cup), a glassy solid phase was formed, capturing all the elements present in the liquid flux without the formation of any additional crystals - although perovskite was present as a separate phase in the glassy region. Figure 7.10 represents the transition from the liquid flux (now a glass phase) to the needle shaped crystalline structure that formed at higher cooling rates.

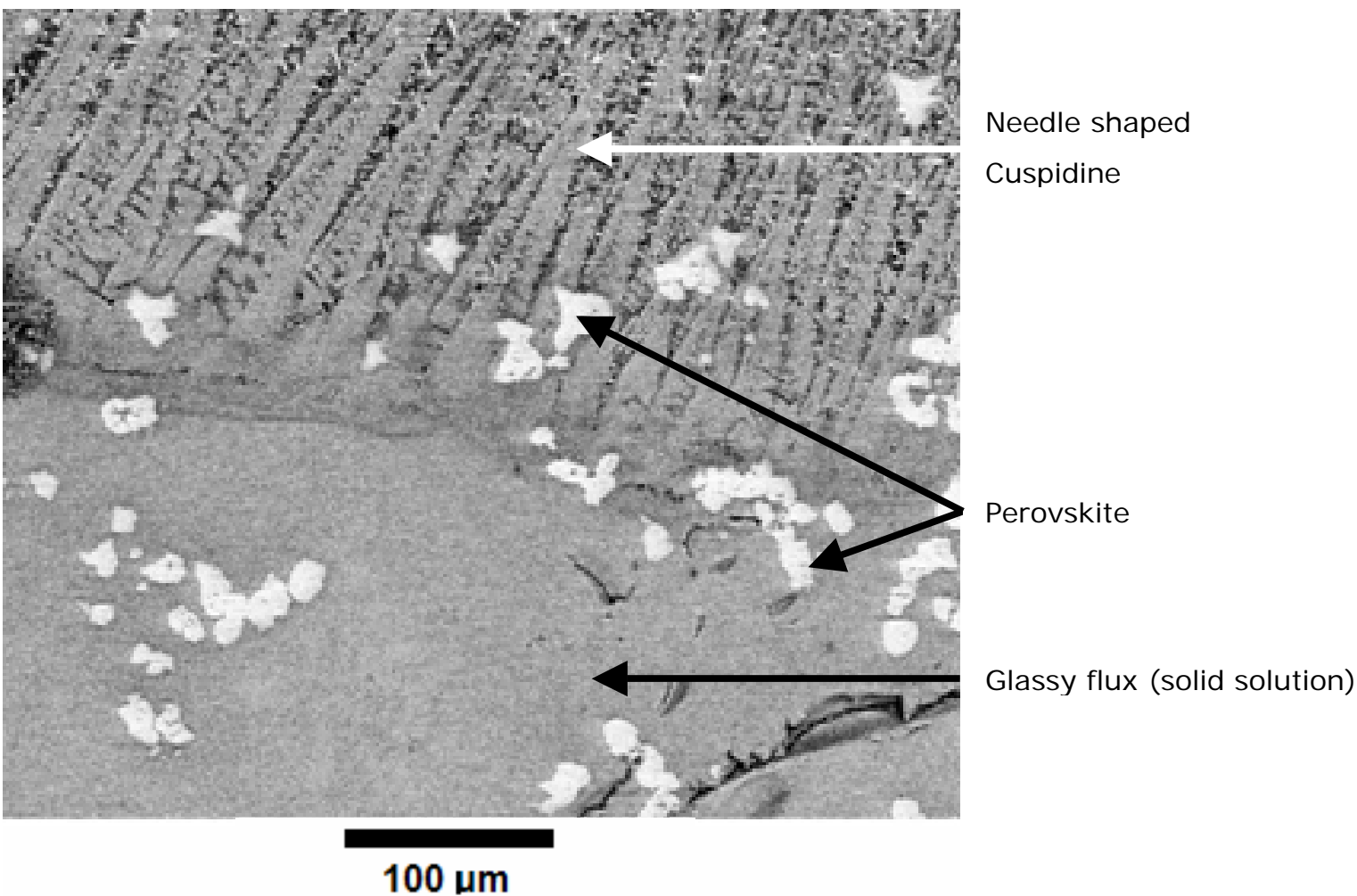

FIGURE 7.10: SEM-analyses: Back scattered electron image of the crystalline to glassy structure found in solidification front of test powder (SPH-KA1) doped with $10.0 \% \mathrm{TiO}_{2}$.

The point analyses of the solidification front (table 7.5) verifies that the large needle shaped crystalline structure is primarily cuspidine while perovskite is present in the 
crystalline zone and in the glassy flux zone which represents the liquid flux before solidification.

TABLE 7.5: Single point analyses of the solidification front:

Sample with $10.0 \% \mathrm{TiO}_{2}$ added - Cold side (cup).

\begin{tabular}{|l|c|c|c|c|c|c|c|c|c|}
\hline Phase & $\mathrm{Na}_{2} \mathrm{O}$ & $\mathrm{MgO}$ & $\mathbf{F}$ & $\mathrm{CaO}$ & $\mathrm{TiO}_{2}$ & $\mathrm{Al}_{2} \mathrm{O}_{3}$ & $\mathrm{SiO}_{2}$ & $\mathrm{MnO}$ & $\mathrm{FeO}$ \\
\hline Cuspidine & 1.6 & 1.6 & 5.1 & 51.4 & 5.2 & 2.4 & 27.7 & 3.7 & 1.2 \\
\hline Perovskite & 0.5 & 0.1 & 0.5 & 38.8 & 58.1 & 0.6 & 0.5 & 0.5 & 0.3 \\
\hline
\end{tabular}

A remarkable observation can be made when investigating the liquid flux phases in figure 7.10 and figure 7.11. Perovskite is present in the glassy region. This indicates that perovskite is the first solid structure to crystallise (primary phase) when cooling SPH-KA1 mould powder with $10.0 \% \mathrm{TiO}_{2}$. Solid perovskite is therefore present in liquid flux due to the higher solidification temperature of the solid phase.

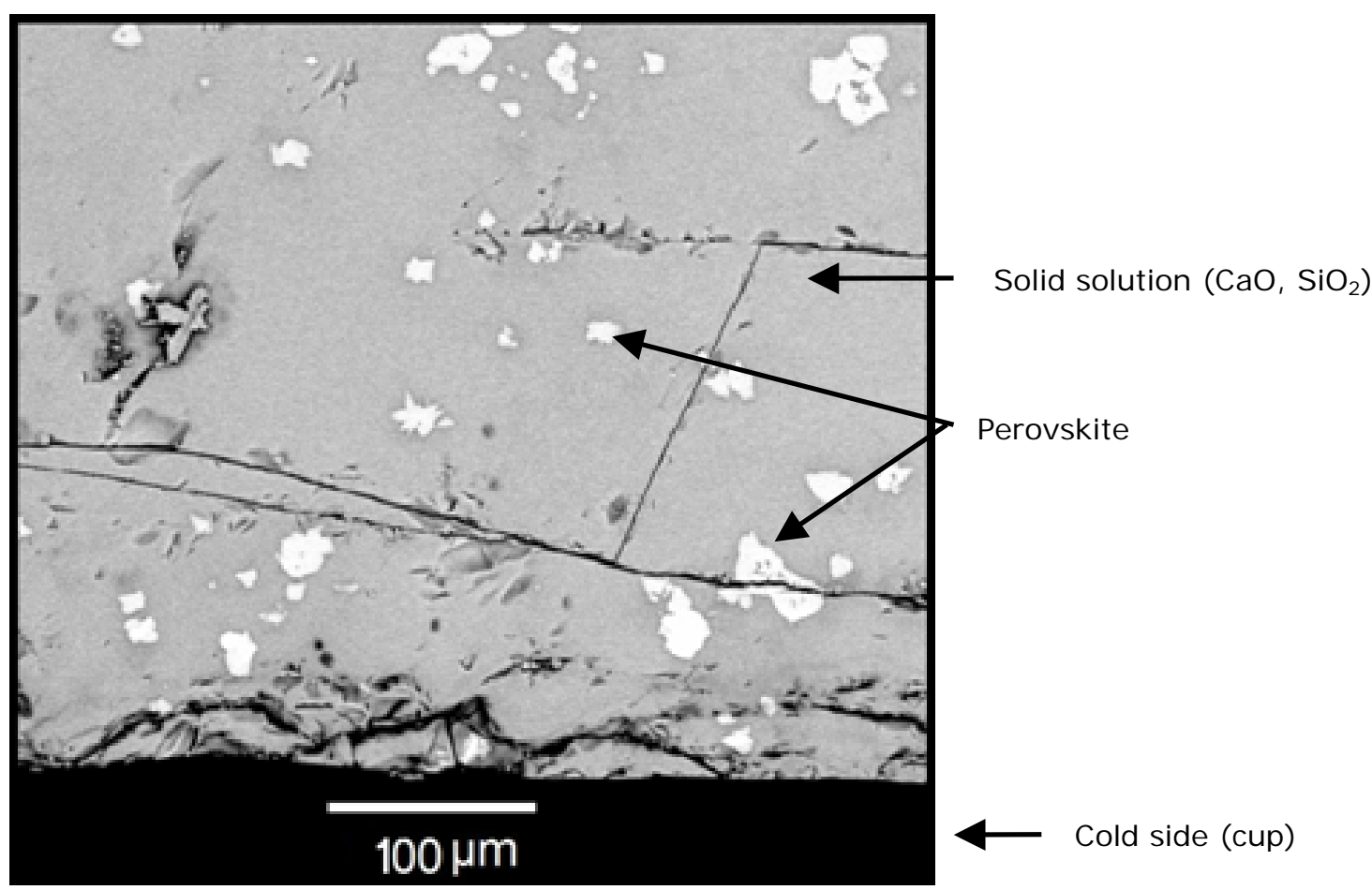

FIGURE 7.11: SEM-analyses: Back-scattered electron image of the glassy structure found in solidified test powder (SPH-KA1) doped with $10.0 \% \mathrm{TiO}_{2}$. 


\subsection{RECORDING TEMPERATURE PROFILES}

The experimental apparatus was specifically designed to measure the onedimensional heat transfer from the probe to the cup (figure 7.12). The flux layer - of fixed thickness - between the nose of the probe and the bottom of the cup acted as thermal resistance to heat transfer. The experimental cooling sequence (discussed in section 5.4) was initiated by forcing a jet of helium gas to cool the bottom of the cup as indicated in figure 7.12 (temperature position $T_{1}$ ). The carbon steel cup was manufactured to have a base thickness of $6.0 \mathrm{~mm}$. This was specifically done to control the cooling rate of the experimental apparatus in order to subject the test flux to similar thermal conditions as found during industrial casting. The observation of both glassy and crystalline regions in the mould flux after experiments (as reported earlier in this chapter) served to confirm that the cooling rates were appropriate.
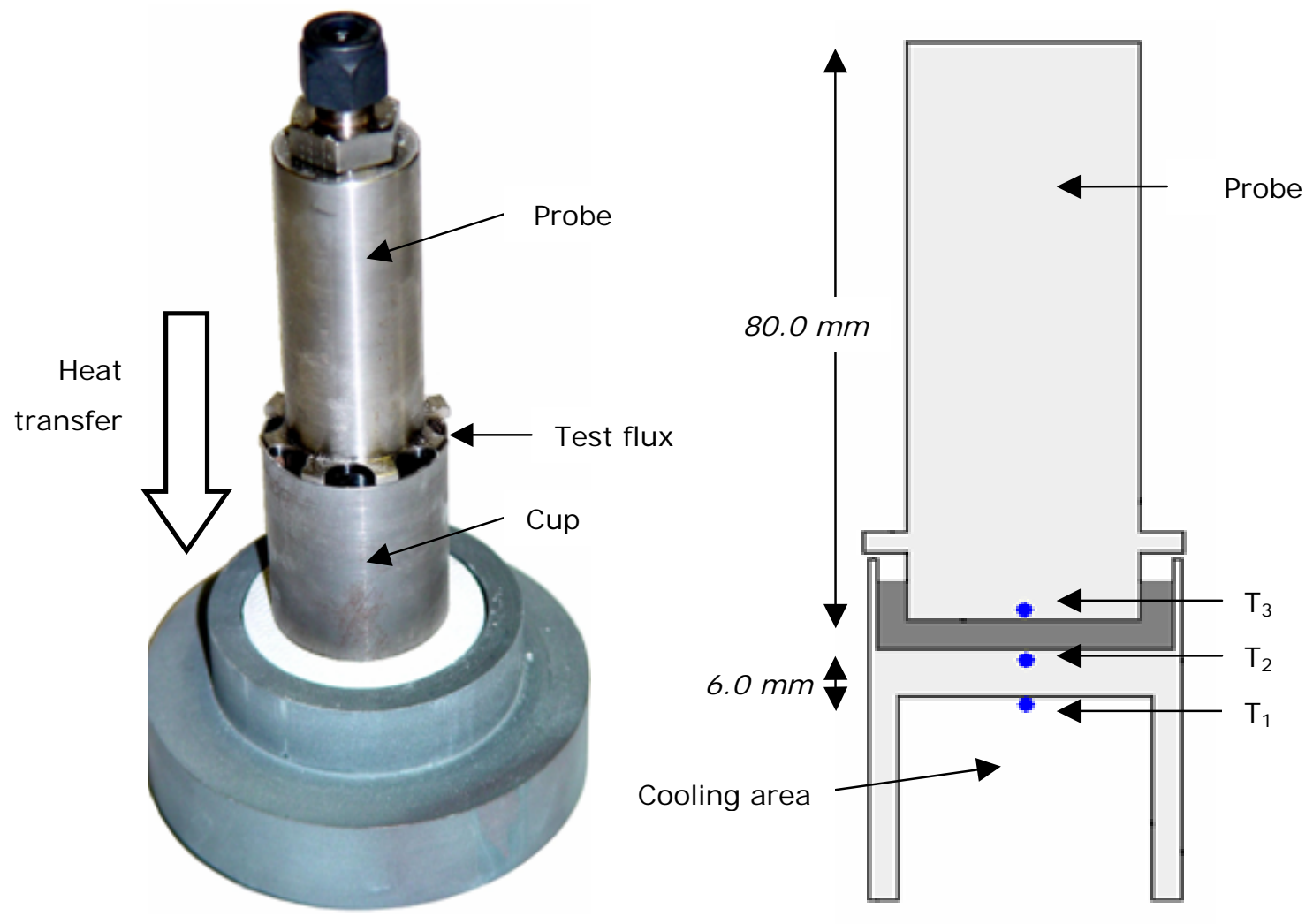

FIGURE 7.12: Thermocouple position during experimental testing.

A second thermocouple $\left(T_{2}\right)$ was positioned at the contact between the base of the cup and the test flux in the cup. To constantly measure the temperature of the heat source in contact with the test flux, thermocouple $T_{3}$ was positioned on the nose of 
the probe. $T_{2}$ therefore recorded the temperature profile of the test flux subjected to the highest cooling rate, while $T_{3}$ recorded the temperature profile of the test flux subjected to the lowest cooling rate.

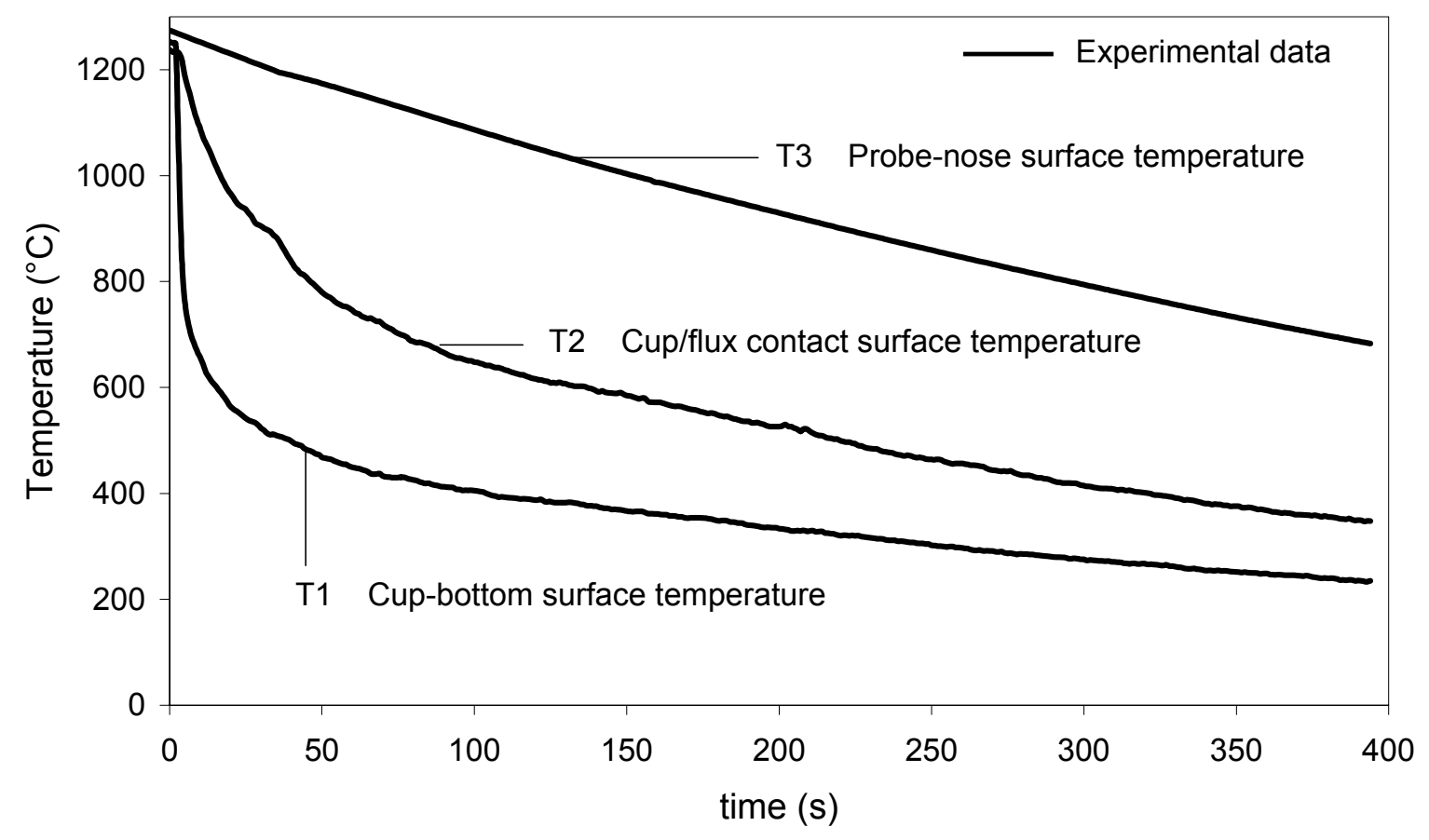

FIGURE 7.13: Temperature profiles for the experimental data recorded during the experimental testing of mould flux (see appendix).

All temperature readings $\left(T_{1}, T_{2}\right.$ and $\left.T_{3}\right)$ were electronically logged at $1 \mathrm{~Hz}$ during the cooling sequence, until the probe temperature $T_{3}$ reached a temperature below $800^{\circ} \mathrm{C}$. An example of the experimental results is given in figure 7.13.

\subsection{CALCULATION MODEL TO PREDICT TEMPERATURE PROFILES}

A one-dimensional explicit unsteady-state finite-difference model was used to calculate cooling curve predictions using experimental data (figure 7.13) as input. The surface temperature at the bottom of the cup $\left(T_{1}\right)$ was a model input, as the boundary condition, to calculate the cup/flux contact surface temperature $\left(T_{2}\right)$ and the probe nose surface temperature $\left(T_{3}\right)$. The overall thermal conductivity of the mould flux was the other main input to the model. The model thus used $T_{1}$ as boundary condition and by selecting the appropriate flux conductivity, $T_{2}$ and $T_{3}$ could be calculated. The calculation was repeated for different values of the thermal 
conductivity, until the calculated values of $T_{2}$ and $T_{3}$ matched the experimental measurements. The physical situation which the model described is shown below.

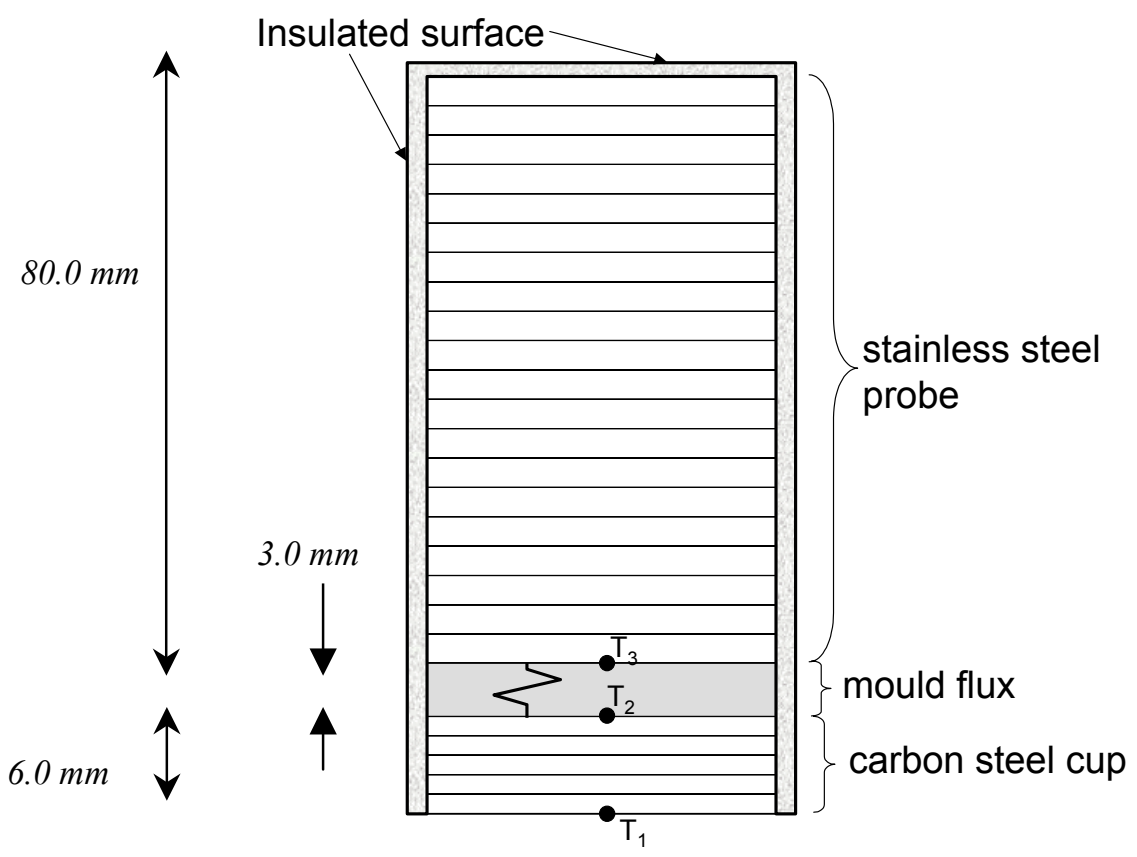

FIGURE 7.14 Illustration of the calculation model.

As figure 7.14 indicates, the base of the carbon-steel cup (6mm thick) was typically divided into 5 nodes, and the 310 -stainless steel probe $(80 \mathrm{~mm}$ long) typically into 20 nodes. In the figure, $T_{1}, T_{2}$ and $T_{3}$ refer to the three thermocouple positions where the temperature was measured as indicated in figure 7.12.

Table 7.6 gives a summary of the thermal properties used for the finite-difference calculations. The thermal conductivity was decreased by multiplying the expression given by Mills (Mills et al., 2004a) for 3-series stainless alloys, using a constant factor of 0.87 . This was used to match the thermal conductivity of type 310 stainless steel at $500^{\circ} \mathrm{C}$ as given in the Metals Handbook (a value of $18.7 \mathrm{~W} / \mathrm{mK}$ ).

The mould flux was described by means of a single thermal resistance while the heat capacity of the mould flux was assumed not to affect the cooling behaviour. This was a reasonable assumption, since the thermal mass (product of heat capacity and mass) of the mould flux was much smaller than the total thermal mass of the metal components. 
TABLE 7.6: Thermal properties used in finite-difference model.

\begin{tabular}{|c|c|c|c|}
\hline Material & Property & Correlation & Reference \\
\hline \multirow[t]{2}{*}{$\begin{array}{l}\text { Carbon } \\
\text { steel }\end{array}$} & $\begin{array}{l}\text { Thermal } \\
\text { conductivity }\end{array}$ & $\begin{array}{lll}k=A+B T, T \text { in }\left[{ }^{\circ} \mathrm{C}\right] & \\
\text { For } T<700^{\circ} \mathrm{C}: & A & =57.95 \quad \mathrm{~W} / \mathrm{m}^{\circ} \mathrm{C} \\
& B & =-0.03975 \mathrm{~W} / \mathrm{m}\left({ }^{\circ} \mathrm{C}\right)^{2} \\
\text { For } 700<T<810^{\circ} \mathrm{C}: & A & =68.2 \quad \mathrm{~W} / \mathrm{m}^{\circ} \mathrm{C} \\
& B & =-0.05439 \mathrm{~W} / \mathrm{m}\left({ }^{\circ} \mathrm{C}\right)^{2} \\
\text { For } T>810^{\circ} \mathrm{C}: & A & =12.83 \quad \mathrm{~W} / \mathrm{m}^{\circ} \mathrm{C} \\
& B & =0.01395 \mathrm{~W} / \mathrm{m}\left({ }^{\circ} \mathrm{C}\right)^{2}\end{array}$ & \multirow[t]{2}{*}{$\begin{array}{l}\text { Brimacombe } \\
(1976)\end{array}$} \\
\hline & $\begin{array}{l}\text { Heat } \\
\text { capacity }\end{array}$ & $\begin{array}{ll}\text { For } T<500^{\circ} \mathrm{C}: & \rho c_{\mathrm{p}}=4.452 \mathrm{MJ} / \mathrm{m}^{3 \circ} \mathrm{C} \\
\text { For } 500<T<700^{\circ} \mathrm{C}: & \rho c_{\mathrm{p}}=5.41 \mathrm{MJ} / \mathrm{m}^{3 \circ} \mathrm{C} \\
\text { For } 700<T<750^{\circ} \mathrm{C}: & \rho c_{\mathrm{p}}=12.15 \mathrm{MJ} / \mathrm{m}^{3 \circ} \mathrm{C} \\
\text { For } 750<T<1455^{\circ} \mathrm{C}: & \rho c_{\mathrm{p}}=4.376 \mathrm{MJ} / \mathrm{m}^{3 \circ} \mathrm{C}\end{array}$ & \\
\hline \multirow{2}{*}{$\begin{array}{l}\text { Stainless } \\
\text { steel }\end{array}$} & $\begin{array}{l}\text { Thermal } \\
\text { conductivity }\end{array}$ & $\begin{array}{l}k=0.87\left(9.2+0.0175 T-2 \times 10^{-6} T^{2}\right) \\
k \text { in }[\mathrm{W} / \mathrm{mK}] \text { and } T \text { in }[\mathrm{K}]\end{array}$ & \multirow{2}{*}{$\begin{array}{l}\text { Mills et al., } \\
(2004 a)\end{array}$} \\
\hline & $\begin{array}{l}\text { Heat } \\
\text { capacity }\end{array}$ & $\begin{array}{l}c_{\mathrm{p}}=472+0.136 T-2.2 \times 10^{6} T^{-2} \\
\rho=8000-0.47(T+273) \\
c_{\mathrm{p}} \text { in }[\mathrm{J} / \mathrm{kgK}], T \text { in }[\mathrm{K}], \rho \text { in }\left[\mathrm{kg} / \mathrm{m}^{3}\right]\end{array}$ & \\
\hline
\end{tabular}

Two forms of the model code were used. In the first, the bottom surface temperature $\left(T_{1}\right)$ of the carbon-steel cup was used as the boundary condition. However, it was found that in many cases the measured value of $T_{1}$ was too low compared with $T_{2}$ and $T_{3}$ : The $T_{1}$-thermocouple at the bottom surface of the steel cup registered faster cooling than expected. This appeared to be the result of difficulties with obtaining good thermal contact between the $\mathrm{T}_{1}$-thermocouple and the bottom surface of the cup, which therefore resulted in rapid cooling of the thermocouple as soon as the cooling jet was directed at the bottom surface of the cup. This effect is illustrated by Figure 7.15 which shows the measured temperatures $\left(T_{1}, T_{2}\right.$ and $\left.T_{3}\right)$ together with the fitted model, for the case where $T_{1}$ was taken as the boundary condition, for two different runs.

A smooth curve was used to fit the experimentally measured $T_{1}$ values (see below in Figure 7.15 for an example). Equation 33 gives the empirical equation which was fitted to the data (SigmaPlot was used to perform data fitting): 


$$
T=y_{0}+a e^{(-b t)}+c e^{(-d t)}+g e^{(-h t)}+j t
$$

$$
\begin{array}{rlrl}
T & =\text { Temperature }\left({ }^{\circ} \mathrm{C}\right) & t=\text { time }(\mathrm{s}) \\
y_{0} & =\text { Initial temperature before cooling } & & a, b, c, d, g, h, j=\text { curve constants }
\end{array}
$$
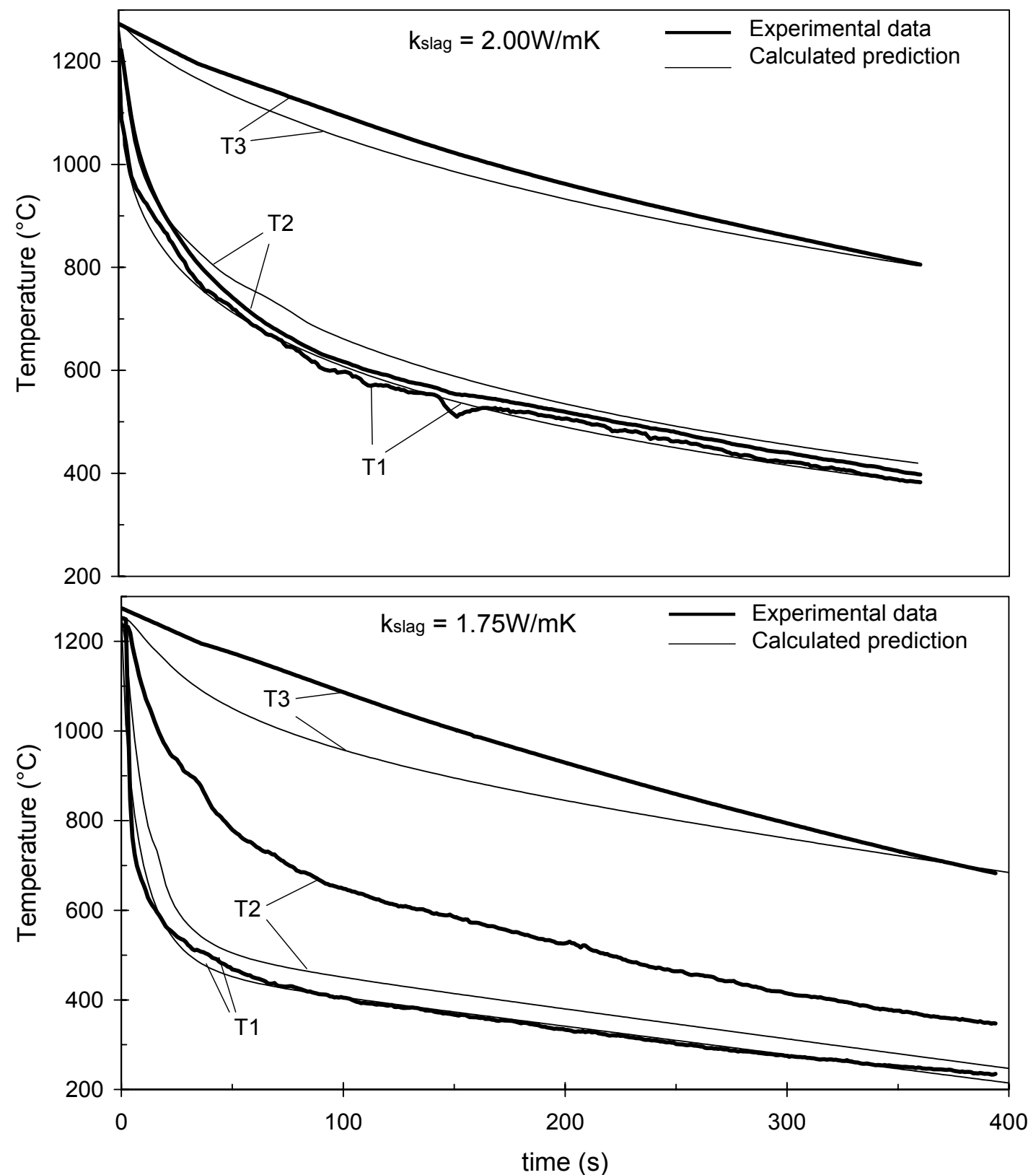

FIGURE 7.15 Comparing measured and predicted temperature changes at positions 1,2 and 3 , for two different runs 
The results in figure 7.15 are for a $3 \mathrm{~mm}$ thick mould flux layer, with $10.0 \% \mathrm{TiO}_{2}$. The two graphs are for two different sets of measurements. In both cases, the value of the thermal conductivity $(k)$ of the mould flux was adjusted until the predicted value of $\mathrm{T}_{3}$ at the end of the measurement period matched the measured value. As the figure shows, in the first case the fit between measured and predicted temperatures was reasonably good.

However, in the second case the measured difference between $T_{1}$ and $T_{2}$ is much larger than the predicted difference, and it was not possible to obtain reasonable fits between the measured and predicted values of both $T_{2}$ and $T_{3}$ simultaneously. It appears that a non-zero thermal contact resistance between the thermocouple at position 1 and the bottom surface of the carbon steel cup caused the measured values of $T_{1}$ to be unreliable. For this reason the prediction model was modified to make use of temperature $T_{2}$ as the new boundary condition to calculate the probe nose temperature $T_{3}$, based on the flux thermal conductivity as input. This model (in Visual Basic) is given in the appendix. Note that the same form of function (equation 33) was used to fit the measured values of $T_{2}$, when using $T_{2}$ as the model input.

During experimental testing $T_{1}$ was selected as the boundary condition to the finitedifference calculation. The two graphs in figure 7.15 are for two different runs. The thermal conductivity of the mould flux was adjusted to fit $T_{3}$ at the end of the measurement period. In each graph, the measured temperatures are given by the heavier lines and the predicted temperatures by the thinner lines.

To obtain the best possible fit between the calculated $T_{3}$ line prediction and the experimentally measured data the mean-absolute-error (MAE) between the data points was calculated (see equation 34). The lowest value for the MAE was taken to indicate the most accurate fit between the calculated and experimental data sets for $T_{3}$ (that is, the best estimate of the thermal conductivity of the mould flux).

$$
A M E=\frac{\sum|E-P|}{n}
$$

$E=$ experimental data point,$P=$ calculated prediction, $n=$ total data points (equal to the total experimental run time $(t)-$ seconds) 
This value would then represent the thermal conductivity for the specific test flux (figure 7.16). All the values for mould flux thermal conductivity were calculated individually making use of the lowest MAE argument (see appendix for the complete data sets).

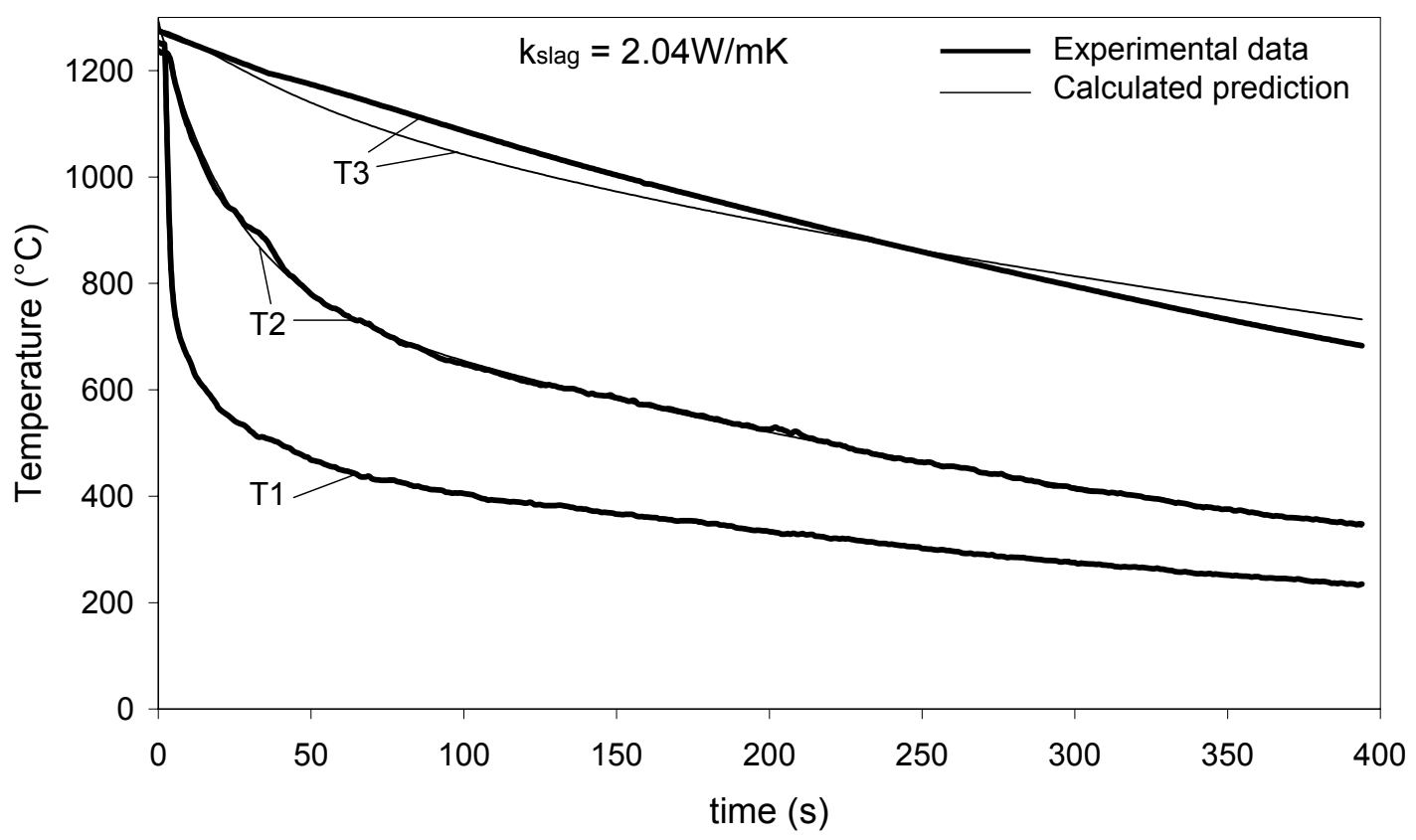

FIGURE 7.16 Data fitting of $\mathrm{T}_{3}$ using the calculated model prediction $\mathrm{T}_{2}$ as boundary condition to select the lowest MAE to calculate the slag thermal conductivity $(\mathrm{W} / \mathrm{mK})$.

To demonstrate the sensitivity of the prediction model, figure 7.17 indicates the effect on the predicted temperature profiles if thermal conductivity values of $20 \%$ lower, and a $20 \%$ higher, relative to the optimal fit (refer to figure 7.16 ) were used. The top graph (in figure 7.17 ) represents a $20 \%$ lower, and the bottom graph a $20 \%$ higher than the best-fit conductivity value. $T_{2}$ was used as model input (boundary condition).

As indicated in the top graph, a decreased thermal conductivity causes the $T_{3^{-}}$ calculated and the $T_{3}$-experimental values to drift apart at longer times, with the predicted temperature higher than the measured value (as expected, given the lower rate of heat transfer through the mould flux). Conversely, an increased k-value (figure 7.17 - bottom graph) causes a larger mismatch between the $T_{3}$-calculated and the $T_{3}$-experimental values early in the cooling period, after about $100-150$ seconds. This example shows that this approach, combining the experimental measurements with a simple finite difference model, gave reasonable and reliable values of the thermal 
conductivity of the mould flux: the model fit is quite sensitive to changes in the thermal conductivity.

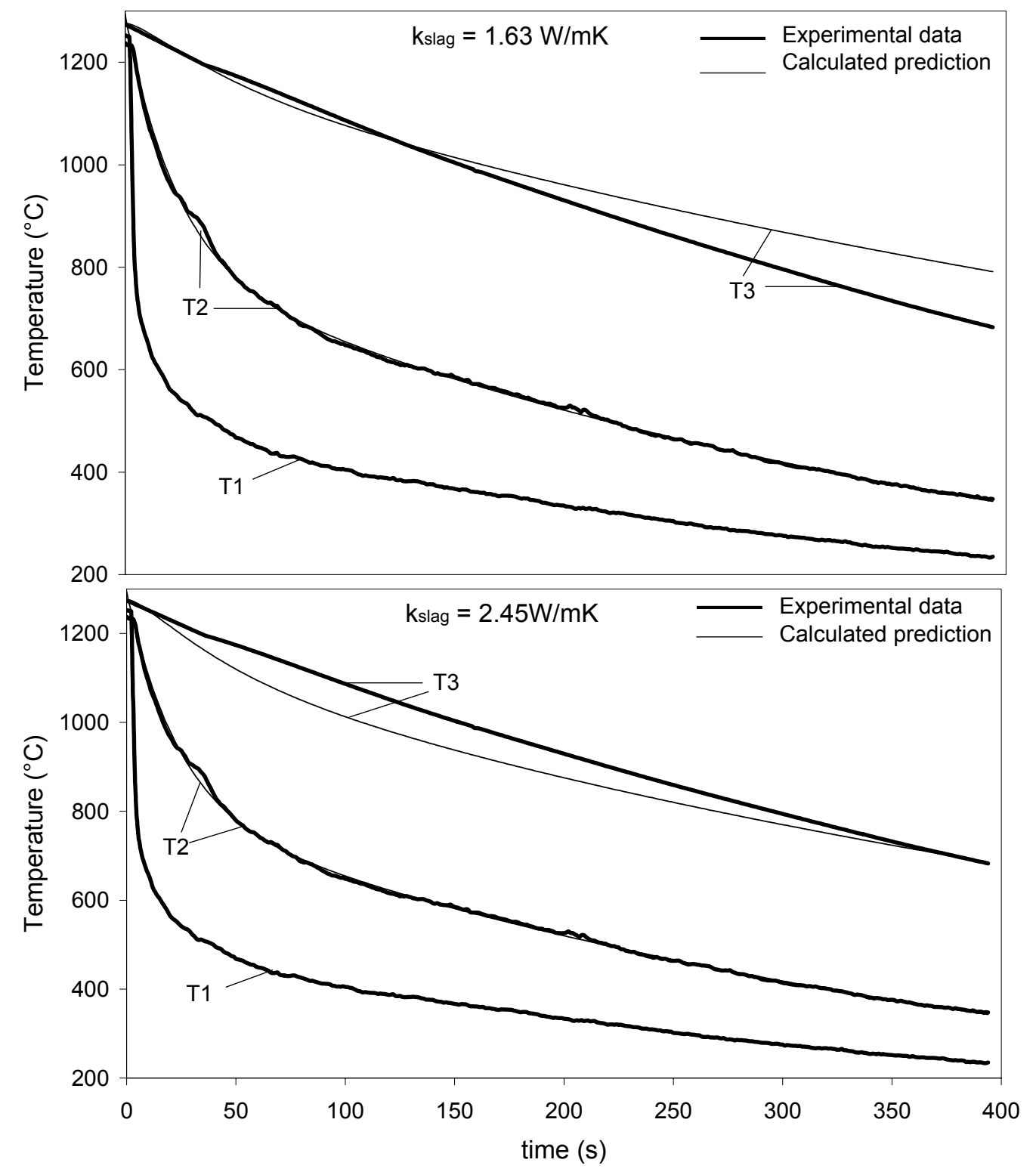

FIGURE 7.17: Calculated cooling curves of the probe tip $\left(T_{3}\right)$ for mould flux thermal conductivity values.

\subsection{FLUX THERMAL RESISTANCE RESULTS}

The minimum, maximum and average thermal conductivities for $3.0 \mathrm{~mm}$ and $6.0 \mathrm{~mm}$ thick test flux layers are given in table 7.7 and table 7.8. (All values were calculated using the prediction model to determine the most accurate thermal resistance value for each individual test, as described in the previous section.) For every combination 
of titanium oxide addition $\left(\mathrm{TiO}_{2}=0.0 \%, 5.0 \% \& 10.0 \%\right)$ with various mould flux thicknesses $(3.0 \mathrm{~mm} \& 6.0 \mathrm{~mm})$ at least two successful test runs were completed to compile the results in table 7.7 and 7.8 .

TABLE 7.7: Calculated thermal conductivity $(\mathrm{W} / \mathrm{mK})$ for $3.0 \mathrm{~mm}$ thick test flux with various additions of $\mathrm{TiO}_{2}$.

\begin{tabular}{|c|c|c|c|}
\hline $\mathbf{3 m m}$ Flux & $\mathbf{0 . 0 \%} \mathrm{TiO}_{\mathbf{2}}$ & $\mathbf{5 . 0 \%} \mathbf{T i O}_{\mathbf{2}}$ & $\mathbf{1 0 . 0 \%} \mathbf{T i O}_{\mathbf{2}}$ \\
\hline Minimum & 1.84 & 2.30 & 1.69 \\
\hline Maximum & 2.27 & 2.36 & 2.04 \\
\hline Average & 2.03 & 2.33 & 1.87 \\
\hline
\end{tabular}

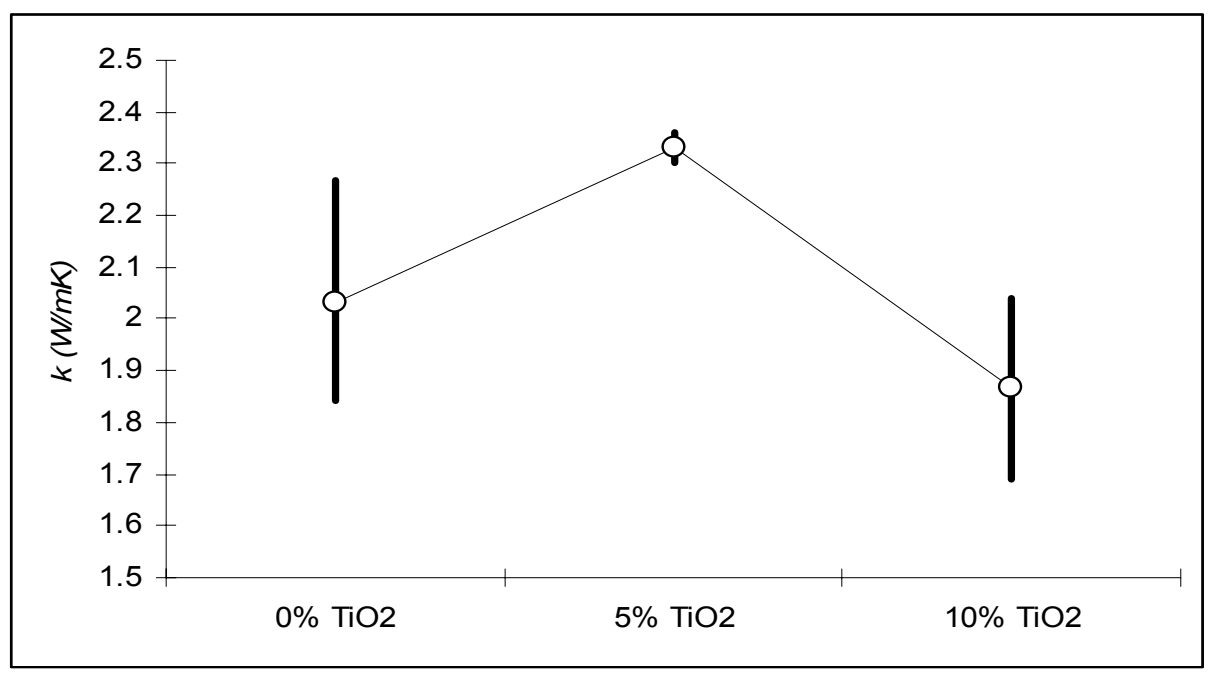

FIGURE 7.18: Box-and-whisker plots: Thermal conductivities for $3.0 \mathrm{~mm}$ thick test flux with various additions of $\mathrm{TiO}_{2}$.

Figure 7.18 indicates the minimum and maximum values (vertical bars) as well as the average thermal conductivities (round data points) for the addition of titanium oxide to a test flux $\left(3.0 \mathrm{~mm}\right.$ thick). Figure 7.18 indicates that $5.0 \% \mathrm{TiO}_{2}$ results in the highest average thermal conductivity for a $3.0 \mathrm{~mm}$ test flux. For the thicker flux layer, the effect on thermal conductivity is not as strong, and is obscured by the variability of the data. 
TABLE 7.8: Calculated thermal conductivity $(\mathrm{W} / \mathrm{mK})$ for $6.0 \mathrm{~mm}$ thick test flux with various additions of $\mathrm{TiO}_{2}$.

\begin{tabular}{|c|c|c|c|}
\hline 6mm Flux & $\mathbf{0 . 0 \%} \mathrm{TiO}_{\mathbf{2}}$ & $\mathbf{5 . 0 \%} \mathbf{T i O}_{\mathbf{2}}$ & $\mathbf{1 0 . 0 \%} \mathbf{T i O}_{\mathbf{2}}$ \\
\hline Minimum & 2.84 & 2.89 & 2.97 \\
\hline Maximum & 3.22 & 3.31 & 3.09 \\
\hline Average & 3.03 & 3.10 & 3.03 \\
\hline
\end{tabular}

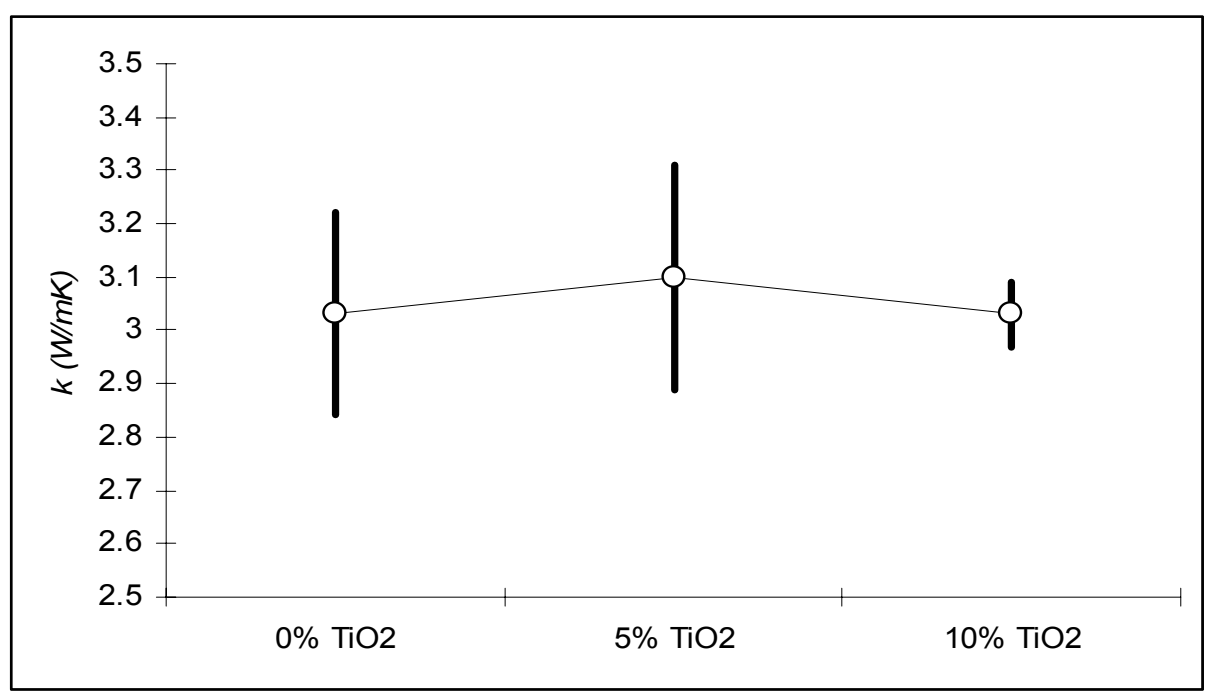

FIGURE 7.19: Box-and-whisker plots: Thermal conductivities for $6.0 \mathrm{~mm}$ test flux having various additions of $\mathrm{TiO}_{2}$.

Converting the average thermal conductivities for a $3.0 \mathrm{~mm}$ and a $6.0 \mathrm{~mm}$ test flux to individual thermal resistances at various $\mathrm{TiO}_{2}$ additions yields the results in table 7.9. The thermal resistances for the $6.0 \mathrm{~mm}$ thick test flux are similar, with an average of $1.97 \times 10^{-3} \mathrm{~m}^{2} \mathrm{~K} / \mathrm{W}$ (average) while the thermal resistances for the $3.0 \mathrm{~mm}$ thick test flux varied around the average value of $1.46 \times 10^{-3} \mathrm{~m}^{2} \mathrm{~K} / \mathrm{W}$ (average).

TABLE 7.9: Calculated thermal resistances of SPH-KA1 test flux with various additions of $\mathrm{TiO}_{2}$, and for flux thicknesses of $3 \mathrm{~mm}$ and $6 \mathrm{~mm}$.

\begin{tabular}{|c|c|c|c|c|}
\hline & \multicolumn{2}{|c|}{$\begin{array}{c}\text { Thermal Conductivity } \\
(\mathrm{W} / \mathrm{m} \cdot \mathrm{K})\end{array}$} & \multicolumn{2}{c|}{$\begin{array}{c}\text { Thermal Resistance } \\
\left(\mathbf{m}^{2} \cdot \mathrm{K} / \mathrm{W}\right) \times 1 \mathbf{1}^{3}\end{array}$} \\
\hline $\mathbf{T i O}_{\mathbf{2}}$ & $\mathbf{3 . 0} \mathbf{~ m m}$ & $\mathbf{6 . 0 ~} \mathbf{~ m m}$ & $\mathbf{3 . 0} \mathbf{~ m m}$ & $\mathbf{6 . 0} \mathbf{~ m m}$ \\
\hline $\mathbf{0 . 0} \%$ & 2.03 & 3.03 & 1.478 & 1.980 \\
\hline $\mathbf{5 . 0} \%$ & 2.33 & 3.10 & 1.288 & 1.935 \\
\hline $\mathbf{1 0 . 0} \%$ & 1.87 & 3.03 & 1.609 & 1.980 \\
\hline
\end{tabular}




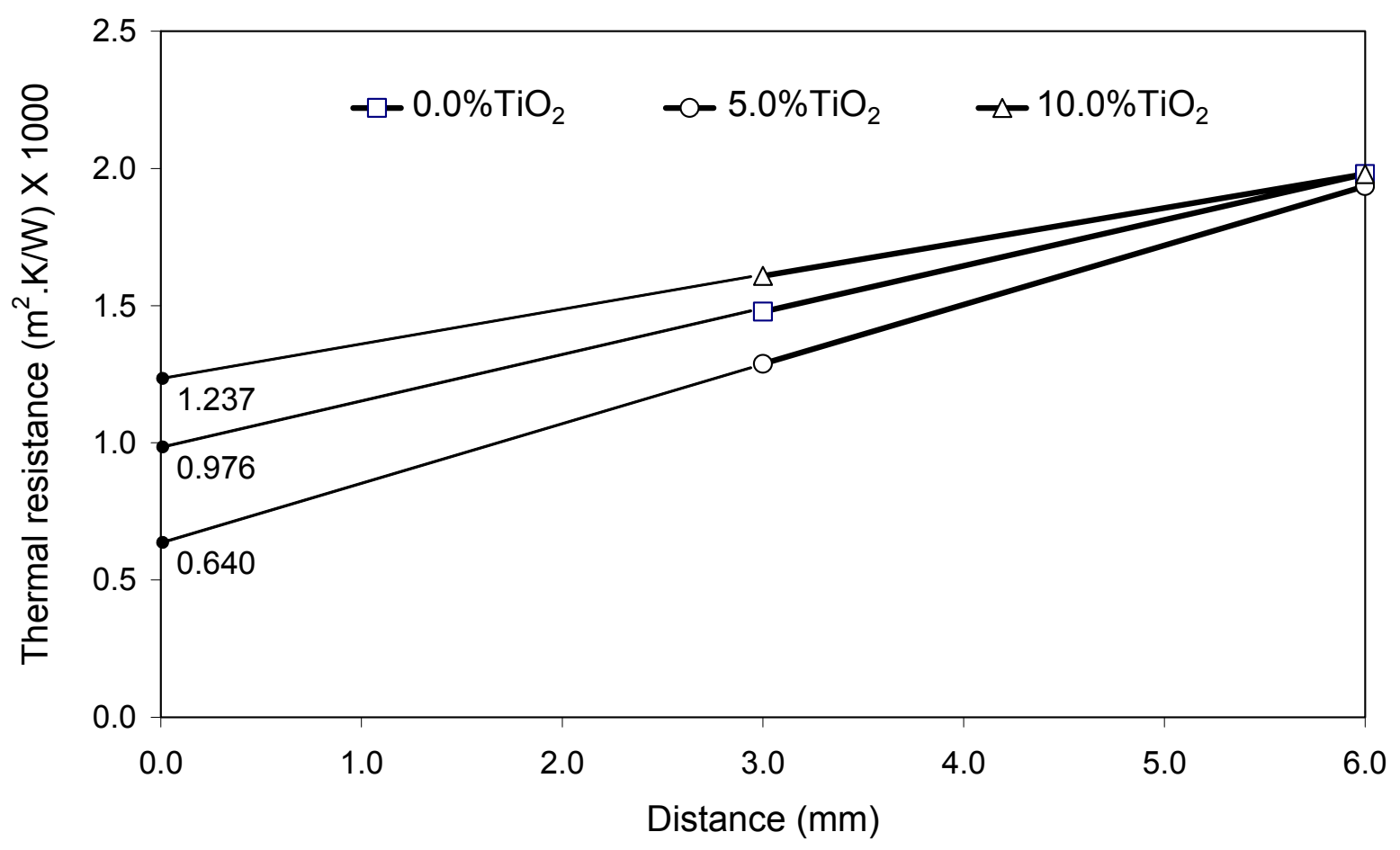

FIGURE 7.20: Thermal resistances for SPH-KA1 mould flux with additions of $\mathrm{TiO}_{2}$.

The presumed linear relationship between the thermal resistance and flux thickness is shown in Figure 7.9, with extrapolation of the relationship to zero thickness. The thermal resistance at zero thickness indicates the total contact resistance (between the mould flux and the solid steel surfaces). This contact resistance is expected to depend on changes in crystallisation behaviour. Figure 7.20 shows that the thermal contact resistance for the $5.0 \% \mathrm{TiO}_{2}$ test flux is the lowest, while $10.0 \% \mathrm{TiO}_{2}$ test flux has the highest contact resistance. This behaviour is consistent with the predicted effect of $\mathrm{TiO}_{2}$ pick-up on mould flux crystallisation (see, for example the equilibrium prediction in Figure 6.7): $\mathrm{TiO}_{2}$ pick-up of less than $6 \%$ suppresses cuspidine formation (lower liquidus temperature) whereas higher levels of $\mathrm{TiO}_{2}$ pick-up promote perovskite formation as primary phase, with higher liquidus temperatures. Of the three flux compositions tested, the $5 \% \mathrm{TiO}_{2}$ flux is hence expected to have the lowest tendency to crystallise at elevated temperatures, and this is consistent with this flux showing the lowest contact resistance. 


\section{CHAPTER 8}

\section{CONCLUSION}

This project had two primary aims: constructing an experimental apparatus which allows the measurement of the effective thermal conductivity of mould flux under realistic conditions (of heat flux and thickness), and using this experimental setup to investigate the effect of titanium oxide pick-up on the heat transfer behavior of a practically used mould flux.

The experimental apparatus used a transient method to evaluate the thermal resistance of the mould flux, and yielded realistic solidification structures (including a glassy layer where it was cooled most rapidly).

A slag rim sample (recovered from a continuous caster mould) showed significant pick-up of titanium oxide. With increased levels of titanium oxide, perovskite appeared as a major phase, at the expense of cuspidine. This effect was also predicted by phase equilibrium calculations (with FactSage). The equilibrium calculations also indicated that low levels of $\mathrm{TiO}_{2}$ pick-up (below approximately $6 \%$ ) decreased the liquidus temperatures. The liquidus temperature increased again at higher levels of $\mathrm{TiO}_{2}$ pick-up, associated with a change in primary phase from cuspidine to perovskite.

The two opposing effects of $\mathrm{TiO}_{2}$ pick-up - suppressing cuspidine formation and the liquidus temperature at low levels of pick-up, but favouring perovskite as primary phase and increasing the liquidus temperature at higher pick-up - was also visible in the measured thermal resistances: compared with the $\mathrm{TiO}_{2}$-free flux, the flux with $5 \% \mathrm{TiO}_{2}$ had a lower contact resistance (and lower total thermal resistance at $3 \mathrm{~mm}$ flux thickness), whereas the flux with $10 \% \mathrm{TiO}_{2}$ has both a higher contact resistance and a higher total thermal resistance at $3 \mathrm{~mm}$ thickness.

The results also show that, although titanium oxide pick-up has a significant effect on the microstructure of the solidified flux, its effect on the thermal resistance between the strand and the mould is relatively small compared to the thermal contact resistance formed as a result of gas entrapment during flux solidification. 


\section{REFERENCES}

ASTM - international, Designation: A 240/A 240M - 03b "Standard Specification for Chromium and Chromium-Nickel Stainless Steel Plate, Sheet, and Strip for Pressure Vessels and for General Applications", June 2003, Revision 14, 1-11

Balakrishnan A.R., Pei D.C.T., "Heat transfer in gas-solid packed bed systems." Industrial Engineering Chemistry Process, December 1979, Volume 18 (No.1):47-50.

Billany T.J.H. et al., "Surface cracking in continuously cast products." Ironmaking and Steelmaking, 1991, Volume 18 (No.6): 403-410.

Brimacombe, J.K., "Design of continuous casting machines based on a heat-flow analysis: state-of-the-art review." Canadian Metallurgical Quarterly, 1976, vol.15: 163175.

Budinski K.G., Budinski M.K., 1999, Engineering Materials - Properties and Selection, 6th edition, New Jersey: Prentice Hall: 266-267.

Camisani-Calzolari F.R., Craig I.K., Pistorius P.C., "Quality prediction in continuous casting of stainless steel slabs." The Journal of the South African Institute of Mining and Metallurgy, 2003, Volume 103 (No10): 651-665.

Courtney L., Nuortie-Perckiö S., Valadares C.A.G., Richardson M.J., "Crystallisation of slag films formed in continuous casting." Ironmaking and Steelmaking, 2001, Volume 28 (No.5):412-41

Cho J.W., Shibata H., "Effect of solidification of mould fluxes on the heat transfer in casting mould." Journal of Non-crystalline solids, 2001, Volume 282: 110-117.

Cho J.W., Shibata H., Emi T., Suzuki M., "Radiative heat transfer through mold flux film during initial solidification in continuous casting of steel." ISIJ International, 1998, Volume 38 (No.3): 268-275.

Cho J.W., Shibata H., Emi T., Suzuki M., "Thermal resistance at the interface between 
mold flux and mold for continuous casting of steels." ISIJ International, 1998, Volume 38 (No.5): 440-446.

Cho J.W., Emi T., Shibata H., Suzuki M., "Heat transfer across mold flux film in mould during initial solidification in continuous casting." ISIJ International, 1998, Volume 38 (No.8): 834-842.

Fukuyama H., Tabata H., Nagata K., "Determination of Gibbs energy of formation of cuspidine $\left(3 \mathrm{CaO} .2 \mathrm{SiO}_{2} \cdot \mathrm{CaF}_{2}\right)$ from the electromotive force method using $\mathrm{CaF}_{2}$ as the solid electroyte. Metallurgial and Materials Transactions B, 2003, Volume 34B, pp. 307-311.

Görnerup M., Hayashi M., Däcker C.Å., Seetharaman S., "Mould fluxes in continuous casting of steel - characterization and performance tuning." VII International Conference on molten slags fluxes and salts. The South African Institute of Mining and Metallurgy, 2004.

Grieveson P., Baga S., Machingawuta N., Liddell K., Mills K.C., "Physical properties of casting powders: Part 2 Mineralogical constitution of slags formed by powders." Iron making and Steelmaking, 1988, Volume 15 (No.4): 181-186.

Holzhauser J.F., Spitzer K.H., Schwerdtfeger K., "Laboratory study of heat transfer through thin layers of casting steel: minimization of the slag/probe contact resistance." Steel Research, 1999, Volume 70 (No.10): 430-436.

Howe A., Steward I., "Reduction of reciprocation marks by high frequency vibration of the continuous casting mould.” ISS Transactions,, 1987, Volume 70: 417-425.

Irving W.R., Perkins A., "The influence of engineering process and chemical factors on surface and international quality of continuous cast slabs", International Symposium Dugapur, The Indian Institute of Metals, October 1982, Paper 2.1.

Itoh Y., Nabeshima S., Sorimachi K., "Direct observation at early stage of solidification in continuous casting with copper alloy and mould powder." Proceedings of the $6^{\text {th }}$ International Conference on molten slags, fluxes and salts., The South African Institute of Mining and Metallurgy, 2000. 
Jones D.A. 1996. Principles and prevention of corrosion. $2^{\text {nd }}$ edition, USA: PrenticeHall Inc. 310p.

Kashiwaya Y., Cicutti C.E., Cramb A.W., Ishii K., "Development of double and single hot thermocouple technique for in situ observation and measurement of mould slag crystallization." ISIJ International, 1998, Volume 38 (No.4): 348-356.

Kashiwaya Y., Cicutti C.E., Cramb A.W., "An investigation of the crystallisation of a continuous casting mould slag using the single hot thermocouple technique." ISIJ International, 1998, Volume 38 (No.4): 357-365.

Kishi, T., Takeuchi H., Yamimaya M., "Mold powder technology for continuous casting of titanium-stabilized stainless steel.", Nippon Steel Technical Report, 1987, Volume 34: 11-20.

Kowalski, M., Spencer, P.J., Neushütz, D., 1995. "Phase diagrams" Verein Deutscher Eisenhüttenleute (eds.), Slag Atlas, $2^{\text {nd }}$ edition. Stahleisen Verlag. Düsseldorf: 140.

Ludlow V., Harris B., Riaz S., Normanton A., "Continuous casting mould powder and casting process interaction: why powders do not always work as expected." VII International Conference on molten slags, fluxes and salts. The South African Institute of Mining and Metallurgy, 2004.

Mills K.C., Billany T.J.H., Normanton A.S., Walker B. \& Grieveson P., "Causes of sticker breakout during continuous casting." Iron making and Steelmaking, 1991, Volume 18 (No.4): 253-265.

Mills, K.C., Su, Y., Li, Z., Brooks, R.F., "Equations for the calculation of thermophysical properties of stainless steel." ISIJ International, 2004a, vol. 44: 1661-1668.

Mills K.C., Fox A.B., Thackray R.P. \& Li Z., "The performance and properties of mould fluxes." VII International Conference on molten slags, fluxes and salts. The South African Institute of Mining and Metallurgy, 2004b. pp. 713-721

Mueller M., Willenborg W., Hilpert K., Singheiser L., "Structural dependence of alkali 
oxide activity in coal ash slags." VII International Conference on molten slags, fluxes and salts. The South African Institute of Mining and Metallurgy, 2004.

Mukongo T., Pistorius P.C., "Effects of titanium pickup in mould fluxes for stainless steel”, Iron and Steel Society, Proc. ISSTech2003, April 2003: 675-682.

Mukongo T., Pistorius P.C., Garbers-Craig A.M., "Effects of titanium pickup in mould fluxes for stainless steel", Ironmaking and Steelmaking, 2004, Volume 31, (No.2):135143

Ogibayashi S. et al., "Mold powder technology for continuous casting of low-carbon aluminium-killed steel." Nippon Steel Technical Report, 1987, Volume 34: 1-10.

Orrling C., Cramb A.W., Tilliander A., Kashiwaya Y., "Observations of the melting and solidification behaviour of mold slags." ISS Transactions, 2000: 53-63.

Pinheiro C.A., Samarasekera I.V., Brimacombe J.K., "Mold flux for continuous casting." Iron Steelmaker, October 1994, 55; November 1994, 63; December 1994, 12-14; January 1995, 43-44; February 1995, 37-39; March 1995, 76-77; April 1995, 45-47; May 1995, 59-61; June 1995, 43-44; July 1995, 41-43; August 1995, 41-43; September 1995, 71-72; October 1995,101-104; November 1995, 54-56; December 1995, 43-44; January 1996, 51-52; February 1996, 59-60; March 1996, 85.

"Processes for the production of stainless steel." [Available on internet:] http://www.columbus.co.za/steelplant/CCM [Date visited:] 20 January 2006.

Reed-Hill R.E., Abbaschian R. 1994. Physical Metallurgy Principles. $3^{\text {rd }}$ edition, Boston: P.W.S Publishing Company: 5-10.

Rocabois P., Pontoire J.N., Lehmann J., Gage H., "Crystallization kinetics of $\mathrm{Al}_{2} \mathrm{O}_{3}$ CaO-SiO ${ }_{2}$ based oxide inclusions." Journal of Non-crystalline solids, 2001: 98-109.

Sedriks A. J., 1996. Corrosion of stainless steels. $2^{\text {nd }}$ edition, New York: John Wiley \& Sons: 2. 
Schwerdtfeger K.L., "Heat withdrawal in continuous casting of steel." A Cramb (ed.), The Making, Shaping and Treating of Steel, $11^{\text {th }}$ ed., Casting Volume. The AISE Steel Foundation, 2003: 1-41

Shin H.J., Lee G.G., Kang S.M., Kim S.H., Thomas B.G., "Effect of mould oscillation an powder consumption and hook formation in ultra low-carbon steel slabs", Iron \& Steel Technology, September 2005: 56-69.

Siyasiya C., Van Rooyen G.T., Stumph, W.E., "Metallurgical factors that affect the strand width during continuous casting of DIN1.4003 stainless steel." The Journal of the South African Institute of Mining and Metallurgy, 2004: 473-481.

Sridhar S., Mills K.C., Afrange O.D.C., Lörz H.P., Carli R., "Break temperatures of mould fluxes and their relevance to continuous casting." Ironmaking and Steelmaking, 2000, Volume 27 (No.3): 238-241.

Stone D.T., Thomas B.G., "Measurement and modelling of heat transfer across interfacial mold flux layers." Canadian Metallurgical Quarterly, 1999, Volume 38 (No.5): 363-375.

"The five basic functions of mould flux." [Available on internet:] http://www.stollberg.com/functions [Date visited:] 21 August 2004.

Turkdogan E.T., 1996. Fundamentals of steelmaking. Cambridge: The University Press: 138-179.

Yamauchi A., Sorimachi K., Sakuraya T., Fujii T., "Heat transfer between mold and strand through mold flux film in continuous casting of steel." ISIJ International, 1993, Volume 33 (No.1):140-147.

Yamauchi A., Sorimachi K., Sakuraya T., "Effect of solidus temperature and crystalline phase of mould flux on heat transfer in continuous casting mould." Ironmaking and Steelmaking, 2002, Volume 29 (No.3): 203-207. 


\section{APPENDIX}

APPENDIX A:

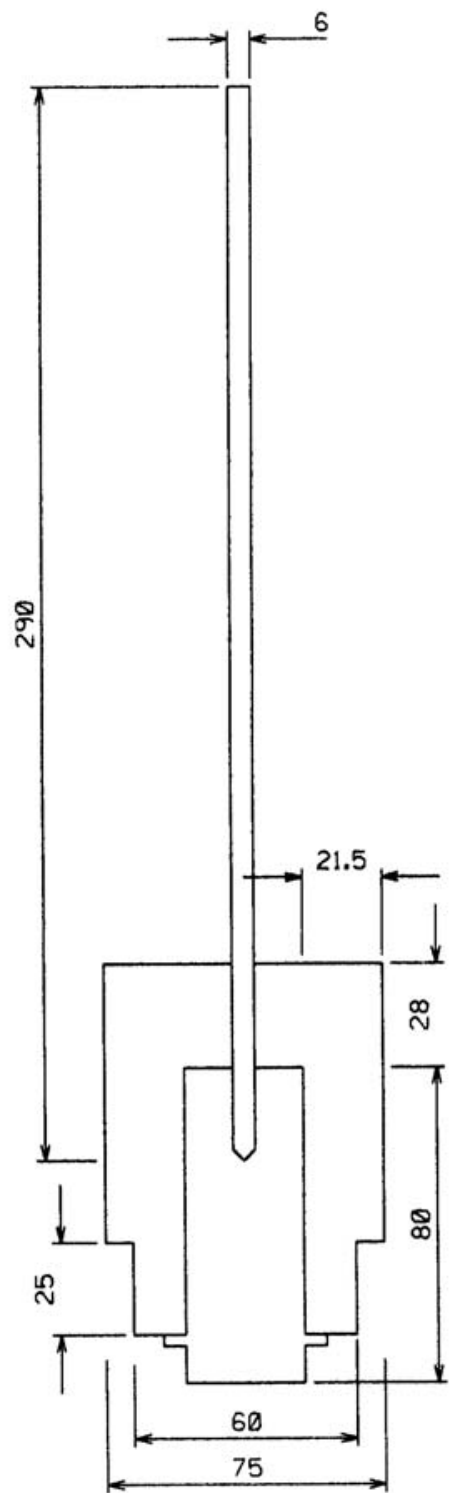

DETAIL DRAWING OF THE EXPERIMENTAL APPARATUS.

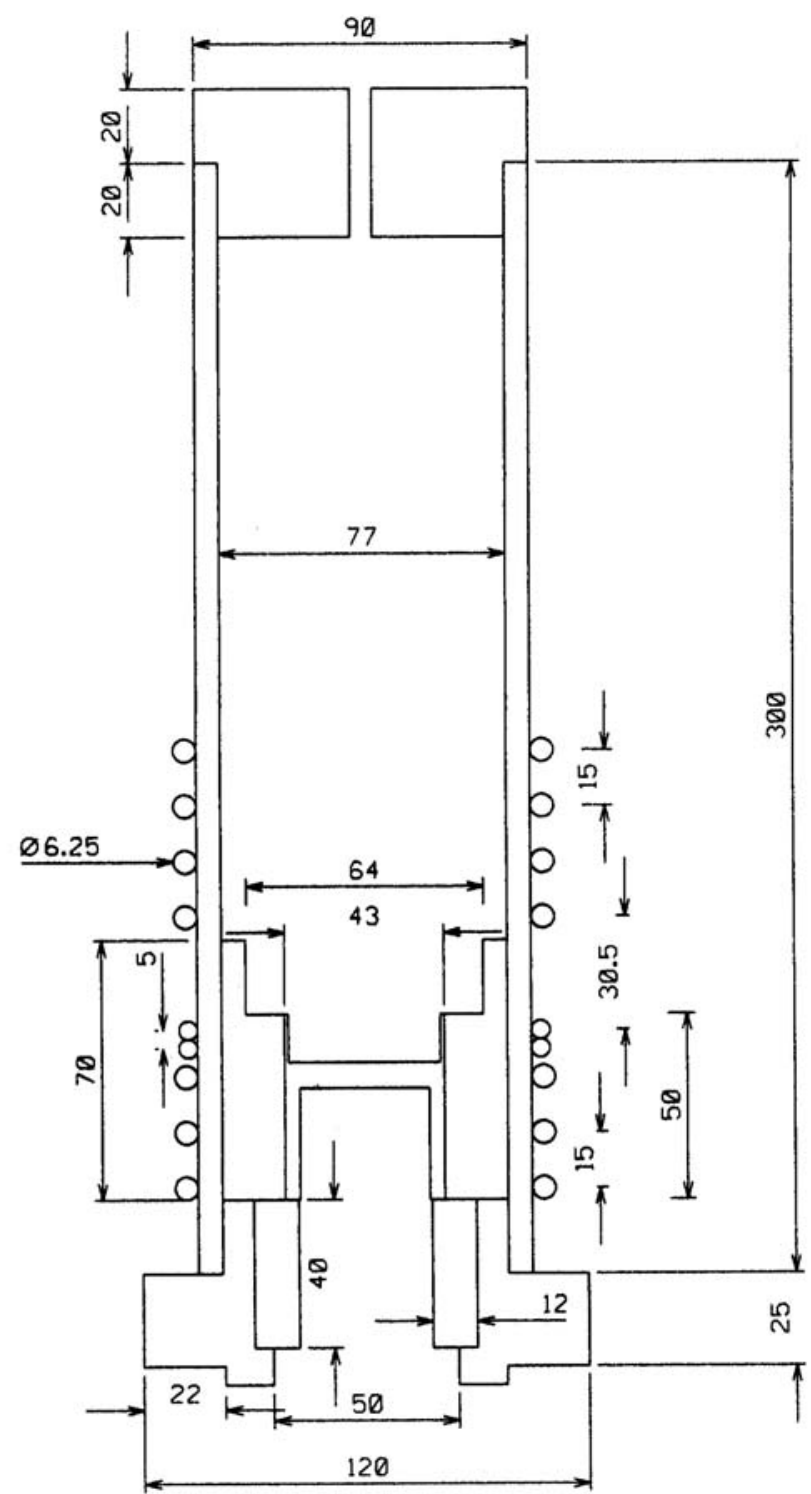

All dimensions in meter/1000 - $(\mathrm{mm})$ 
APPENDIX B: $\quad$ DETAIL DRAWING OF THE CUP AND PROBE.

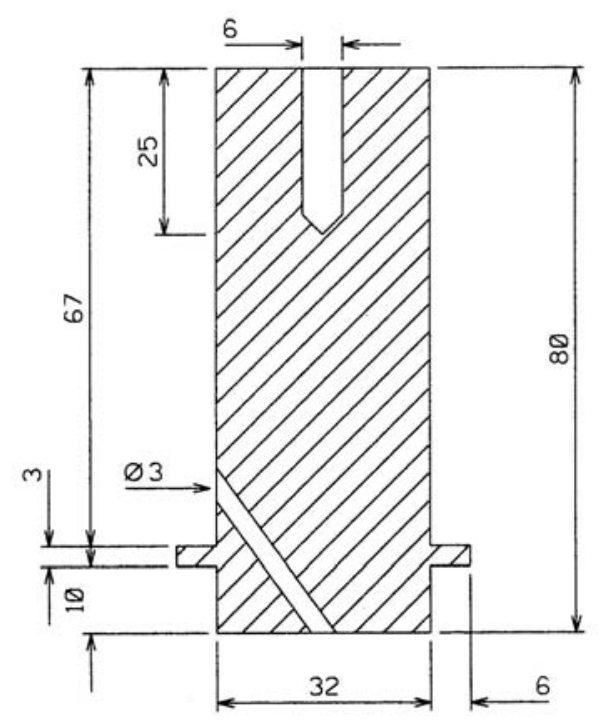

PROBE - 310 STAINLESS STEEL

CUP - CARBON STEEL
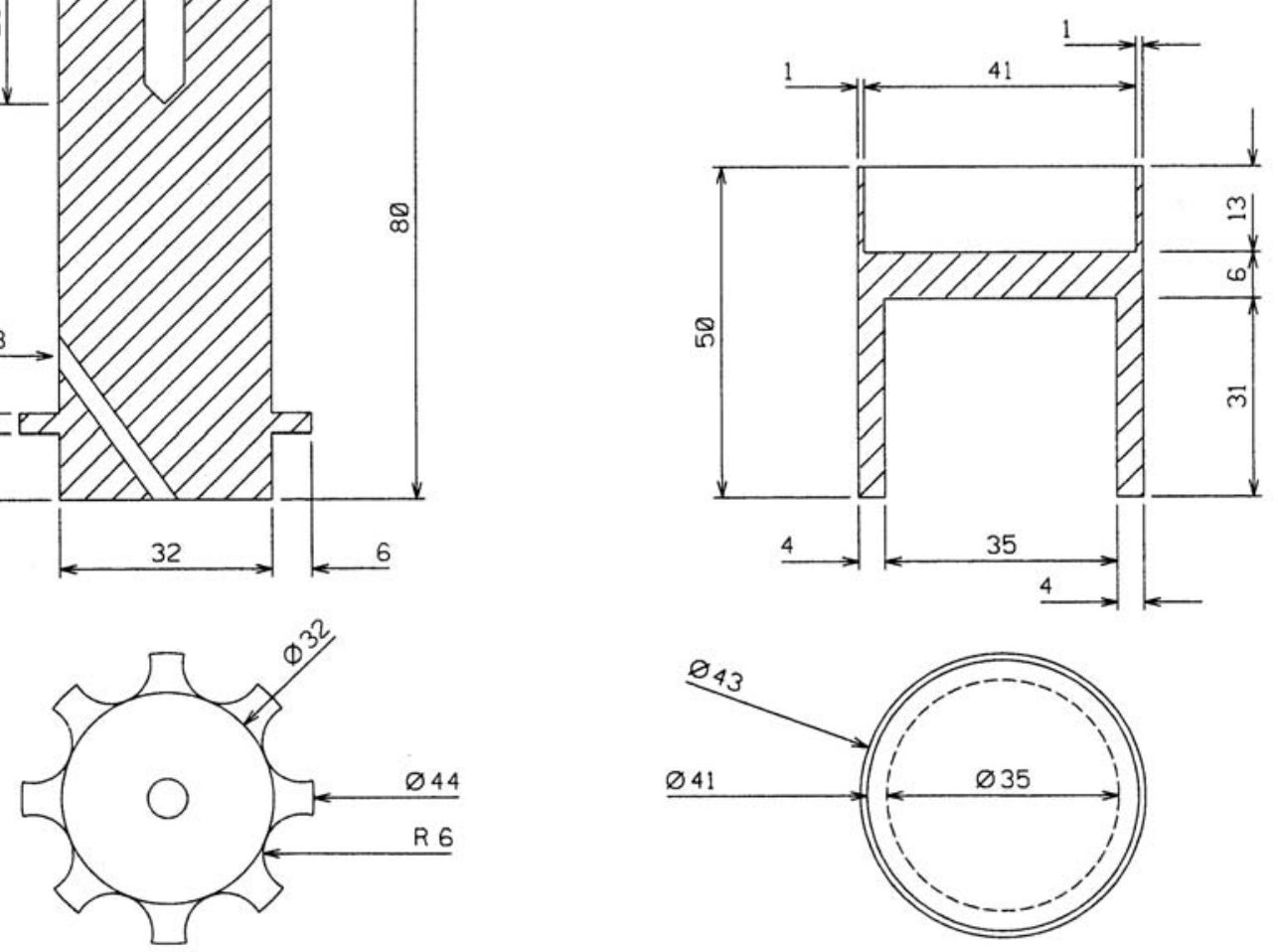

All dimensions in meter/1000 - ( $\mathrm{mm})$ 


\section{APPENDIX C: $\quad$ EXPERIMENTAL HEATING SEQUENCE.}

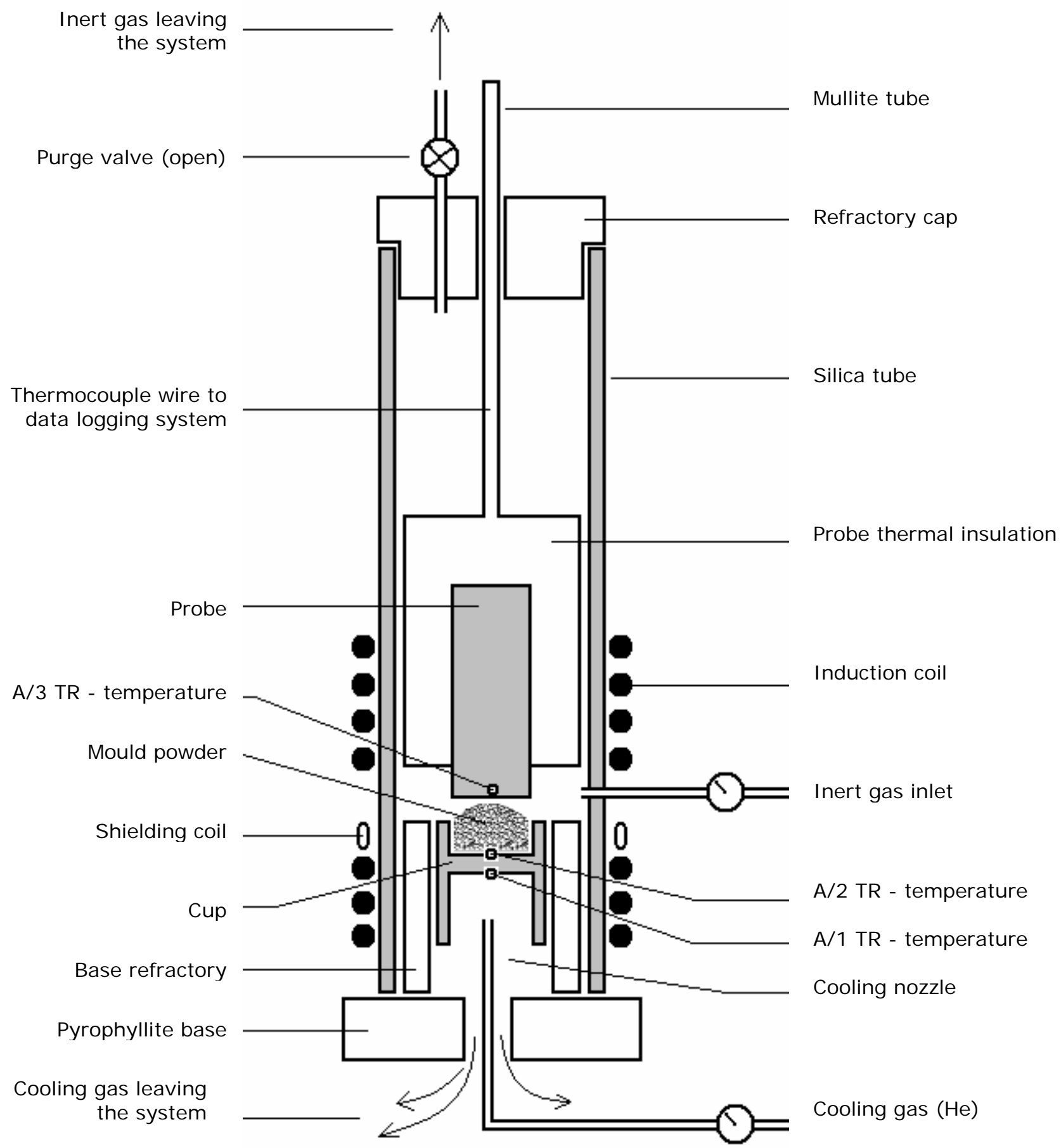


APPENDIX D: $\quad$ EXPERIMENTAL COOLING SEQUENCE.

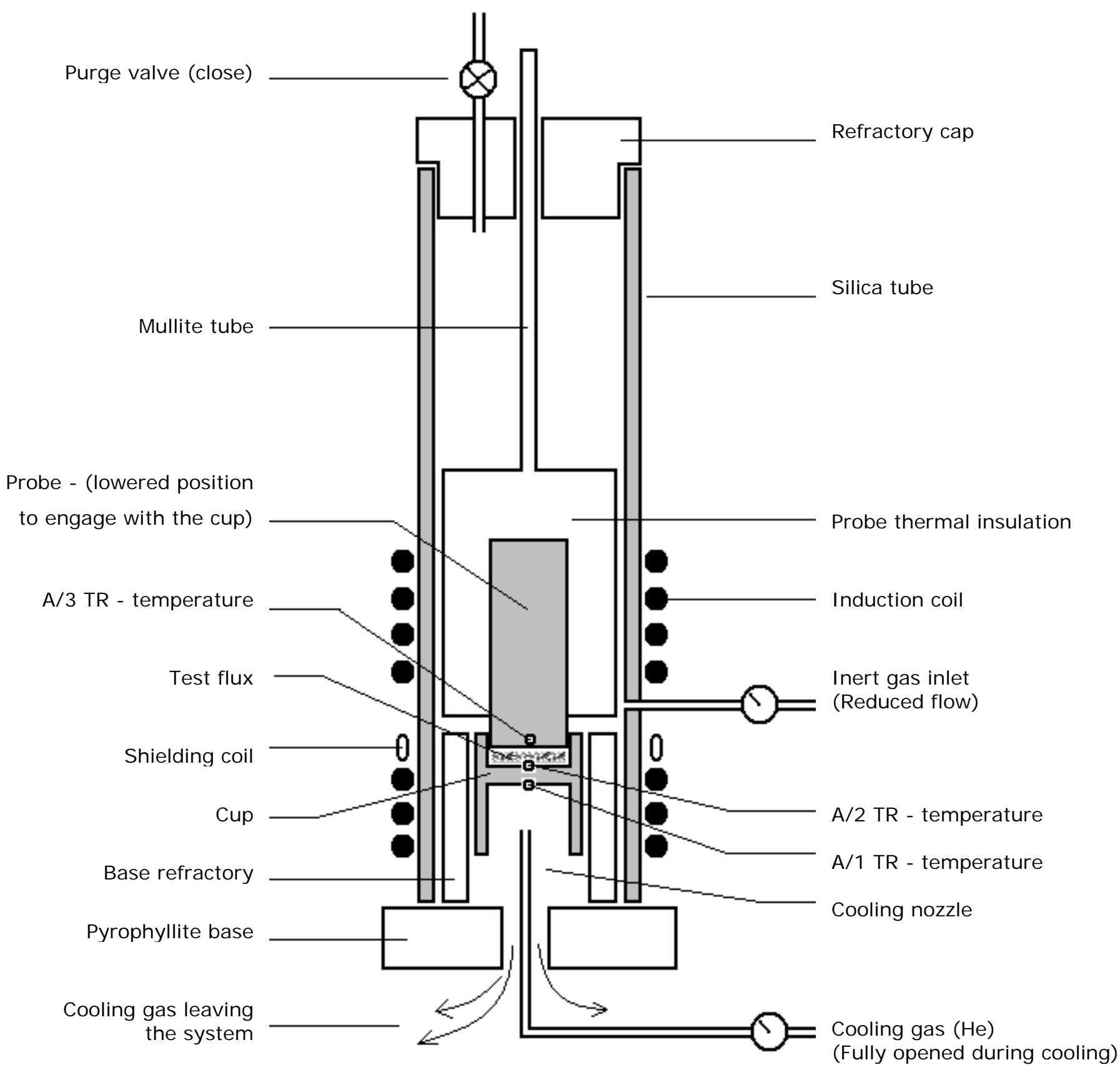


APPENDIX E: MAJOR FLUX PHASES IDENTIFIED BY X-RAY POWDER DIFFRACTION FOR SPH-KA1 SLAG RIM.

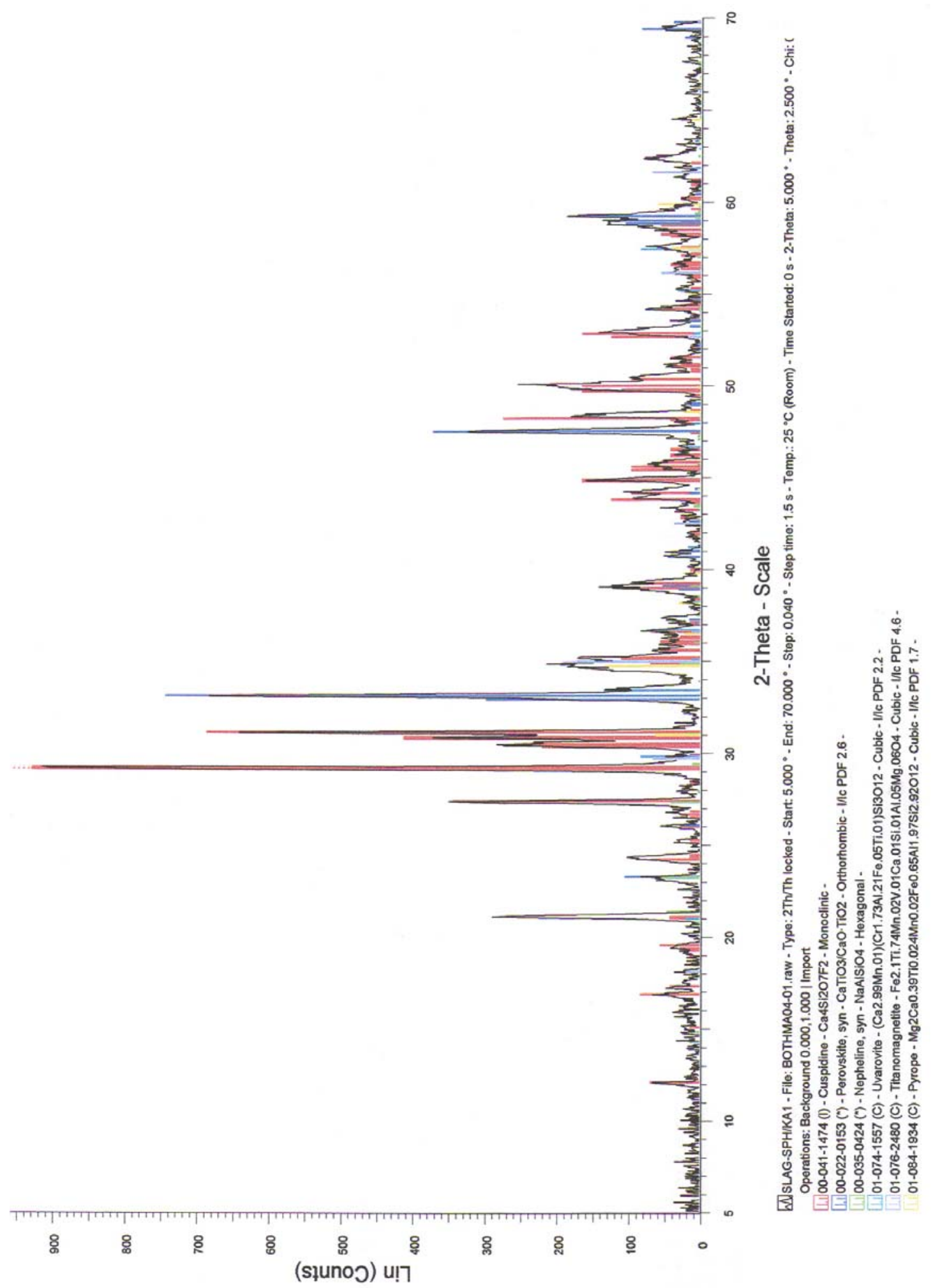




\section{APPENDIX F: $\quad$ VISUAL BASIC CODE OF FINITE-DIFFERENCE MODEL}

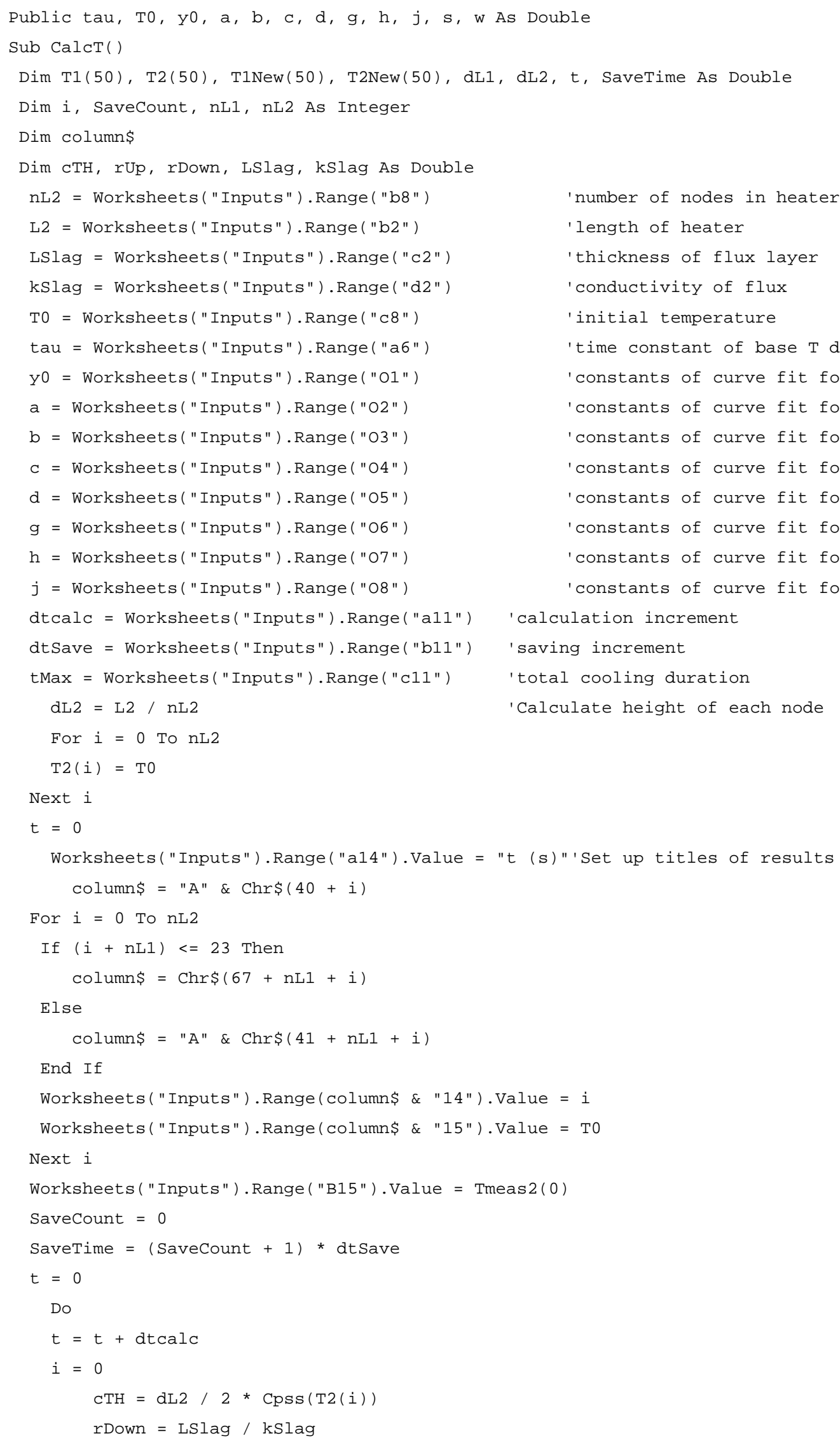




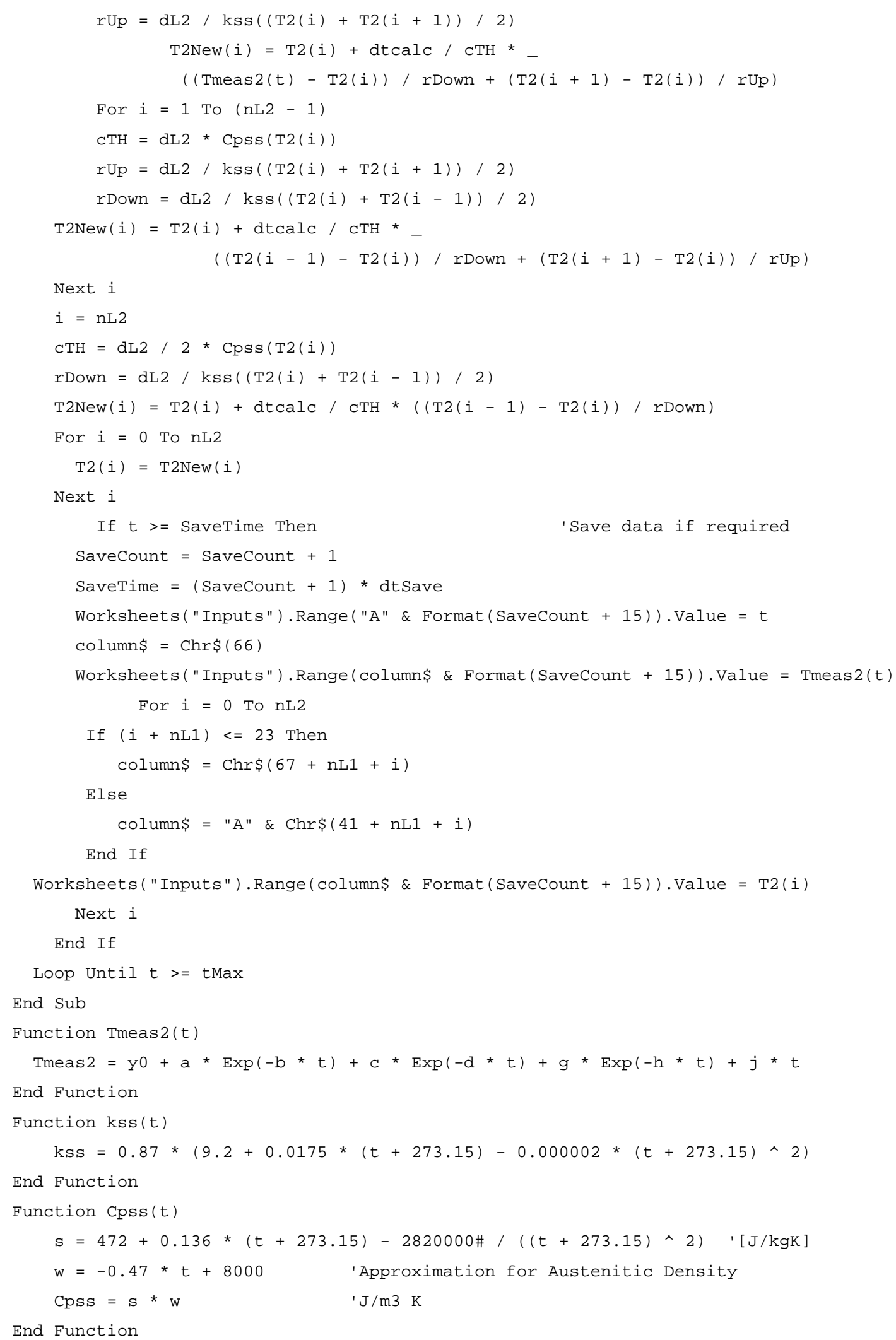




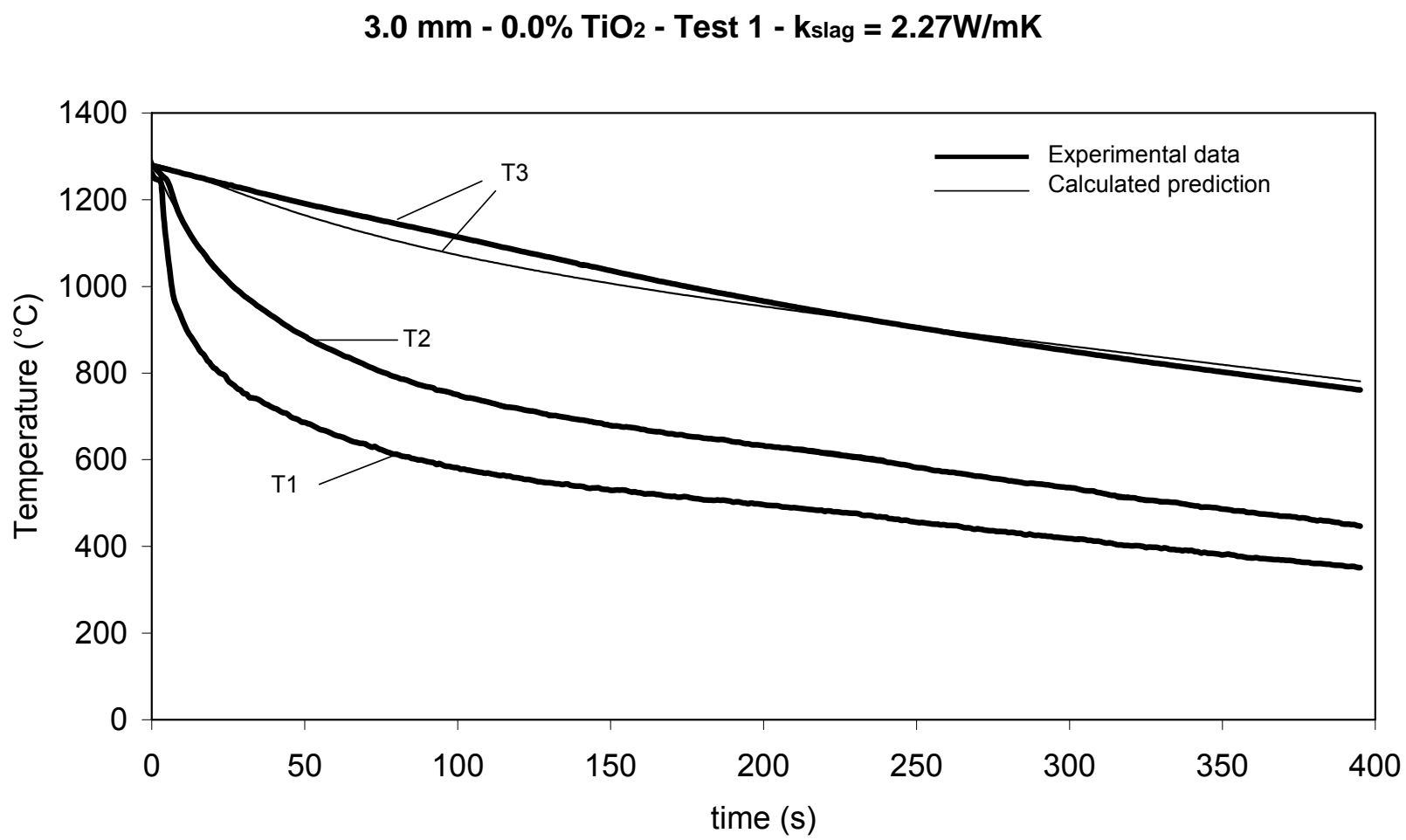

$3.0 \mathrm{~mm}-0.0 \% \mathrm{TiO}_{2}-$ Test $2-\mathrm{kslag}=1.84 \mathrm{~W} / \mathrm{mK}$

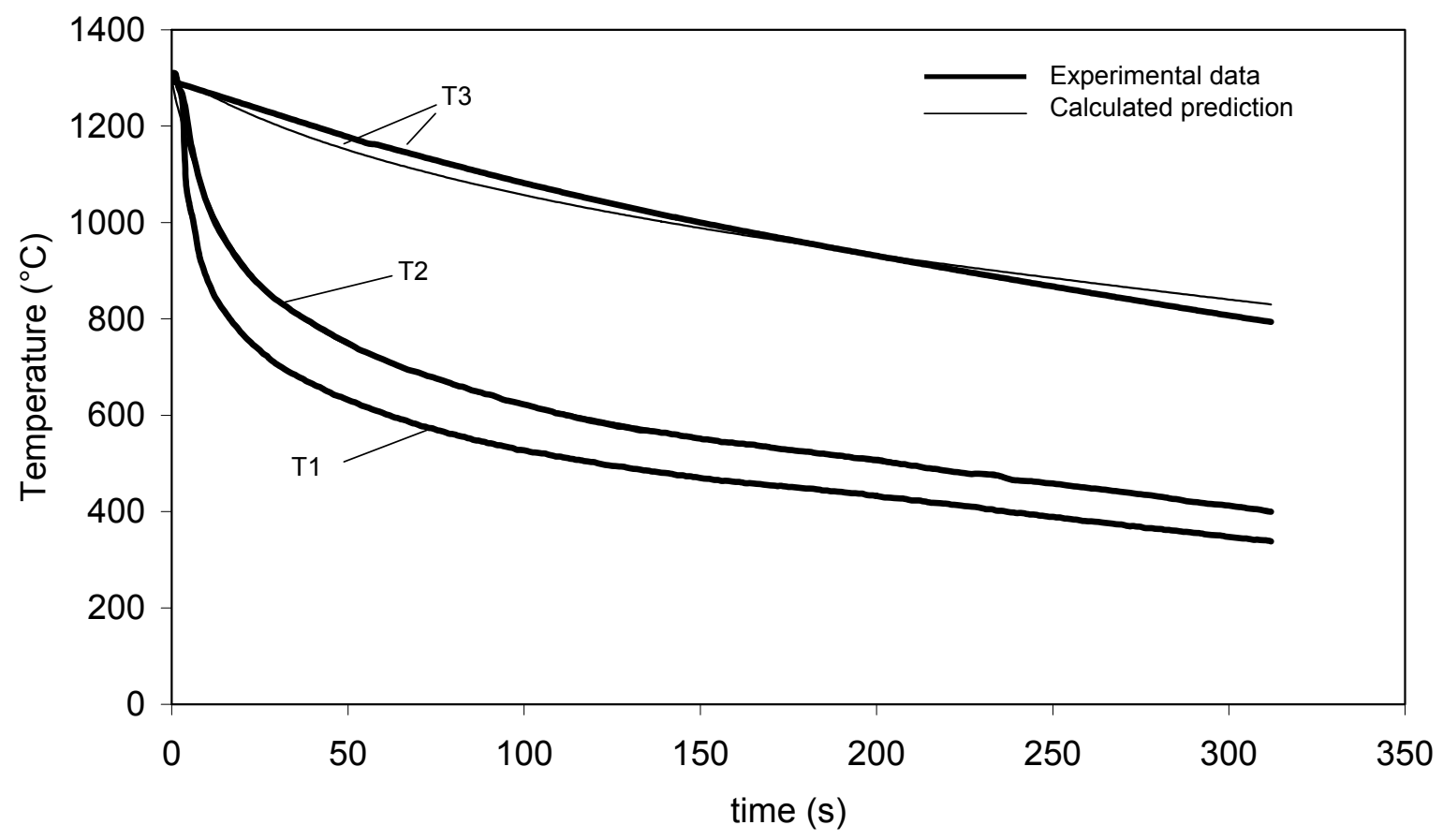

J.A. BOTHMA - MASTER OF ENGINEERING (METALLURGY) - UNIVERSITY OF PRETORIA - 2006 
APPENDIX H:

COOLING PROFILE: $3.0 \mathrm{~mm} \& 5.0 \% \mathrm{TiO}_{2}$

$3.0 \mathrm{~mm}-5.0 \% \mathrm{TiO}_{2}-$ Test $1-\mathrm{kslag}=2.30 \mathrm{~W} / \mathrm{mK}$

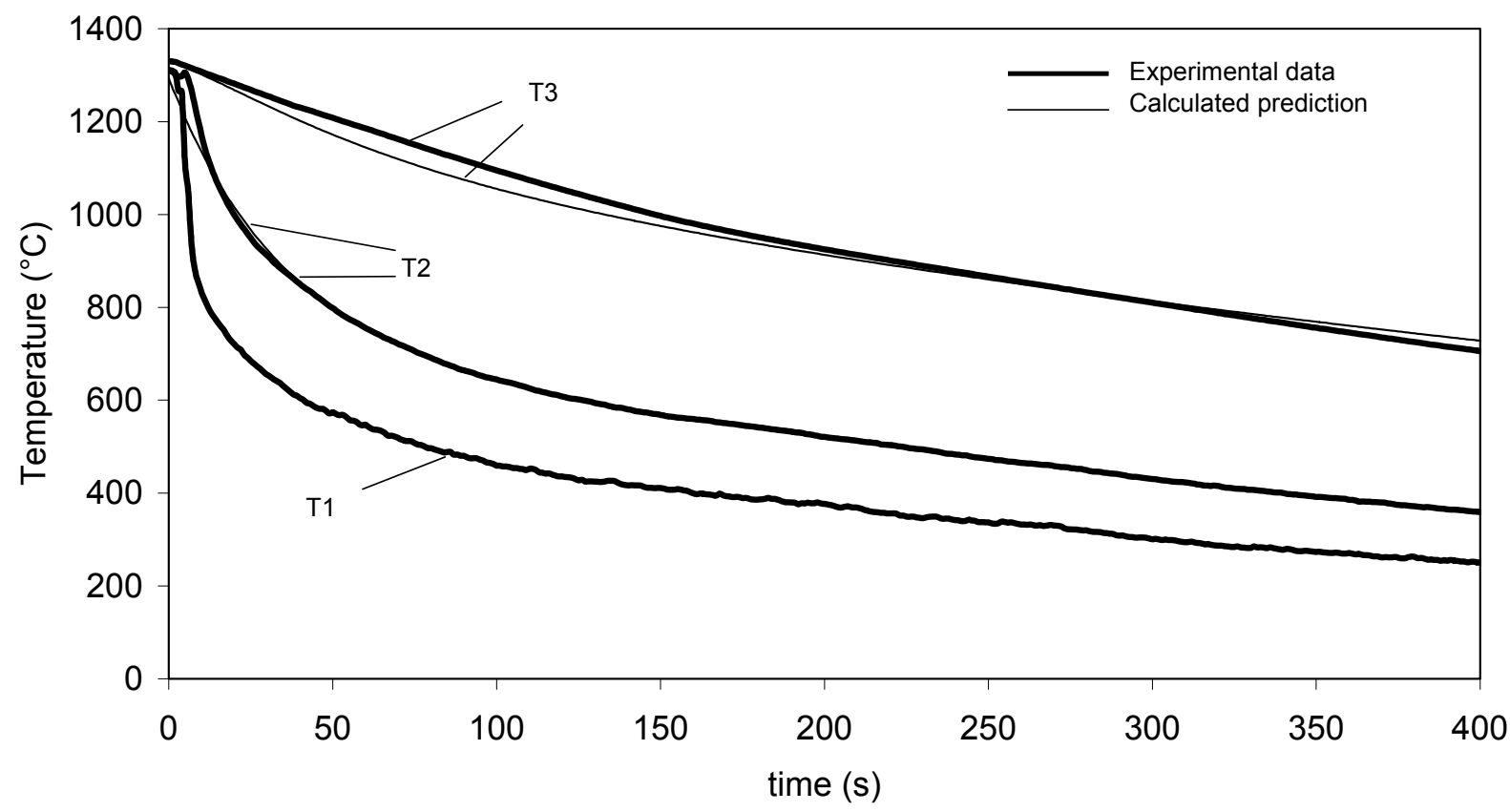

$3.0 \mathrm{~mm}-5.0 \% \mathrm{TiO}_{2}-$ Test $2-\mathrm{kslag}=2.36 \mathrm{~W} / \mathrm{mK}$

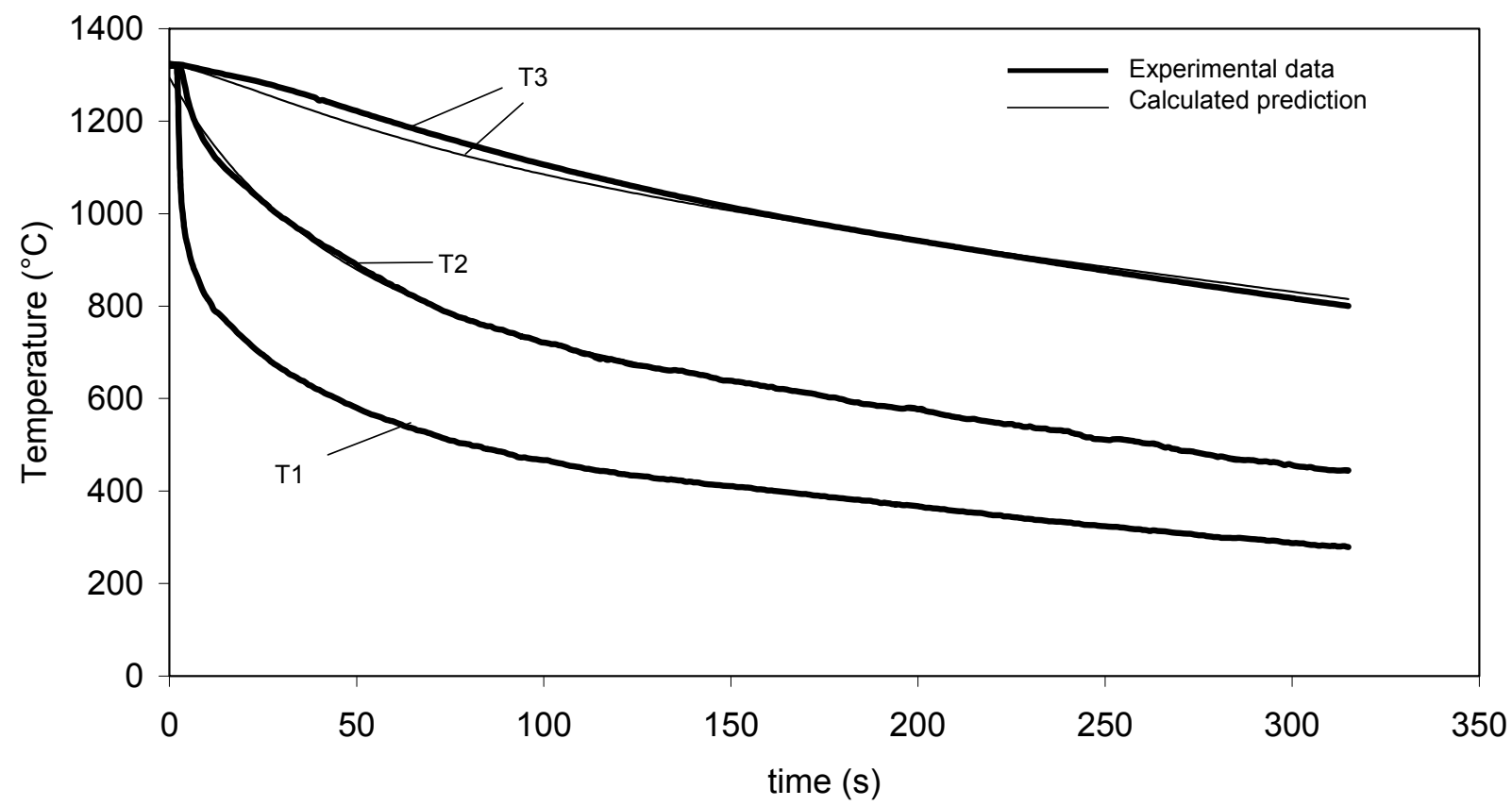

J.A. BOTHMA - MASTER OF ENGINEERING (METALLURGY) - UNIVERSITY OF PRETORIA - 2006 


\section{$3.0 \mathrm{~mm}-10.0 \% \mathrm{TiO}_{2}-$ Test $1-\mathrm{kslag}=1.69 \mathrm{~W} / \mathrm{mK}$}

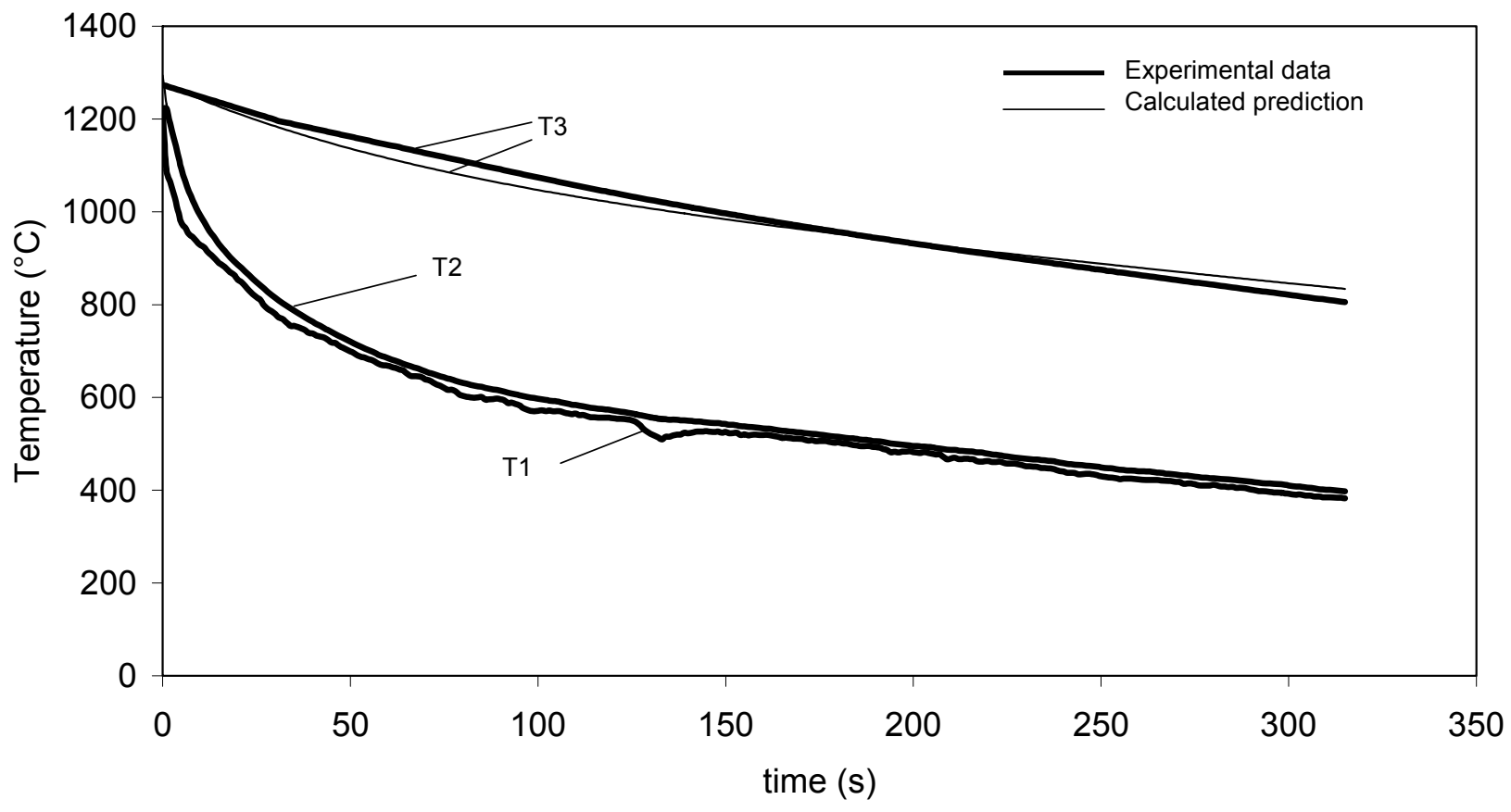

$3.0 \mathrm{~mm}-10.0 \% \mathrm{TiO}_{2}-$ Test $2-\mathrm{kslag}=2.04 \mathrm{~W} / \mathrm{mK}$

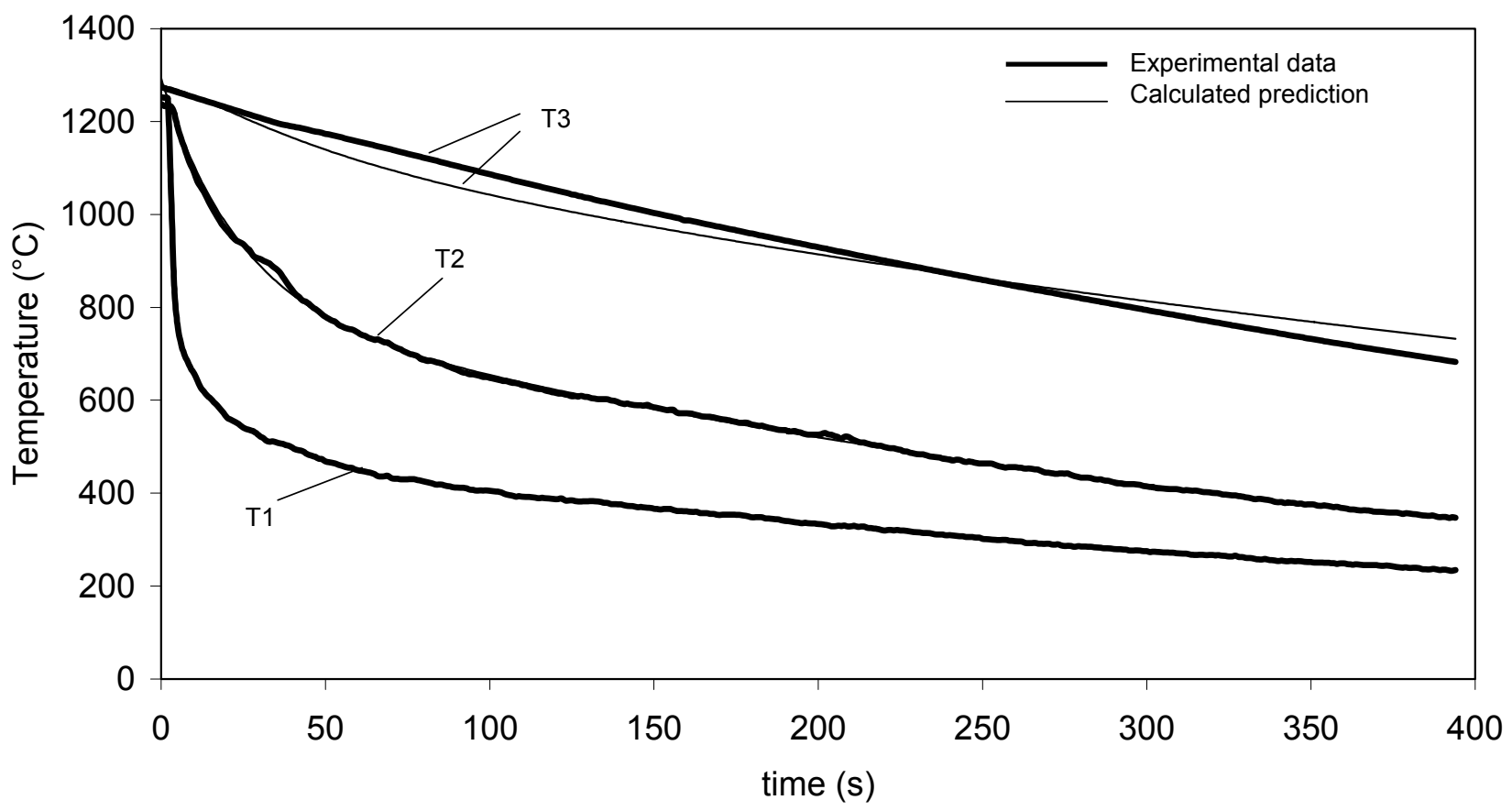




\section{$6.0 \mathrm{~mm}-0.0 \% \mathrm{TiO}_{2}-$ Test $1-\mathrm{kslag}=3.22 \mathrm{~W} / \mathrm{mK}$}

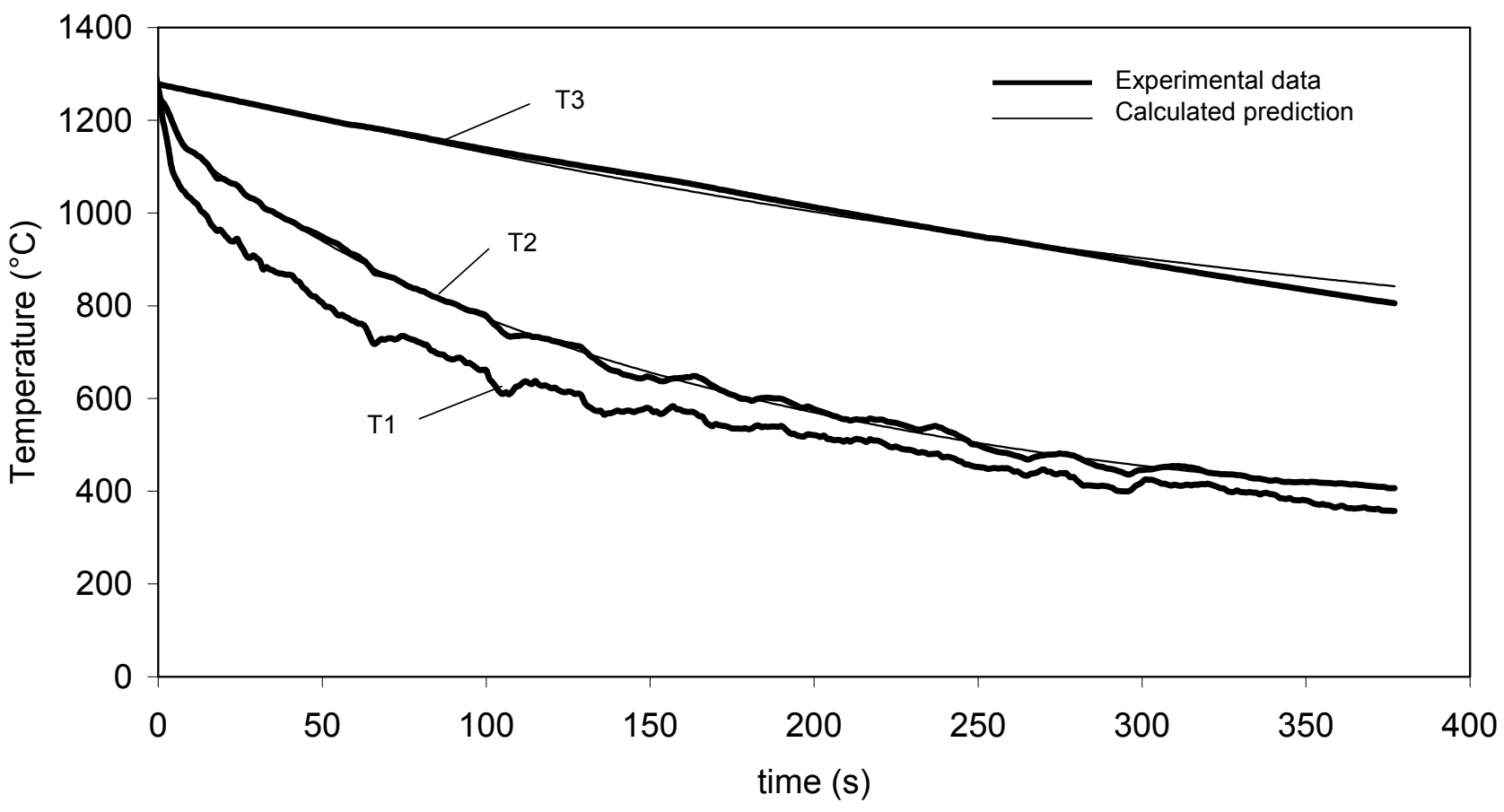

$6.0 \mathrm{~mm}-0.0 \% \mathrm{TiO}_{2}-$ Test $2-\mathrm{kslag}=2.84 \mathrm{~W} / \mathrm{mK}$

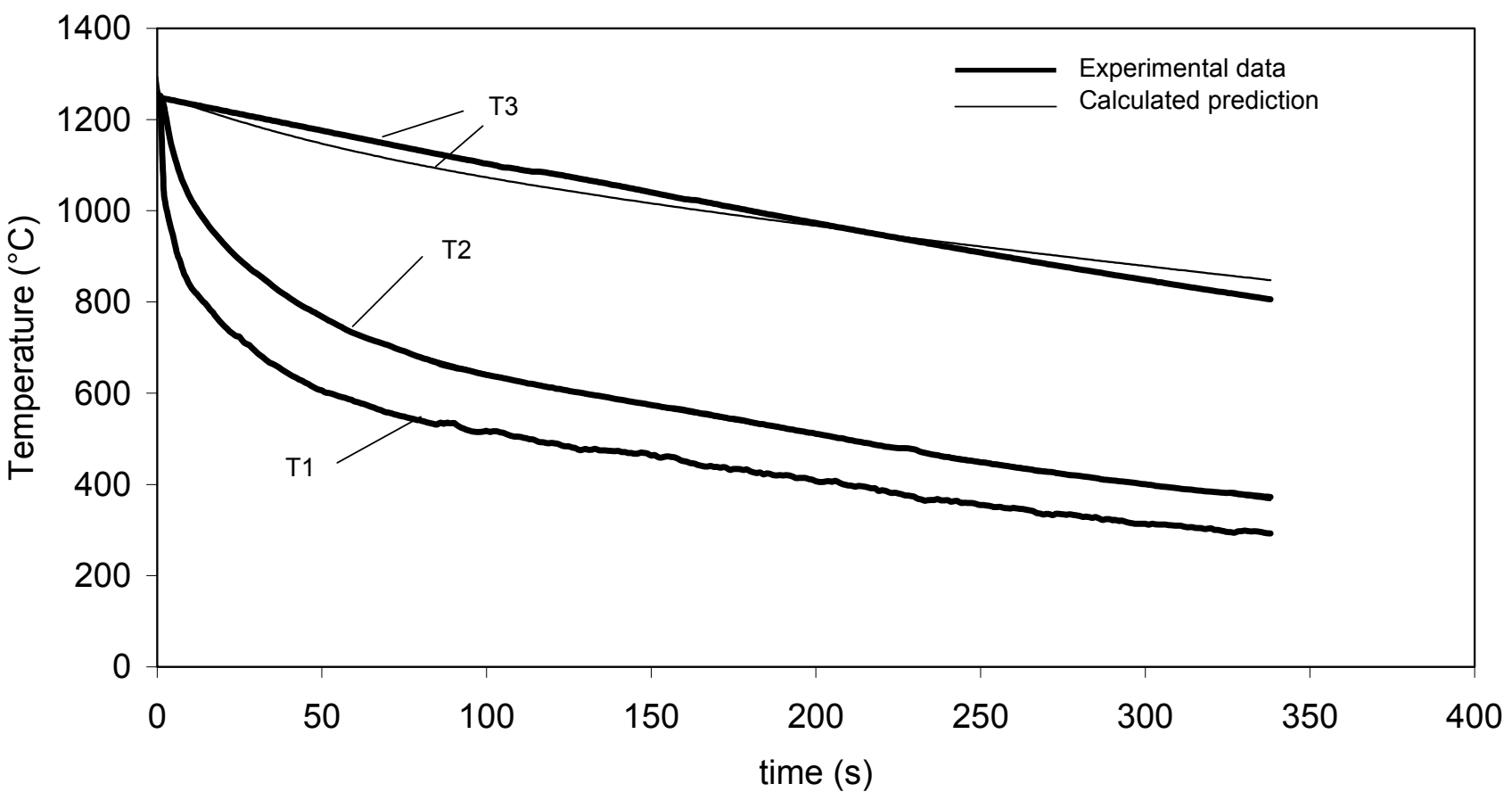


$6.0 \mathrm{~mm}-5.0 \% \mathrm{TiO} 2-$ Test $1-\mathrm{kslag}=3.31 \mathrm{~W} / \mathrm{mK}$

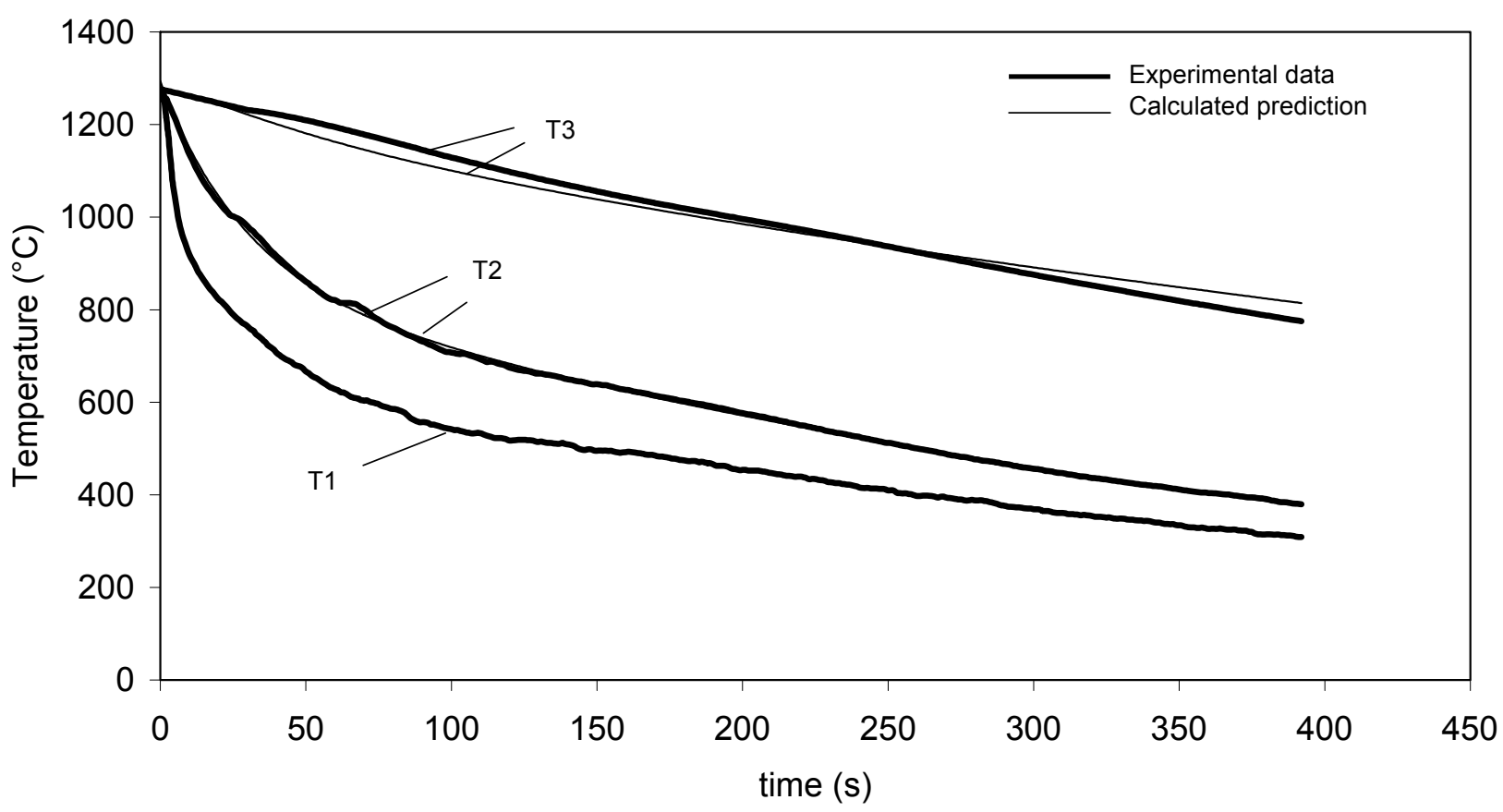

$6.0 \mathrm{~mm}-5.0 \% \mathrm{TiO}_{2}-$ Test $2-\mathrm{kslag}=2.89 \mathrm{~W} / \mathrm{mK}$

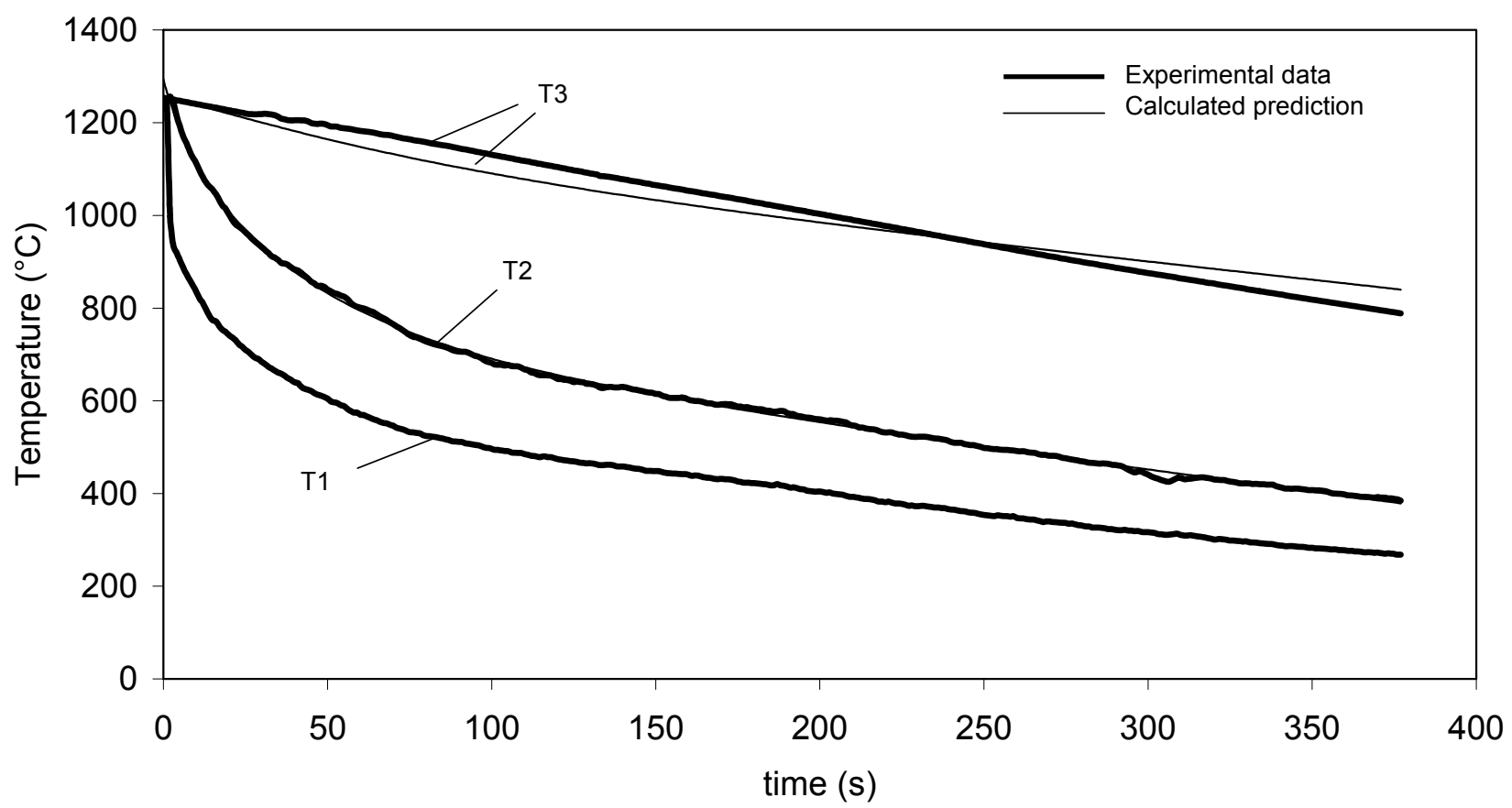

J.A. BOTHMA - MASTER OF ENGINEERING (METALLURGY) - UNIVERSITY OF PRETORIA - 2006 


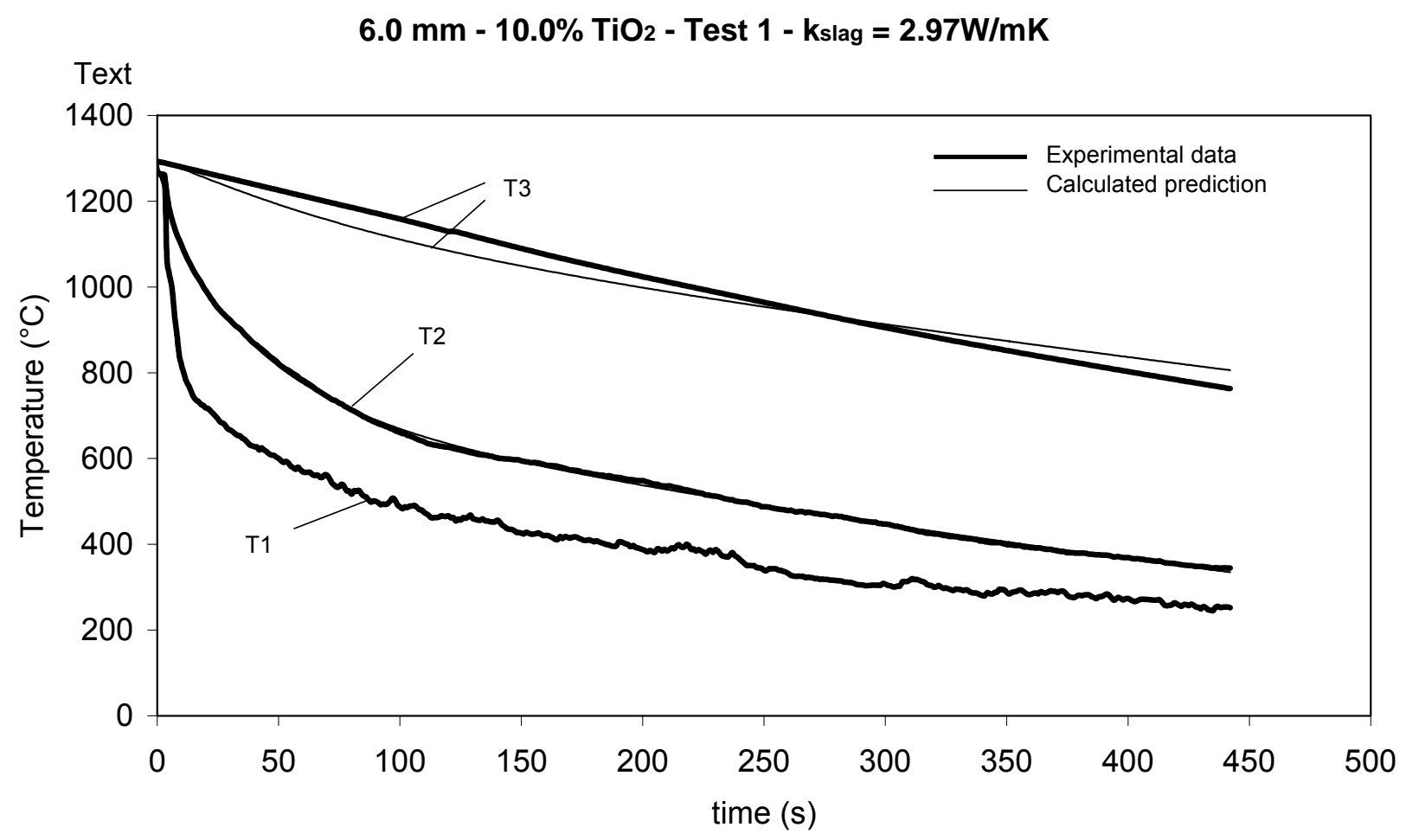

$6.0 \mathrm{~mm}-10.0 \% \mathrm{TiO}_{2}-$ Test $2-\mathrm{kslag}=3.09 \mathrm{~W} / \mathrm{mK}$

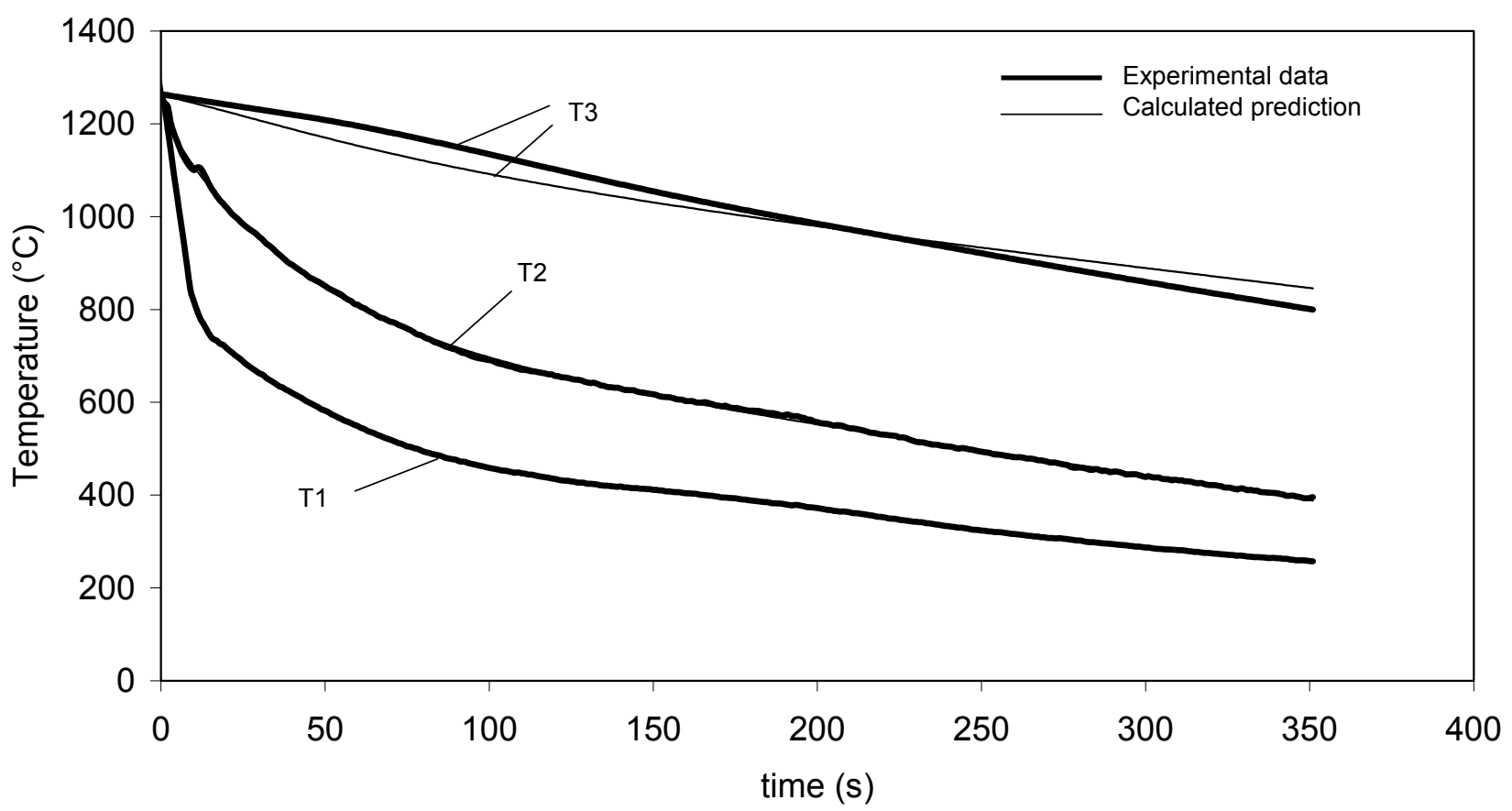

J.A. BOTHMA - MASTER OF ENGINEERING (METALLURGY) - UNIVERSITY OF PRETORIA - 2006 